medios

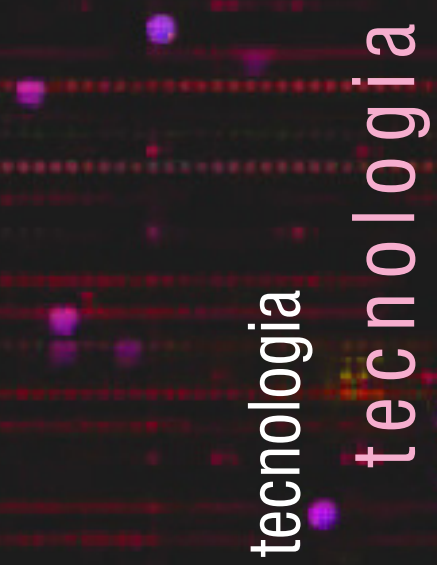

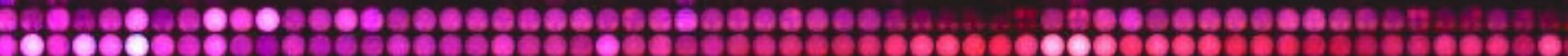

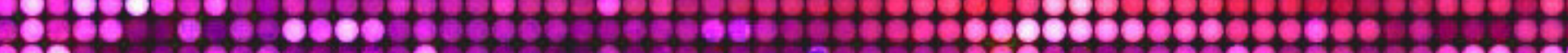

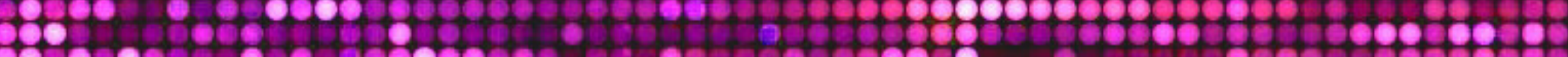

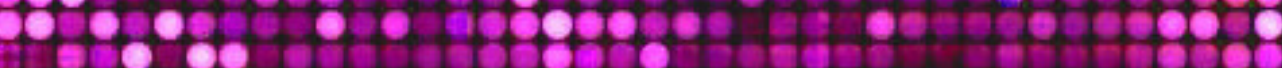
getrangegeger

\title{
LA MARCA DE LA CONVERGENCIA Medios, tecnologías y educación
}

Doce ensayos en busca de una narrativa 


\title{
LA MARCA DE LA CONVERGENCIA \\ Medios, tecnologías y educación
}

\section{2 ensayos en busca de una narrativa}

\author{
Sebastián Novomisky \\ Tesis Doctoral | Junio 2019
}



A mi esposa Eleonora y a mis hijas Catalina y Helena, que perdonaron mis desatenciones durante los meses de trabajo, restando horas de juegos, mimos y paseos que espero podamos recuperar.

A mis padres, Eduardo y Luli, y a mi hermano Luciano, quienes, sin saberlo, marcaron un camino en el cual la búsqueda de conocimiento sería el alimento más preciado. 
La marca de la convergencia. Medios, tecnologías y educación 12 ensayos en busca de una narrativa

Doctorando: Sebastián Novomisky

Directores: Leonardo Gonzalez y Claudia Villamayor

Asesora: Antonieta Teodosio

Maquetación y normalización de referencias: Adela Ruiz

Diseño de tapa: Margarita Ávila

Junio 2019

Doctorado en Comunicación Facultad de Periodismo y Comunicación Social Universidad Nacional de La Plata

(c) (1) Esta obra está bajo una Licencia Creative Commons Atribución-NoComercial(c) ${ }_{\text {BY NC SA }}$ CompartirIgual 4.0 Internacional 


\section{Presentación 7}

\section{Introducción 9}

\section{Digitalización de la cultura}

Un fenómeno que resignifica el campo

de comunicación / educación

Epistemología de la convergencia

\section{7}

Claves conceptuales desde comunicación / educación

Digitalización de la cultura

La estructuración de un nuevo modelo de relaciones sociales

y sus consecuencias en el sujeto y en sus prácticas

Sensorium y hegemonía

Una relación clave para describir un nuevo estar allí

Una aproximación necesaria

al campo material de la cultura digital

Conversaciones con Gabriel Baum 
Una aproximación a la tensión

entre racionalidad / sensibilidad

Diálogos con Joan Ferrés Prats

Formación de sujetos y tecnologías

Políticas de inclusión digital en escuelar

Encuentro y Pakapaka

Experiencias que marcan la historia

Netflix: el sueño es mi mayor enemigo

Un final, a riesgo de equivocarnos 223

Referencias 235 


\section{Presentación}

\section{Cómo llegamos hasta aquí}

Esta tesis es el resultado de un recorrido en el cual se articulan espacios de formación, experiencias y prácticas profesionales que, desde múltiples lugares, abonaron a consolidar un texto que constituye una serie de ensayos, en los que se inscriben problematizaciones epistemológicas, comunicacionales, culturales, educativas y tecnológicas, en la búsqueda de madurar conceptualmente el acontecimiento de la convergencia tecnológica digital con su afectación en la sociedad, en el sujeto y en la cultura.

El camino recorrido, primero, en un profesorado en lengua hebrea, con fuerte formación pedagógica y profunda mirada histórica y analítica; luego, en un breve paso por la carrera de Ingeniería Electrónica en la Universidad Nacional del Sur; y, finalmente, en la Licenciatura en Comunicación Social y en la Maestría en Planificación y Gestión de Procesos Comunicacionales (Plangesco) en la Universidad Nacional de La Plata (UNLP), construye una mirada que aquí se traduce en texto y en experiencia.

Es por ello que la enunciación del autor, en este caso, no puede desprenderse de la trama que se construye en estas páginas; que no es totalizadora, sino que es emergente y que aparece en el sentido que señala Gilles Deleuze (2018), del sujeto como devenir singular.

Los años en la Facultad de Periodismo y Comunicación Social de la UNLP, en la cátedra de Comunicación y Educación, con el querido Jorge Huergo; la experiencia en Opinión Pública cátedra 2, bajo la formación de uno de los directores de esta tesis, Leonardo Gonzalez, con quien luego fundaríamos el Centro de Investigaciones en Industrias Culturales y Televisión (CEID-TV); mi paso como docente en la materia Prácticas de la Enseñanza, primero, y como director de la carrera Profesorado en Comunicación, 
después, dieron también la posibilidad de refundar como profesor titular la cátedra Diseño y Planeamiento del Currículum, desde una perspectiva comunicacional, haciendo de este recorrido, como de las páginas que siguen, un anudamiento de trayectos, de lecturas y de experiencias que podemos afirmar, sin dudas, nos permiten llegar hasta acá. También es necesario destacar una década de trabajo a cargo de los bachilleratos para adultos, trabajadores de la empresa Siderar, que dieron su fruto en la tesis de la ya mencionada maestría bajo la dirección de la querida Claudia Villamayor, nuevamente directora en este trabajo; los años como responsable pedagógico en la Dirección General de Cultura y Educación de la Provincia de Buenos Aires en el programa de Mejoramiento de la Educación Rural PROMER; las clases sobre medios de comunicación educativos en San Pablo y en Montevideo; y, desde allí, la posibilidad de asesorar y de capacitar al personal de la señal de televisión TV Ciudad de Uruguay sobre cómo reorientar las lógicas de producción en contextos de digitalización y de multipantallas.

Todo esto fue construyendo un recorrido de investigación y de trabajo profesional, por un lado, relacionado con temáticas del campo educativo y, por el otro, vinculado a los medios de comunicación, en general, y a la TV, en particular, que desde hace varios años se fue articulando con la cuestión de las tecnologías, ya que políticas de la dimensión del Programa Conectar Igualdad para entrega de netbooks a todos los estudiantes de escuelas secundarias del país y la creación de las señales Canal Encuentro y Pakapaka, dependientes del Ministerio de Educación de la Nación, hicieron necesario revisar las matrices de abordaje tanto de los problemas comunicacionales como de los educativos y empezar a debatir, fuertemente, si los horizontes del campo no debían ser resignificados.

Años después, la posibilidad de realizar una estancia de investigación a comienzos de 2018 en la Universidad Pompeu Fabra, en Barcelona, bajo la tutoría de los doctores Carlos Scolari y Joan Ferrés Prats, terminó de integrar con formas novedosas mucho de lo que de manera disociada venía produciendo y que en el Doctorado en Comunicación se empezaba a sintetizar. La suma de miradas atentas, novedosas y sumamente actualizadas con los tiempos que corren hizo que los primeros borradores comenzaran a tomar forma.

El encuentro con María Antonieta Teodosio clarificó notablemente que el género ensayo era pertinente para esta tesis, que merodeaba su objeto sin decidirse formalmente a avanzar en una linealidad reflexiva. El formato era el correcto, pero no sería uno solo, sino una serie de escritos para hallar esa regularidad de la que hablaba Michel Foucault (2008), en la dispersión de procesos que hoy llevan impresa la marca de la convergencia. 


\section{Introducción}

\section{Doce ensayos en busca de una narrativa}

Para comenzar a enfocarnos en el trabajo realizado partiremos de una afirmación de Carlos Scolari (2018) sobre el contexto actual.

Según Klaus Schwab, la cuarta revolución industrial tiene características diferentes a las anteriores: más que un nuevo estrato tecnológico generado por alguna nueva forma de energía o de transferencia de información, la era en la que estamos entrando se caracteriza por una "fusión entre tecnologías y su interacción a través del dominio físico, digital y biológico". La cuarta revolución industrial comienza cuando lo digital se cruza con la nanotecnología, la genética dialoga con la computación cuántica y el Big Data, y la inteligencia artificial se mezcla con la internet of things o las fuentes renovables de energía.

Klaus Schwab considera que no existe una infraestructura política o de liderazgo a escala global capaz de procesar lo que se viene ni mucho menos de gestionarlo; también apunta a la falta de una narrativa que permita visualizar los desafíos y oportunidades que se perfilan al horizonte.

Más allá de la mayor o menor simpatía que pueda generar el World Economic Forum, vale la pena revisar un documento que, sin dudas, está marcando la agenda de las conversaciones globales (en línea).

Es por ello que podemos afirmar en principio que el propósito de esta tesis es contribuir a formular una pequeña parte de esa narrativa, aún no establecida, que permita desde el sur, describir, primero, y comprender, después, fenómenos que están modificando 
radicalmente las formas de ser y de estar en el mundo de los sujetos, desde una perspectiva latinoamericana y tradiciones críticas, habilitando no solo la posibilidad de saber qué sucede, sino posteriormente poder intervenir sobre esta situación difundiendo su relevancia y participando en su direccionalidad.

Una de las inquietudes iniciales que guía este trabajo es que la falta de un diagnóstico serio y profundo de la situación actual imposibilita la intervención sobre un mundo que se reconfigura digitalmente día tras día. Es por ello que elegimos el ensayo como género discursivo, ya que nos permite traspasar los límites de lo visible, de lo pensable y de lo decible y situarnos de cara a lo complejo, siguiendo a Jorge Larrosa (2003).

Por sus orígenes, cuando en el siglo XVI Montaigne lo utilizó para indagar, en los albores del iluminismo, "qué podemos conocer", el género ensayo quedó de algún modo ligado al paradigma de la naciente racionalidad moderna y no menos a la idea de completitud que rondaba la enciclopedia y a la paradojal libertad, aplicada en la elección de las formas. Se trata, en consecuencia, de una escritura apropiada a un contexto específico - occidental, moderno - producida con el objeto de trasvasar esos conocimientos que la memoria ya no permitía organizar cabalmente sin ayuda de alguna clase de dispositivo externo. A estas características dispuestas desde sus inicios falta solo agregar el carácter subjetivo de aquel que asume una libertad plena, esa que le permite sostener un posicionamiento firme - la asunción consciente de que nuestras capacidades humanas son finitas y que no puede pensarse el conocimiento fuera del contexto desde el cual emerge- - tanto como un límite, ese punto final que, por un lado, expresa el alivio frente a la tarea cumplida y que, por el otro, pone un intervalo de silencio reflexivo entre la obra escrita y sus posibles contestaciones. Porque esa subjetividad da cauce a su conocido carácter argumentativo, polémico.

Sin lugar a dudas, por tratarse de una tecnología cifrada sobre la escritura, que da cuenta del contexto donde fue diseñada, fue que tuvo, como lo observa Germán Arciniegas (1979), la repercusión conocida en América desde los tiempos de la colonia. En su perspectiva, fue el ensayo el que hizo posible la independencia americana, y no la guerra.

El ensayo fue un género ligado a la academia y de gran difusión en América latina. La talla de los escritores que se dieron a su cultivo en nuestra región da cuenta en forma elocuente de su capacidad y su potencia ilocucionaria tanto como de la necesidad de vincular ideas e imaginarios que hicieran visibles las grandes utopías americanas. 
Escritores como José Martí, José Carlos Mariátegui o Domingo F. Sarmiento, por solo mencionar algunos que son parte de una muy larga tradición que llega hasta nuestros días, vieron en el ensayo la posibilidad de decir las luchas del pensamiento y su fuerza para llegar y para dialogar con las distintas realidades. El ensayo superaba la cercanía obligada de la lectura del periódico tanto en tiempo como en espacio. Habilitada la lectura atenta, reflexiva, paciente, el horizonte podía ir dibujándose con los trazos de esta escritura.

Ya los tiempos coloniales habían conocido en nuestra América la pluma de un Bartolomé de las Casas blandida en la defensa de los indios. Arciniegas (1979) lo atribuye a que América había nacido como un problema que desafiaba la inteligencia. Y así lo defiende:

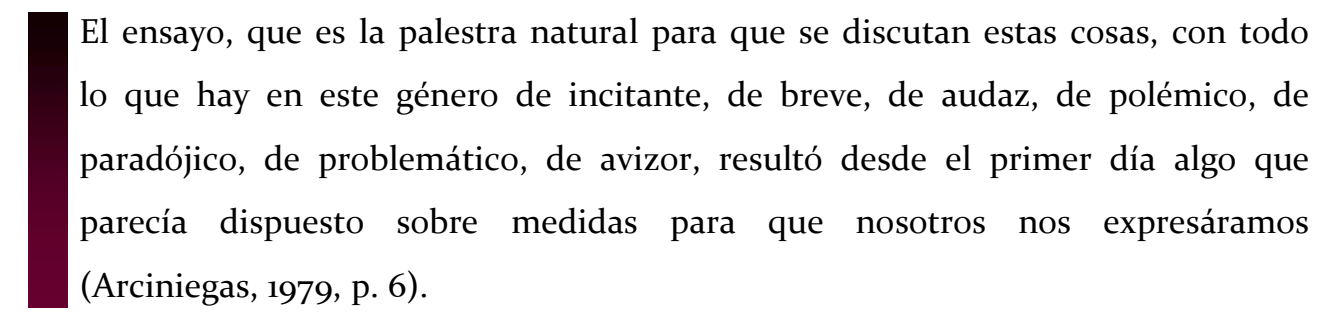

Se observa en sus palabras que el valor depositado en el ensayo tiene una relación directa con la necesidad americana de ser y de ser distintos, originales. Así lo evidencia Arciniegas (1979), al citar a Andrés Bello, quien en 1948, dirigiéndose a Chile, decía:

¿Estaremos condenados todavía a repetir servilmente las lecciones de la ciencia europea, sin atrevernos a discutirlas, a ilustrarlas con aplicaciones locales, a darles una estampa de nacionalidad? Si así lo hiciésemos, seríamos infieles al espíritu de esa misma ciencia europea, y le tributaríamos un culto supersticioso, que ella misma condena... Pocas ciencias hay que, para enseñarse de un modo conveniente, no necesiten adaptarse a nosotros, a nuestra naturaleza física, a nuestras circunstancias sociales (p. 14).

La cuestión de la originalidad, la misma por la que bregaban Simón Rodríguez y Simón Bolívar, fue la que puso límites a la Ilustración tanto como al Romanticismo importados. Las realidades propias de nuestra América impidieron la proyección directa de los problemas foráneos. De alguna manera, es lo que afirma Larrosa (2003) cuando señala que no hay revuelta intelectual sin revuelta lingüística... Justamente, en esa línea de pensamiento es que sostiene que hay en el ensayo algo como de acto de herejía, de violencia contra lo que cierta ortodoxia pretende ocultar. 
Sin embargo, Larrosa (2003) piensa en otras luchas, en las que el ensayo y los ensayistas emprenden contra un normalismo - si cabe- académico, terreno en el cual la razón tecno-científica vino a derrotar al ensayo, lo que a fin de cuentas trajo aparejada una cierta dependencia intelectual. Y lo que se entronizó desde el método es la ruptura con la libertad emergente de los ensayos, esa que los habilita a combinar la ciencia, la objetividad y la racionalidad con la imaginación y la creatividad, con la subjetividad, con la irracionalidad.

"Lo que hace el ensayo es poner en cuestión las fronteras", plantea Larrosa (2003, p. 34) para explicar que se trata de un género híbrido, impuro. Pero ya sabemos, declara, que "las fronteras son mecanismos de exclusión" (p. 35). El autor lo levanta por ser lo prohibido, lo que la ortodoxia ha condenado, especialmente en nuestros países. Porque el ensayo traspasa los límites de lo visible, de lo pensable y de lo decible. Se da en él una libertad temática y formal que molesta a un campo reprimido y regulado como el del saber organizado. El ensayo duda del método, que es el gran aparato de control del discurso. "El ensayo no procede ni por inducción ni por deducción, ni por análisis ni por síntesis [...]. El ensayo se sitúa de cara en lo complejo”, sigue Larrosa (2003, p. 37).

Por lo dicho, creemos que es una cuestión de vindicación latinoamericana pero también de libertad académica sostener para este trabajo la comprometida libertad que da el ensayo, ya que como afirma Larrosa (2003): "Pensar de otro modo es leer de otro modo y escribir de otro modo" (p. 30).

Así, el trabajo realizado se desprende en una serie de escritos que se vinculan fuertemente entre sí, intentando abordar de forma profunda y compleja diferentes elementos epistemológicos, conceptuales y casos que dan cuenta, al menos, de una parte de la radicalidad del proceso que se intenta describir.

En el primer ensayo abordamos cómo la "cuarta revolución industrial", como la designa Schwab (2016) y que nosotros denominaremos "convergencia tecnológica", interpela a nuestro propio campo de acción. En la misma medida que modifica la cultura, necesariamente nos convoca a revisar los núcleos categoriales con los que hasta hoy nos manejábamos en comunicación / educación.

En el segundo, se hace necesario tomar un posicionamiento epistemológico, ya que estamos frente a un fenómeno complejo, profundo, contradictorio, que justifica nuestro abordaje desde el paradigma de la complejidad. 
En el tercer escrito se recuperan las bases tradicionales de la comunicación / educación que siguen siendo, sin duda, fundamentos necesarios, insustituibles, para un trabajo que se asume desde la perspectiva latinoamericana desde la cual consideramos el fenómeno.

En el cuarto ensayo abordamos nada menos que la "digitalización de la cultura" y no solo como un fenómeno que requiere de una descripción profunda para desentrañarlo, sino como un fenómeno ya instalado, es decir, ineludible dada su internalización en forma de habitus.

Cuando hablamos de un fenómeno ya instalado, no nos referimos simplemente a la masiva utilización de todo tipo de nuevas tecnologías de la comunicación por parte de los jóvenes y de la sociedad en general, sino al nuevo sensorium desde el cual —inevitablemente - todos percibimos, analizamos, construimos sentido y significado, y nos interpelamos unos a otros. Los enormes beneficios que con algún grado de ingenuidad se creyó que estas "novedosas" posibilidades de comunicación traerían, vienen teñidos de oscuros presagios por la utilización que en algunos casos se está haciendo de ellas con los viejos vicios de la mercantilización, el control, la dominación, la exclusión. Por eso nos parece fundamental asociar el concepto de sensorium al de hegemonía en el quinto ensayo.

A continuación, la certeza de que la convergencia constituye algo más que un tema de comunicación, nos llevó a consultar sobre la base informática: ¿Determinación o condicionamiento? Así hablamos con Gabriel Baum, Director del Laboratorio de Investigación y Formación en Informática Avanzada de la Universidad Nacional de La Plata, en busca de algunas definiciones clave de esa disciplina en la actualidad. A partir de esta entrevista pudimos formular una suerte de glosario aumentado que nos ayudó a entender el escenario $-\mathrm{y}$ esperamos que haga otro tanto con nuestros lectoresy desarrollar una hipótesis geopolítica que ensaya en sexto lugar una mirada de mundo.

En el séptimo ensayo abordamos una vieja tensión que se actualiza: entre la forma en que los niños aprenden cotidianamente a través de los medios (cultura mediática) y la forma con la cual se les pretende enseñar en la escuela (cultura escolar). Actualizar este concepto - central en la obra de Jorge Huergo - creemos que es fundamental para comprender y para diagnosticar, tanto como para producir ulteriores intervenciones en el campo. Se trata, así, de seguir aquellos lineamientos con la libertad y la confianza necesarias para darles vuelo. 
Entre otros aspectos de la convergencia, es preciso destacar — junto con su antes nunca vista capacidad de acopio y de procesamiento de datos (Big Data)—, la construcción de mensajes destinados a generar adhesión - y no reconocimiento- mediante el manejo de las emociones, lo cual nos habla de la importancia de dominar estos nuevos códigos tanto para procesar como para intervenir desde la comunicación y la educación. Por eso en el octavo ensayo entrevistamos a Joan Ferrés Prats, quien nos habla de la importancia del mundo emocional en las interpelaciones mediáticas y educativas.

Sobre la base de lo dicho hasta allí, en el noveno ensayo entendemos que el enfoque de la utilización de las nuevas tecnologías de la información y comunicación (TIC) en las escuelas debe encararse — como ya lo señalaron Jorge Huergo y Belén Fernández (2000), siguiendo lo propuesto por Jesús Martín-Barbero ([1987] 1997)—, más como una cuestión de mediaciones que de medios.

En este sentido, en el décimo ensayo 10 revisamos el programa Conectar Igualdad como una política social —imprescindible y urgente — para disminuir la brecha que se produce cuando un niño/a o un/a joven no tiene la posibilidad de acceder al tren de la historia y se siente marginado en el andén. Al mismo tiempo, sobre la base de una investigación realizada en 2014 desde la Facultad de Periodismo y Comunicación Social, analizamos cómo podría ser reenfocado y completado con estrategias de lectura, de deconstrucción y de producción de mensajes multimediales.

En el undécimo ensayo, experiencias como las de los canales de televisión del Ministerio de Educación, Pakapaka y Encuentro, nos permiten afirmar que es posible interpelar con otro sentido político y desde las nuevas lógicas al capitalismo de plataformas.

El ensayo número doce, titulado "Netflix: el sueño es mi mayor enemigo", nos despierta la magnitud del fenómeno que estamos abordando. El ecosistema mediático ha cambiado sustancialmente, como lo demuestra la programación de series que atrapan la atención del espectador, que puede pasar un día entero frente a la pantalla para no perderse la continuidad de la historia. No se trata de una gran historia, imperdible, sino de una estrategia para atrapar la atención de la audiencia durante el mayor tiempo posible, porque en este tiempo de hipermediaciones, multipantallas, hipertextos, la atención (de los demás) ha resultado ser el bien más preciado y más escaso, del cual todas las empresas pretenden apropiarse. Si antiguamente la ambición rondaba la "fiebre del oro", hoy se afanan tras una "economía de la atención”. 
Finalmente, creemos que este camino recorrido y por el cual nos sentimos agradecidos a quienes de una u otra forma nos han acompañado, nos habilita para formular algunas propuestas, a riesgo de equivocarnos pero convencidos de que el peor error sería no intentarlo, encerrarnos en nuestras respuestas previas y querer con ellas enfrentar las nuevas preguntas. Por eso el último ensayo, el número trece, asume la precariedad propia de nuestra naturaleza humana y se titula "Ensayo para equivocarnos".

Aunque la escritura de una tesis es un trabajo personal, e incluso solitario, deseo agradecer a Leonardo Gonzalez y a Claudia Villamayor, directores de esta tesis, y a Gabriel Baum y Joan Ferrés Prast, quienes desde sus lugares de saber apuntalaron y promovieron este desafío. También a Carlos Scolari que, aunque no acepta ser entrevistado para tesis doctorales, aportó elementos sustanciales a este trabajo. A los demás autores, quienes, precisamente por la magia de Internet, me acompañaron desde sus propios caminos hechos y generosamente publicados. Por último, a María Antonieta Teodosio, a Alberto Ivern, a Sebastián Suárez Correz, a Adela Ruiz y a Gladys Manccini por su generosa ayuda.

Sebastián Novomisky

La Plata, junio de 2019 


\section{Referencias}

Arciniegas, G. (1979). Nuestra América es un ensayo. Latinoamérica.

Cuadernos de cultura latinoamericana, (53). Ciudad de México, México:

Universidad Nacional Autónoma de México.

Deleuze, G. (2018). Diferencia y repetición. Ciudad Autónoma de Buenos Aires, Argentina: Amorrortu.

Foucault, M. [1969] (2003). La arqueología del saber (Trad. A. Garzón del Camino).

Ciudad Autónoma de Buenos Aires, Argentina: Siglo XXI.

Huergo, J. y Fernández, M. B. (2000). Cultura escolar y cultura mediática / Intersecciones. Bogotá, Colombia: Universidad Pedagógica Nacional.

Larrosa, J. (2003). El ensayo y la escritura académica. Propuesta educativa, 12(26), 34-40.

Martín-Barbero, J. [1987] (1997). De los medios a las mediaciones. Bogotá, Colombia: Gustavo Gili.

Ruiz, A. (2018). La incorporación de citas en los textos científico académicos. Estilos y consideraciones para su redacción (apunte de cátedra). Taller de Edición Técnica, Facultad de Periodismo y Comunicación Social, Universidad Nacional de La Plata. Recuperado de http://sedici.unlp.edu.ar/handle/10915/73792

Schwab, K. (2016). La cuarta revolución industrial. Madrid, España: Debate.

Scolari, C. (10 de junio de 2018). La IV Revolución Industrial [entrada de blog]. Recuperado de https://hipermediaciones.com/2018/06/10/la-40-revolucionindustrial 


\section{Digitalización de la cultura Un fenómeno que resignifica el campo de comunicación / educación}

O inventamos o erramos.

Simón Rodríguez (1842)

Mientras escribimos este ensayo nos sigue resonando la noticia aún fresca del triunfo del candidato de derecha con rasgos fascistas Jair Bolsonaro en Brasil, y una crónica brillante de Atilio Borón (2018), quien nos relata de qué forma en el sentido común, en la más profunda de las creencias, se instalaron conceptos o ideas que operan en favor de proyectos que - al menos como mínimo- son contrarios a los intereses del sector de quienes los votan.

El ejemplo de Bolsonaro en Brasil, de Trump en Estados Unidos, del Brexit en Inglaterra o de cualquier otro de los muchos que nos enfrentan a diario, son solo la punta de un iceberg, o, mejor, efectos de un fenómeno de gran envergadura al que llamaremos "convergencia tecnológica" y que también ha sido denominado "cuarta revolución industrial" (Schwab, 2016). Aún sin comprenderlo nos sentimos interpelados. ¿Acaso podríamos seguir sin abordar la transformación cultural que generan estos procesos políticos y sociales? ¿Cuál es el lugar de las mediaciones? ¿Cómo es que hoy los discursos (hiper)mediáticos cobran sentido y modelizan las prácticas? Y a medida que nos aproximamos y vamos adquiriendo una mayor información acerca de su naturaleza y de sus alcances, sentimos que interpela a nuestro propio campo de acción: al modificar la cultura necesariamente nos convoca a revisar los núcleos categoriales con los que hasta hoy nos manejábamos en comunicación / educación.

En efecto, lo que se pensaba como TIC, su uso y su incorporación en las prácticas educativas - temas profundamente trabajados por la comunicación / educación-, en la actualidad cobra otra dimensión: social, política, pedagógica. 


\section{De la plaza a la pantalla}

Catorce caras posibles tenía el candidato a presidente de los Estados Unidos en la campaña, todas ellas modificables según el interés de quien fuera el destinatario del mensaje en Facebook, algoritmos que programan lo que se nos mostrará y nos dicen cuál es el tipo de Trump que tenemos que ver, ofreciendo desde el marketing político el sueño de una comunicación a medida de cada votante.

Comenzamos a migrar de la comunicación masiva hacia nuevos modelos, nos encontramos en una etapa donde los microrrelatos no son fruto de las tácticas del débil, sino de una serie de estrategias diversificadas del poderoso, cuando desde el análisis de datos se logra construir conocimiento sobre los perfiles de cada sujeto y, desde allí, tomar la decisión de cómo interpelar, según su propio mundo cultural.

Articulando conocimientos del campo de las neurociencias que, más allá de ser denostado y mal utilizado, hoy rige como un saber eficiente a la hora de intentar interpelar al otro, se configuran discursos en los que se apela desde el lenguaje emocional, para construir campañas que se despliegan por las multipantallas a las cuales estamos anexados casi permanentemente, con frases como Keep Control (recupera el control), marca sustantiva que inscribe en el discurso la estrategia enunciativa de los sectores conservadores en Gran Bretaña ante el Brexit.

El uso de grupos de WhatsApp acoplados a los tradicionales de organizaciones de feligreses en el Brasil de la Iglesia Universal, perfiles dinámicos de Facebook hechos a la carta según las preferencias de cada uno (compactadas por sistemas que recogen cada click que hacemos en nuestras redes), campañas de noticias falsas, trolls y un sistema de medios tradicional cada vez más concentrado, arman escenarios en los cuales los recursos técnico-comunicacionales vinculan de manera novedosa el poder con los sistemas de creencias históricas, siendo parte del modo de ser concebidas y de existir las democracias y el funcionamiento de las mismas.

La narrativa digital que hace parte de las sociedades de discurso, que arman diferentes formas de la circulación del poder, se imbrica en el proceso de socialización y constitución de los sujetos, por eso es clave comprender el cruce entre estas nuevas tramas y las reconfiguraciones identitarias que se generan en estas épocas, en la medida que esto es central en la construcción de la realidad. Todos ellos son elementos estratégicos en el campo de comunicación / educación. 
¿De qué forma entonces insertamos estos emergentes o, mejor dicho, síntomas, en una discusión sobre el estatuto del campo de Comunicación / Educación, para poner en tensión las formas de interpelación social, el tipo de reconocimientos que se realizan y por supuesto el perfil de formación de sujetos que se establece? En palabras de Borón (2018), Big Data, redes sociales, mentiras y fake news reviven los fantasmas sesentistas del control y la manipulación:

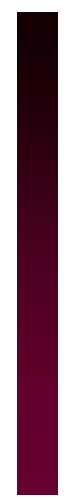

El acceso a los Big Data permitió la intrusión de la propaganda de Bolsonaro en millones de grupos de WhatsApp, no sometidos al mismo control que hay en Facebook, y desde allí lanzar una avasallante andanada diaria de mentiras y difamaciones en contra de los petistas y diseminar centenares de fake news cada día. El objetivo de éstas es incentivar la disonancia cognitiva entre los receptores y crear una sensación de incertidumbre y caos — convenientemente magnificada por los medios- que exige la mesiánica aparición de un líder fuerte que ponga orden entre tanta confusión (Borón, 28/10/2018, en línea).

Desde ciertos lugares en la academia nos cuesta reconocer que se nos oculta la magnitud de un fenómeno que llama a gritos desde los hechos que surgen como ininteligibles: las nuevas formas de circulación de la información; las estrategias de interpelación emocional, presentes en lugares en los cuales hasta la aparición del smartphone era imposible imaginar su existencia. La videopolítica no solo modifica la estructura tradicional, el discurso político, sino también a los sujetos que forma en el proceso.

Posiblemente una clave para la comprensión del fenómeno se relaciona con cómo estas prácticas políticas se entraman con las dinámicas cotidianas. Porque estos escenarios están entre nosotros, a solo un click, entre los jóvenes, en la escuela, en los espacios académicos y en las esquinas, en las manos que pueden compartir una imagen de una cerveza, mientras sostienen firmes el poder de ver y estar al mismo tiempo.

Podemos ensayar como idea que lo que cambia es el espacio de disputas por el sentido, la forma y los lugares en los que se configura hegemonía, a la manera de Ernesto Laclau y de Chantal Mouffe (1987). Se rearticula en este nuevo escenario la relación en la significación de determinados significantes nodales (patria, nación, democracia), con un tipo de significado (por sobre otros posibles), muchas veces de manera planificada estratégicamente para generar, como mencionaba anteriormente Borón (2018), incertidumbre y caos. 
Pero estos elementos, de enorme complejidad en su abordaje, los tomamos como disparadores para poner en escena la cuestión. Si sumamos otros elementos visibles en el cotidiano, como el uso de las TIC en los más pequeños, la relación de los jóvenes con las redes, la profunda transformación de los sistemas de producción y hasta el recambio de las empresas que lideran el ranking de las cinco más importantes del mundo, dentro de las cuales hoy ya cuatro son empresas de TIC, nos obligan a hacernos nuevas preguntas que en muchos casos podrían modificar el estatuto en sí del campo de comunicación y educación, ya que tanto la producción social de sentidos como la formación de sujetos y subjetividades se ve hoy en este contexto violentada.

Las nuevas formas de la comunicación hipermediada se instalan sin pedir permiso, se despliegan por el tejido social, se multiplican y operan configurando mundos posibles mientras se restringen otros. Este tipo de procedimientos reemplaza en parte históricas violencias físicas, de la mano de aparatos represivos formales e institucionales, por nuevas formas seductoras, oportunas, que aunque sean del orden simbólico, no dejan de avasallar.

¿Cómo repensar las dinámicas de un campo estratégico que hoy, en contextos de digitalización de la cultura, se ve profundamente alterado?

Pensar el encuentro, la relación, la articulación entre la comunicación, la educación y la cultura vuelve a ser un desafío, ya que las perspectivas que dieron origen al campo aún nos proporcionan una matriz de análisis, pero si no se actualizan al calor de estos sucesos corren riesgo de perder no solo su histórica potencia de interpretación del mundo sino, y sobre todo, su capacidad de transformarlo.

\section{¿Hacia una redefinición del campo?}

En esa línea, Jorge Huergo (2000, 2003) sostenía que el campo de comunicación / educación es estratégico por su capacidad analítica pero, sobre todo, por su capacidad potencial de intervención. Y estas nuevas formas de comunicación interpelan y producen sentidos, siendo por ello — en el sentido que Rosa Nidia Buenfil Burgos (1993) le otorga a esta palabra-, estrictamente educativas, ya que finalmente modifican nuestras prácticas cotidianas. 
En las últimas tres décadas, parte del arco de lo educativo se ha visto revisado, complementado y enriquecido con las tecnologías de la información y la comunicación. A pesar de ello, no sería prudente plantear que haya llegado a resignificar enteramente el campo de la comunicación / educación. Sin embargo, este nuevo fenómeno que ahora estamos atisbando propone una transformación del escenario de tal magnitud que estaríamos ante un hecho capaz de darle nuevos sentidos a la cultura, a la tecnología, a la comunicación y, por ende, también a la educación.

De la misma forma, el campo de comunicación / educación está avanzando en diferentes direcciones, sosteniendo tradiciones emancipadoras y posiciones políticas que lo alejan de miradas tecnicistas, pero ante el desafío hoy de abordar nuevos elementos que le son propios y estratégicos es que nos planteamos la necesidad de ensanchar sus horizontes de manera radical.

Sin ninguna duda, es cada vez más importante reponer y revisar las perspectivas críticas, dentro de las cuales la clase continúa siendo una variable necesaria para reconocer las injusticias, sumando la etnia, el credo, la raza, la posición de género y otros tantos elementos que complementan un análisis cada vez más complejo para mirar nuestras cotidianeidades.

A la hora de abordar uno de los ejes centrales del campo, como es el de los medios y las tecnologías en educación, tenemos que plantearnos salir de la tradicional dicotomía de Umberto Eco ([1964] 1984), entre apocalípticos e integrados o, como también plantea Huergo (2000), de la tensión que generan los discursos tecnofílicos y los discursos tecnofóbicos. Esta tensión, que concretamente alude al momento fundacional del campo de la comunicación / educación en América latina, nace como dimensión central en el contexto del proyecto desarrollista de fines de los años cincuenta y comienzos de los sesenta. Una de las estrategias de pasaje de las sociedades tradicionales (latinoamericanas) a una sociedad modernizada se basaba principalmente en la incorporación de medios y tecnologías (Mattelart, 1994).

Frente a estas transformaciones, aparecen posicionamientos diversos — señala Huergo (2000) - entre los cuales están los que sostienen que las llamadas nuevas tecnologías vendrían “a renovar el 'paisaje escolar' y a desarreglar los viejos procesos de escolarización". Por lo tanto, su incorporación en el sistema escolar lo revitalizaría, superando la crisis de hegemonía de la escuela en la formación de los sujetos. Pero también, las tecnologías contribuirían a reforzar 


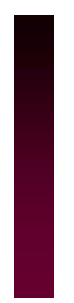
un imaginario tecnoutópico emergente. Instalan la ilusión (presente en la historia de las comunicaciones) de que las redes tecnológicas producen una democracia directa, una comunicación social armoniosa y un mundo mejor; es decir, el sueño de que es posible re-ligar (con su carga "religiosa") la tecnología con la felicidad de la humanidad (Mattelart, 1995) (Huergo, 20oo, en línea).

Es decir que nos encontramos aún en un debate que, según el propio Huergo (2000), es constitutivo del campo desde sus orígenes. Pero actualizando lo que tan solo unas décadas después sucede, podemos resignificar parte del planteo e ir más allá del mero hecho de la incorporación de tecnologías en procesos pedagógicos, y trasladar la cuestión al problema del acople de las máquinas a nuestros procesos vitales cotidianos, que requiere antes que una toma de posición, una mirada atenta que profundice en su descripción, dado que con certeza aún no tenemos dimensión de su grado de impacto en este nuevo escenario.

Seguramente mucho hay que hacer para oponerse a lo que en la articulación mercado / tecnologías / subjetividad se genera. En el terreno de las fake news, las campañas por redes dirigidas y la reconfiguración de la política, modificada sustancialmente por los caminos conocidos hasta hoy en esta nueva democracia, cada vez más nos encontramos con elementos que podemos encuadrar dentro del proceso de digitalización de la cultura. El salto de la niñez y la juventud al territorio digital, expandido al infinito por la presencia de interfaces en todo tiempo y lugar, es un elemento que aún no posee ni marcos de interpretación claros ni posibilidades de ser juzgado, dada la velocidad de los cambios y la multiplicidad de impactos que genera en la formación de estos sujetos. Sin embargo, nos obliga a repensar el campo de comunicación / educación como un escenario que debe reconfigurarse a partir de la digitalización de la cultura.

Hace unos diez años — con una lucidez y una perspectiva tan agudas que lo hacen cada día más actual—, Jesús Martín-Barbero (2009) advertía:

\footnotetext{
[...] atravesamos una revolución tecnológica cuya peculiaridad no reside tanto en introducir en nuestras sociedades una cantidad inusitada de nuevas máquinas sino en configurar un nuevo modo de relación entre los procesos simbólicos —que constituyen lo cultural—y las formas de producción y distribución de los bienes y servicios: un nuevo modo de producir, asociado a un nuevo modo de comunicar, convierte a la información y al conocimiento en fuerza productiva $\operatorname{directa}($ p. 24).
} 
En el momento en el que la digitalización comienza a afectar las bases fundamentales de la reproducción cultural, los bienes simbólicos se despliegan sobre una lógica binaria que les da forma y los performa. En palabras de Martín-Barbero (2009):

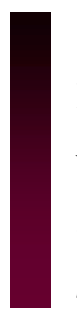
El lugar de la cultura en la sociedad cambia cuando la mediación tecnológica de la comunicación deja de ser meramente instrumental para espesarse, densificarse y convertirse en estructural. De ahí que la tecnología remita hoy tanto o más que a unos aparatos a nuevos modos de percepción y de lenguaje, a nuevas sensibilidades y escrituras (p. 24).

Autores como Éric Sadin (2017) nos fuerzan a pensar los extremos de esta situación, en imágenes que muchas veces se confunden con la ciencia ficción: La aparición del smartphone en tanto objeto globalizado que permite una continuidad de uso espacio-temporal y el acceso, como corolario, a una infinidad de servicios, consagra de cierta manera el fin de esa "revolución" y la emergencia de una antrobología: una nueva condición humana aún más secundada o duplicada por robots inteligentes. Es la última etapa antes de la infiltración generalizada de chips en el interior de los tejidos biológicos, que operará así una conectividad permanente entre organismos y "servidores deductivos" consagrados a orientar, "para bien" y en toda ocasión, el curso de la vida (p. 29).

Por lo tanto, necesitamos reconocer que el foco ya no va a estar puesto simplemente en la gama de aparatos, tangibles e intangibles disponibles cada vez más, sino en cómo estos elementos afectan de manera profunda, y quizás ya sin vuelta atrás, nuestra forma de ser y de estar en el mundo.

El concepto clave que de manera operativa puede anudar estos elementos es el de convergencia.

Para autores como Henry Jenkins (2008), la convergencia designa una situación en la que coexisten múltiples sistemas mediáticos y en la que los contenidos discurren con fluidez a través de ellos. El concepto se entiende, aquí, como un proceso o una serie de intersecciones entre diferentes sistemas de medios y no como una relación fija. Específicamente el autor define en el mismo texto la convergencia cultural como el cambio en la lógica con la que opera la cultura, enfatizando el flujo de contenidos a través de los canales mediáticos, lo cual puede hoy ser repensado en términos más concretos, como dijimos anteriormente, de digitalización de la cultura. 
Consecuentemente, aquellas estructuras estructurantes que favorecen la reproducción desde el habitus (Bourdieu \& Passeron, [1979] 2018), hoy cuentan con la motivación externa que dispara esta convergencia digital para actualizarse en las prácticas cotidianas. Es decir que como sujetos somos garantes de la reproducción. En palabras de Jenkins (2008):

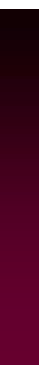
Los contenidos de entretenimiento no son lo único que fluye a través de las múltiples plataformas mediáticas. Nuestras vidas, relaciones, recuerdos, fantasías y deseos también fluyen por los canales de los medios. La vida del amante, la madre o el profesor discurre por múltiples plataformas. A veces arropamos a nuestros hijos en la cama por la noche y otras veces les mandamos mensajes instantáneos desde el otro extremo del planeta (p. 27).

Consecuentemente, también estamos siendo no simplemente garantes de esta reproducción, sino también probablemente parte de las generaciones que decodifiquen en su accionar cotidiano una nueva forma de relación con el mundo y con nuestros semejantes.

Hasta aquí, probablemente esto no constituya ninguna novedad, pero sí quizás lo sea para repensar los márgenes del campo de comunicación / educación, cuya densidad y opacidad creemos que en este momento está siendo profundamente afectada.

Trabajamos desde la perspectiva de un campo que se piensa en y desde la cultura, que reconoce los contextos históricos y socioculturales, que rompe con el afán cientificista de las miradas disciplinares y por lo tanto en el momento en el que tenemos que volver a revisar esta tríada de comunicación / educación / cultura, es de manera situada, aquí y ahora. Esta relación, se establece en prácticas concretas, donde hay un social histórico que observar a partir de los conceptos de convergencia y de cambios tecnológicos y socioculturales que debemos describir y objetivar en contextos específicos.

Por eso, consideramos necesario avanzar en la construcción de nuevos "mapas nocturnos", para perdernos primero y luego encontrar algunas pistas que nos permitan reconocer interrogantes clave que esta situación abre y que son parte de lo que cotidianamente encontramos en trabajos presentados en congresos, en nuevas publicaciones y en debates académicos o territoriales pero que aún quizás no encuentran la vía para ser reconfigurados a la luz de estos nuevos "tiempos modernos". 
Para empezar, qué impacto real tiene en las prácticas cotidianas de los sujetos este contexto; cómo problematizamos la coexistencia de temporalidades en donde en términos gramscianos lo nuevo no termina de nacer y lo viejo no termina de morir, con sujetos que disponen de multipantallas atravesando todo y otros que aún no poseen luz eléctrica; cómo actualizar en el siglo xxi el reconocimiento del universo vocabular de los sujetos como clave de inicio de cualquier proceso educativo emancipador y cómo hacer del allí del otro —en este caso, jóvenes y niños hipermediatizados - mi aquí, para consolidar estrategias de interpelación profundas y significativas; en momentos de reconexión de lo racional-operativo con lo artístico-creativo, cómo podemos reconfigurar estrategias de interpelación docente que nos permitan resignificar los procesos pedagógicos y acercarnos a los sujetos con los cuales vamos a trabajar en los próximos años; cómo reconocer nuestras marcas como docentes realizadas e internalizadas en el palimpsesto, cuando necesitamos vincularnos con sujetos del hipertexto; cómo relacionar las interfaces tecnológicas con sus configuraciones discursivas emocionales e incorporarlas al análisis como una renovada forma de lo que antiguamente fueron los aparatos ideológicos del Estado, esta vez no al servicio de naciones puntuales sino de un proceso de escala global que forma sujetos y produce unos sentidos para configurar un horizonte de posibilidades y, en el mismo movimiento, restringir otros; considerar de qué manera los medios y las tecnologías en educación pueden ser tomados desde una perspectiva emancipadora y propia de América Latina; cuál es el lugar de lo popular entendido como clave de lectura para Latinoamérica cuando está siendo reconfigurado en formas, gustos, accesos, mediaciones, aspiraciones y sueños.

Esto son solo algunos de los interrogantes que surgen al problematizar nuevamente la relación comunicación / cultura / educación, en tiempos de convergencia en los que los sujetos individuales y colectivos se redefinen en las narrativas digitales con grados de afectación diferenciados. Estos sujetos interactúan en prácticas significantes concretas, que un pensar situado tiene en cuenta a la hora de reflexionar sobre todo desde un campo como el de comunicación / educación.

Por lo dicho, y para cerrar este breve ensayo, afirmamos, entonces, que es fundamental revitalizar la reflexión en nuestro campo pero, sobre todo, actualizarlo para repotenciar su capacidad de intervención y de transformación del mundo, es decir su dimensión político estratégica. 


\section{Referencias}

Borón, A. (28 de octubre de 2018). Big data, fascismo y confusión. Página/12.

Recuperado de https://www.pagina12.com.ar/151631-big-data-fascismo-y-confusion

Bourdieu, P. y Passeron, J. C. [1979] (2018). La reproducción. Elementos para una teoría del sistema educativo. Madrid, España: Siglo XXI.

Buenfil Burgos, R. N. (1993). Análisis de discurso y educación. Documentos DIE 26. Ciudad de México, México: Instituto Politécnico Nacional.

Eco, U. [1964] (1984). Apocalípticos e integrados. Madrid, España: Lumen.

Huergo, J. (2000). Tecnologías y educación. Interrogaciones desde la trama entre cultura y política. Razón y palabra, 4(16). Recuperado de http://www.razonypalabra.org.mx/anteriores/n16/jhuergo16.html

Huergo, J. (2003). Lo que articula lo educativo en las prácticas socioculturales. Nodos de comunicación / educación, (1). Recuperado de https://perio.unlp.edu.ar/catedras/system/files/huergo-jorge lo-que-articulalo-educativo.pdf

Jenkins, H. (2008). Convergence Culture. La cultura de la convergencia de los medios de comunicación. Barcelona, España: Paidós.

Laclau, E. y Mouffe, C. (1987). Hegemonía y estrategia socialista. Hacia una radicalización de la democracia. Madrid, España: Siglo XXI.

Martín-Barbero, J. (2009). Culturas y comunicación globalizada. I/C Revista científica de información y comunicación, (6), 175-192.

Mattelart, A. (1994). La comunicación-mundo. Historia de las ideas y de las estrategias. Madrid, España: Fundesco.

Rodríguez, S. (1842). Sociedades americanas en 1828. Lima, Perú: Imprenta del Comercio.

Sadin, E. (2017). La humanidad aumentada. La administración digital del mundo. Ciudad Autónoma de Buenos Aires, Argentina: Caja Negra.

Schwab, K. (2016). La cuarta revolución industrial. Madrid, España: Debate. 


\section{Epistemología de la convergencia}

Para que la oruga se convierta en mariposa debe encerrarse en una crisálida.

Lo que ocurre en el interior de la oruga es muy interesante: su sistema inmunitario comienza a destruir todo lo que corresponde a la oruga, incluido el sistema digestivo, ya que la mariposa no comerá los mismos alimentos que la oruga.

Lo único que se mantiene es el sistema nervioso.

Así es que la oruga se destruye como tal para poder construirse como mariposa.

Y cuando ésta consigue romper la crisálida, la vemos aparecer, casi inmóvil, con las alas plegadas, incapaz de desplegarlas. Y cuando uno empieza a inquietarse por ella, a preguntarse si podrá abrir las alas, de pronto la mariposa alza en vuelo.

Edgar Morin (1984)

Desde que decidimos investigar la convergencia tecnológica supimos que estábamos frente a un fenómeno complejo, profundo, contradictorio. Que se trataba de un objeto a todas luces desafiante, tanto por lo gigantesco como por involucrar una buena cantidad de saberes provenientes de diferentes campos y disciplinas.

Una serie de situaciones que podían percibirse aisladas, como el pantallismo, el Big Data, la minería de datos, la posverdad, las fake news, los algoritmos que dan lugar a la catarata de información que diariamente fluye y a pesar de los esfuerzos por ponerle fin y su articulación hipotética con la conocida industria cultural, compuesta por cine, TV, radio, internet y redes sociales, parecen mancomunarse para intervenir sobre el usuario, el consumidor, el sujeto cada vez más sujetado.

Sabemos que la episteme (Díaz \& Heller, [1987] 1999) es aquello que designa las condiciones de posibilidad del conocimiento en un lugar y una época, de tal modo que debimos situarnos en contexto, vale decir, en los inicios del tercer milenio y, puntualmente, en esta segunda década, en esta parte del mundo, en la Argentina, en el cono sur, donde ya no se trata solo de una cuestión de medios ni de tecnologías, ni de masividad e industrias culturales. 
Lo que llaman convergencia digital, abanico de enorme dispersión conceptual, configura un nuevo objeto de conocimiento que parece haberse situado en el centro de la cotidianeidad de nuestras prácticas sociales, desarmando las categorías conocidas, de ámbitos públicos y privados, disolviendo las fronteras entre trabajo y ocio, entre publicidad y propaganda, entre masividad, redes e individualidad, entre conciencia y alienación, verdad y falsedad, disciplinamiento y aprendizaje, libertad y control, deseo y cooptación, información y educación, lo formal y no formal. Podría afirmarse, en ese sentido, que el objetivo general de este trabajo es de orden epistémico y epistemológico, en tanto práctica de conocimiento y reflexión sobre la episteme.

Se dice que cuando un saber se hace fuerte genera nuevos conceptos, valores y técnicas. Y surgen entonces nuevos sujetos. Así como las prácticas sociales son del orden del poder, para estudiarlas como seres libres debemos ser seres libres. Si no aceptáramos este desafío por una restricción de las disciplinas científicas, entonces caeríamos en una especie de oscurantismo.

Y si de dominios de saber se habla, se habla del orden de la verdad. Y no hay poder que no requiera de un saber que lo legitime; en este caso, el innovador desarrollo tecnológico que debe llegar a todos los ámbitos: de la ciencia, la comunicación, la educación, la salud y la política, entre otros. A Michel Foucault (1979) le preocupaba entender las condiciones de posibilidad del conocimiento. Y en esa intención creemos que está la clave para entender que las condiciones de posibilidad de este objeto de saber han sido creadas desde el poder que lo sostiene mientras la convergencia tecnológica es utilizada en su favor. Lo que no aparece visible es la dinámica de red con que el poder fluye, por ejemplo como veremos más adelante cuando las dinámicas del capitalismo se imprimen en la redes de socialidad, dejando integradas las lógicas del mercado en las formas de relación social.

Por otra parte, si la ideología es falsa conciencia, la verdadera conciencia está más allá. La verdad es la correspondencia entre una proposición y el estado de cosas al que este refiere. En definitiva, la Verdad es una construcción histórica.

La necesidad de una fundamentación epistemológica en el caso de las ciencias sociales, en general, y de la comunicación, en particular, adquiere una importancia mayor por lo ya dicho y por las implicaciones sociopolíticas que posee el estudio de la sociedad. Además, al tratarse de una tesis del campo de comunicación / educación, tenemos que partir de una premisa: no existe proyecto / proceso educativo que no posea un sentido 
político. Es decir que no podemos desconocer que anudados a la dimensión formativa, en las prácticas educativas existen una dimensión política y un horizonte cultural que completan el sentido de la misma.

De alguna manera, lo que se plantea es la dificultad de abordaje del problema desde una / alguna disciplina. Por consiguiente, las preguntas iniciales ubican el objeto de conocimiento en una zona de contacto que determina la necesidad de trabajo interdisciplinar. Dicho de otro modo, la cuestión que se plantea, la convergencia tecnológico digital, aparece como un fenómeno complejo.

En razón de eso, encontramos en el paradigma de la complejidad una posibilidad de avanzar en la construcción de un escrito que no pretenda ser acabado, que reconozca sus limitaciones no solo por ser una tesis, sino básicamente por ser una instancia de racionalización de un proceso real, existente.

Lo que se pretende es en primera instancia alcanzar un conocimiento, para lo cual se percibe necesaria la conformación de una malla o una matriz conceptual que nos permita atravesar la práctica — nudo de prácticas—, deconstruirla, darle nuevas formas y trabajar en la construcción de un conocimiento que sea fruto de ese encuentro entre una gestión que formula procesos concretos de índole cultural y una conceptualización específica.

Uno de los principales desafíos que reconocemos en este recorrido tiene que ver con que consideramos que ni el objeto está allí a la espera de ser analizado, ni los conceptos cerrados, aguardando ser puestos a trabajar sobre un fenómeno en particular. La praxis, entendida como el encuentro entre acción y reflexión, apunta a reconstruir la práctica, ya no como un suceso real, sino como un elemento a ser analizado y en esa línea, la trama conceptual aparecerá diseñada teniendo en cuenta dos sentidos: las características propias que pueda imprimir el tipo de objeto a analizar, por un lado, y la reflexividad del sujeto que reelabora estas dimensiones, por el otro.

En el entramado interno de las páginas que siguen, lo que da coherencia, más allá de marcos generales, es la indagación, el proceso y las diversas dificultades o problemáticas que se reconocieron como analizables, es decir que lo que construimos no es un decálogo de conceptos o ideas, sino una especie de instrumento diseñado ad hoc para luego poder elaborar una pieza en particular. Si nuestro trabajo fuera el de un artesano, en estos momentos aún estaríamos en la etapa previa, correspondiente a la fabricación de 
nuestras propias herramientas, a partir de materiales existentes, sabiendo que las mismas nos posibilitarán algunas formas más acabadas, pero simultáneamente nos obturarán otras alternativas, y sobre esto se hace necesario también ensayar.

\section{La complejidad del pensamiento complejo}

Para comenzar a trabajar en una mirada epistemológica de nuestro trabajo, se hace necesario reconocer en principio el porqué del posicionamiento que se propone para el abordaje de esta tesis.

Encontramos en el paradigma de la complejidad una posibilidad de avanzar en la construcción de un escrito que no pretenda ser acabado, que reconozca sus limitaciones no solo por ser una tesis, sino básicamente por ser una instancia de racionalización de un proceso concreto, existente, un fenómeno que altera cada vez más diferentes órdenes de la vida y que, por lo tanto, se hace difícil identificar con claridad. Por ello, para complementar el ensayo como género seleccionado consideramos necesario plantear las bases de una mirada epistemológica que acompañe el desarrollo de la indagación aquí propuesta.

En cuanto al carácter complejo de la tarea emprendida, y siguiendo el rastreo realizado por Edgar Morin (1999), podemos encontrar una primera definición en el Diccionario de uso del español, de María Moliner (1998), que define complejidad como: complejo, complicado/ "se aplica a un asunto en el que hay que considerar muchos aspectos por ser difícil de resolver o comprender". Desde un punto de vista etimológico, complejidad es de origen latino, "complectere", cuya raíz "plaectere" significa trenzar, enlazar. El agregado del prefijo com- añade el sentido de dos elementos opuestos que se enlazan íntimamente, pero sin anular su dualidad.

Debemos hablar de pensamiento complejo porque nos introducimos en una epistemología de segundo orden o conocimiento del conocimiento. Una epistemología compleja cuyo esfuerzo se oriente, no tanto al estudio de los sistemas observados, como a las dinámicas reflexivas.

Si bien la complejidad emerge en el campo de las ciencias naturales, no es menos cierto que si existe un ámbito al que le corresponde por antonomasia el calificativo de complejo es al mundo social y humano, que por cierto es primordial para la experiencia educativa (Morin, Ciurana \& De Motta, 2003). 


\section{Pero, entonces, ¿qué es la complejidad?}

A primera vista, la complejidad es un tejido [...] de constituyentes heterogéneos inseparablemente asociados: presenta la paradoja de lo uno y lo múltiple. [...] la complejidad es, efectivamente, el tejido de eventos, acciones, interacciones, retroacciones, determinaciones, azares, que constituyen nuestro mundo fenoménico (Morin, 1994, p. 32).

Aquello que es complejo recupera por una parte el mundo empírico, la incertidumbre, la incapacidad de lograr la certeza, de formular una ley eterna y por el otro la incapacidad de evitar contradicciones. En una visión clásica, cuando la contradicción aparecía en un razonamiento era señal de error. Significaba dar marcha a atrás y emprender otro razonamiento. Pero en la visión compleja, cuando se llega por vías empírico-racionales a contradicciones significa el hallazgo de una capa profunda de la realidad, que justamente por ser profunda no puede ser traducida a nuestra lógica.

El texto y el contexto, la relación entre lo singular y lo plural, entre el individuo y el grupo, o entre el sujeto y la sociedad. La unidad y la multiplicidad se presentan como momentos de un proceso dinámico donde, dependiendo del foco, nos posaremos en uno $\mathrm{u}$ otro extremo, pero ya sin desconocer que simplemente se está realizando una operación analítica, arbitraria en sí misma, que separa allí donde existen tramas que no pueden dejarse de lado y deben ser explicitadas. Se hace imposible ya suponer una visión donde los componentes aislados puedan tener una relevancia en sí mismos, sino que solo son en tanto están en relación con otros componentes o con el sistema como totalidad (abierta).

Aquí y como se mencionó anteriormente, se plantea una clara limitación del pensamiento científico al reconocer su imposibilidad de comprender ciertos niveles del mundo objetivo y de decodificarlo en un lenguaje que podamos entender. Pero en este punto no creemos que se esté haciendo referencia a una cuestión de falta de instrumentos (técnicos o conceptuales), sino a limitaciones en sí mismas del pensamiento cientificista que durante mucho tiempo creyó ser el camino que lograría comprender los esquemas más profundos de la realidad y que hoy debe reconocer su limitación como algo constitutivo del propio campo. Sin lugar a dudas, esto afecta la forma en que se valora el pensamiento científico, pero también permite ver que aunque no todo puede ser comprendido por esta vía o quizás, mejor dicho, no todo puede ser 
comprendido por la racionalidad del hombre (por sus propias limitaciones). Pero siendo más claros los límites, mayor es el potencial de acción dentro de los espacios en los que claramente el saber de las ciencias ha logrado avanzar, por lo tanto, reconocer ciertas condiciones no sería en este caso una debilidad, sino un paso necesario para lograr afianzar aquello que queda por dentro del campo de las ciencias.

La existencia de capas profundas de la realidad incognoscible, o por lo menos el hecho de asumirlas dentro de un marco epistemológico, nos deja abierta la posibilidad de afirmar que finalmente el verdadero problema no es convertir la complicación de los desarrollos en reglas de base simple, sino asumir que la complejidad está en la base.

Actualmente, la complejidad designa el estudio de sistemas dinámicos que están en algún punto intermedio entre el orden total y el desorden absoluto. Hay muchos sistemas en la naturaleza que van cambiando su comportamiento con el transcurrir del tiempo. Dichos fenómenos aparecen cuando los sistemas se hacen extremadamente sensibles a las condiciones iniciales de modo que, alteraciones muy pequeñas en sus causas son capaces de provocar grandes diferencias en los efectos y por lo tanto es imposible predecir cómo se comportarán más allá de cierto tiempo.

Pero los investigadores han encontrado que los sistemas dinámicos en estas condiciones presentan pautas de regularidad colectiva aunque no sea posible distinguir el comportamiento individual de cada uno de sus componentes (Morin, Ciurana \& De Motta, 2003).

En consecuencia, se rompe con la idea de un orden universal, con la visión de que solo se puede hacer ciencia de lo general. Al complejizarse, la idea de orden se relativiza. El orden no es absoluto, sino relacional y relativo, depende de sus condiciones de aparición, de existencia y de continuación y ha de ser reproducido sin cesar: todo orden tarde o temprano tiene fecha de defunción.

$\mathrm{Al}$ respecto, Morin (2003) afirma de manera contundente que «esquemas simplificadores dan lugar a acciones simplificadoras y esquemas unidimensionales dan lugar a acciones unidimensionales» (p. 64), por lo tanto, podemos deducir la necesidad de construir esquemas o mejor dicho sistemas complejos, para poder producir esquemas de comprensión y planificaciones para la acción, multidimensionales y que logren abordar la pluralidad de elementos que intervienen en los procesos mediados por la tecnología, en un contexto en el que la convergencia reconecta de formas diferentes y novedosas elementos de la vida social anteriormente aislados o dominados por lógicas diferentes. 
Es en este sentido donde se debe tener presente esta mirada si de lo que se trata es de procesos educativo comunicacionales. Mucho más que en otros campos, esta perspectiva es central para comprender la producción social de sentidos, las prácticas culturales, los procesos de resignificación y los diversos modos de relación que existen entre los sujetos.

Finalmente, Morin (1999) define como paradigma de la complejidad

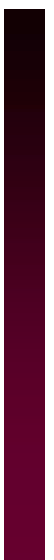

un principio de distinciones / relaciones / oposiciones fundamentales entre algunas 'nociones matrices' que generan y controlan el pensamiento, es decir la constitución de teoría y la producción de los discursos de los miembros de una comunidad científica determinada. De ello resulta una evidente ruptura epistémica, una transformación fundamental de nuestro modo de pensar, de percibir y de valorar la realidad signada por un mundo global que interconecta pensamientos y fenómenos, sucesos y procesos, donde los contextos físicos, biológicos, psicológicos, lingüísticos, antropológicos, sociales, económicos, ambientales, son recíprocamente interdependientes (p. 63).

\section{Características del pensamiento complejo}

El pensamiento complejo no desprecia lo simple: critica la simplificación.

Para reconocer procesos o fenómenos sociales en los cuales se intenta intervenir, es central dar cuenta de lo analizado, poniendo en tensión la necesidad operativa de una síntesis aprehensible y comunicable, con una mirada que no reduzca, que no achate la realidad. Se puede interpretar como una contradicción, la necesidad de ser simples en la exposición de los resultados obtenidos con la simplificación de los procesos o de los fenómenos analizados. Pero esto debe mantenerse como dos momentos diferenciados del proceso: uno denso, con tramas superpuestas interrelacionadas entre sí, y otro que permita utilizar los resultados como insumo básico para una propuesta de planificación.

La complejidad concierne no solo a la ciencia, sino también a la sociedad, a la ética y a la política. Por eso es un problema de pensamiento y de paradigma. Concierne a una epistemología en general. Va más allá de una forma de reflexión sobre cómo conocemos; constituye una mirada sobre el mundo, una forma de comprender cómo nos vinculamos con él, desde el lugar de sujetos, sujetados y amarrados a una cultura en la cual estamos inmersos, pero que por cuestiones mismas de la limitación en nuestras capacidades (racionales) de conocer, debemos aceptar nuestro potencial pero también nuestras incapacidades constitutivas. 
De esta manera, Edgar Morin, Emilio Roger Ciurana y Raúl Domingo Motta (2003) concluyen en una apreciación que será clave para comprender las limitaciones del trabajo de conceptualización de una experiencia de intervención: "Un pensamiento complejo nunca es un pensamiento completo. No puede serlo" (p. 66) El pensamiento complejo está animado por una tensión permanente entre la aspiración a un saber no parcelado, no dividido, no reduccionista y el reconocimiento de lo inacabado e incompleto de todo conocimiento.

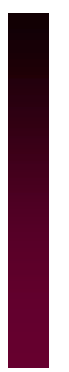
La educación debe considerar que la experiencia del siglo $\mathrm{xX}$, tanto en ciencias como en arte, muestra un nuevo rostro de la incertidumbre y de la confusión. No se trata solamente del clásico tópico de la ignorancia humana en general, sino de la ignorancia agazapada, disimulada, casi nuclear en el corazón de nuestro conocimiento reputado como el más cierto, es decir como conocimiento científico (Morin, Ciurana \& Motta, 2003, p. 68).

Así, del "conócete a ti mismo" socrático pasamos al conócete a ti mismo conociendo. En ese sentido, el "método" es reaprender a aprender en un caminar sin meta definida de antemano (Morin, Ciurana \& De Motta, 2003). Y este sería el sentido principal de un posicionamiento ante una primera etapa de diagnóstico comunicacional, estableciendo una serie de prenociones o de preconceptos que permitan comenzar a operar, pero sin una hoja de ruta pretrazada, sin un lugar al cual llegar para confirmar o para justificar nuestros juicios. Se trata en cambio de lograr articularnos con la dinámica que el propio proceso vaya desarrollando y en ese mismo movimiento nos revele la información y el conocimiento necesarios para comprender el escenario en el cual nos toca intervenir.

En la concepción que Rolando García (2007) propone de los sistemas complejos, lo que está en juego es la relación entre los objetos de estudio y las disciplinas a partir de las cuales se realiza el estudio. En dicha relación, la complejidad está asociada a la imposibilidad de considerar aspectos puntuales de un fenómeno, de un proceso o de una situación a partir de una disciplina específica. En otros términos, en el mundo real, las situaciones o los procesos no se presentan de manera que puedan ser clasificados por su correspondencia con alguna disciplina en particular. En este sentido podemos hablar de una realidad compleja. Un sistema complejo es una representación de un recorte de esa realidad, conceptualizado como una totalidad organizada (de ahí la denominación de sistema) en la cual los elementos no son separables y, por lo tanto, no pueden ser estudiados aisladamente (García, 2007). 
La delimitación de un sistema complejo no solo requiere de una concepción común entre los miembros de un equipo, sino también de una base conceptual y de una concepción compartida de la investigación científica y de sus relaciones con la sociedad. En este sentido, podemos afirmar que lo desarrollado por este autor, en última instancia (y vinculado a la relación entre la investigación científica y la sociedad), se relaciona con la dimensión política del proyecto de trabajo y con la valoración del proceso realizado en términos de transformación social. Por ello afirma que en el estudio de los sistemas complejos es indispensable que dicha conciencia esté siempre en acción, puesto que se suele tratar de temáticas globales donde los factores sociales juegan un rol fundamental.

De la conciencia particular de las condiciones sociales que determinan la direccionalidad particular que está impresa en cualquier investigación, depende el carácter realmente explicativo que alcance el modelo que resulte del análisis (García, 2007). A nuestro entender, se ponen en relación el pensamiento complejo con la convergencia, mediante operaciones que siendo digitales son naturalmente semióticas, que no solo reconfiguran racionalidad o formas del conocimiento, sino que desatan procesos simbólicos opacos, aleatorios, impredecibles, en muchos casos, fruto de un nuevo orden de mediación entre los sujetos y el mundo (Bajtín, [1982] 1998).

En conclusión, entendemos que la adopción de la mirada desde la perspectiva de la comunicación / educación, tal como la entendiera Jorge Huergo, es posible, y además necesaria, como construcción a partir de una articulación disciplinar de un campo epistémico que se reconoce, a la vez, como campo de carácter político.

Por todo lo dicho, los problemas y las dificultades planteados por el objeto convocan un modo de acceso epistemológico particular que rechace el binarismo y la linealidad. La convergencia tecnológica, entendida como fenómeno cultural, requiere para su comprensión de una matriz que desde la complejidad habilite una mirada profunda, a veces contradictoria, que navegue por la superficie de los hiperdinámicos hechos que a diario modifican nuestro paisaje cotidiano, pero que se detenga por momentos y bucee en sus profundidades. Estos diferentes niveles de relación, en los que se articulan líneas que abordan problemas mediático comunicacionales y elementos educativos, son líneas paralelas que deben desplegarse para luego mirar transversalmente en cada uno elementos que son constantes, es decir regularidades de la convergencia en la dispersión de fenómenos como los del campo de comunicación / educación. 


\section{Referencias}

Bajtín, M. [1982] (1998). Estética de la creación verbal. Ciudad de México, México: Siglo XXI.

Díaz, E. y Heler, M. [1987] (1999). El conocimiento científico. Hacia una visión crítica de la ciencia. Ciudad Autónoma de Buenos Aires, Argentina: Eudeba.

Foucault, M. (1979). Historia de la sexualidad. 1. La voluntad del saber. Ciudad Autónoma de Buenos Aires, Argentina: Siglo XXI.

García, R. (2007). Sistemas complejos. Conceptos, método y fundamentación epistemológica de la investigación interdisciplinaria. Madrid, España: Gedisa.

Moliner, M. (1998). Diccionario de uso del español. Madrid, España: Gredos.

Morin, E. (1984). Ciencia con consciencia (Trad. Ana Sánchez). Barcelona, España: Anthropos.

Morin, E. (1994). Introducción al pensamiento complejo (Trad. Marcelo Pakman). Barcelona, España: Gedisa.

Morin, E. (1999). La cabeza bien puesta. Ciudad Autónoma de Buenos Aires, Argentina: Nueva Visión.

Morin, E., Ciurana, E. R. y Motta, R. D. (2003). Educar en la era planetaria. Barcelona, España: Gedisa. 


\section{Claves conceptuales desde comunicación / educación}

Las bases tradicionales de comunicación / educación continúan siendo, sin duda, fundamentos necesarios, insustituibles, para repensar el trabajo en esta tesis, sobre todo desde la perspectiva desde la cual analizamos el fenómeno que intenta retomar múltiples miradas pero tamizarlas con las tradiciones de un campo que se funda al calor de las luchas y el desarrollismo en América Latina.

Es por ello que más allá de que encontraremos en cada escrito autores y conceptos clave para abordar el proceso de convergencia tecnológica y de digitalización de la cultura en múltiples perspectivas, el punto de partida necesario está puesto en las matrices de las cuales estamos hechos (Huergo, 2015).

\section{La perspectiva de la comunicación / educación}

A continuación, se propone partir de la consideración del campo de comunicación / educación, reconociendo en él sus principales categorías, el sentido de la articulación y una apretada síntesis de su genealogía a fin de hacer de él una herramienta conceptual fuerte para la aproximación al objeto que motiva esta tesis. De esta manera, se pone de manifiesto que se trata de un objeto de conocimiento marcado por la complejidad y que requiere de un abordaje conceptual que reconozca la necesidad de superación de viejos límites disciplinares al tiempo que produce un acercamiento fiel a las raíces latinoamericanas desde las que el objeto pretende ser aprehendido.

Los conceptos se presentan a continuación con una lógica secuencial y explicativa, sabiendo que en realidad se interrelacionan, constituyendo una matriz conceptual que opera de manera conjunta. 
Si retomamos la idea de que las categorías bajo las que se formulan las preguntas iniciales de la investigación no constituyen un hecho empírico observable, sino una construcción condicionada por el marco epistémico, podemos afirmar que este entramado conceptual que a continuación se desarrolla, está justamente anclado y profundamente vinculado con la visión que propone Rolando García (2007) sobre la complejidad.

En este sentido, hay que considerar en un primer nivel el entramado de conceptos como comunicación, por un lado, y educación, por otro, lo que se realiza necesariamente en relación, como se planteaba más arriba, con la cultura donde se fraguan las identidades, y la política, espacio peculiar de construcción de sentidos que nos atraviesan, en contextos particulares donde los discursos materializan y ponen en tensión esta articulación que se orienta a prácticas sociales liberadoras y plenas de sentido.

Se trata, en consecuencia, de una matriz que tradicionalmente ha sido trabajada desde "el imperialismo de las disciplinas" (Martín-Barbero, 1989), razón por la cual Jorge Huergo (2006) propuso la necesidad de considerar su articulación, con el objeto de evitar las soluciones parciales o los consejos, provengan de uno u otro campo de conocimiento.

Cuando proponemos de hecho en el texto sustituir la cópula "y", de Comunicación "y" Educación, por la barra "/": Comunicación / Educación (a la manera de Schmucler, 1984), lo que tenemos como propósito es significar:

- la recuperación de procesos (en los diferentes niveles mencionados) de vinculación / expresión / liberación, aunque se pierdan los objetos disciplinares delimitados por un afán cientificista, o a costa de la posible ruptura con los “imperialismos" de las disciplinas (Martín-Barbero, 1989);

- el reconocimiento de los contextos históricos, socioculturales y políticos (además de los campos disciplinares) donde surgen o se originan los problemas y las producciones teóricas (cfr. la perspectiva al respecto de Armand Mattelart);

- la propuesta de algunas bases preliminares (que implican aquella recuperación y aquel reconocimiento histórico, y no una propuesta "fundacional") para la construcción de un espacio teórico transdisciplinario, movido más por un campo problemático común con relaciones tensas, que por miradas disciplinares escindidas; lo que significa devolver el carácter ético-político al campo de Comunicación / Educación (Huergo, 2006, en línea). 


\section{La articulación comunicación / educación}

Esta matriz conceptual comienza con identidad, continúa con educación y llega, finalmente, a una noción de comunicación que se nutre del resto de las perspectivas planteadas, cerrando el punto central de la mirada y del enfoque que este trabajo intenta sostener.

Como punto de partida se trabaja sobre la base de la imposible disociación de comunicación / educación con la cultura y, más precisamente, con las formas en las que los sujetos se encuentran vinculados con ella.

Sabemos que la comunicación es indisociable de la cultura porque es dentro de ella que los procesos de producción social de sentidos se realizan. Es la dimensión significativa de los fenómenos lo que hace que desde la comunicación se puedan observar. Es desde la cultura (desde dentro de ella) y sobre la cultura, en donde se enmarca esta reflexión, y se vincula con su subjetivación en forma de identidad, a modo de cultura distintivamente internalizada.

Este concepto es importante ya que lo que se intenta describir son procesos educativo / comunicacionales que se desarrollan dentro y fuera de las instituciones educativas.

\section{Sobre las identidades sociales}

Tradicionalmente, las identidades sociales estaban determinadas por la filiación a un Estado-Nación y por fronteras nacionales nítidas y rígidas, por la cultura escrita, por papeles sociales fijos y estables, por relaciones sociales basadas en la autoridad y en la jerarquía, por identificaciones sexuales y culturales bien definidas y determinadas.

Para Stuart Hall ([1996] 2003), la identidad se debe pensar como una producción que no está nunca completa, que está siempre en proceso y está siempre "constituida en el interior y no fuera de la representación" (p. 62). En esa perspectiva, "la identidad no está conformada en torno a un núcleo de autenticidad, de una experiencia cultural compartida, que definiría las diferentes culturas" (Hall, [1996] 2003, p. 63). La propia diferencia es siempre el resultado de un proceso de construcción. "La identidad cultural tiene una historia, no es algo que, simple, naturalmente, exista" (Hall, [1996] 2003, p. 97). 
La identidad social adquiere importancia por la emergencia y por la visibilidad de los distintos grupos y movimientos que reivindican voz y participación en el juego de la política de identidad, y esta está en el centro de las disputas por la representación y distribución de recursos materiales y simbólicos. "No es preciso decir que la educación institucionalizada y el currículum oficial o no, están paralelamente, en el centro de la formación de identidad" (Hall, [1996] 2003, p. 102).

Para construir un encuadre sobre esta noción, primeramente tomaremos a Gilberto Giménez (1997). Como propuesta inicial, el autor plantea:

[...] situar la problemática de la identidad en la intersección de una teoría de cultura y de una teoría de los actores sociales [...] concebir la identidad como un elemento de una teoría de la cultura distintivamente internalizada como "habitus" (Bourdieu, 1979) [pp. 10-11].

La identidad, pues, no sería más que el aspecto subjetivo de la cultura considerada bajo el ángulo de su función distintiva.

Un rasgo principal de este concepto es el de la distinguibilidad, es decir, la posibilidad o la necesidad de ser particulares y de poseer una identidad personal. Esta característica se asienta sobre tres pilares:

- La pertenencia social, siendo la pluralidad de pertenencias la que define y constituye la identidad personal.

- Los atributos identificadores. Son un conjunto de características tales como disposiciones, hábitos, tendencias y la imagen del propio cuerpo, que se derivan de la percepción que se presenta en los procesos de interacción social.

- Una narrativa biográfica. Esta narrativa reconfigura una serie de actos y trayectorias personales del pasado para otorgarle un sentido.

Por lo tanto, el individuo se ve a sí mismo y es reconocido como perteneciendo a una serie de colectivos, como siendo una serie de atributos y como cargando un pasado biográfico incanjeable e irrenunciable.

Ttambién es necesario hacer referencia a las particularidades que el autor encuentra en las identidades colectivas. En este caso, se trata de entidades relacionales que se presentan como totalidades diferentes de los individuos que las componen y que, en cuanto tales, obedecen a procesos y a mecanismos específicos (Giménez, 1997). 
En este sentido, el autor propone una serie de cualidades en torno a las mismas: por un lado, sus condiciones sociales de posibilidad son las mismas que las que condicionan la formación de todo grupo social. Pero la formación de las identidades colectivas no implica en lo absoluto que estas se hallen vinculadas a la existencia de un grupo organizado, por lo tanto, la identidad colectiva no es sinónimo de actor social. Por otro lado, no todos los actores de una acción colectiva comparten unívocamente y en el mismo grado las representaciones que en ese momento circulan; ni toda identidad colectiva genera una acción colectiva, o viceversa. Es decir que tanto en el terreno de las acciones, como en el de las representaciones, las identidades colectivas no tienen necesariamente por efecto la despersonalización o la uniformización de los comportamientos individuales, sino que actúan de manera complementaria y relacional con otras identidades que entran en juego con el sujeto.

La identidad implica la percepción de ser idéntico a sí mismo a través del tiempo, del espacio y de la diversidad de situaciones. Es necesario hablar de continuidad en el cambio, por lo que la identidad corresponde a un proceso evolutivo, y no a una constancia sustancial. La dialéctica entre permanencia y cambio es lo que caracteriza a las identidades colectivas y a las individuales. La identidad se define primariamente por la continuidad de sus límites. Se halla siempre dotada de cierto valor para el sujeto, generalmente distinto del que le confiere a los demás sujetos que constituyen su contraparte en el proceso de interacción social.

Las identidades sociales requieren, en primera instancia y como condición de posibilidad, de contextos de interacción estables en forma de mundos familiares, de la vida cotidiana. Este contexto endógenamente organizado permite a los sujetos administrar su identidad y sus diferencias. Debe postularse una relación de determinación recíproca entre la estabilidad relativa de los contextos de interacción y la identidad de los actores que inscriben en ellos sus acciones concertadas.

Los límites de los contextos son variables según la escala a considerar y se tornan visibles cuando implican también procedimientos formales de inclusión-identificación. $\mathrm{Al}$ interior de las sociedades modernas existe una pluralización del mundo de la vida, lo que amplía el espectro de los contextos. "La dinámica de la identidad moderna es cada vez más abierta, proclive a la conversión, exasperadamente reflexiva, múltiple y diferenciada" (Sciolla, 1983, p. 48, citado por Giménez, 1997, p. 22). 
Las interacciones sociales no se producen en el vacío, sino que se encuentran imbricadas dentro de los diferentes campos sociales. Desde esta perspectiva, se puede decir que la identidad no es más que la representación de los agentes (individuales o colectivos) de su posición (distintiva) en el espacio social y de su relación con otros agentes que ocupan la misma posición o posiciones diferenciadas en el mismo espacio. El conjunto de representaciones que define la identidad de un determinado agente nunca desborda o transgrede los límites de compatibilidad definidos por el lugar que ocupa en el espacio social.

En la vida social, las posiciones y las diferencias de posiciones que fundan la identidad existen bajo dos formas: una objetiva, independiente de todo lo que los agentes puedan pensar de ellas; y una simbólica o subjetiva, bajo la forma de representación que los agentes se forjan de ellas, dando lugar a diferentes apreciaciones, miradas o perspectivas.

La teoría de la identidad permite entender mejor la acción y la interacción social: es la identidad la que permite a los actores ordenar sus preferencias y escoger ciertas alternativas de acción. Desde esta perspectiva, se define a la identidad como la capacidad de un actor de reconocer los efectos de su acción como propios y atribuírselos.

Para ampliar la mirada sobre este concepto, también nos parece necesario retomar algunas reflexiones que propone Isidro Moreno (1991) sobre la temática. Según este autor, son tres los principios identitarios fundamentales (o polos de identidad, según se los nombrará posteriormente) que actúan en cada individuo: la identidad étnica, la identidad de género y la identidad de clase o profesional. Estas tres identidades forman parte de un sistema en el que funciona la contraposición "nosotros-ellos".

Estos principios funcionan en cada sociedad y época histórica estrechamente interrelacionados. Cada uno de ellos tiende a modelar una cultura globalizante: cultura étnica, cultura de género, cultura de trabajo, que no tienen una existencia real por separado sino que configuran otros tantos modelos abstractos de referencia, que están, además, interconectados y que funcionan en el marco general de la cultura hegemónica dominante. [...]

El resultado de esta interacción conforma lo que podemos llamar matriz cultural: un sistema no armónico, con contradicciones y desajustes, que funciona en cada individuo humano como base de sus percepciones, interpretación de las experiencias y sus comportamientos; en definitiva, como matriz de identidad. Siendo el concepto último cercano aunque no equivalente, al concepto de habitus de Pierre Bourdieu (Moreno, 1991, p. 21). 
Es muy coherente para el tipo de análisis que se pretende llevar adelante en este trabajo recuperar la noción de identidad en términos de matriz cultural, lo que implica dejar abierta la posibilidad de pensar rasgos o parcialidades de la misma, por no estar planteada como una totalidad cerrada, cristalizada y positiva, es decir, con valor propio.

Desde esta mirada, se alcanza una primera aproximación teórica al modo en el que se conforman las identidades, pero para relacionarlas con el mundo de las prácticas y de las representaciones es necesario ampliar y profundizar el concepto de habitus.

\section{Identidad y habitus}

Pierre Bourdieu ([1980] 2007) afirma que los condicionamientos asociados a una clase particular de condiciones de existencia producen habitus, esto es,

\footnotetext{
un sistema de disposiciones duraderas y transferibles, estructuras estructuradas predispuestas para funcionar como estructuras estructurantes, es decir, como principios generadores y organizadores de prácticas y de representaciones que pueden estar objetivamente adaptadas a su fin sin suponer la búsqueda consciente de fines y el dominio necesario de las operaciones para alcanzarlos, objetivamente reguladas y regulares sin ser el producto de la obediencia a reglas, $\mathrm{y}$, a la vez que todo esto, colectivamente orquestadas sin ser producto de la acción organizadora de un director de orquesta.

$[\ldots]$

El mundo práctico que se constituye en la relación con el habitus como sistema de estructuras cognitivas y motivacionales, es un mundo de fines ya realizados, modos de empleo o caminos a seguir y de objetos dotados de un carácter teleológico permanente; las regularidades propias de una condición arbitraria tienden a aparecer como necesarias, naturales incluso, debido a que están en el origen de los principios de percepción y de apreciación a través de los que son aprehendidas (p. 92).

$[\ldots]$

Producto de la historia, el habitus produce prácticas individuales y colectivas [...]; asegura la presencia activa de las experiencias pasadas que, depositadas en cada organismo bajo la forma de principios de percepción, de pensamiento y de acción, tienden con mayor seguridad que todas las reglas formales y normales explícitas, a garantizar la conformidad de las prácticas y su constancia a través del tiempo (p. 91).
} 
Es "el pasado que sobrevive en la actualidad y que tiende a perpetuarse en el provenir actualizándose en las prácticas estructuradas según sus principios, ley interior a través de la cual se ejercen continuamente la ley de necesidades externas irreductibles a las constricciones inmediatas de la coyuntura" (Bourdieu, [1980] 2007, p. 95). Interiorización de la exterioridad, permite a las fuerzas exteriores ejercerse, pero según la lógica específica de los organismos en los que están incorporadas; es decir, de manera duradera, sistemática y no mecánica.

Según Bourdieu ([1980] 2007), a través del habitus la estructura que lo produce gobierna la práctica, no por la vía de un determinismo mecánico. Como capacidad de generación infinita y por tanto estrictamente limitada, el habitus es una capacidad infinita de engendrar en total libertad (controlada) productos — pensamientos, percepciones, expresiones, acciones- que tienen siempre como límite las condiciones de su producción, histórica y socialmente situadas.

Una de las principales argumentaciones que le permite construir este concepto es que

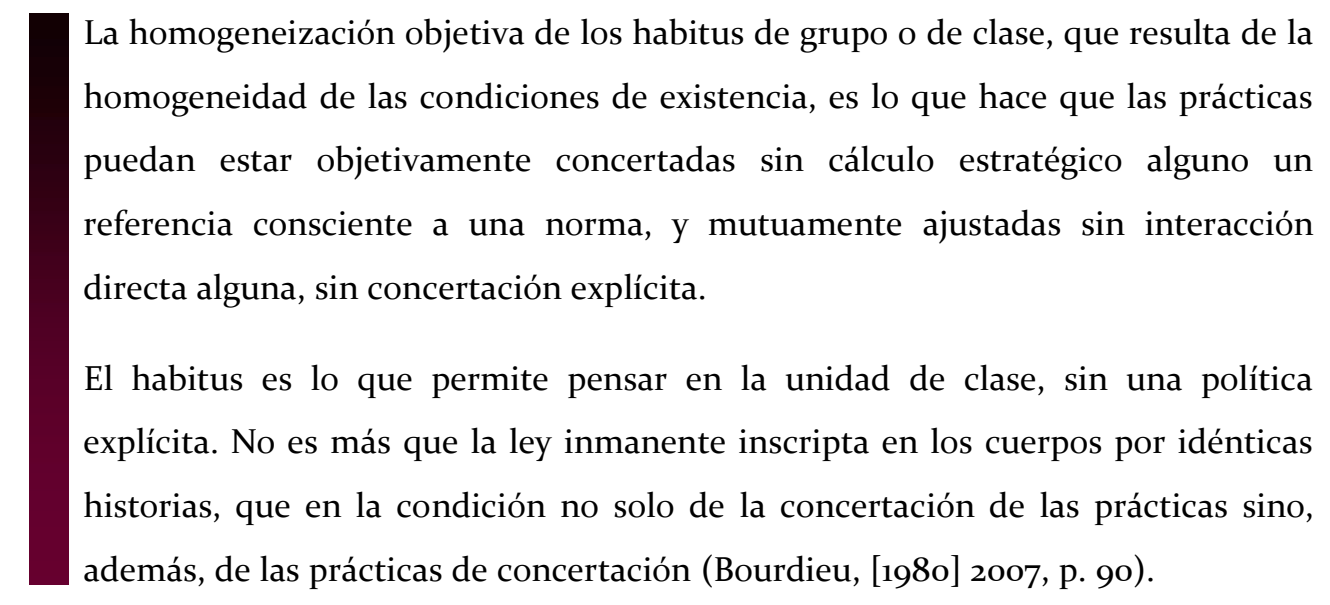

Lo anteriormente mencionado, más allá de que no sea pertinente al análisis que se realizará en esta tesis, resulta importante para mantener el contexto en el cual el concepto es desarrollado y el tipo de fenómeno que originariamente describía. El habitus le permitió a Bourdieu ([1980] 2007) afirmar la unidad de clase sin necesidad de existir factores explícitos o formales. Pero en nuestro caso, lo retomamos y lo ponemos en relación con el concepto de identidad, ya dejando de pensar la determinación en una situación de clase, y viéndolo también como resultado de procesos comunicacionaleseducativos. 
Siguiendo con el análisis realizado por Huergo (2005), las prácticas producidas por el habitus tienden, con mayor seguridad que cualquier regla formal o norma explícita, a garantizar la conformidad con una estructura y la constancia o la duración a través del tiempo. Las prácticas, además, cargan con una historia incorporada y naturalizada; en ese sentido, olvidada como tal y actualizada en la práctica. En los sujetos, entonces, hay una especie de "investimiento" práctico que está condicionado por el orden cultural (objetivo) y que crea disposiciones subjetivas.

\section{Partiendo de los procesos educativos}

Lo anterior posibilita comenzar a centrarnos en una de las cuestiones fundamentales de esta tesis: los procesos educativos como formadores de sujetos y como generadores de nuevos rasgos de identidad. Para explicitar desde dónde se piensa lo educativo, retomaremos a la pedagoga mexicana Rosa Nidia Buenfil Burgos (1993).

Según esta autora, el concepto de educación ha sido tradicionalmente limitado a la escolaridad, principalmente, por la necesidad de delimitar un objeto de estudio de la pedagogía. Es así como toda una serie de prácticas y de espacios sociales que forman sujetos han quedado relegados en su estudio y en su conceptualización. La escuela es una institución educativa dominante por el reconocimiento social que detenta, por ser la única institución con capacidad jurídica de certificar los conocimientos o un cierto tipo de educación y no porque siempre abarque a la mayor parte de la población.

Buenfil Burgos (1993) expresa que atender al discurso escolar no basta; es también imprescindible atender aquellos otros espacios, institucionales o no, que contribuyen a la conformación del sujeto social, delimitar sus condiciones, reconocer sus prácticas, qué fuerzas políticas actúan, qué contradicciones son emergentes, en fin, qué tipo de sujetos se constituyen y qué alternativas se pueden ofrecer.

En este punto, se hace necesario recurrir a la noción de polo de identidad que la autora retoma de Marx, Lenin, Gramsci y Althusser, y que destaca el polo correspondiente a la identidad de clase.

Huergo (15/04/2007) también trabaja el concepto en términos de "polo de identificación": 
Esos discursos polares múltiples, en algún momento se constituyen en interpeladores en cuanto a la formación de sujetos, esto es, son educativos. Y lo son en ese novedoso cruzamiento entre lo cultural y lo político. Por lo general es posible sostener que lo educativo a través de tales polos de identificación es implícitamente entendido como un discurso caracterizado por su apertura, su transitoriedad y su relatividad referencial (en línea).

Si seguimos esta idea del juego de interpelación y de reconocimiento, podemos proponer que un rasgo de identidad, por un lado, es un aspecto parcial, una porción o un componente dentro de la matriz de identidad que interpela al individuo a ser sujeto; $y$, por otro, dentro del proceso de reconocimiento, el rasgo de identidad es aquella fracción que es incorporada por el sujeto luego de la interpelación. Por lo tanto, podemos decir que también es aquello que al final logramos observar o analizar en términos de una transformación de las prácticas cotidianas o de una reafirmación más fundamentada de posiciones anteriores.

Continuando con nuestro trabajo y retomando a Buenfil Burgos (1993), vemos cómo salir de las formas tradicionales de exploración de la escuela puede ser incómodo, pero puede aportar más elementos para el análisis y la explicación de los procesos educativos. En esta línea, se hace necesario, por un lado, indagar qué es lo que permite que cualquier práctica social pueda ser, en un momento dado (incluso aquellas descartadas dentro del análisis de lo que sucede en ámbitos educativos formales), una práctica educativa y averiguar en qué radica que los espacios sociales puedan constituirse en agencias educativas. Por el otro, analizar qué tipo de sujetos se constituyen en dichos ámbitos y si tienden a reproducir o a transformar las relaciones sociales vigentes. Es decir qué discursos interpelan y qué impacto tienen estas interpelaciones en los sujetos y en los discursos.

Según la autora, es importante comprender las instituciones de la sociedad civil como espacios en los que se libran batallas por la hegemonía, así como el carácter tanto reproductor como virtualmente transformador de las prácticas políticas educativas, que en estos aparatos tiene lugar; entender las relaciones políticas que en ellas se generan, relaciones y prácticas productoras de sujetos y cuyo carácter no se reduce a una referencia clasista sino también, y de manera articulada, a referencias y a polos de identidad raciales, religiosos, nacionales, sexuales, etc. Entender de esta manera la educación es premisa para la elaboración de una práctica educativa compleja, múltiple y contestataria. 
El sujeto aparece marcado por diversos antagonismos políticos irreductibles al antagonismo de clase, por lo que cabe señalar la exigencia de comenzar a reflexionar respecto de la multiplicidad de polos de identidad que se imbrican en este proceso. Las prácticas educativas juegan un papel fundamental en la constitución de los sujetos sociales y, como tales, tienen un carácter netamente social. Pero como este tipo de procesos ocurre conjuntamente con otros, cabe entonces exponer lo específico de los mismos, lo que los hace educativos.

En este sentido, Buenfil Burgos (1993) afirma que un proceso educativo consiste en que

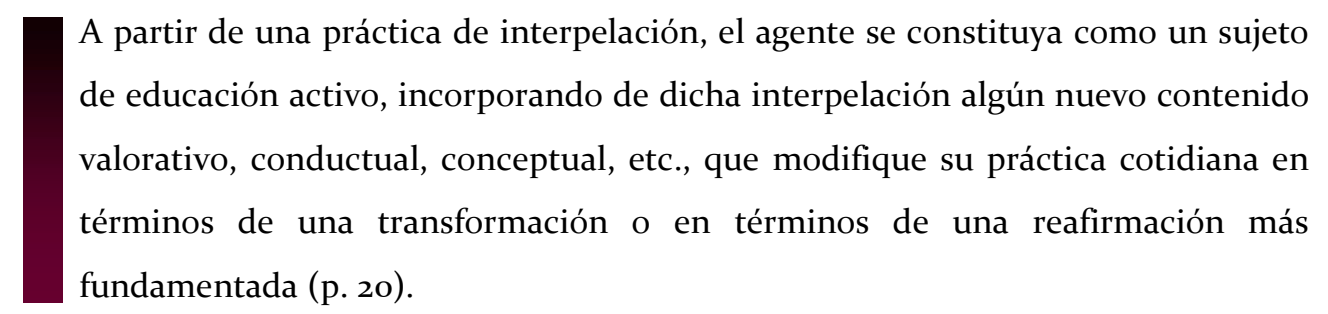

Es decir, que a partir de los modelos de identificación propuestos desde algún discurso específico el sujeto se reconozca en dicho modelo, se sienta aludido o acepte la invitación a ser eso que se le propone.

En esta línea, un primer elemento que es necesario mencionar es la necesidad de

I

[...] conocer la lectura que el otro tiene del mundo para saber si coincide con la mía en un proceso donde se pretenda la participación. Solo a partir de conocerla podía poner en discusión mi lectura del mundo con ellos, que igualmente se guarda y se funda en otro tipo de saber (Freire, [1994] 2010, p. 52).

Esto implica hacer conscientes las condiciones en las cuales el sujeto se formó para reconocerlas y, a partir de allí, comprender mejor la propia mirada del mundo.

Otra cuestión clave se vincula con la propuesta de que el educando necesita asumirse como tal, pero reconocerse como educando significa asumirse como un sujeto que es capaz de conocer, y que quiere conocer con otro sujeto que igualmente es capaz de conocer, el educador, y entre los dos, posibilitando la tarea de ambos, el objeto de conocimiento. 
Como sostiene Freire ([1992] 2008), “enseñar y aprender son así momentos de un proceso mayor: el de conocer que implica re-conocer" (p. 44). De esta forma, lo que el autor deja en claro es que el educando se torna realmente educando en la medida en que va conociendo los contenidos y los objetos cognoscibles y no en la medida en la que el educador va depositando en él la descripción de los objetos o de los contenidos.

El educando se reconoce, conociendo los objetos, conociendo que es capaz de conocer asistiendo a la inmersión de los significados en cuyo proceso también se va tornando como significador crítico. Más que ser educando por una razón cualquiera, el educando necesita volverse educando asumiéndose como sujeto cognoscente y no como incidencia del discurso del educador. Es aquí donde reside en última instancia la gran importancia política del acto de enseñar (Freire, [1992] 2008).

Pretender la inserción crítica de los educandos en la situación educativa requiere de una seria disciplina intelectual. Pero así como no es posible enseñar, sin enseñar algún cierto contenido a través de cuyo conocimiento se aprende a aprender, tampoco se enseña la disciplina de la que hablo a no ser en y por la práctica cognoscitiva de la que los educandos van volviéndose cada vez más críticos (Freire, [1992] 2008).

Conceptualmente, Freire ([1992] 2008) aporta otro componente clave para ubicar la tensión existente entre el respeto y la recuperación de los conocimientos del alumno y la incorporación de nuevos contenidos.

El debate sobre el punto de partida del proceso educativo y la recuperación de los saberes del sentido común, no puede quedarse en un romanticismo por el saber popular, negando la necesidad de avanzar en otro tipo de conocimiento (ya que esta operación ocultaría un profundo elitismo sobre un cierto tipo de saber reservado para un cierto tipo de personas), ni tampoco se debe desconocer y desvalorizar este saber (o mejor dicho la mirada del mundo que el educando posee) y pretender avasallar esta con una nueva forma de comprender su existencia, ya sea desde una posición reproductivista, como desde una que intente la "concientización" de los sujetos (Freire [1992] 2008).

En este sentido, asegura Freire ([1992] 2008), la tensión se resuelve teniendo claro que "lo que no es posible es la falta de respeto al sentido común, lo que no es posible es tratar de superarlo sin partir de él, sin pasar por él” (p. 8o). 
Cualquiera que sea la calidad de la práctica educativa, democrática o autoritaria, es siempre directiva. Sin embargo, en el momento en el que la directividad del educador o la educadora interfiere con la capacidad creadora, formuladora, indagadora del educando en forma restrictiva, entonces, la directividad necesaria se convierte en manipulación, en autoritarismo (Freire, [1992] 2008).

El horizonte educativo estaba puesto en la autonomía del sujeto como un lugar de llegada, pero teniendo los recaudos precisos, y sin confundir el horizonte político transformador, con el punto de partida necesario para cumplirlo.

Siempre está presente en la práctica de la autoridad coherentemente democrática un esfuerzo que la vuelve casi esclava de un sueño "fundamental": el de persuadir o convencer a la libertad de que ella va construyendo consigo misma, en sí misma, su autonomía, con materiales que, aunque llegados de fuera, son reelaborados por ella. Es con ella, con la autonomía que se construye penosamente, como la libertad va llenando el "espacio" antes "habitado" por su dependencia. Su autonomía se funda en la responsabilidad que va siendo asumida.

En el fondo, lo esencial de las relaciones entre educador y educando, entre autoridad y libertades, entre padres, madres, hijos e hijas es la reinvención del ser humano en el aprendizaje de su autonomía. "Nadie es autónomo primero para después decidir. La autonomía se va constituyendo en la experiencia de varias, innumerables decisiones, que van siendo tomadas" (Freire, [1996] 2004, p. 64).

Para avanzar, continuamos con lo que el propio autor determina como clave, cuando asume:

\footnotetext{
Mi error no estaba en reconocer la importancia fundamental del conocimiento de la realidad en el proceso de su transformación. Mi error consistió en no haber tomado como polos —el conocimiento de la realidad y transformación de la realidad- en su dialecticidad. Era como si revelar la realidad significase su transformación (Freire, [1992] 2008, p. 99).
}

Finalmente, para terminar de abordar una mirada de lo educativo, recuperamos un concepto clave como es el de diálogo, del que Freire advierte que no anula la identidad de uno y otro sino que es un proceso en el que las partes se enriquecen y se mueven a crecer. Lo define como "el encuentro de los hombres mediatizados por el mundo para 
pronunciarlo, no agotándose en la relación yo-tú. Por eso es imposible el diálogo entre los que quieren pronunciar el mundo y los que no, los que han sido negados en su derecho de pronunciar el mundo" (Freire, [1968] 2005, p. 107).

\section{De la educación a la comunicación}

Llegamos así a una mirada de la comunicación que la entiende como proceso de significación, por ello vamos a proponer, como lo hace María Cristina Mata (1985), las prácticas comunicativas como espacios de interacción entre sujetos en los que se verifican procesos de producción de sentido. Pero no como definición única sino como complejización del modelo informacional.

Los emisores ya no transmiten mensajes — significados elaborados en virtud de un instrumento neutro- con códigos que son recibidos y decodificados más o menos adecuadamente por los receptores en función de su utilización equivalente del mismo instrumento.

Asumiendo que un discurso es toda configuración temporo espacial de sentido, una de las proposiciones clave de la teoría del discurso es, sin duda, el carácter no lineal de la circulación del sentido. Sostienen al respecto Eliseo Verón y Silvia Sigal (1986):

\footnotetext{
[...] del sentido, materializado en un discurso que circula de un emisor a un receptor, no se puede dar cuenta con un modelo determinista. Esto quiere decir que un discurso, producido por un emisor determinado en una situación determinada, no produce jamás un efecto y uno solo. Un discurso genera, al ser producido en un contexto social dado, lo que podemos llamar un campo de efectos posibles. Del análisis de las propiedades de un discurso no podemos nunca deducir cuál es el efecto que será en definitiva actualizado en recepción. Lo que ocurrirá probablemente, es que entre los posibles que forman parte de ese campo, un efecto se producirá en unos receptores y otros efectos en otros. De lo que aquí se trata es de una propiedad fundamental del funcionamiento discursivo, que podemos formular como el principio de la indeterminación relativa del sentido: el sentido no opera según una causalidad lineal (p. 89).
} 
Estas consideraciones sobre el producto de la actividad discursiva (comunicativa) tienen a nuestro juicio una extrema importancia, por cuanto obligan a reconocer que tanto en la esfera de la emisión como en la de la recepción existe producción de sentido - y no mera transferencia de los primeros a los segundos- aun cuando ella sea desigual, no simétrica (Mata, 1985).

Por lo tanto, la comunicación en este caso se posiciona en el lugar de las disputas, de las batallas por el proceso de significación-resignificación.

Planteado de este modo, el proceso de formación de sujetos es un proceso comunicacional, vale decir, un proceso de diálogo y, como tal, de producción social de sentidos y de significaciones. Y es así como podemos ver que en el juego de interpelación-reconocimiento, lo que interpela al sujeto es un discurso, o por lo menos nos proponemos analizarlo como tal.

Es así como, retomando nuevamente a Buenfil Burgos (1993), definimos discurso como la significación inherente a toda configuración social. Lo discursivo se entiende como un rasgo, algo característico de toda configuración social. Por lo tanto alude tanto a las prácticas lingüísticas como las extralingüísticas. Alude a la significación de los elementos, sin importar la naturaleza de su soporte material. El discurso como tal es diferencial, ya que cobra sentido solo desde una perspectiva relacional; inestable en el suceder temporal y abierto ya que siempre es incompleto.

Finalmente, el discurso, en la medida en que es constitutivo de lo social, es el terreno de constitución de los sujetos, es el lugar desde el cual se proponen modelos de identificación (interpelación), es la constelación de significaciones compartidas que organizan las identidades sociales. El discurso es, en este sentido, espacio (espacio social atravesado por redes de relaciones) de las prácticas educativas, ya que, si se quiere, no hay prácticas educativas al margen de una estructura de significaciones (Mata, 1985).

La pertinencia de este enfoque es evidente, en el sentido en que "series de signos, vehiculizados en diversos soportes materiales; vienen a ser articulados en una configuración discursiva (escolar, familiar, religiosa, etc.) adhiriendo significados específicos desde los cuales se organizan las identidades sociales" (Mata, 1985, p. 12). 
A partir de poner en relación la formación de sujetos con la producción de sentidos, Buenfil Burgos (1993) propone tres rasgos característicos de la educación:

- El carácter relacional de la educación: se rechaza toda noción positiva de la educación y se pone de relieve la imposibilidad de establecer una definición de educación al margen del discurso, es decir al margen de las relaciones entre lo educativo y otros componentes del discurso que se trate.

- El carácter abierto de la educación: la imposibilidad de indicar de manera exhaustiva, la totalidad de características, componentes y prácticas que podrían definir lo específico de la educación.

- El carácter precario de la educación: no puede alcanzar una estabilidad final, sino que es susceptible de ser articulada por la penetración de elementos en las fisuras del propio discurso educativo. La contingencia, la irrupción de componentes exteriores al discurso educativo imprevistos que modifican el carácter mismo del concepto, el proceso y los sujetos involucrados modificando así la identidad de lo educativo.

Comprender los procesos educativos desde una dimensión discursiva da la posibilidad de mirar nuevas prácticas como formadoras de sujetos. Esta proposición ya queda como fundamental, pero ahora es necesario ampliar el concepto de discurso y enmarcarlo dentro de una perspectiva de la comunicación.

Siguiendo la tradición de los estudios culturales británicos, como ya mencionamos, tomaremos a la comunicación como la producción social de sentido. Es decir como el interjuego, la lucha que se genera por el sentido.

La comunicación dejó de ser una cuestión técnica, de medios como instrumentos, para transformarse así en dimensión constitutiva de las prácticas sociales. Pero también la noción de cultura se entendió desde el desplazamiento o desbloqueo: no como mera reproducción, reflejo de las condiciones materiales de existencia, sino también como producción y recreación social del sentido. La cultura como esfera que unifica las esferas de la producción (la economía) y de las relaciones sociales (la política). Como el terreno donde se lucha por la hegemonía, es decir, por el poder nombrar legítimamente las visiones y divisiones del mundo (Saintout, 2007). 
Desde esta posición, nos vemos obligados a reconocer que tanto en la esfera de la emisión como en la de la recepción existe producción de sentido $-\mathrm{y}$ no mera transferencia de los primeros a los segundos-, aun cuando ella sea desigual, no simétrica. Los emisores, en unas ciertas circunstancias culturales, despliegan un conjunto de competencias que les permiten investir, dotar de sentido a ciertas materias significantes. Los receptores, a su turno, atribuirán un sentido a lo recibido y esa atribución, asentándose necesariamente en los posibles sentidos delineados en un discurso dado, se realiza también en virtud de unas determinadas condiciones de recepción, de unas ciertas competencias comunicativas que poseen esos sujetos. Ser receptor, en consecuencia, no es ser pasivo recipiente o mecánico decodificador; es un ser actor, inserto en un determinado contexto cultural y unas ciertas relaciones de poder, sin cuya actividad el sentido quedaría en suspenso.

Pero para resguardar esta posición, David Morley (1996) se plantea la pregunta sobre si es pensable, realmente, una democracia semiótica. Así, y en relación con estudios que tienen que ver con los medios masivos de comunicación explica:

\footnotetext{
La valorización implícita del placer de las audiencias lleva fácilmente a un relativismo cultural que se incorpora rápidamente a una retórica neoliberal populista. Se puede transformar en una ideología conservadora del pluralismo consumidor soberano. Se corre el riesgo de que el texto como tal termine disolviéndose en sus lecturas y que el momento de recepción sea el único importante del proceso de comunicación. Sería erróneo reemplazar el concepto de activo por el de poderoso (Morley, 1996, p. 121).
}

Con esto, queremos dejar en claro que pensar los procesos de producción de sentido implica pensar las relaciones de poder y la negociación de sentidos dentro del campo de la hegemonía.

Retomando la línea de Mata (1985), podemos seguir ampliando la idea de que analizar el proceso de comunicación en términos de un mensaje recibido y de un mensaje producido, sobre la base de un determinado código, resulta una simplificación terminológica. Porque lo que la autora propone es pensar que lo que se emite y lo que se recibe no son mensajes cerrados, reconocibles en sí mismos, sino conjuntos textuales. Con ello, podemos reconocer el resultado de prácticas que remiten no solo a un código -lingüístico, sonoro, visual- en virtud del cual los signos se articulan con un cierto significado, sino, fundamentalmente, a otras prácticas y a sus respectivos productos. 
La perspectiva que acabamos de anunciar resulta clave para la comprensión de la comunicación como hecho y matriz cultural (Mata, 1985).

La misma autora es la que deja sentada la necesidad de pensar la comunicación de esta manera. Lo expresa al afirmar que "esa perspectiva resulta particularmente enriquecedora si lo que estamos tratando de comprender son las características que asumen los llamados procesos de comunicación popular o la propia comunicación educativa y si deseamos operar en esos terrenos" (Mata, 1985, p. 17). De allí la pertinencia que encontramos en este enfoque para el tipo de análisis que se realiza.

Desde una mirada comunicacional, lo que entendemos como conjuntos textuales nos permite comprender las interpelaciones que se dan como procesos de formación de sujetos. Como afirma Buenfil Burgos (1993), tenemos que desplazarnos de los ámbitos escolares para atender a todos aquellos otros espacios, institucionales o no, que contribuyen a la conformación del sujeto social, delimitar sus condiciones, reconocer sus prácticas, qué fuerzas políticas actúan, qué contradicciones son emergentes, qué tipo de sujetos constituyen, y qué alternativas se pueden ofrecer. Esta conceptualización tiene especial valor en este caso en que lo educativo/comunicacional, dispuesto desde la convergencia digital, ya que la misma produce un nuevo escenario que debemos abordar.

\section{Abordajes posibles}

Se trata de comprender que hay que en estas coyunturas hay que atender, a juicio de Huergo (2013), tres ejes transversales: la tecnicidad imperante y los saberes, que ya no circulan legítimos solo por la escuela; la subjetividad que deja de ser de dominio exclusivo de las instituciones escolares, y los itinerarios de reconocimiento, donde el desafío es más que reconocer la dignidad del otro y establecer una igualdad de honor, sino hacer de estos reconocimientos un ejercicio de tal reciprocidad que compongamos un nosotros a partir del diálogo.

En primer término, entender el papel de la tecnicidad es una necesidad propia del contexto, para no sobrevalorarla ni minimizar sus consecuencias. Estamos ante un organizador del campo perceptivo, un concepto que se revela como articulador de los procesos de apropiación cultural. 
La técnica no produce efectos instrumentales y lineales, sino que se articula con la cultura cotidiana, de modo de producir transformaciones en el sensorium (como lo planteaba Walter Benjamin); esto es, en los modos de sentir, de percibir y de conocer, y en las formas de producirse la experiencia social (Huergo \& Morawicki, 2008, p. 53).

Esto tiene consecuencias sobre los saberes, que se han hecho más complejos. El saber y su estatuto, su transmisión y su experiencia están ligados al problema de la comunicación de los saberes, lo que desestabiliza la pretensión escolar de hegemonía en la distribución y en la reproducción de saberes socialmente significativos. En consecuencia, las preguntas que surgen llevan saberes, subjetividad y reconocimiento al terreno de las tecnicidades de hoy, y cuestionan cómo se hace para, desde ahí, producir reconocimientos, participación, identidades menos instantáneas, hacer crecer la autonomía de los sujetos en la creación de espacios y de escenas de comunicación / educación.

En palabras de Huergo (2013): "Uno de los grandes desafíos históricos de la Comunicación/Educación frente a la hegemonía tecnicista es la construcción incesante de un lenguaje de posibilidad y de campos de posibilidad para la experiencia" (p. 25).

Para Freire, hay que partir del aquí y del ahora del otro, y abrir espacios para que el otro cuente su propia historia. En el campo de las tecnologías, donde hoy se libra la lucha por el sentido.

En resumen, podríamos considerar como desafíos en la cultura mediático-tecnológica el desarrollo de la dimensión político-liberadora atendiendo la distribución y el acceso a la tecnicidad, la comprensión y los saberes, la subjetividad en lucha por el reconocimiento de sí y del otro, mientras que para asegurar itinerarios de reconocimiento se trata de incrementar el sentido de pertenencia. Y como el sentido de estas prácticas es la liberación, la propuesta pide mantener encendida la llama de la utopía. 


\section{Referencias}

Bourdieu, P. [1980] (2007). El sentido práctico (Trad. Ariel Dilon). Madrid, España: Taurus.

Buenfil Burgos, R. N. (1993). Análisis de discurso y educación. Documentos

DIE 26. Ciudad de México, México: Instituto Politécnico Nacional.

Freire, P. [1968] (2005). Pedagogía del oprimido. Ciudad de México, México: Siglo XXI.

Freire, P. [1992] (2008). Pedagogía de la esperanza. Ciudad Autónoma de Buenos Aires, Argentina: Siglo XXI.

Freire, P. [1996] (2004). Pedagogía de la autonomía. Saberes necesarios para la práctica educativa. Ciudad Autónoma de Buenos Aires, Argentina: Siglo XXI.

García, R. (2007). Sistemas complejos. Conceptos, método y fundamentación epistemológica de la investigación interdisciplinaria. Barcelona, España: Gedisa.

Giménez, G. (1997). Materiales para una nueva teoría de las identidades sociales. Frontera Norte, 9(18), 9-28. Recuperado de https://fronteranorte.colef.mx/index.php/fronteranorte/article/viewFile/1441/891

Hall, S. [1996] (2003). Introducción: ¿quién necesita 'identidad'? En S. Hall y P. du Gay (Comps.), Cuestiones de identidad cultural (pp. 13-39) (Trad. Horacio Pons). Ciudad Autónoma de Buenos Aires, Argentina: Amorrortu.

Huergo, J. (2005). Hacia una genealogía de Comunicación/Educación. Rastreo de algunos anclajes político-culturales. La Plata, Argentina: Ediciones de Periodismo y Comunicación.

Huergo, J. (2006). Comunicación y educación: aproximaciones. Recuperado de https://comeduc.blogspot.com/2006/o4/jorge-huergo-comunicacin-yeducacin.html

Huergo, J. (15 de abril de 2007). Espacios discursivos. Lo educativo, las culturas y lo político. Recuperado de http://comeduc.blogspot.com/2007/o4/jorge-huergoespacios-discursivos-lo.html 
Huergo, J. y Morawicki, K. (2008). El sentido de la "experiencia social". La Plata, Argentina: Dirección General de Cultura y Educación.

Huergo, J. (2013). Mapas y viajes por el campo de comunicación / educación. Tram(p)as de la comunicación y la cultura, (75), 19-30. Recuperado de https://perio.unlp.edu.ar/catedras/system/files/1 huergo trampas 75 .pdf

Huergo, J. (2015). La educación y la vida. La Plata, Argentina: Ediciones de Periodismo y Comunicación.

Martín-Barbero, J. (1989). Procesos de comunicación y matrices de cultura. Itinerario para salir de la razón dualista. Ciudad de México, México: FELAFACS / G. Gili.

Mata, M. C. (1985). Nociones para pensar la comunicación y la cultura masiva [Módulo de clase]. Especialización en Educación para la comunicación. Ciudad Autónoma de Buenos Aires: La Crujía.

Moreno, I. (1991). Identidades y rituales. En J. Prat, U. Martínez, J. Contreras e I. Moreno (Eds.), Antropología de los pueblos de España. Madrid, España: Taurus. Morley, D. (1996). Televisión, audiencias y estudios culturales. Ciudad Autónoma de Buenos Aires, Argentina: Amorrortu.

Saintout, F. (2007). Los estudios socioculturales y la comunicación: un mapa desplazado. ALAIC. Revista Latinoamericana de Ciencias de la Comunicación, 5(8-9). Recuperado de https://www.alaic.org/revista/index.php/alaic/article/view/64

Verón, E. y Sigal, S. (1986). Perón o muerte. Ciudad Autónoma de Buenos Aires, Argentina: Legasa. 
Digitalización de la cultura

\section{La estructuración de un nuevo modelo de relaciones sociales y sus consecuencias en el sujeto y en sus prácticas}

Los fenómenos que estamos explorando y que sintetizamos con la categoría de “digitalización de la cultura” nos convocan a ensayar nuevas lógicas de pensamiento que nos permitan abordarlos desde la complejidad. Se trata de fenómenos ya instalados socialmente, internalizados en forma de habitus y que, por sus características, están modificando sustancialmente nuestras formas de ser y de estar en el mundo y con los otros.

Para ello, seguimos articulando con los autores que tradicionalmente nos permitieron construir miradas profundas de la sociedad y que hoy alumbran al menos una parte de este oscuro escenario de acople entre las tecnologías y los seres humanos.

En 2007, cuando Steve Jobs presentaba el Iphone, quizás no suponía que estaba abriendo paso a uno de los hitos más importantes de la historia de la humanidad, al poner al alcance de la mano de millones de usuarios en el mundo (no solo por lo realizado por Apple, sino porque fue el modelo que marcó el surgimiento de un dispositivo clave para todo lo que luego se desarrolló y que no quedó compañía que no saliera tras él) una pantalla que se transformaría en el punto de articulación de diferentes, y hasta allí desconectados, procesos de la vida cotidiana, como son: hablar por teléfono, sacar fotos, reservar un viaje, agendar un turno con el médico, escuchar música, mirar películas, hallar el mejor camino, jugar videojuegos, concertar una cita, guardar información, leer un libro y hasta monitorear algunas de nuestras funciones biológicas básicas. 
Al decir de Jesús Martín-Barbero (2009a),

[...] atravesamos una revolución tecnológica cuya peculiaridad no reside tanto en
introducir en nuestras sociedades una cantidad inusitada de nuevas máquinas
sino en configurar un nuevo modo de relación entre los procesos simbólicos
—que constituyen lo cultural—y las formas de producción y distribución de los
bienes y servicios: un nuevo modo de producir, asociado a un nuevo modo de
comunicar, convierte a la información y al conocimiento en fuerza productiva
directa (p. 24$)$.

Un cambio de estas características modifica sustancialmente la cultura y, consecuentemente, la comunicación por estar una imbricada en la otra. Al modificarse uno de los dos, el otro necesariamente cambia, como bien señalaba Héctor Schmucler (1984) al asociar comunicación / cultura como dos elementos inseparables. Pero este cambio no se produce de cualquier forma, sino asociado a una nueva arquitectura, que mediante ceros y unos ordena una marea de algoritmos que intermedian permanentemente nuestras prácticas cotidianas.

Jesús Martín-Barbero (2009b) nos alertaba hace ya más de diez años al respecto: "El lugar de la cultura en la sociedad cambia cuando la mediación tecnológica de la comunicación deja de ser meramente instrumental para espesarse, densificarse y convertirse en estructural" (p. 183). De ahí que la tecnología remita hoy tanto o más que a unos aparatos, a nuevos modos de percepción y de lenguaje, a nuevas sensibilidades y escrituras.

La pregunta por la tecnología se nos vuelve entonces cada día más crucial en la medida en que la diversidad cultural de la técnica, persistentemente testimoniada por los antropólogos, es aceleradamente sustituida por la existencia de una tecnicidad-mundo que desvincula a la tecnología de las herencias culturales permitiéndole instalarse en cualquier región o país como dispositivo de producción a escala planetaria: "Como conector universal en lo global" (Martín-Barbero, 2009a, p. 24).

Es decir que la tecnología salió del lugar instrumental, puesta al servicio de tal o cual procedimiento, y se transformó en el elemento distintivo que ordena y organiza una parte cada vez más importante de nuestras vidas, de nuestro trabajo, de nuestras relaciones afectivas y gustos. De allí que no sea solamente un fenómeno local o regional, sino que afecta a una porción cada vez mayor de habitantes en el mundo. A la par de 
Estados Unidos, China, Rusia e India, por nombrar solo algunos países, vienen participando en la carrera tecnológica y del mundo digital, y ampliando sin dudas el fenómeno a una escala cada vez más planetaria.

Estamos ante un nuevo tipo de técnica cuya peculiaridad reside en constituirse en ingrediente estructural de la formación de un verdadero ecosistema comunicativo, ecosistema que emerge asociado a una nueva economía cognitiva regida por el desplazamiento del número que, de signo del dominio sobre la naturaleza, está pasando a convertirse en mediador universal del saber y del operar técnico/estético, lo que viene a significar la primacía de lo sensoriosimbólico sobre lo sensorio-motriz. La numerización digital hace posible una nueva forma de interacción entre la abstracción y lo sensible, que replantea por completo las fronteras entre arte y ciencia (Martín-Barbero, 2009a, p. 24).

$[\ldots]$

Es por ello que nuestra inserción en la nueva mundanidad técnica no puede ser pensada como un automatismo de adaptación socialmente inevitable sino más bien como un proceso densamente cargado de ambigüedades, de avances y retrocesos, un complejo conjunto de filtros y membranas (Santos: 2004) que regulan selectivamente la multiplicidad de interacciones entre los viejos y los nuevos modos de habitar el mundo (Martín-Barbero, 2009a, p. 25).

Entonces, podemos afirmar que las modificaciones a las que estamos haciendo mención tienen específicamente una articulación entre dispositivos culturales, narrativas digitales y subjetivación, lo que implica una triada en la cual las prácticas, los sujetos y los discursos se ven afectados profundamente por la convergencia tecnológica y por los procesos de hipermediación.

Por ello, es preciso detenerse un instante para poder asimilar en su abismal magnitud el impacto del cambio que estamos viviendo. No puede suceder como lo relevara hace ya casi diez años Barbero, que nos entreguemos a un proceso de "automatismo y adaptación”, necesitamos emprender un camino de articulación de miradas analíticas con propuestas políticas que desde el Estado puedan disputar, al menos, parte de los sentidos socialmente producidos en este escenario por un mercado que no problematiza nada, más allá de la necesidad de reproducción del capital, y que configure cuál es el horizonte de un salto de esta dimensión y qué tipo de consecuencias estamos preparados para sobrellevar. 
Es preciso hacer lugar - $-\mathrm{y}$ esta es la dimensión política de este análisis-, para la participación en los sentidos y en los significados que decidamos que tengan y hacia donde se direccionen estas nuevas posibilidades desde la comunicación y la educación.

En efecto, José Van Dijck (2016), observa:

Que la socialidad "se vuelva tecnológica" no solo alude a su desplazamiento al espacio online, sino también al hecho de que las estructuras codificadas alteran profundamente la naturaleza de las conexiones, creaciones e interacciones humanas. Los botones que imponen las nociones de "compartir" y de "seguir" como valores sociales tienen efectos sobre las prácticas culturales y las disputas legales que exceden el ámbito de las propias plataformas (p. 42).

Las plataformas que venimos describiendo poseen un círculo de crecimiento que necesitamos reconocer para dimensionar el desarrollo posible que poseen y de ahí también imaginar acciones. En la misma línea, Nick Srnicek (2018) afirma:

1

Las plataformas líderes tienden conscientemente a perpetuarse también a sí mismas de otro modo. Las ventajas en la recolección de datos implican que cuanta más actividad tenga una compañía, más datos puede extraer y más valor puede generar de esos datos, y por lo tanto puede tener acceso a más actividad (p. 91).

Por lo tanto, en el planteo de la dimensión del cambio que estamos realizando, debemos tener en cuenta este tipo de procesos que necesariamente amplían y maximizan los horizontes de penetración de estas redes. Simplemente el estar ahí usándolas, dejando marcas con cada clic, con cada selección de qué mirar y qué no, alimenta un proceso de Big Data que permite refinar las estrategias de interpelación y construir cada vez más formas de captación de nuestra atención. Estar allí hace que sepan más de nosotros y, mientras más saben, más débiles nos volvemos ante ellas.

Desde Michel Foucault sabemos que el saber es aliado del poder, y, por lo tanto, este manejo y este procesamiento de información, transformado en conocimiento utilizable, vuelve a las plataformas y, por supuesto, a sus propietarios (comerciales, políticos, ideológicos y culturales) cada vez más poderosos. Big Data es un dispositivo de información propio de una época y de un contexto particular (global) que resulta funcional a los poderes en él instalados. De ahí que ese proceso de expansión, por el momento, resulte imparable y es por ello que consideramos la necesidad de avanzar en su conceptualización. 


\section{¿Cultura de la convergencia?}

Uno de los elementos centrales que comienza a aparecer en el camino de la digitalización de la cultura es la modificación de las formas de relación de los sujetos y la hipermediación de las redes sociales en los vínculos cotidianos. La llamada también “cultura de las plataformas" es hoy clave para comprender la densidad del fenómeno que estamos analizando.

El articulado de los vínculos humanos con estructuras digitales que potencian, restringen y refuncionalizan pero, sobre todo, monetizan procesos que hasta hace poco tiempo estaban por fuera del mundo digital, transforman las más profundas estructuras de socialización de los sujetos. Lo que resulta es un ensamble entre las lógicas de codificación que cargan las redes sociales, provenientes en muchos casos de culturas tan disímiles como la del software libre o la corporativa de las empresas más ricas del planeta, y las prácticas que tradicionalmente como sujetos llevamos adelante en nuestra comunicación social.

Allí se produce un encuentro entre las prácticas culturales cotidianas y una nueva arquitectura de algoritmos programados para procesar parte de nuestras vidas en un novedoso repertorio de experiencias vitales que Ana Brizet Ramírez Cabanzo (2014) da en llamar "temporalidades online-offline" (s/p), que se despliegan ya sin interrupción y estructuran una realidad que carga dentro de sí misma la virtualidad como un modo más de relación con los otros y con el mundo.

En esta línea, el trabajo de la investigadora holandesa José Van Dijck (2016) es clave, ya que avanza en un concepto de "cultura de la conectividad" que consideramos fundamental y que quizás sea el antecedente más directo de lo que aquí se va a presentar.

\footnotetext{
La interconexión de estas plataformas tuvo por resultado la emergencia de una nueva infraestructura: un ecosistema de medios conectivos, conformado por peces gordos y otros no tanto. Este paso de una comunicación en red a una socialidad moldeada por plataformas, y de una cultura participativa a una verdadera cultura de la conectividad, ocurrió en un breve lapso temporal de no más de diez años (Van Dijck, 2016, p. 19).
} 
Y esto es clave en el abordaje del fenómeno que aquí intentamos describir, ya que se trata de algo que va transformando profundamente la vida cotidiana de los sujetos y que en menos de una década avanzó sin pausa hasta ser hoy un eje vertebrador de nuestra subjetividad.

Al enunciar Van Dijck (2016) el paso "de una comunicación en red a una socialidad moldeada por plataformas" (p. 19) está acercándose a una definición de un contexto que resulta formativo para el sujeto y que, como veremos más adelante, articulando la categoría de habitus (Bourdieu, [1980] 2007), va a ser clave para comprender la profundidad del cambio en las formas no solo de relacionarnos con las nuevas tecnologías, sino en un nuevo sensorium que se establece.

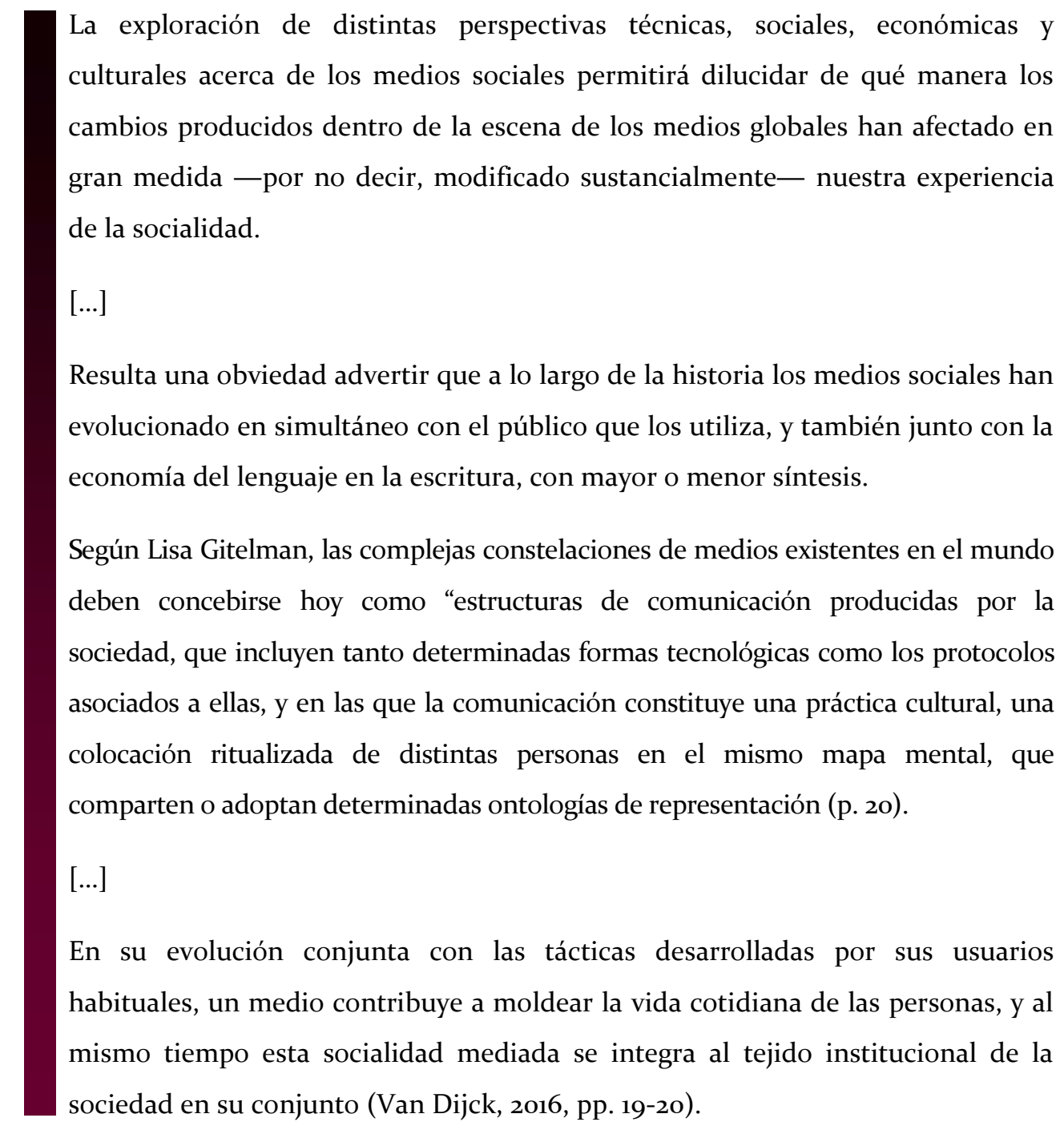

Esto implica, entonces, que la entrada de estos nuevos modos de interconexión afecta el entramado social, reestructurando formas de relaciones y, por lo tanto, a los sujetos que las componen. 
Es por ello que necesitamos dar un paso más y enunciar un proceso cuyo desarrollo continuaremos en las páginas siguientes pero que podemos sintetizar como "digitalización de la cultura".

Inicialmente, y sobre la base de lo anteriormente dicho, podemos profundizar en el análisis y arriesgar una definición de este proceso al que, primeramente, caracterizamos como una nueva forma de estructuración del campo simbólico, que iremos justificando.

Consideramos que se trata de un proceso porque se observa claramente una situación en la cual hay una modificación entre el estadio inicial analógico y el que se va construyendo byte a byte cada día con mayor velocidad y del que desconocemos completamente hasta dónde puede llegar. Al pensar en proceso, se pone énfasis en el elemento tiempo y en la transformación que este produce.

Paralelamente, al enunciar que se trata de una nueva forma de estructuración del campo simbólico, estamos describiendo la configuración de una nueva arquitectura simbólicodigital, programada sobre la base de ceros y de unos que funcionan como una estructura estructurante.

Finalmente, es necesario mencionar también que esto genera un nuevo tipo de relación entre los sujetos, hipermediada por software y por hardware, que suprime, supera y a la vez conserva las formas comunicacionales precedentes, y que, codificada bajo un flujo binario digital, reconfigura cada vez más las identidades desde las cuales nos vinculamos con el mundo que nos rodea y con los sujetos que allí habitan.

Por ejemplo, va a decir Van Dijck (2016) que "hacer social la red' en realidad significa 'hacer técnica la socialidad”' (p. 30). Esta socialidad tecnológicamente codificada convierte las actividades de las personas en fenómenos formales, gestionables y manipulables, lo que permite a las plataformas dirigir la socialidad de las rutinas cotidianas de los usuarios. Sobre la base de este conocimiento íntimo y detallado de los deseos y los gustos de las personas, las plataformas desarrollan herramientas pensadas para crear y para conducir necesidades específicas. El mismo botón que nos permite saber qué miran, escuchan, leen y compran nuestros amigos es el que registra los gustos de nuestros pares al tiempo que los moldea. Allí, la digitalización de la cultura aparece como un elemento evidente y la plataforma tecnológica como su hábitat natural.

Como describe Srnicek (2018), "las plataformas se volvieron una manera eficiente de monopolizar, extraer, analizar y usar cada vez más cantidad de datos, que se estaban registrando" (p. 95). 
Con el correr del tiempo, la web 2.o que nos permitió integrar la socialidad en Internet está dando un paso a la llamada Internet de las cosas (heladeras inteligentes, autos autónomos, sensores corporales, zapatillas conectadas, etc.), por lo que cada vez más procesos quedarán sujetos a una instancia algorítmica de resolución y, por lo tanto, más inmersos estaremos en lógicas que luego reactualizaremos en nuestras prácticas. Más aún si pensamos en programas como SIRI, de Apple; CORTANA, de Microsoft; Alexa, de Amazon; o Bixby, de Samsung, ${ }^{1}$ asistentes de inteligencia artificial con capacidad de aprendizaje a partir de la interacción con el usuario, que avanzan para convertirse en parte fundamental de la toma de decisiones cotidianas de los sujetos.

Entonces, lo cultural, lo mediático, lo articulado por las redes sociales en esta reestructuración del campo simbólico sobre la base de una nueva arquitectura digital, no solo lo podemos ver analíticamente en esta triada de sujetos, de prácticas y de discursos, sino que directamente lo encontramos vinculado a la voluntad, es decir, a las formas en las que decidimos sobre diferentes alternativas existentes.

Y para ello es central volver a traer el concepto de habitus de (Bourdieu, [1980] 2007), en el cual se vinculan de forma precisa y contundente las relaciones entre la cultura distintivamente internalizada y su posterior actualización en las prácticas de los sujetos que, nuevamente, estructuran el mundo mediante las formas de esas estructuras estructuradas predispuestas para funcionar como estructuras estructurantes de nuestro mundo cotidiano.

Podemos apuntar, entonces, que las actividades cotidianas en las que como sujetos estamos inmersos se irán transformando, también, por el hecho de ser quienes en nuestro accionar cotidiano actualizamos estas estructuras producto de la digitalización de la cultura, de manera que no solo las vamos a encontrar en nuestros procesos hipermediados tecnológicamente, sino también en las cosas más sencillas de la vida.

Sin embargo, esto no es nuevo: la aparición del reloj como tecnología cambió radicalmente nuestra relación con el mundo y nuestra concepción del tiempo, ya que las fuerzas de la naturaleza dejaron de ser nuestra guía para pasar a serlo un artefacto inventado. De todos modos, podemos esbozar en esta línea una cierta preocupación sobre el tipo de transformación que en pocos años este proceso llevará a cabo, dado el enorme poder que poseen las tecnologías contemporáneas y, sobre todo, la velocidad con la que crecen y se incrustan en nuestra cotidianeidad.

\footnotetext{
${ }^{1}$ Ver al respecto, https://www.xataka.com/tag/asistente-virtual
} 
De ahí que acordemos con Paulia Sibilia (2009) cuando señala:

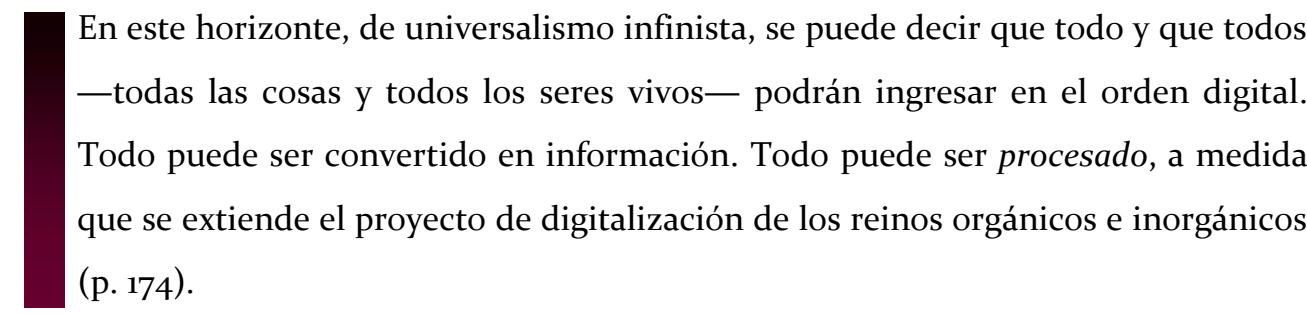

Podemos afirmar, entonces, que el proceso de digitalización de la cultura hace parte de la socialización de los sujetos, de su subjetivación, y de la trama de relaciones que entre ellos se constituye. Por lo tanto, desde un punto de vista comunicacional / cultural, esta digitalización de la cultura reinscribe las formas de vinculación, los tipos de mediación cultural que tejen la articulación de lo social.

\section{El ensamble de las lógicas del mercado en el proceso de digitalización de la cultura}

Otro elemento que debemos exponer se relaciona con las formas en las que esta nueva arquitectura simbólica se configura, puesto que no es solo una lógica de programación informática la que le da sustento, sino que la conformación de procesos mediados por la tecnología carga también con "una cultura en que la organización del intercambio social está ligada a principios económicos neoliberales" (Van Dijck, 2016, p. 42).

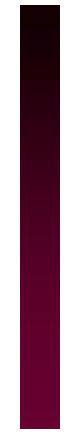

La conectividad es el resultado de una presión constante - tanto por parte de los pares como de la tecnología- por expandirse a través de la competencia y por conquistar mayor poder mediante alianzas estratégicas. Distintas tácticas de las plataformas, como el principio de popularidad o los mecanismos que ranquean la participación, presentan escasa relación con estructuras tecnológicas contingentes; por el contrario, están muy arraigadas en una ideología que valora la jerarquía, la competencia y el lugar del ganador (Van Dijck, 2016, pp. 42-43).

Esto es clave ya que, como hemos señalado, la configuración de una cultura digital, que contiene en sus lógicas imbricadas las formas de expansión del capitalismo neoliberal, reivindica algunos valores por sobre otros y articula formas que estabilizan prácticas entre sujetos de maneras en que antes no sucedía, o al menos no con la contundencia que hoy tienen, sobre todo en los más jóvenes, con relaciones hipermediadas. 


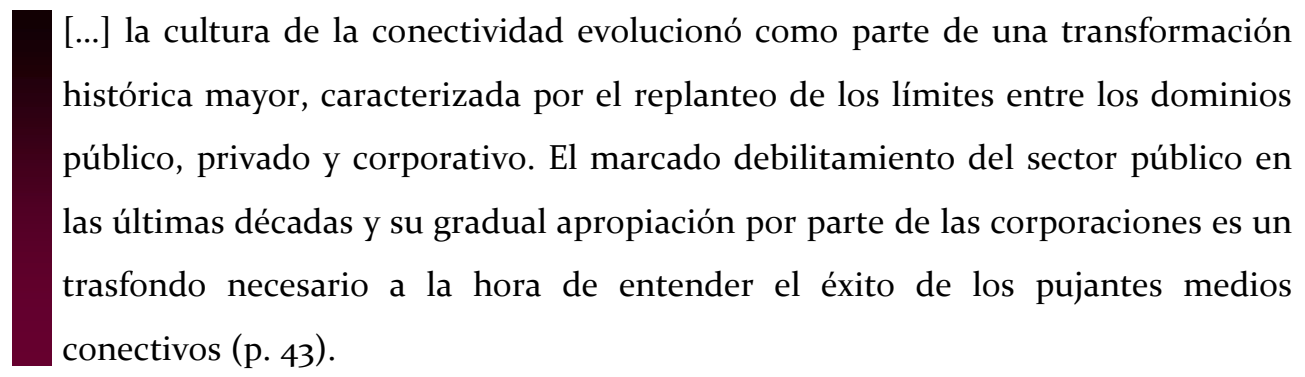

La cultura de la conectividad es, según lo dicho, un paso previo a la digitalización de la cultura. La conectividad es un fenómeno necesario pero no suficiente; por lo que decimos que es una instancia anterior, sobre la cual esta interconexión permite montar un proceso por el que la modelización de la socialidad pasa por una arquitectura digital y desde allí ordena, de una manera diferente y novedosa, las relaciones de los sujetos entre sí y su vinculación con el mundo.

Si las lógicas de funcionamiento de las redes sociales y de otras plataformas como Netflix, que más adelante desarrollamos ampliamente, poseen por sobre todo otro principio el de la necesidad de producir ganancias, una parte importante de los procesos de consumo o de interacción que generemos a partir de ellas tendrán también este sentido, y en eso no podemos ser ingenuos.

Ser infuencer en una red es una posición de poder frente a otros, pero sobre todo es una forma de anudar un punto de tráfico centralizado en Facebook o en Instagram. Consumir un capítulo detrás de otro en las series, o una serie tras otra en las plataformas, no solo modela un gusto glotón, llamado a la saciedad, sino también un perfil de consumidor compulsivo operativamente más funcional que otro para las lógicas del mercado audiovisual.

De esta manera, reconocer que el campo cultural está profundamente afectado por procedimientos que están mediados tecnológicamente nos invita a pensar cómo también allí encontramos desplegadas estrategias que, cada vez más, se articulan profundamente con nuestras vidas cotidianas, aun cuando son funcionales a un modelo de acumulación. a través de redes humanas; sin embargo, estas también afectan los modos de hacer y de pensar de los individuos que las conforman (Christakis \& Fowler, 2009). En igual medida, los medios sociales son sistemas automatizados que 
inevitablemente diseñan y manipulan las conexiones. Para poder reconocer aquello que las personas quieren y anhelan, Facebook y las demás plataformas siguen el rastro de sus deseos y reducen a algoritmos las relaciones entre personas, cosas e ideas. De esta forma, lo "social" parece abarcar tanto la conexión (humana) como la conectividad (automática), confusión alimentada por muchos CEO en una deliberada ambigüedad.

Las empresas tienden a hacer hincapié en el primero de estos sentidos (la conexión humana) y a minimizar la importancia del segundo (la conectividad automatizada). Replicando el modelo de los eslóganes de las tarjetas de crédito, agregaron un suplemento significativo: "Las relaciones, después de todo, son lo único que uno no puede comoditizar" (Tapscott \& Williams, 2006, p. 44).

Siguiendo lo expuesto por Van Dijck (2016), acaso irónicamente, comoditizar relaciones - es decir, transformar conexiones en conectividad por medio de las tecnologías de cifrado - fue el huevo de oro que las plataformas corporativas, en particular Google y Facebook, encontraron bajo sus flamantes gallinas. Además de contenido, la producción entre pares genera un valioso subproducto que los usuarios a menudo no han tenido intención de brindar: información acerca de su comportamiento y sus preferencias. Bajo el disfraz de la conexión, producen un recurso precioso: conectividad. Si bien el término "conectividad" proviene de la tecnología, donde denota transmisiones por medios informáticos, en el contexto de los medios sociales rápidamente adoptó la connotación de "proceso por medio del cual los usuarios acumulan capital social", aunque el término, en realidad, hace cada vez más referencia a los propietarios de las plataformas que amasan capital económico.

\footnotetext{
Según algunos críticos, la incorporación de estas plataformas entorpeció el desarrollo del verdadero potencial de la web 2.0 como un instrumento para el fomento de una cultura de participación, de autorregulación y de democracia. En vez de ello, las plataformas comerciales habrían introducido nuevos modelos de vigilancia y convertido la privacidad en acumulación de capital social (Cohen, 2008; Haythornthwaite \& Kendall, 2010). Otras críticas contra estas plataformas afirman que sus usuarios son objeto de una doble explotación, tanto como trabajadores - que producen el contenido de las plataformas que se basan en él- y consumidores obligados a readquirir sus propios datos procesados, al tiempo que resignan parte de su privacidad (Terranova, 2004; Petersen, 2008).
} 
Con mayor profundidad, algunos observan que existe el riesgo de considerar erróneamente que la venta de la privacidad constituye una consecuencia natural de la avidez de los usuarios por conectarse y por autopromoverse, y no el corolario de una economía política arraigada en la comoditización de los públicos (Fuchs, 2011) (Van Dijck, 2016, pp. 37-38).

Los patrones de comportamiento existentes en la socialidad offline (física) se mezclan cada vez más con las normas sociales y sociotécnicas generadas en el entorno online, que adquieren así una nueva dimensionalidad. Las reglas en cuanto a los modos de "compartir" información privada y de recibir publicidad personalizada dentro del espacio social de una persona, por ejemplo, eran muy distintas en 2004, cuando se iniciaba el espacio web 2.o, de lo que son en la actualidad.

Estos cambios se implementaron de manera gradual y, a medida que los usuarios fueron habituándose a las nuevas características, también cambiaron las normas concernientes a los grados aceptables de privacidad y de monetización. Son precisamente estos cambios la materia que nos interesa abordar aquí, y sus implicancias fuera de las redes. Es decir, analizar, también, cómo este tipo de procesos hipermediados tiene efectos concretos en otros y, desde allí se reestructura al menos en parte la cultura.

\section{(Tecno) Cultura distintivamente internalizada: (Tecno) identidad}

Este breve apartado retoma lo expuesto para desarrollar un elemento de la dinámica descripta en la que la cultura se digitaliza, pero para darle movimiento al proceso y para dejar de considerarlo como un hecho aislado o solo vinculado al encuentro con las TIC.

Para ello, se hace necesario solidificar una parte del argumento aquí planteado para, por lo tanto, poder extender la capacidad de incidencia de lo que proponemos. Saldremos de la convergencia y abordaremos cómo un proceso que reestructura la cultura dialoga de manera imprescindible con la conformación del sujeto y, para ello, ahora sí pondremos en funcionamiento la categoría de habitus en nuestro trabajo.

Este concepto es central en esta tesis, ya que lo que se intenta describir finalmente son procesos de formación de sujetos y de subjetividad de los sujetos que estamos atravesados por este, ya no tan nuevo, contexto tecnocultural y allí la configuración de identidades (individuales y sociales) se hace cada vez más en las hipermediaciones. 


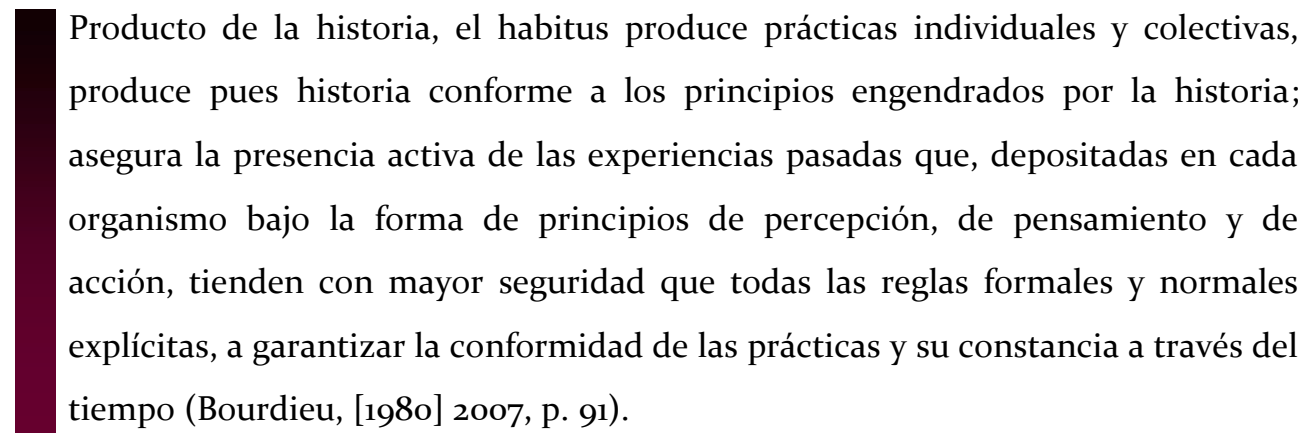

Y en esta línea, es el propio Bourdieu ([1980] 2007) quien, como ya se mencionó, afirma que a través del habitus la estructura que lo produce gobierna la práctica, no por la vía de un determinismo mecánico.

En este sentido, el concepto nos facilita el análisis de las formas en las que la cultura digital, distintivamente internalizada, produce prácticas culturales que necesariamente van a estar modeladas en este nuevo escenario tecnológico, y que como resultado seguramente sigan en un proceso de retroalimentación desarrollando nuevas estructuras en donde la codificación digital vaya ganando cada vez más lugar en las bases mismas de la codificación cultural de nuestras prácticas cotidianas.

Es decir, necesitamos afirmar aquí que la hipermediación tecnológica no solo afecta un determinado tipo de dinámica cultural, sino que de a poco se va articulando con todas nuestras prácticas, y que si un sujeto que jamás utilizó una red social para citas comienza una relación por otra vía con quien viene acostumbrado a vincularse por plataformas como Tinder o Grindr (apps de citas hetero y gay), seguramente, el tipo de vinculación que se produzca cargará con algunas prácticas que se establecieron anteriormente en un formato de encuentro que comienza mediado por una plataforma configurada para tal fin.

Esto implica, también, recuperar un concepto clave, elaborado por Eliseo Verón (1992). El autor plantea la idea de una evolución de sociedades mediáticas a sociedades mediatizadas a través del proceso que denomina de mediatización, que implica una gradual transformación de prácticas sociales y de hábitos culturales.

Las sociedades postindustriales son sociedades en vías de mediatización, es decir, sociedades en que las prácticas sociales (modalidades de funcionamiento institucional, mecanismos de toma de decisión, hábitos de consumo, conductas más o menos ritualizadas, etc.) se transforman por el hecho de que hay medios. El proceso de mediatización no avanza al mismo ritmo en los distintos sectores del funcionamiento social; es cierto que el mecanismo estatal (y, por lo general, 
el campo de lo político) es uno de los sectores en que esta mediatización es bien visible. Una sociedad en vías de mediatización (distinguible de la sociedad mediática del período anterior, es decir, una sociedad en que poco a poco se implantan tecnologías de comunicación en la trama social) no por eso es una sociedad dominada por una sola forma estructurante, lo cual explicaría la totalidad de su funcionamiento. La mediatización opera a través de diversos mecanismos según los sectores de la práctica social que interese, y produce en cada sector distintas consecuencias. Dicho de otro modo: una sociedad mediatizada es más compleja que las que le han precedido (Verón, 1992, p. 124).

Desde allí, podemos afirmar que en la actualidad la mediatización en la cultura digital es cada vez mayor, que excede un tipo de prácticas, y es en el concepto de habitus donde vinculamos de manera dinámica al sujeto con la cultura, donde se relaciona lo individual con lo social, es donde podemos encontrar una serie de procesos que nos permiten destacar que la digitalización de la cultura no es solo un proceso de interacción con máquinas o con dispositivos binarios, sino más bien un profundo y complejo entramado en las prácticas que va modificando sustancialmente las formas de ser y de estar en el mundo de cada uno de nosotros y de todos juntos como comunidad. 


\section{Referencias}

Bourdieu, P. [1980] (2007). El sentido práctico (Trad. Ariel Dilon). Madrid, España: Taurus.

Martín-Barbero, J. (2009a). Cuando la tecnología deja de ser una ayuda didáctica para convertirse en mediación cultural. Teoría de la Educación. Educación y Cultura en la Sociedad de la Información, 10(1), 19-31. Recuperado de http://www.redalyc.org/articulo.oa?id=201018023002

Martín-Barbero, J. (2009b). Culturas y comunicación globalizada. I/C Revista científica de información y comunicación, (6), 175-192. Recuperado de http://icjournal-ojs.org/index.php/IC-Journal/article/view/207/204

Ramírez Cabanzo, A. B. (diciembre de 2014). Una mirada a las tecnicidades mediáticas de las infancias en Bogotá - Colombia, en clave de etnografía multisituada Trabajo presentado en las VIII Jornadas de Sociología de la UNLP. Ensenada, Argentina. Recuperado de http://www.memoria.fahce.unlp.edu.ar/trab eventos/ev.4794/ev.4794.pdf

Sibilia, P. (2009). El hombre postorgánico. Cuerpo, subjetividad y tecnologías digitales. Ciudad Autónoma de Buenos Aires, Argentina: Fondo de Cultura Económica.

Schmucler, H. (1984). Un proyecto de comunicación/cultura. Comunicación y cultura, (12).

Srnicek, N. (2018). Capitalismo de plataformas (Trad. Aldo Giacometti). Ciudad Autónoma de Buenos Aires, Argentina: Caja Negra.

Tapscott, D. y Williams, A. D. (2006). Wikinomics. How Mass Collaboration Changes Everything. Nueva York, Estados Unidos: Penguin Group.

Van Dijck, J. (2016). La cultura de la conectividad. Una historia crítica de las redes sociales (Trad. Hugo Salas). Ciudad Autónoma de Buenos Aires, Argentina: Siglo XXI.

Verón, E. (1992). Interfaces. Sobre la democracia audiovisual avanzada en el nuevo espacio público. Barcelona, España: Gedisa. 


\section{Sensorium y hegemonía Una relación clave para describir un nuevo estar allí}

Para profundizar en la descripción de esta experiencia del mundo hipermediado, necesitamos recurrir a una serie de conceptos muy actuales y a otros que ya poseen su historia dentro del campo de las ciencias sociales.

Uno de los grandes pendientes en comunicación / educación es el de nombrar y dar cuenta de los procesos de subjetivación en la cultura digital, con toda la complejidad que eso conlleva en términos tecnológicos y socioculturales. Continuando con las posiciones de Paulo Freire, afirmamos que poder narrar el mundo también permite poder reescribirlo, es decir, recuperar su dimensión político transformadora.

Antonio Gramsci (1986) define una crisis orgánica como una época en la que lo viejo no termina de nacer y lo nuevo no termina de morir. Escribir el mundo nos habilita a dar cuenta del proceso entre lo uno y lo otro, a tomar posición y a intervenir en este devenir. Nuestra perspectiva sobre el mundo digital tiene un profundo sentido puesto en comprender el fenómeno, construyendo horizontes de posibilidad para intervenir en él.

La maquinización del ser humano, producto de la digitalización de la cultura, va deconstruyendo un modelo del tiempo en el que lo productivo no lo absorbía todo. Una forma en la que la simple espera, o como lo definía Rodolfo Kusch (200o), el mero estar, se va extremando en la radicalización del ser alguien, o como diría Raymond Williams (1980), para quien lo arcaico, lo residual y lo emergente pugnan en la cultura para configurar un nuevo orden hegemónico.

Estos elementos, expuestos de diferentes formas por distintos autores, hoy nos permiten avizorar una reestructuración de las más profundas a las que ha asistido la humanidad, con su consecuente reordenamiento de las relaciones de poder y de nuestra percepción del mundo. 
En este punto, la incorporación del concepto de hegemonía potencia enormemente la capacidad de construir una matriz para interpretar algunas claves socioculturales, sobre una categoría que es presentada por Gramsci (1986), que se amplía notablemente con la producción de Ernesto Laclau y de Chantal Mouffe (1987), en una visión orientada ya desde la dimensión simbólica de los procesos sociales.

Desde este lugar, se sienta una base que articula las relaciones de poder, la construcción de la verdad y, por supuesto, las disputas que genera ese proceso en el campo de la comunicación social.

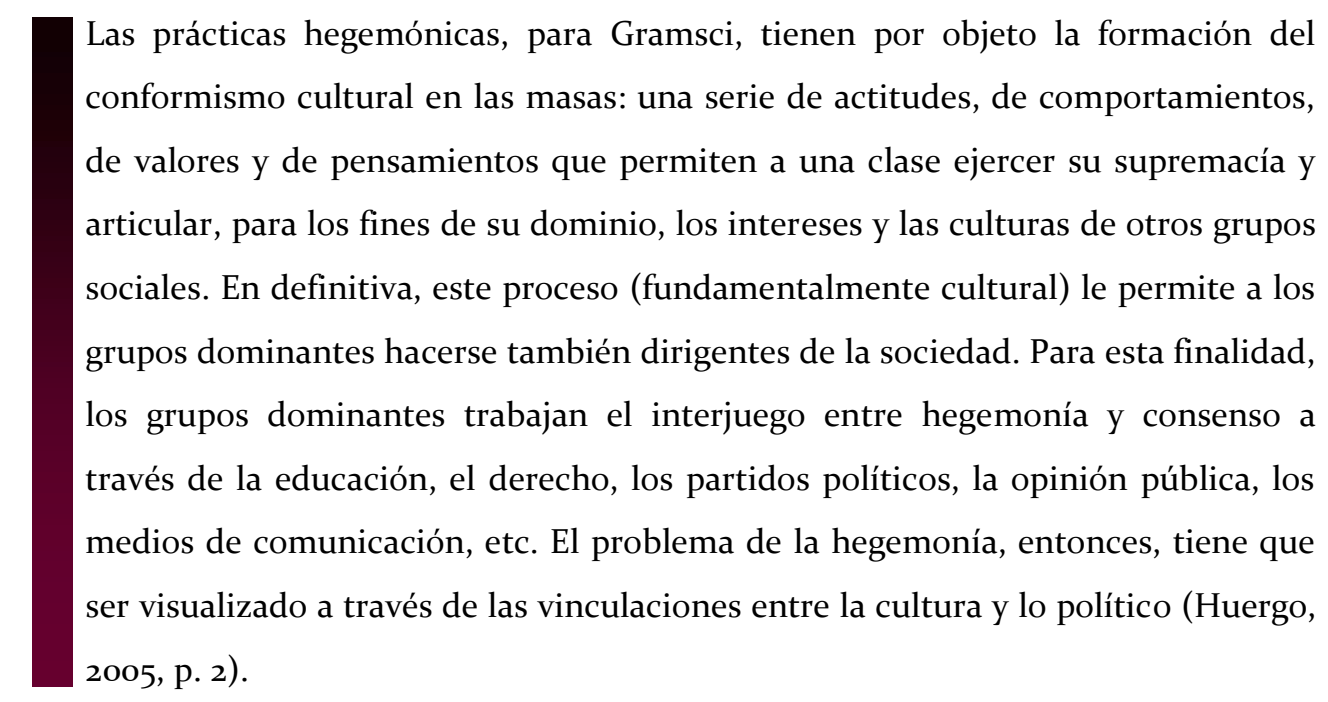

Si la hegemonía es vista desde la producción social de algunos sentidos por sobre otros, o mejor dicho, como la construcción de los sentidos socialmente válidos o dominantes, el análisis y la pertinencia del campo comunicacional es central a la hora de reconocer estos fenómenos.

En este sentido, y como elemento articulador de lo presentado hasta aquí, es necesario retomar una perspectiva del nuevo ecosistema comunicacional, que integre dentro de las dinámicas sociales, no solo los procesos de inclusión-exclusión, sino también lo que puede pensarse como la batalla por la visibilidad, por la construcción de unos relatos por sobre otros, unas historias por sobre otras, unos valores sobre otros, es decir finalmente unos sentidos - hegemónicos y hegemonizantes- en un contexto de sobreabundancia de información y plataformas mediático tecnológicas, que día a día median cada vez más nuestra experiencia vital. 
Por ello, a la perspectiva de Gramsci (1986) es necesario complementarla ya que la mirada de la sociedad anclada en una dualidad causal, de clase, no nos alcanza para dar cuenta de procesos sociales que son sinuosos, fragmentados, refractarios y en donde la dimensión discursiva cobra especial sentido, ya que si hablamos de transformaciones en el orden de la cultura, el giro discursivo es el camino que debemos tomar para continuar.

\footnotetext{
Hegemonía es, simplemente, un tipo de relación política; una forma, si se quiere, de la política; pero no una localización precisable en el campo de una topografía de lo social. En una formación social determinada puede haber una variedad de puntos nodales hegemónicos. Evidentemente, algunos de ellos pueden estar altamente sobredeterminados; pueden constituir puntos de condensación de una variedad de relaciones sociales y, en tal medida, ser el centro de irradiación de una multiplicidad de efectos totalizantes; pero, en la medida en que lo social es una infinitud irreductible a ningún principio unitario subyacente, la mera idea de un centro de lo social carece de sentido (Laclau \& Muffe, 1987, p. 183).
}

Entonces, si los procesos de producción de hegemonía son discursivos y descentrados (al menos parcialmente), es necesario volver a hacer la pregunta por la posición que ocupa el sujeto actualmente en ese proceso. Tal es así que necesitamos preguntarnos qué pasa cuando empezamos a tener conciencia de que casi toda nuestra experiencia vital va camino a estar atravesada por ceros y por unos, por una arquitectura construida por sistemas que desde las lógicas internas de un algoritmo producen unos sentidos y clausuran otros, qué marcas del poder cargan, y cómo condiciona esta nueva mediación un reordenamiento del poder, analizado desde su dimensión simbólica.

Es decir que si vamos a pensar la digitalización de la cultura como una nueva arquitectura simbólica que media nuestra experiencia debemos ver qué marcas o, mejor dicho, qué elementos descentralizados se estructuran en las nuevas dinámicas surgidas.

$\mathrm{Si}$, como dijimos anteriormente, por ejemplo, las plataformas de interacción social no poseen como finalidad conectarnos, sino retenernos para monetizar nuestra atención, si la posibilidad de monitorear en nuestra heladera los alimentos que faltan para pedirlos mediante una Inteligencia Artificial (IA) al supermercado no tiene como fin que no nos desabastezcamos, sino saber paso a paso qué comemos, si cada nuevo aparato que se conecta a internet lo hace más como una terminal de recopilación de información que como un servicio específico, podemos entonces preguntarnos qué pasará con la circulación del poder cuando en breve sepan más de nosotros que nosotros mismos. 
Paralelamente, en estas nuevas arquitecturas informáticas, que podemos definir, acudiendo a un juego bourdiano, como programas programados predispuestos para funcionar como programas programantes, estamos ante sistemas que cotidianamente toman decisiones por nosotros y que dejan fuera otras opciones que en el error, o en la lógica que está por fuera de las lógicas de programación binarias, también serían una posibilidad. En esta trama de sujetos y de procesos de significación se conforma la hegemonía.

Este despliegue tecnológico, en el que los sujetos interactúan en prácticas significantes concretas, produce un efecto de sentido performativo que reconfigura la hegemonía y por ello mismo la significación.

Necesitamos desmontar estos espacios que hoy comienzan a condensar poder, a jugar en el plano discursivo que, como bien lo señalan Laclau y Mouffe (1987), no es meramente el de la palabra, sino más bien el de la configuración de lo social.

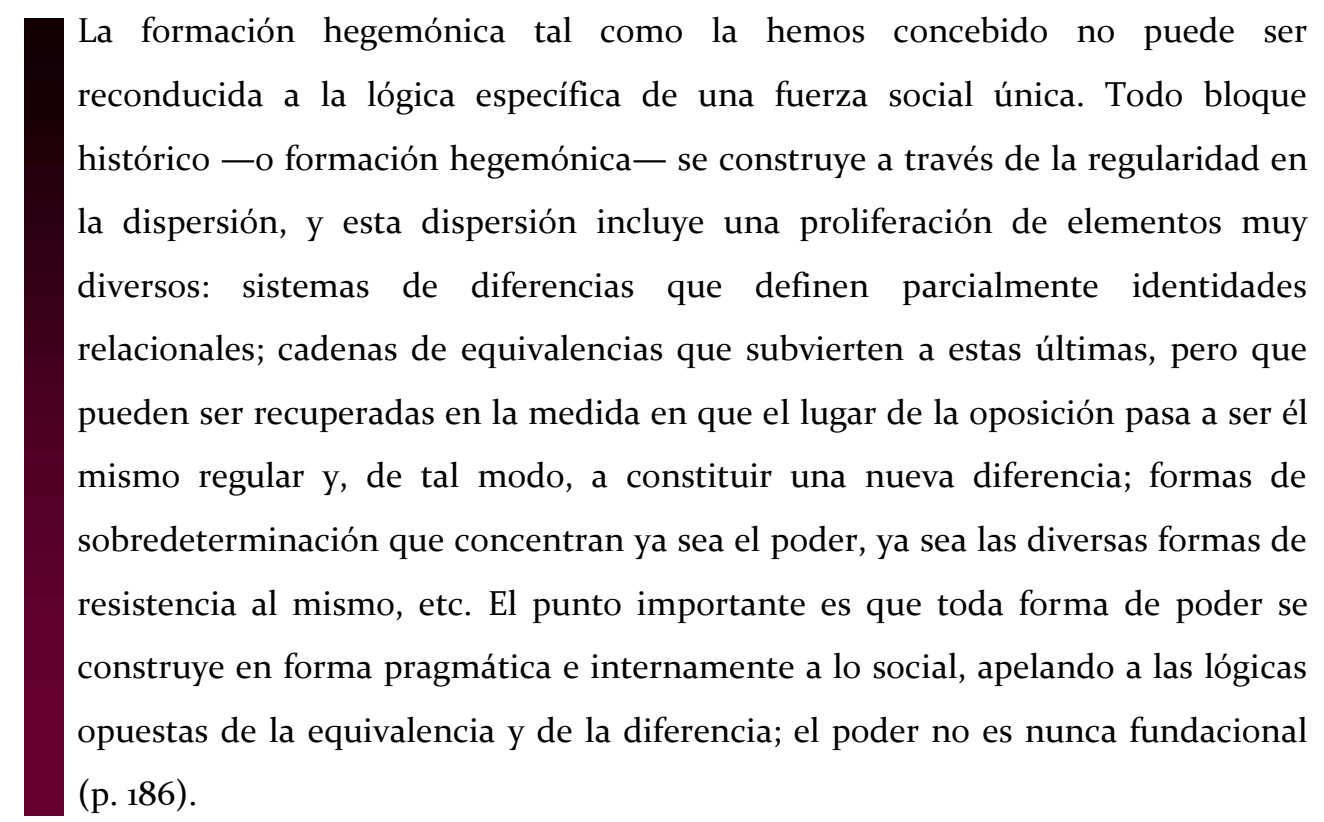

Podemos decir, entonces, que el poder nunca es fundacional, y que entonces debemos, hoy más que nunca, rastrear dónde se funda el poder que se aloja en cada algoritmo, qué equivalencias propone y qué cadenas de diferencias. Para ello, retomamos uno de los elementos que ha llamado la atención: la reproducción de órdenes racistas y discriminatorios, automatizados dentro de los algoritmos, y sus potenciales peligros. 
Tras investigar un poco y probar con algunos nombres, surgió una hipótesis un poco extravagante, ¿y si los resultados variaban dependiendo de si tenías un nombre "negro" o no?

Parecía ridículo. Al fin y al cabo, un algoritmo es un algoritmo ¿Qué hay más objetivo que un algoritmo? ¿Cómo podía un algoritmo ser racista? Lamentablemente, y tras una investigación por todo Estados Unidos, Sweeney descubrió que, en efecto, a medida que crecía la probabilidad de que un nombre perteneciera a una persona de color, mayor era la probabilidad de que apareciera vinculado a arrestos o antecedentes penales. Efectivamente, los ordenadores eran racistas (Jiménez, 2015, en línea).

Esta afirmación, que comienza tímidamente, termina siendo contundente y abona un camino de análisis necesario. Está hoy demostrado en este estudio citado, y en muchos otros, que los algoritmos cargan con los prejuicios y con el racismo de quienes los programan, y, por supuesto, quienes los programan responden a lógicas de configuración de la hegemonía que los exceden pero que se encuentran dentro.

Google fue duramente criticado cuando, en 2015, se difundió que su sistema de reconocimiento de imágenes confundía fotos de gorilas con personas. El tema enseguida se difundió en Twitter: "Mi amigo no es un gorila", escribió el usuario y adjuntó una captura de pantalla que dejaba en evidencia el problema. La compañía salió a pedir disculpas y prometió solucionar el error del algoritmo.
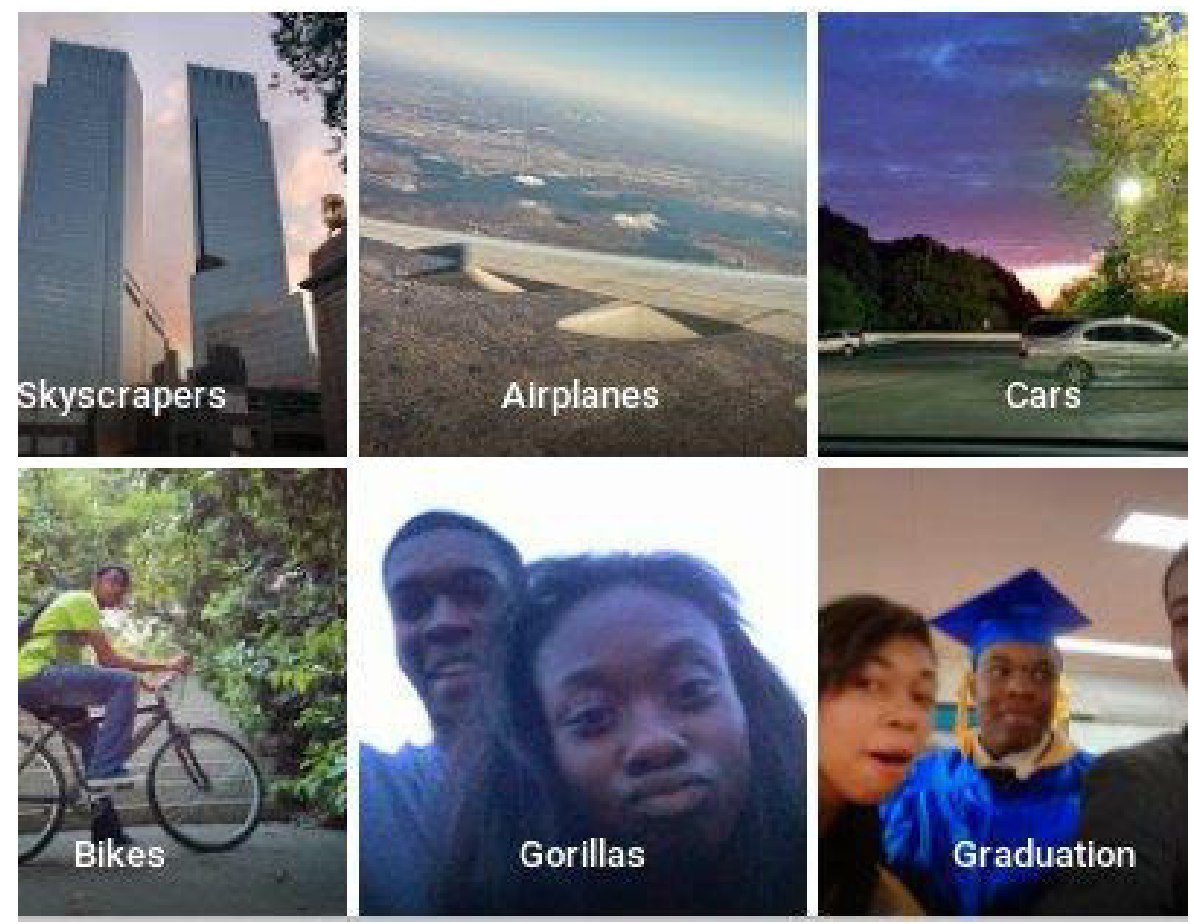
No fue el único caso de racismo. Un sistema empleado por la justicia de Estados
Unidos para pronosticar la tasa de reincidencia de criminales (y que se utiliza
para decidir el futuro de un acusado) marcaba como más propensas a cometer
delitos a personas negras que blancas, aun cuando tuvieran un prontuario similar.
A esa conclusión llegó una investigación realizada por ProPublica (Jaimovich,
5/7/2018, en línea).

En la imagen se observa cómo el sistema que ordena automáticamente fotos en Google, ubica dos personas negras en una carpeta que "automáticamente" bautiza "Gorillas".

Entonces, vemos cómo un sistema extiende ciertas lógicas y las ritualiza, en forma automatizada, para dar una respuesta preconfigurada con formas programadas por alguien, que cristalizando dentro del código binario una serie de parámetros deja dentro las marcas del poder que se van a reproducir hasta el infinito mientras alguien haga girar esas variables. Consecuentemente, los negros serán reconocidos como más peligrosos si una cámara los toma de noche y el sistema predice el riesgo que genera ese sujeto. Allí, las mujeres serán computadas como más débiles para algunos espacios de poder si el programa así lo dispone, el militante político será peligroso en democracia pero será un delincuente en regímenes totalitarios, automáticamente detectados y analizados sobre la base de una serie de variables que sabemos claramente pueden ser desmontadas antes de su producción, pero sobre las que perdemos control una vez que se automatizaron.

Esta serie de elementos resulta clave para revisar la reconfiguración de lo social en un contexto como el que venimos analizando y nos dejan abierta la necesidad de avanzar en otro concepto clave, para ver de qué manera, nuestra experiencia hipermediada configura una nueva mirada sobre el mundo, es decir configura un nuevo sensorium pero que no solo se está alterando por las lógicas de mediación tecnológica, sino por las relaciones de poder que se imbrican dentro.

\section{Alteraciones en el sensorium y nuevas formas de percepción}

Para avanzar en otro elemento que consideramos clave en esta tesis que está vinculado con la posición del sujeto en relación con este nuevo ecosistema comunicacional, tenemos que incorporar una categoría que se ubica en el encuentro entre el aparato sensoriomotriz y las tecnologías disponibles, para reflexionar sobre cómo esto modifica radicalmente la percepción del mundo que tenemos. 
Walter Benjamin (1982), primero, y, luego, Jesús Martín-Barbero (2010) advierten sobre esta situación y sobre estas inferencias que realizan ambos autores consideramos necesario detenernos:

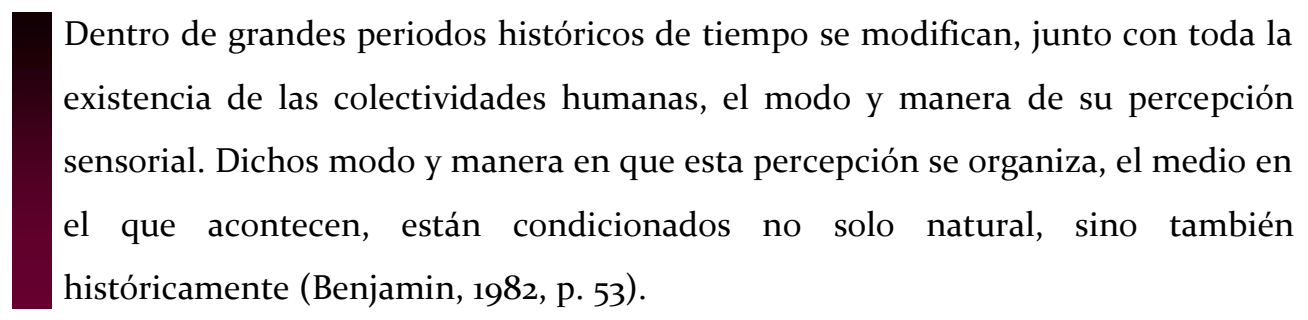

Así comienza a analizar Benjamin (1982) el cambio que, según él, se inauguraba con la era de la reproductibilidad técnica, en la que los bienes simbólicos comienzan a reproducirse con las lógicas de los bienes materiales.

Afirma Martín-Barbero (2010):

Más que un conjunto de nuevos aparatos, de maravillosas máquinas, la
comunicación designa hoy un nuevo sensorium (Benjamin): nuevas
sensibilidades, otros modos de percibir, de sentir y de relacionarse con el tiempo
y el espacio, nuevas maneras de reconocerse y de juntarse.
La experiencia audiovisual replantea los modos mismos de relación con la
realidad ya que introduce transformaciones en nuestra percepción del espacio y
el tiempo. Del espacio, profundizando el desanclaje, desterritorializando las
formas de percibir lo próximo y lo lejano hasta tornar más cercano lo vivido
"a distancia” que lo que cruza nuestro espacio físico cotidianamente.
Paradójicamente esa nueva espacialidad no emerge del recorrido viajero que me
saca de mi pequeño mundo sino de su revés, de una experiencia doméstica
convertida en ese territorio virtual (p. 81 ).

Hablar de sensorium, entonces, es focalizar en primer lugar, la transformación de la experiencia y su relación con la historia; es decir, de la experiencia histórica que se manifiesta en una época determinada.

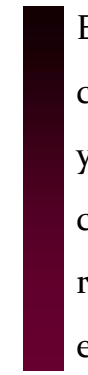

Es en esta dirección que la autora [en alusión a Buck-Morss] nos lleva por caminos ya explorados por Benjamin (1982) en relación con el sensorium, pero yendo mucho más allá, valiéndose de los estudios contemporáneos sobre el cerebro y el sistema nervioso como partes del cuerpo que están en completa relación con los datos de los sentidos. Para ello, parte de la premisa según la cual el sistema nervioso no se limita al cuerpo interno, sino que se relaciona con el 

medioambiente en el que se encuentra: "El circuito que va de la percepción sensorial a la respuesta motora comienza y termina en el mundo" (Buck-Morss, 2005, p. 182). Y, seguidamente, añade: "El campo del circuito sensorial, entonces, se corresponde con el de la 'experiencia'" (Idárraga Franco, 2009, p. 80).

Así, lo que vamos desentramando es la necesidad de repensar cómo este proceso, que tiene origen en el despliegue de una serie de aparatos, reconfigura hasta el extremo las formas de habitar el mundo, porque en realidad lo que modifica es la experiencia de estar en él, y desde allí todo lo demás nunca volverá a ser lo mismo.

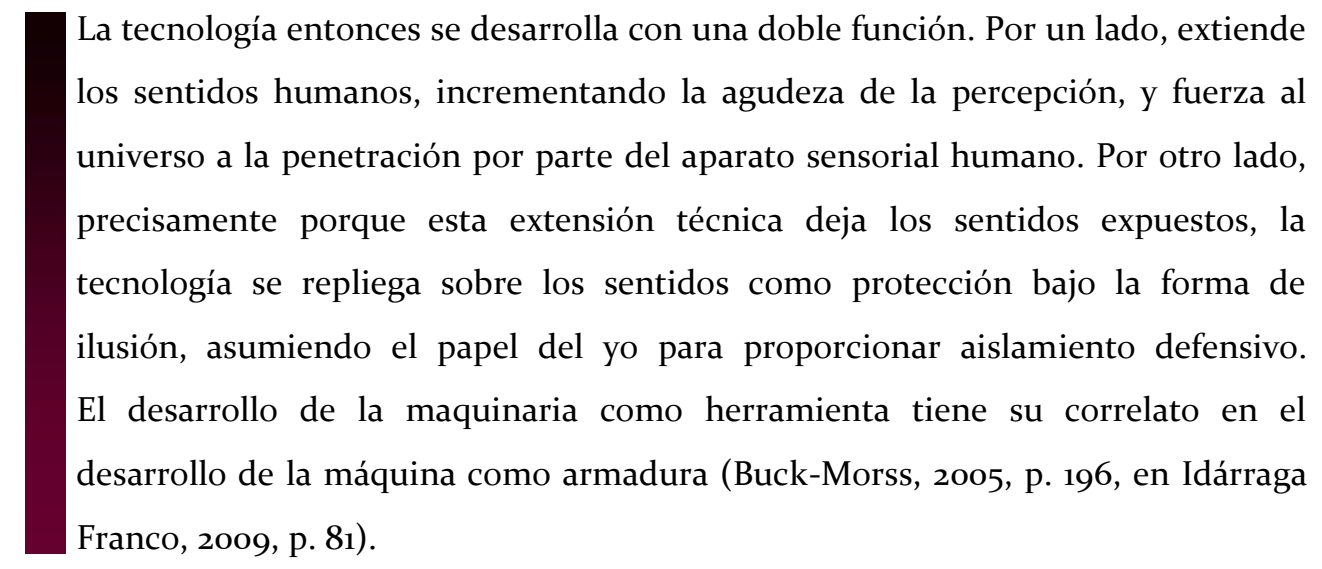

Entonces, podemos ver cómo la posibilidad de ver más allá nos inviste de unas determinadas características tanto en la conformación de nuestras formas de percibir, como también en la configuración subjetiva del yo, ya que dejamos de vincularnos con el mundo por nosotros mismos en el mismo movimiento en el que lo percibimos más profundamente, y así las mismas herramientas que potencian nuestra mirada se transforman en los elementos que nos alejan del mundo.

Ese juego es central para reconocer cómo finalmente la nueva relación que tenemos con el mundo ya no puede ser sino en esta hipermediación; es decir. en el acople entre el hombre y la máquina, y desde allí lo que surge es diferente según el tipo de ensamble que se vaya construyendo.

\footnotetext{
Al sensorium lo definimos entonces como la configuración y la organización de nuestro aparato sensorial y nervioso, que está determinado no solo naturalmente sino también históricamente. Este elemento histórico se refiere al tipo de conocimiento que en él se hace presente —en nuestro caso, el conocimiento científico-, por el desarrollo de la técnica — de la cual hablaremos en adelante como tecnología-y, junto a este desarrollo, por la transformación de los modos de producción (Idárraga Franco, 2009, p. 10).
} 
Benjamin (1982) describió cómo los desarrollos que dieron lugar a la aparición del cine y la fotografía eran una forma de entrenamiento frente a las exigencias del mundo tecnificado que empezó a tomar forma con el nacimiento de las ciudades modernas. Entendemos, entonces, que es preciso actualizar su propuesta de análisis frente a la aparición de Internet como nueva mediación tecnológica que da cuenta de las transformaciones que se venían dando desde antes de su aparición.

En efecto, esta nueva mediación técnica suplementa los sentidos permitiéndonos obtener una mayor información del mundo. La velocidad del tiempo y de los shocks, así como la fragmentación del espacio como consecuencia del cambio tecnológico, han modificado la forma en la que conocemos el mundo y la forma también en la que actuamos en él, exigiendo a nuestro sensorium un nuevo tipo de configuración.

\section{Un nuevo sensorium. breve mención sobre lo escolar}

Martín-Barbero (2010) entiende que ante todo "es preciso comprender la densidad de las transformaciones que atraviesan los modos de comunicar" (p. 23). A su juicio,

\footnotetext{
Lo que cuesta aceptar es la aparición de una experiencia cultural nueva. Unos nuevos modos de percibir y de sentir, de oír y de ver, una nueva sensibilidad colectiva [y que] los medios de comunicación y las tecnologías de información significan para la escuela en primer lugar un reto cultural, que hace visible la brecha cada día más ancha entre la cultura que enseñan los maestros y aquella otra desde la que aprenden los alumnos (Martín-Barbero, 2010, p. 30).
}

Sin embargo — como ya lo ha demostrado la experiencia reciente—, no se trata de la mera introducción de medios y tecnologías de comunicación en la escuela, lo cual puede ser la más tramposa manera de ocultar sus problemas de fondo, tras la mitología efímera de su modernización tecnológica. La pregunta es más profunda: ¿qué transformaciones necesita transitar la escuela para descubrir el rol que la sociedad actual necesita que cumpla y cómo lograrlo? Para eso —entendemos — debe resolver antes que nada dos cuestiones: cómo se comunican los niños y jóvenes hoy o, dicho de otro modo, cuál es o cuáles son sus nuevos universos vocabulares y qué es lo que la sociedad actualmente necesita que haga la escuela para formarlos. Es decir que antes que una cuestión de medios, el nuevo escenario comunicacional debería ser para la educación una cuestión de fines, de cómos y paraqués. 
Es evidente que la educación debe ser re-pensada a partir de superar el estrecho margen de la escolaridad, particularmente en este nuevo escenario que plantea un ecosistema comunicativo que es, a la vez, experiencia cultural (nuevo sensorium) y espacio educacional difuso y descentrado (que se extiende más allá de las paredes del aula) [Martín-Barbero, 2001].

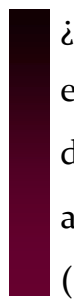
¿Cómo insertar a la escuela en ese ecosistema y cómo seguir siendo en ese nuevo escenario el lugar donde el proceso de aprender guarde su encanto: a la vez rito de iniciación en los secretos del saber y desarrollo del rigor de pensamiento, del análisis y la crítica, sin que lo segundo implique renunciar al goce de crear (Martín-Barbero, 2001, p. 11).

Entonces, tomada debida conciencia de lo que significan los cambios en la comunicación, es preciso repensar cómo enseñar, qué es lo que la sociedad necesita que la escuela enseñe, cuáles son los principales problemas, conflictos, intereses y motivaciones desde los cuales es necesario estructurar los procesos de aprendizaje y los demás retos que plantean, a las políticas educativas, los cambios en la comunicación y en la cultura.

Como advierte Martín-Barbero (2010):

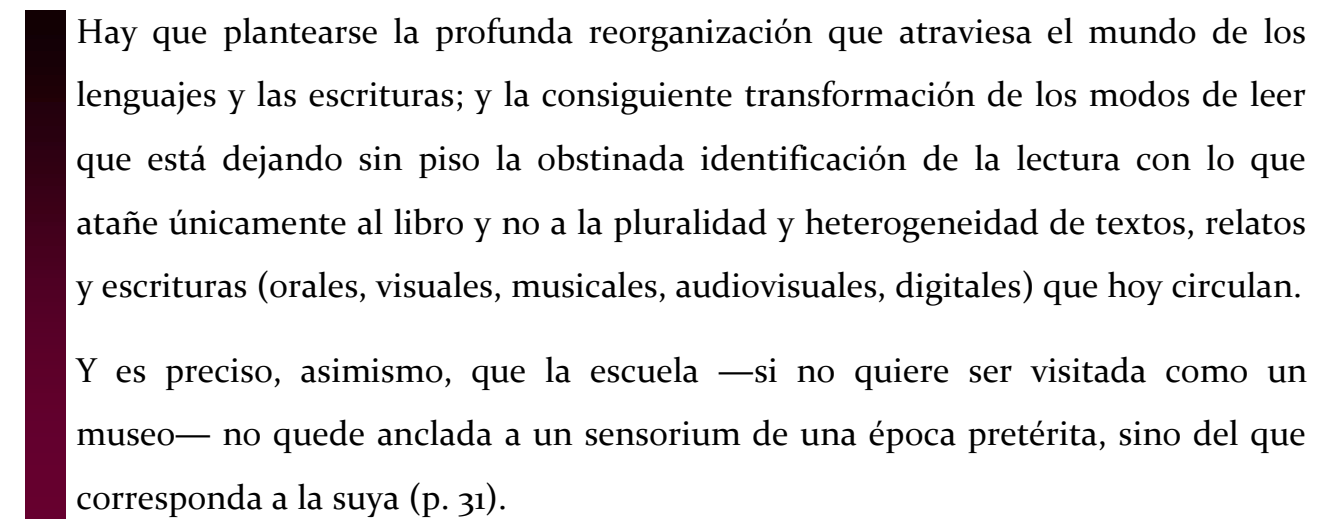

Por lo tanto, reponiendo las distintas huellas de este ensayo, consideramos necesario repensar la hegemonía recuperando su dimensión simbólica, desde un campo de significaciones que hoy se encuentra hipermediado. Esto implica que las formas en las que se redistribuye reticularmente el poder no pueden estar aisladas de las lógicas de las plataformas y de la nueva arquitectura tecnológica sobre la cual se entrelaza nuestra vida cotidiana. 
Así, la forma en que percibimos el mundo, este sensorium que magistralmente Mijaíl Bajtín (1982), primero, y Martín-Barbero (1989), luego, recuperan como elemento clave para integrar la forma en que percibimos el mundo, hoy está aumentado, complejizado, mixturado y porque no revuelto en la cultura digital. Por ello, integrar la percepción del mundo que poseemos con las formas de organización del poder en un contexto de digitalización de la cultura, se alza como un elemento central para desde allí, no solo reconocer este fenómeno, sino también intervenir sobre él y modificarlo. 


\section{Referencias}

Bajtín, M. [1982] (1998). Estética de la creación verbal. Ciudad de México, México: Siglo XXI.

Benjamin, W. (1982). Discursos interrumpidos. Madrid, España: Taurus.

Gramsci, A. (1986). El materialismo histórico y la filosofía de B. Croce.

Ciudad de México, México: Juan Pablos Editor.

Huergo, J. (2005). Hegemonía, un concepto clave para comprender la comunicación (ficha de cátedra). La Plata, Argentina: Facultad de Periodismo y Comunicación Social, Universidad Nacional de La Plata.

Idárraga Franco, H. F. (2009). Sensorium e Internet. Una aproximación al fenómeno tecnológico desde la obra de Walter Benjamin (tesis de maestría). Recuperado de https://repository.javeriana.edu.co/handle/10554/238

Jaimovich, D. (5 de julio de 2018). Algoritmos racistas, machistas y extremistas: ¿se necesita enseñarles ética a los robots? Recuperado de https://www.infobae.com/america/tecno/2018/07/05/algoritmos-racistasmachistas-y-extremistas-se-necesita-ensenarles-etica-a-los-robots/

Jiménez, J. (3 de diciembre de 2015). ¿Pueden ser racistas los algoritmos? Recuperado de https://www.xataka.com/robotica-e-ia/pueden-ser-racistas-losalgoritmos

Kusch, R. (2000). Geocultura del hombre americano. En Obras completas, tomo 3. Rosario, Argentina: Fundación Ross.

Laclau, E. y Mouffe, C. (1987) Hegemonía y estrategia socialista. Hacia una radicalización de la democracia, Madrid, España: Siglo XXI.

Martín-Barbero, J. (2001). Los oficios del comunicador. Renglones, revista del ITESO, (48). Recuperado de https://rei.iteso.mx/handle/11117/480

Martín-Barbero, J. (2010). Jóvenes: entre la ciudad letrada y el mundo digital. En G. Lluch (Ed.), Las lecturas de los jóvenes. Un nuevo lector para un nuevo siglo (pp. 39-58). Barcelona, España: Anthropos. 


\title{
Una aproximación necesaria al campo material de la cultura digital Conversaciones con Gabriel Baum
}

\author{
Comprender el modo de funcionamiento técnico de lo digital \\ resulta clave para situarse en el mundo de manera crítica y, sobre todo, \\ para aspirar a participar como ciudadanos plenos de su construcción.
}

Mara Borchardt e Inés Roggi (2017)

La cultura digital posee diferentes abordajes, uno de ellos, central y estratégico, es su campo material con lógicas específicas de funcionamiento y formas que le son propias. Es clave esto, porque si no comprendemos de qué se tratan las formas en que la codificación informática configura unos determinados procesos, con dinámicas y lógicas particulares, provenientes de las múltiples formas de combinación entre ceros y unos, no lograremos acercarnos a una parte estratégica del problema que se centra, dentro de esta nueva arquitectura simbólica en cómo ella se construye, cuáles son sus materiales, sus herramientas principales, sus límites, alcances y formas de estructuración.

Estas dinámicas no son externas al proceso de formación de sujetos y de producción social de sentido, son parte de su trama y le dan forma a la red sobre la cual suceden muchos de los procesos aquí analizados. En la actualidad, lo comunicacional, lo educativo y lo cultural son indisociables del soporte tecnológico en el cual se encuentran imbricados.

La producción de saberes en este sentido puede generarse a partir de múltiples vincularidades: trayectorias de investigación, lecturas bibliográficas, producción de materiales previos de quien suscribe y de otros y otras. Los ensayos en sí mismos son escritura y reflexión que forman una búsqueda comprensiva de la cultura digital y su implicancia en los procesos de comunicación / educación. En ese camino, apelamos al 
género entrevista en profundidad como parte de la producción de conocimiento que sigue la huella del diálogo de saberes al tiempo que supone el reconocimiento de trayectorias que contribuyen a alumbrar un camino sinuoso y a la vez productivo de aprendizaje.

\section{Algunos conceptos clave previos a la conversación}

A continuación, se realiza un rastreo de una serie de categorías centrales que desarrollamos a modo de glosario para luego poder avanzar en la presentación de una síntesis de la entrevista, en la cual encontraremos mucho de este contenido desplegado.

Una vez comprendido el esquema conceptual vinculado a la digitalización de la cultura, necesitamos comenzar a profundizar la idea de cómo funciona la informática en sí y problematizar terminologías como machine learning, Big Data e Inteligencia Artificial, entre otras. $\mathrm{Al}$ respecto, caben dos observaciones que si bien pueden resultar propias del sentido común, pocas veces tenemos en cuenta: por un lado, que es real que cada vez convivimos más con dispositivos y programas que hacen uso de muy complejos algoritmos para entregarnos los resultados de una búsqueda $u$ ofrecernos el entretenimiento que queremos. Por otro lado $-\mathrm{y}$ es por ahí lo más interesante a rescatar- es que muy pocas veces nos preguntamos, indagamos o tratamos de dar respuesta a qué hacemos y para qué con estas tecnologías que hoy en día están cada vez más presentes en nuestra cotidianeidad.

Con fines expositivos, es interesante rescatar las palabras - y en articulación con lo antes dicho- de Natalia Zuazo, autora de Los dueños de internet. Cómo nos dominan los gigantes de la tecnología y qué hacer para cambiarlo (2018), cuando en una entrevista define lo que hace y lo que entiende que es tecnología:

\footnotetext{
Yo no hago periodismo tecnológico. Hago periodismo. La tecnología es una excusa para hablar de política, economía y otras cosas. Eso no significa hablar del último celular. La tecnología está cada vez más presente y el problema que veo es que muchos colegas que se especializan tienen cada vez más compromisos con las empresas (Zuazo en Borelli, 10/6/2018, en línea).
}

En forma esquemática, podemos decir que cuando un usuario interactúa - hace uso del aparato técnico, del celular / tablet- con los dispositivos, por un lado, está creando una semiosis cultural y, por el otro, está poniendo en funcionamiento un sistema de 
arquitecturas informáticas gigantescas que hacen que de forma casi automática obtenga una respuesta a su búsqueda, pueda procesar una imagen en forma online, entre otras acciones. A modo de ejemplificación, según el medio digital Xataka (2016), "en 2015, Estados Unidos movía un tráfico de 45,7 Exabytes mensuales. China, unos 21,9 Exabytes”. Es decir, 10 con 18 ceros de bytes (de datos), que año a año se multiplican.

Todas estas acciones o, mejor dicho, servicios (servicios SaS) que el usuario obtiene con la denominada cloud computing (la famosa nube) son programas que corren en granjas gigantescas de servidores que procesan en milisegundos las solicitudes que el usuario realiza. Sin embargo, para enriquecer esta idea sería interesante poner en común algunos términos, para luego avanzar en una conversación con el Dr. Gabriel Baum, que abrirá aún más interrogantes y desarrollará varios de estos temas que, aunque no forman parte del corpus central de este trabajo, no pueden ser dejados de lado sin explicarlos. ${ }^{2}$

Podemos decir, de modo esquemático y simplificado, que las computadoras están formadas por dos partes indisociables: por un lado el hardware -la parte dura y material- y el software, que es la capa de abstracción lógica que permite que luego, mediante la presencia o ausencia de corriente eléctrica, se desarrollen diferentes acciones o no; sin embargo lo importante es entender que una no puede funcionar sin la otra y que en definitiva el programador o quienes trabajan con las ciencias informáticas lo que hacen es pensar, analizar, reducir a su expresión más básica problemas que pueden ser resueltos por computadoras, esto es, generar algoritmos ${ }^{3}$ que luego van a generar lo que denominamos programa informático.

Este esquema simplificado es el que permite comprender — con sus diversos grados de complejidad - una arquitectura de hardware y software de forma clara, concisa y capaz de ser trasladada a cualquier equipo tecnológico. Podríamos preguntar, entonces, ¿cuál es la diferencia que hay entre una calculadora y una computadora? La diferencia esencial es que una computadora permite —además de almacenar y de procesar informaciónprogramar, es decir, dar una respuesta lógica y de carácter general a una serie de inputs / outputs (entradas y salidas de información) que le son indicados. Dicho de otro modo, ambos dispositivos van a poder realizar una tarea con las operaciones matemáticas pero

2 El sentido de esta inclusión radica en la necesidad de detener la maquinaria del uso -irreflexivo, automático- de las tecnologías para producir una metacomprensión del mismo y un conocimiento fundado.

3 Definidos por la Real Academia Española como "conjunto ordenado de operaciones sistemáticas que permiten hacer cálculos y hallar la solución de un tipo de problemas”. Recuperado de https://dle.rae.es/?id=1nmLTsh 
es la generalidad (en referencia a una máquina de propósito ${ }^{4}$ general, es decir, preparada para realizar diversidad de tareas) de la computadora $-\mathrm{y}$ a partir de la programación— 5 la que permite realizar además de las operaciones matemáticas, una multiplicidad de tareas.

El esquema anteriormente descrito ha hecho que durante al menos las décadas del ochenta y noventa y parte de la década de 2000, todos los desarrollos informáticos y modelos de negocios se establecieran en la comercialización de equipamiento informático y venta de licencias de software instalable, cuestión que pudo ser posible de la mano de la estandarización de tecnologías, abaratamiento de costos y miniaturización del hardware, es decir, se logró un modelo de negocios basado en la venta de licencias de programas (derechos de uso) instalables; luego, en los últimos veinte años se viene instaurando de a poco lo que hoy en día se define como Software as Service, es decir un "modelo de distribución de software donde el soporte lógico y los datos que maneja se alojan en servidores de una compañía de tecnologías de información y comunicación (TIC), a los que se accede vía Internet desde un cliente. La empresa proveedora TIC se ocupa del servicio de mantenimiento, de la operación diaria y del soporte del software usado por el cliente" (Wikipedia, s/f, Software como servicio); es entonces que si bien seguimos trabajando con programas y con hardware, ahora son las empresas proveedoras de infraestructura quienes nos proveen de un nuevo modelo de negocios que como vimos se apoya en la venta de infraestructura tecnológica y un servicio informático en particular, en esencia se sigue vendiendo software pero de forma más concentrada y en la nube.

¿Y qué es la nube? Sería una pregunta adecuada para comprender de forma más clara la lógica de Internet. En términos de RedHat (s/f) - empresa de cloud computing de software libre--, en esencia, la nube es

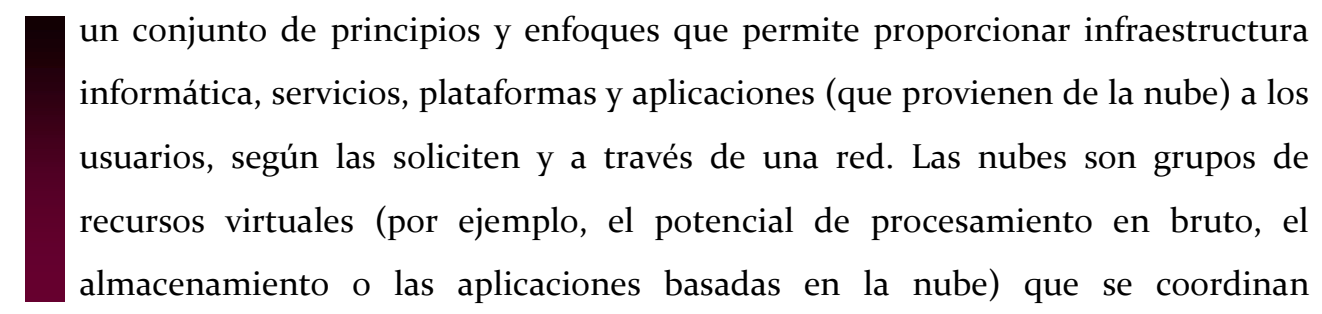

4 Ver más información en https://es.wikipedia.org/wiki/Arquitectura de Von Neumann

5 Entendemos la programación como el proceso por el cual una persona desarrolla un programa valiéndose de una herramienta que le permite escribir el código y de otra que sea capaz de "traducirlo" a lo que se conoce como lenguaje de máquina, el cual puede ser entendido por un microprocesador (Wikipedia, s/f, Programación). 
1 mediante un software de gestión y automatización, para que los usuarios puedan acceder a ellos según lo soliciten, a través de los portales de autoservicio a los que dan soporte el escalado automático y la asignación dinámica de recursos (en línea).

Esta definición que nos proporciona RedHat nos permite entender que a lo que denominamos "computación en la nube" no son más que una serie de servidores bajo los cuales corren una serie de programas que son ordenados bajo una serie de recursos y de lógicas de organizar la información, lo que también permite realizar inferencias, generar valor o, sobre todo, información.

Es en esta lógica y modelo comercial que se comienza desde el mundo empresario a buscar un modelo de diferenciación de la competencia y a tratar de hacer algo apelando a nuevos campos de conocimiento como lo son la Inteligencia Artificial (IA) y el Machine Learning, entre muchos otros.

Sin embargo, antes de seguir avanzando, es pertinente conceptualizar / desarrollar la idea de qué se entiende por Ciencias de la Computación. Este es el punto de partida para entender o comenzar a rastrear las características o ideas claves de lo que hoy denominamos como campo de la informática.

Si bien existen diversas definiciones de Informática, la más interesante es la que da la Asociación de Docentes de Informática y Computación de la República Argentina (ADICRA) y que considera a la Informática:

\footnotetext{
[...] la disciplina o campo de estudio que abarca el conjunto de conocimientos, métodos y técnicas referentes al tratamiento automático de la información, junto con sus teorías y aplicaciones prácticas, con el fin de almacenar, procesar y transmitir datos e información en formato digital utilizando sistemas computacionales. Los datos son la materia prima para que, mediante su proceso, se obtenga como resultado información. Para ello, la informática crea y/o emplea sistemas de procesamiento de datos, que incluyen medios físicos (hardware) en interacción con medios lógicos (software) y las personas que los programan y/o los usan (humanware) [en línea].
}

ADICRA nos provee una definición lo suficientemente amplia como para permitirnos entender este campo disciplinar no necesariamente anclado meramente a los dispositivos, sino que la definición pone el foco en que la computadora o, mejor dicho, la 
plataforma utilizada va a usar una serie de mecanismos, métodos y técnicas para procesar información; esto es, se pone el foco en la disciplina y no en la herramienta.

Una vez aclarados los puntos acerca de qué entendemos por Ciencias de la Computación, el concepto de Informática y su interrelación, podemos retomar la idea que dejamos atrás relativa a qué entendemos por Inteligencia Artificial, Big Data, Machine Learning y Deep Learning. A modo de mínimo -y necesario- glosario, señalaremos las definiciones y las características centrales de cada uno y cómo se interrelacionan.

Inteligencia Artificial: comúnmente abreviada IA, es una de las diversas ramas que componen las Ciencias de la Computación. Según Andreas Kaplan y Michael Haenlein (2019), se trata de "la capacidad de un sistema para interpretar correctamente datos externos, para aprender de dichos datos y emplear esos conocimientos para lograr tareas y metas concretas a través de la adaptación flexible" (p. 16). También es una rama del conocimiento, de carácter necesariamente multidisciplinaria, ya que para alcanzar sus objetivos depende de áreas tan diversas como las matemáticas, la lógica simbólica, la semiótica, la ingeniería eléctrica, la filosofía de la mente, la neurofisiología y la inteligencia social.

Machine Learning: es una disciplina científica del ámbito de la Inteligencia Artificial que crea sistemas que aprenden automáticamente. Aprender en este contexto quiere decir identificar patrones complejos en millones de datos. La máquina que realmente aprende es un algoritmo que revisa los datos y es capaz de predecir comportamientos futuros. Automáticamente, también en este contexto, implica que estos sistemas se mejoran de forma autónoma con el tiempo, sin intervención humana. En otras palabras, se trata de que un sistema informático sea entrenado por complejos algoritmos para encontrar patrones en bases de datos gigantescos y a partir de ellos poder realizar comportamientos futuros o realizar algo con estos datos.

Big Data: también denominado macrodato, inteligencia de datos o datos a gran escala, es un término que hace referencia al concepto relativo a conjuntos de datos tan grandes y complejos como para que hagan falta aplicaciones informáticas no tradicionales de procesamiento de datos para tratarlos adecuadamente. ${ }^{6}$ Para clarificar este concepto, podemos pensar en grandes bases de datos como las que pueden manejar los Estados y

6 Definición elaborada sobre la base del concepto ofrecido por Wikipedia en su artículo principal sobre Macro Datos, https://es.wikipedia.org/wiki/Macrodatos 
en donde hay una multiplicidad de información heterogénea, entonces el desafío es cómo sistematizar y estandarizar esta información para poder realizar algo con esta información.

Deep Learning: la enciclopedia libre Wikipedia dice en su artículo sobre Deep Learning que en general no existe una única definición de aprendizaje profundo y que en general se trata de una clase de algoritmos ideados para el aprendizaje automático. A modo de ejemplo señala una serie de características y definiciones posibles sobre qué se puede entender por aprendizaje profundo (nombre en español) tales como:

- Estar basados en el aprendizaje de múltiples niveles de características o representaciones de datos. Las características de más alto nivel se derivan de las características de nivel inferior para formar una representación jerárquica.

- Aprender múltiples niveles de representación que corresponden con diferentes niveles de abstracción. Estos niveles forman una jerarquía de conceptos.

A su vez, el mismo artículo señala

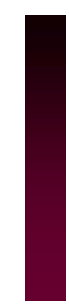

[...] todas estas maneras de definir el aprendizaje profundo tienen en común múltiples capas de procesamiento no lineal y el aprendizaje supervisado o no supervisado de representaciones de características en cada capa. Las capas forman una jerarquía de características desde un nivel de abstracción más bajo a uno más alto (Wikipedia, s/f, Aprendizaje profundo).

Una vez definida cada área específica de las Ciencias de Computación, es interesante establecer una interrelación entre esos conceptos para considerar cómo interactúan entre ellos. En este sentido, podemos señalar que si bien cada área es un campo en sí mismo, por los diversos grados de especialización y complejidad que imponen a la hora de abordarlos, se puede decir que ellos forman parte de un campo mayor, el cual es denominado "Ciencias de la Computación". Otra característica que se desprende es que cada campo si bien se puede trabajar de forma autónoma - por ejemplo con investigación en el campo específico- no se los puede considerar compartimientos estancos sino necesarios entre sí. 
Para comprender aún más esta idea, puede el lector considerar un ejemplo (hipotético) pero que a fines ilustrativos es relevante para entender cómo se pueden interrelacionar estos conceptos. Para esto vamos a tomar el caso que plantea el sitio web Clever Data:

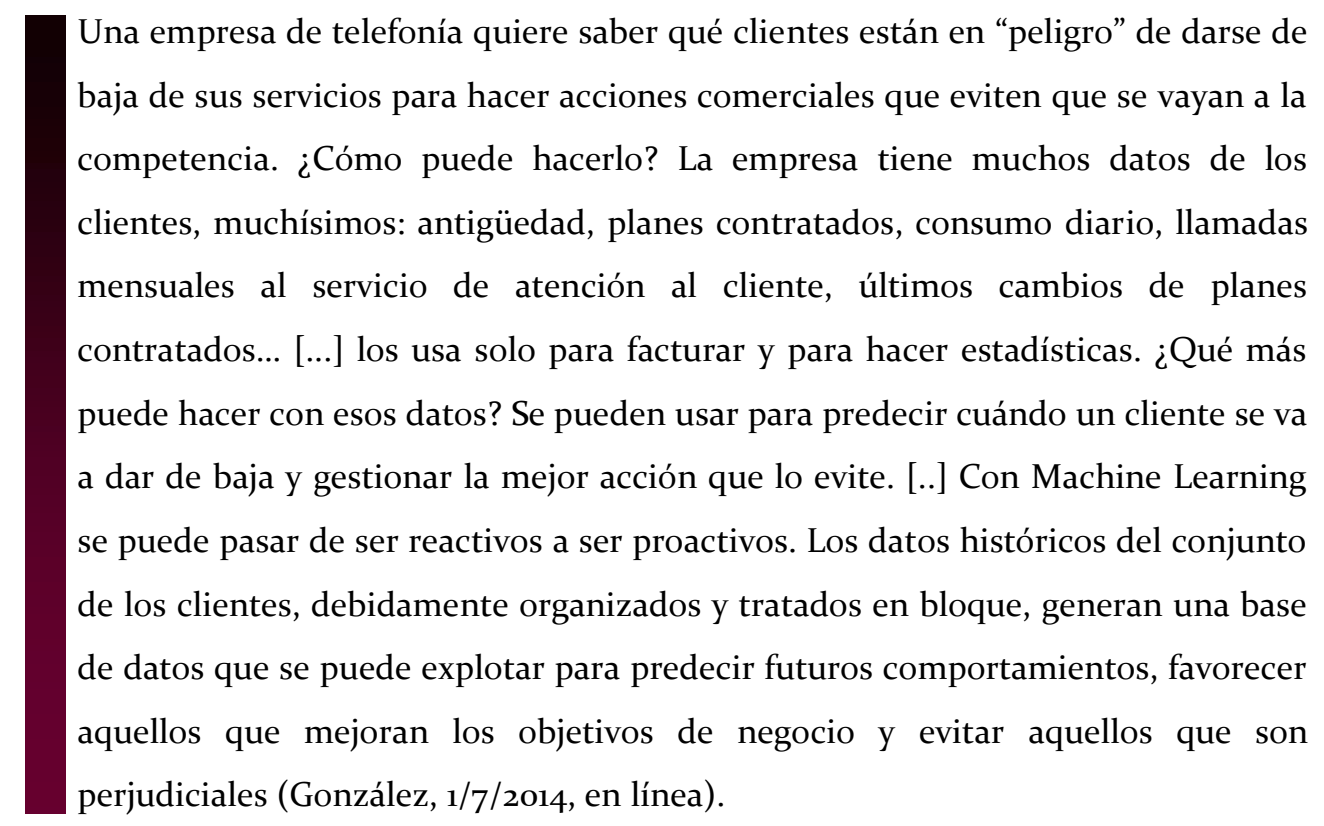

Cómo podemos ver en el ejemplo, hay un cruce de disciplinas necesarios que permiten, por ejemplo, a una empresa reaccionar y tomar decisiones sobre cómo proceder en el futuro y realizar las tomas de decisiones correctas. También podemos pensar que en el caso de los Estados se pueden diseñar políticas públicas de carácter proactivo para abordar posibles problemáticas de gran incidencia social.

Sin embargo hay que señalar que todos estos campos son relativamente nuevos, muchas veces exploratorios y experimentales, en donde no está claro el cruce entre las diversas disciplinas y cómo aprovecharlas y hacer un uso apropiado de las mismas.

En conclusión, estas son áreas que irán cambiando a lo largo del tiempo y que plantean riesgos y desafíos a futuro a medida que se implementen y complejicen según el área. Para quien se encuentre con este material, seguramente le surjan algunos de los siguientes interrogantes: ¿Qué hacer con estos datos? ¿Qué datos son relevantes y cuáles, no? ¿Cómo los tratamos? ¿Quién los administra y cómo? ¿Deben ser únicamente de uso público? Como vemos, estas son preguntas válidas y que, como se ve, no hay una respuesta sencilla por lo nuevo y complejo del campo, pero es importante recordar y tener presentes siempre estas preguntas y pensarlas desde un campo multidisciplinar y transdisciplinar para complejizar, enriquecer y entender qué es lo que se puede hacer y cómo hacerlo. 
Así conformamos una primera matriz de conceptos y de abordajes que desde el campo informático nos permiten profundizar en las características estructurales de lo que hasta aquí denominamos digitalización de la cultura, como proceso que desarrolla una nueva arquitectura simbólica, que como tal puede elementos que le son propios, formas de estructuración y dinámicas de funcionamiento que en su despliegue y vinculación con los sujetos modifican radicalmente los procesos de subjetivación.

Por todo esto, consideramos fundamental recuperar algunos fragmentos de una entrevista realizada al Dr. Gabriel Baum, de la Facultad de Informática de la UNLP, como uno de los principales referentes del campo en la universidad, para profundizar algunos elementos presentados en esta tesis, siguiendo el propuesto paradigma de la complejidad, que implica comprender y poder analizar a través de diferentes perspectivas (incluso entre ellas contradictorias) un fenómeno que, lejos ya de ser de índole meramente tecnológica, ha traspasado los límites de la cultura, para alcanzar las identidades, como se está desarrollando en este trabajo.

Más allá de la mirada específica del entrevistado y del tipo de enfoque que realiza para analizar el problema de las tecnologías, y sobre todo del desarrollo informático, consideramos central reproducir parcialmente tramos de la entrevista, ya que luego de intentar acercarnos a quien nos puede iluminar sobre todo elementos técnicos, nos encontramos con una reflexión profundamente geopolítica de la cuestión y que se hace insoslayable en un trabajo de estas características.

\section{Conversaciones con Gabriel Baum}

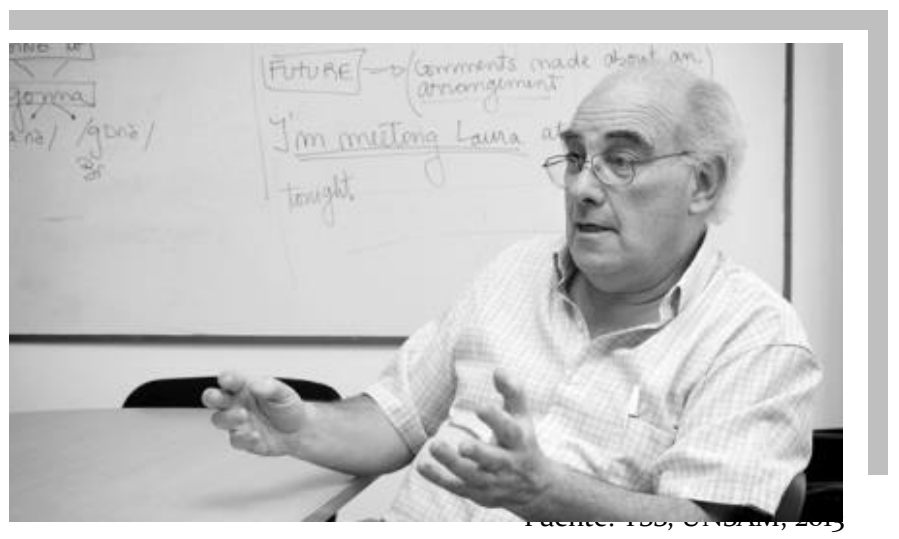

Gabriel Baum se graduó como Licenciado en Informática en la UNLP y es actualmente profesor en la Facultad de Informática de esta institución. Entre 1986 y 1990 fue docente en la Escuela Superior Latinoamericana de Informática (ESLAI) y en 1991 comenzó a trabajar como profesor de tiempo completo en la Facultad de Ciencias Exactas (UNLP) y, más adelante, en la Facultad de Informática (UNLP). 
Desde entonces, es miembro de la junta directiva e investigador en el Laboratorio de Investigación y Formación en Informática Avanzada (LIFIA), y director del área de la teoría de la computación y de métodos formales. Desde 2004 se dedica a actividades que implican la promoción de la industria del software.

Además, el Lic. Baum trabajó en el área de la Teoría de la Computación por algunos años. Desde 1990 se interesó en el área de los métodos formales aplicados al desarrollo y a la prueba del software. Está particularmente interesado en los métodos relacionales aplicados a los aspectos del desarrollo del software, especificaciones, derivación de programas, diseño de algoritmos, prueba y validación.

En los últimos años se dedicó a los aspectos epistemológicos de la computación y particularmente de la programación y del desarrollo del software en general, poniendo especial énfasis en los aspectos económicos, sociales y políticos de la tecnología de información. Ha dado clases en universidades de Argentina y de América, incluyendo el famoso MIT (Instituto Tecnológico de Massachuset).

En tanto referente de la informática en la Universidad Nacional de La Plata en temas como Machine Learning, Deep Learning e IA, me interesa conocer, desde la perspectiva de un campo fundamental como el computacional, su visión sobre sobre los procesos de cambio tecnológico que, a partir de lo que vengo indagando, están reconfigurando las formas de ser y de estar de los sujetos en el mundo.

GB: Lo primero que hay para decir es que hoy la informática avanza con muchísima velocidad y se vincula con procesos de la vida cotidiana. Cada vez más cosas tienen dentro procesadores y por lo tanto, alguien programó las funciones que estos elementos hacen. El diferencial que empezamos a notar ahora es cuando estos procesos son ya no solo de producción o vinculación de información, sino más bien cuando tratan de generar conocimiento.

Así hoy los algoritmos y la IA desarrollan procesos en los cuales podemos decir que hay una novedad en el resultado de lo que allí sucede, muchas veces incluso impredecible. 
En ese sentido, ¿qué tipo de proyectos están trabajando ustedes que vea que acompaña estos desarrollos más bien novedosos y estos cambios en las formas que tenemos los usuarios de relacionarnos con casi todo?

GB: En general, son respuestas técnicas. Me arriesgo a decir que en casi ningún departamento de computación de la Argentina hay una mirada para pensar las cosas desde la realidad, pensar los procesos y sus implicancias sociales. Al menos la informática, en la Argentina, no es localizada; la agenda se pone desde afuera, y la agenda de la tecnología sobre todo se pone desde fuera.

Durante el período del kirchnerismo tuvimos oportunidad, los que quisimos hacerlo - yo entre ellos, entre no muchos en realidad- de aportar al desarrollo tecnológico local. Pero en realidad por el tipo de profesión y la demanda en las empresas, pocos fueron a hacer carrera al CONICET en informática o en cualquiera de las llamadas ciencias duras, resolviendo un problema local. Los que incluso nos vinculamos al campo académico de las ciencias de la computación, teníamos que publicar otras cosas por el tipo de validación de las publicaciones y las lógicas del sistema científico mundial. Así que hay poca gente que tenga esa mirada. Hay sí gente que escribió papers acá pero son especulaciones teóricas o especulaciones no tan teóricas.

Centralmente hay una línea global acerca de cómo pensar la web frente al futuro, donde se mezcla con el machine learning, el Big Data y con internet en general. Pero es muy poco lo que está pasando en todo el mundo académico en la Argentina respecto del impacto de eso en la sociedad, son más bien papers pero con poco desarrollo específico o posiciones profundas y de larga data.

Claro, el problema es que comenzamos a ver, por ejemplo, que los algoritmos no son neutros, que el reconocimiento de rostros, por cómo están configurados, a veces no distinguen una persona de color negro de un mono.

GB: Hoy estamos en una etapa donde se está experimentando en extremo y a una velocidad vertiginosa, y esas cosas están ocurriendo en la realidad. Yo no sé en qué puede terminar. De hecho las fuerzas armadas de Estados Unidos y otros están avanzando mucho en estas líneas de investigación. Un ejemplo clave en esto es que hace pocos días 
que se anunció la creación de la Facultad de Inteligencia Artificial del MIT, con un presupuesto inicial de mil millones de dólares, lo que equivale a todo el presupuesto de ciencia y tecnología de la Argentina puesto en una sola facultad. Y de eso un tercio lo puso el dueño del Blackstorm (Blackstone es el fondo de inversión más grande del mundo. Solo en mercado inmobiliario gestiona 64.000 millones de dólares en activos, la facultad fue bautizada como Schwarzman College of Computing, en honor a Stephen A. Schwarzman, CEO de la firma de capital privado Blackstone) ${ }^{7}$

El debate central entre el presidente del MIT, Rafael Reify, el CEO de Blackstorm, Stephen A. Schwarzman, está ubicado en cómo se le puede ganar a China la carrera tecnológica. Esto es parte del corazón de la disputa por la hegemonía global.

Y nosotros, en mi opinión, lo que nosotros recibimos en el resto del mundo que no es el complejo militar industrial norteamericano, estaría más vinculado a lo que sería la amortización de esas inversiones. Es decir, nosotros amortizamos el desarrollo militar industrial, que ahora se transformó en cibernética; es decir que hacemos muchas veces solo eso, retroalimentamos. Para mí esa es la situación del mundo actual, o de la porción del mundo que aún está incluido, el resto del mundo se muere, es descartable.

Lo que se hace es amortizar esa inversión en defensa, porque el complejo militar norteamericano, tiene que seguir generando recursos para reinvertir, y dentro del complejo estoy incorporando a Facebook, a Google, a Microsoft, a todos. Porque no hay ninguna (de estas empresas) que pueda hacer nada sin autorización del complejo militar de los Estados Unidos. Y el resto del mundo funciona como un enorme testbed o sistema de prueba.

\section{Por lo mencionado entonces, todas las ideas que circularon con la aparición de} Internet sobre la libertad y la horizontalidad, con la web como un espacio democrático, abierto, libre, y resulta que la cultura mucho más horizontal tiene un centro de poder muy claramente identificable con lo militar.

GB: La tecnología de packet switch ¿quién la inventó? DARPA, ${ }^{8}$ Defence Advanced Research Project (Agencia de Proyectos de Investigación Avanzada de Defensa del gobierno de Estados Unidos). Y sí, la inventaron las fuerzas armadas, el complejo militar

7 Para más información ver https://www.elmundo.es/elmundo/2013/08/og/suvivienda/1376037267.html 8 Sitio oficial https://www.darpa.mil/about-us/about-darpa 
industrial inventó la tecnología de internet y la web la inventó su contraparte europea, que es la Agencia Espacial Europea: Berners Lee, él lo inventó. Siempre fue una tecnología militar.

En el libro Funding the revolution, del año 2000, publicado por la editorial de la Academia Nacional de Ciencias de Estados Unidos (NAS, por sus siglas en inglés) cuenta de principio a fin cómo DARPA financió toda la revolución tecnológica, desde el microprocesador hasta el último que se ha inventado hace media hora. Todo lo demás es la operación comercial y el dueño de todo eso es siempre el mismo.

\section{Entonces ¿cree que el núcleo de poder no está en Silicon Valley realmente sino en el complejo militar?}

GB: Silicon Valley es en parte un mito. ¿Quién paga Silicon Valley? Eso es lo que hay que saber. SUN es la generación anterior a la actual de sistemas operativos, que en realidad es la base tecnológica de Linux, que inventó todo lo que después Apple transformó en diseño, desde el mouse en adelante. Pero SUN quiere decir Stanford University Network, que es el primer sistema operativo en red del mundo, que fue el sistema operativo de todas las computadoras que hubo hasta hace muy poco; lo inventaron dos profesores de Stanford, que querían una red para sus alumnos.

Según el mismo libro que antes mencioné, DARPA intervino en la universidad y convirtió el proyecto en una empresa, y más allá que los investigadores reconocían que no sabían cómo hacerlo, desde el organismo militar se los asesoró y crearon SUN, que comenzó a comercializar esta nueva tecnología, y durante los cinco primeros años el 8o\% de sus clientes provenía del departamento de Defensa. Una pregunta que uno finalmente se podría hacer es ¿de quién crees que es finalmente la propiedad de esa empresa? Todas esas empresas o son finalmente del Pentágono o son sus proveedores directos. Esa era la Guerra que triunfó sobre la Unión Soviética, no era que le iban a tirar el cohete desde arriba; fue la guerra tecnológica que dejó fuera a la competencia. Y ahora lo mismo pasa con China, pero la diferencia es que los chinos de alguna manera están ganando la carrera, o están descontando rápidamente la ventaja. Pero yo creo que si uno no parte de la base de entender la carrera armamentística vinculada a la tecnología, no entiende nada de lo que está pasando. 
En esta línea, ¿en qué sentido piensa que estamos ante una nueva revolución, qué nombre le pone y qué características principales considera que tiene?

GB: Sí, supongo que estamos en una, ya no sé cuál ola, pero estamos en algo parcialmente nuevo. Yo hice una prospectiva tecnológica para el MINCYT bastante grande con 250 investigadores de todo el país, en una red discutiendo y se publicó un libro del Ministerio. Empezamos antes de que existiera el MINCYT, en 2006 y se publicó el libro en 2008, aunque el trabajo terminó a fines de 2007. En ese momento, en la presentación que se hizo de las conclusiones es que en los 2000, la tecnología eran tres P: pequeña, portátil y poderosa, que eran los celulares básicamente. En la Argentina la gente no hablaba de esas cosas, a lo sumo tenía un teléfono celular, pero no era smartphone. Lo que sucede ahora es una continuación y lo que claramente pasó fue que la tecnología pequeña, portátil y poderosa genera la suficiente cantidad de datos para la siguiente ola de la revolución, que es esta, la del machine learning, Big Data y demás, y entonces es, digamos, una nueva ola de la revolución previa.

¿Y qué va a pasar después? Nadie tiene la menor idea, porque en realidad en 2006 no se había inventado hablar de Big Data; en 2009 se inventó, fue alguien que bautizó un proceso gigantesco de procesamiento de datos como Big Data. Ahora es una marca comercial, no puede haber ninguna empresa que no diga que hace Big Data. Ni saben lo que es y casi ningún lugar del mundo hay suficiente cantidad de datos para hacer algo similar, sin embargo todos dicen que hacen Big Data.

\section{¿Puede hacer una descripción del Big Data?}

GB: La falacia está en que para que haya Big Data tiene que haber muchos datos, pero muchos, por lo menos muchos terabytes de datos guardados en algún lado y tener la capacidad de procesarlos de alguna manera. Y eso en Argentina no hay, a lo sumo si hay algo en ANSES puede haber, más AFIP, más SUBE, pueden generar la cantidad de datos suficientes como para que tenga sentido procesarlos de una manera. La revolución no consistió ni en que haya muchos datos, ni en que haya comunicaciones rápidas: consistió en el Machine Learning: de alguna manera, en la capacidad de transformar datos en conocimiento, en el proceso de inferencia que consiste en transformar datos en conocimiento, que es lo que hacen las máquinas que hacen machine learning. 
GB: Es una de las disciplinas de inteligencia artificial. En realidad, la inteligencia artificial empezó en 1950 o 1960 cuando hicieron el modelo del ojo del sapo, que era el perceptrón y de ahí fue evolucionando en distintas maneras; digamos, distintos formatos y con distintas técnicas. En algún momento fue PROLOG que era inteligencia artificial deductiva. PROLOG es un lenguaje que deduce. Deduce como deduce un lógico.

Este modelo por unos años desapareció, pero en algún momento vuelve, y se desarrolló en paralelo PROLOG, que se llamaba la escuela heurística de inteligencia artificial, que lo que hacía era tomar la optimización matemática y todos los algoritmos matemáticos para transformarlo en algo que pudiera generar nuevo conocimiento, nuevas conclusiones.

Todo eso derivó en algún momento en la mezcla de eso con la vieja idea del perceptrón que terminó en las redes formatos de redes neuronales, que son como si fuera neuronas interconectadas que aplican criterios de optimización. El programador fija una estructura de neuronas interconectadas, el modelo elemental, entonces en cada neurona hay una función y lo que hace el sistema es optimizar y sacar un número, que es el óptimo de algo. Eso multiplicalo por mil millones y tenés Google, las máquinas de inferencia de Google.

Con estas cantidades de redes neuronales interconectadas, que son monstruosidades que ocupan unas 100 hectáreas en el desierto de Arizona, ahí uno de tantos servers que tiene Google, terabytes de información extraídas de donde pueden, bien o mal habido, se pueden usar para hacerte pedir pizza o para hacerte votar a Trump. Eso es un chiste.

Ahí es donde se puede repensar que en el campo de la comunicación esto genera modificaciones en las formas de configurar los discursos, con otras lógicas y reglas. Cuesta mucho explicarlo, es muy difícil de evaluar porque históricamente una campaña política estaba armada en base a criterios, lo que se analizaba en una encuesta con las limitaciones que esa herramienta tiene. Ahora está evaluada en base a criterios que se arman sobre la base de un procesamiento de datos gigante. 
Es conocido el caso de Facebook, el laboratorio más grande que ha tenido la humanidad. En su historia al menos en cuanto a cantidad de información disponible y cómo de ahí sale Cambridge Analytica. ${ }^{9}$

GB: Exactamente, todo sale de ahí. Y entonces nadie sabe qué hacer.

A mí entender es muy peligroso, porque yo además he vivido situaciones previas, entonces sé cómo era antes, cómo surgieron estas cosas.

Para profundizar la explicación anterior y comprender el riesgo que el manejo de datos con inteligencia artificial implica, es necesario detenernos un momento más. El sistema de procesamiento de datos como dijimos es una red neuronal, son tres pelotitas interconectadas que tienen ciertos inputs y dan un outputs, los inputs pueden ser muchos, pocos, pero cada pelotita de estas se activa de acuerdo a cuántos inputs tiene. La forma más fácil de pensarlo es bueno, si hay diez y hay tres que tienen información positiva o información en general se dispara y esta otra está conectada con esta, es muy fácil de explicar y es cuestión de meterle input, se va a disparar y va a seguir dando. Yo programo eso y es luego un proceso simple de sistematización de información y clasificación.

Ahora todo cambia si esa red en lugar de tres pelotitas tiene tres millones y en lugar de ser una entrada son 50.000, 100.000 o 500.000. Un informático que programa eso, que arma la estructura de esa red para que aprenda, no tiene la menor idea de las consecuencias que va a tener lo que programó, porque no hay forma humana de pensarlo. Si tenés una fila de 1.000 datos y hay dos opciones de clasificación por cada uno de ellos, tenés $2^{1000}$ posibilidades. No pasó el suficiente tiempo de historia de la humanidad para que alguien pueda pensar ese número.

Nadie sabe bien lo que la máquina sistematiza y aprende: ese es el problema. Es decir, puede haber computaciones y secuencias de disparos de esas neuronas que nunca nadie imaginó ni podrá imaginar que puede llegar a configurarse.

Lo que yo quiero sacar es el mito de los programadores superpoderosos que hacen hacer lo que quieren. No, ellos no son superpoderosos, ese es el problema: el sistema lo es.

9 En alusión al caso Cambridge Analytica. Consultar https://es.wikipedia.org/wiki/Cambridge Analytica 
Entonces, dentro de la red neuronal artificialmente construida, comienzan a pasar cosas a partir de que se activan los circuitos. Se desatan procesos que son buscados y predecibles y otros que no lo son. ¿Tiene algún correlato con una idea del mundo distópica en donde la inteligencia artificial puede llegar a lugares que uno no puede predecir?

GB: La última máquina campeona de ajedrez aprendió sola. Es decir: no tuvo aprendizaje supervisado, no imitó a Kasparov, no imitó todas las partidas de Kasparov ni de Fischer, de los campeones.

Aprendió jugando, le dijeron: “Estas son las reglas, estos los objetivos, jugá”. Y ella juega un millón de partidas por milisegundo o por segundo, y entonces en una hora jugó más partidas que cualquier humano en su vida. Puede jugar mucho más partidos que todos los que jugó Kasparov en su vida en un minuto. Y aprendió y le gana, y Alpha Go es lo mismo. Son lo que le llaman deep learning, aprendizaje profundo, que nadie sabe bien qué es.

En este sentido y complementando lo dicho, una de las motivaciones que guía mi tesis es que existe un profundo desconocimiento del fenómeno sobre el cual estamos parados.

GB: Claro, exactamente. Como en neurología, un neurólogo, un neurocientífico ¿qué sabe en serio? En realidad se sabe poco, hay algunas ideas acerca de algunas funciones que por ensayo y error llegaron a descubrir pero aún hay mucho por conocer.

Con el ser humano pasó lo mismo, lo que pasa es que fue un proceso de evolución de millones de años. Lo que pasa con las computadoras no es lo mismo; sería falta de rigor decir que son lo mismo. Son máquinas distintas, digamos; unas son electrónicas y otras son electroquímicas: son diferentes. Unas son muy rápidas y tienen pocas conexiones, y otras son tienen muchísimas conexiones y son más lentas. Es decir, las neuronas tienen muchísimas conexiones y son más lentas que las puramente eléctricas porque hay reacción química, que tarda más que la velocidad de la luz. 
Pero a ver, ¿por qué si tenés miedo te asustás? Eso está escrito hace millones de años en algún lado del cerebro que hace que te asustes. Hay datos guardados y está hardcodeado en lo más profundo del cerebro.

Usted señala que hay procesos que están codificados genéticamente, que vienen en nuestra carga biológica y corresponden a un orden de información no racional como por ejemplo cuando te da miedo y se te erizan los pelos para parecer más grande.

GB: Claro, eso está guardado en lo más profundo del cerebro. En lo más profundo de las redes neuronales hay guardadas otras cosas, que nadie sabe qué son todavía porque pasó poco tiempo. Porque lo que hay que entender es que hay un fenómeno de cantidad que se transforma en calidad. Hay millones de computaciones en paralelo de las cuales el tipo que programó solo conoce la lógica general y algunas de las consecuencias que puede tener, pero no todas.

Es un fenómeno muy interesante que nadie lo entiende, eso es lo que pasa, pero todavía nadie entendió bien de qué se trata porque explotó ahora.

La otra gran discusión es cómo la relación de los sujetos con la tecnología en la vida cotidiana, sobre todo los más pequeños, está cambiando el tipo de ser humano que van a estar recibiendo las instituciones educativas.

GB: Armar un debate crítico acerca de la educación es imprescindible, de toda la educación. Sí, porque evidentemente hubo una revolución tecnológica que se está llevando puesta a la educación, que además tiene consecuencias, aunque no quiero que te lleves la idea de que esto es solo caos. Hay caos, pero hay un núcleo y hay caos que nadie sabe dónde termina, porque es un fenómeno exponencial y que se repotencia todo el tiempo a sí mismo.

Pero además de todo eso obviamente hay capacidad de extracción de conocimiento acotado y bien delimitado, que es lo que hacen todos los jugadores, Amazon, Google, y otros. Y de ahí para arriba, que es lo peor. El Pentágono, China, Rusia. Y a mí me preocupa menos Amazon que el Departamento de Defensa norteamericano o Putin. 
Putin se metió en las elecciones de Estados Unidos, hizo un acuerdo y se entrometió, no hay duda: hay una persona presa, un jefe de gabinete preso. A Trump no lo metieron preso porque demostraron que el sujeto acordó con Putin y le crackearon las elecciones. No sé quién hubiera ganado, pero está demostrado. Eso es un ataque de guerra, por ahí la gente no entiende, pero eso es en una guerra que se está llevando a cabo en este momento.

Los chinos y los norteamericanos se la pasan tirándose tiros, que es cibernética, pero la creación de la Facultad de IA en el MIT tiene un significado muy profundo. Reconocemos ahí el cerebro de la tecnología de defensa norteamericana, es el cerebro del complejo militar industrial. Es la única institución de Estados Unidos que tiene un $15 \%$ de su presupuesto financiado por el Estado norteamericano, ninguna tiene más de un $1 \%$ o quizás Stanford tenga un $2 \%$. Ahí se desarrolla en serio la nueva tecnología.

No es casual eso: se van a dedicar allí a la computación cuántica y a generar un chip de inteligencia artificial con computación cuántica, a meter en un chip IA en una computadora con computación cuántica. No computadora con computación electrónica. Eso significa potencialmente que se pueda crackear, se pueda abrir claves encriptadas, que hoy no puedo hacerlo porque llevaría un tiempo de computación exponencial.

Si alguien consigue meter en el hardware -por eso digo un chip- a la velocidad de computación de la luz un algoritmo que pueda descifrar con inteligencia artificial una clave del sistema de defensa, gana. Por eso gastan un billón de dólares. El objetivo tecnológico es militar, siempre es militar, y ahora es ese para mí.

\section{Y, finalmente, ¿qué cosas en términos más propositivos se están pensando, desde} su mirada, hacia el interior de la Universidad Nacional de La Plata y es interesante que sucedan para que esto que estamos hablando empiece a cambiar?

GB: Yo creo que alguien tiene que abordar el fenómeno desde el punto de vista de investigarlo en su dimensión, no alcanza con la interdisciplina, que es lo que estamos haciendo nosotros. Vos hablás de una cosa, yo de otra, intercambiamos información. Tiene que ser algo transdisciplinario, hay que crear una nueva disciplina que sea esto, porque si no, esto se hace inasible. 
Como muy bien lo señala Gabriel Baum dentro de nuestros desafíos está la superación de la mirada disciplinar. La misma hace parte de un trabajo productivo desde una semiosis comprensiva que habla más de abordajes complejos que de instrumentalidades interdisciplinarias. Los glosarios nos ayudan a trabajar en esa productividad para acordar modos de nombrar pero insistimos, lo hacemos con el propósito de producir unos modos del conocimiento que alteran los modos de mirar para comprender. La acción reflexiva de los procesos de digitalización de la cultura, las lógicas de socialidad y de subjetivación modifican nuestro ser y estar en el mundo y al mismo tiempo lo modelan. Acaso sea por esto último que el capitalismo abreva en estas plataformas invirtiendo cifras siderales que le permiten reproducirse y reinventarse.

Tenemos entonces, por una parte, una voluntad de comprender, revisar, descentrar inclusive nuestros propios procesos cognitivos por el deseo de generar procesos de emancipación en el itinerario investigativo y ensayístico pero también en el desafío de desplegar la imaginación para hacerle insurgencia al todopoderoso capital. No tiene caso demonizar ni la digitalización ni las tecnologías, más bien nos interesa ver cómo funcionan desde una dimensión político cultural y el grado de afectación y configuración de la sociedad y la cultura.

Por ello mismo, es en esa clave que revisamos el campo de comunicación/educación y buscamos producir alteratividad social y sobre todo preguntarnos por el sentido de trabajar los procesos de enseñanza aprendizaje para modelar otras sociedades que hagan justicia cognitiva. Boaventura de Sousa Santos (2018), señala al respecto que hay otras visiones, las que surgen de las luchas sociales, que nombran modos de estar y de ser en el mundo que pueden hacer de estos aprendizajes que buscamos un motivo de emancipación. No se trata de adaptarnos al capital sino de harcele batalla.

Así, llegamos al final de lo que se presenta en la tesis como resultado de la entrevista en profundidad realizada, retomando la última afirmación realizada por el entrevistado, sobre un fenómeno que se transforma en inasible si no logramos articular miradas diferentes entre sí pero a su vez complementarias. La posibilidad de conocer en profundidad la perspectiva presentada, pero sobre todo y más aún las limitaciones que hoy posee el trabajo reflexivo sobre la convergencia tecnológica y sus implicancias socioculturales, es el elemento clave que nos permite reafirmar la necesidad de una búsqueda de una narrativa para lograr desplegar al menos una parte de ese discurso polifónico, fundamental para actualizar desde el campo de comunicación / educación una perspectiva estratégica, que no solo pugna por entender, sino y más que todo por intervenir para transformar. 


\section{Referencias}

Asociación de Docentes de Informática y Computación de la República Argentina (ADICRA) (s/f). ¿De qué hablamos cuando hablamos de Informática? Recuperado de http://adicra.org.ar/informatica/

Borchardt, M. y Roggi, I. (2017). Ciencias de la Computación en los Sistemas Educativos de América Latina. Recuperado de http://eduteka.icesi.edu.co/pdfdir/siteal-ciencias-computacion.pdf

Borelli, J. (1o de junio de 2018). Natalia Zuazo: "Hay que politizar la tecnología: pensar para qué la queremos". Tiempo Argentino. Recuperado de https://www.tiempoar.com.ar/nota/natalia-zuazo-hay-que-politizar-la-tecnologiapensar-para-que-la-queremos

De Sousa Santos, B. (2018). Construyendo las Epistemologías del Sur: para un pensamiento alternativo de alternativas. Ciudad Autónoma de Buenos Aires, Argentina: Consejo Latinoamericano de Ciencias Sociales (CLACSO). Recuperado de http://biblioteca.clacso.edu.ar/clacso/se/20181203040213/Antologia Boaventura V ol1.pdf

González, A. (1 de julio de 2014). ¿Qué es Machine Learning? CleverData.

Recuperado de https://cleverdata.io/que-es-machine-learning-big-data

Kaplan, A. y Haenlein, M. (2019). Siri, Siri in my Hand, who's the Fairest in the Land? On the Interpretations, Illustrations and Implications of Artificial Intelligence. Business Horizons, 62(1), 15-25.

https://doi.org/10.1016/j.bushor.2018.08.004

RedHat (s/f). El concepto de cloud computing. Recuperado de https://www.redhat.com/es/topics/cloud

Wikipedia (s/f). Aprendizaje profundo. Recuperado de https://es.wikipedia.org/wiki/Aprendizaje profundo Wikipedia (s/f). Programación. Recuperado de https://es.wikipedia.org/wiki/Programaci\%C3\%B3n 
Wikipedia (s/f). Software como servicio. Recuperado de

https://es.wikipedia.org/wiki/Software como servicio

Xataka (24 de noviembre de 2016). ¿Sabemos cuánto ocupa todo el contenido

que hay en Internet en este momento? Recuperado de

https://www.xataka.com/tecnologiazen/sabemos-cuanto-ocupa-todo-el-

contenido-que-hay-en-internet-en-este-momento 


\section{Cultura escolar vs. Cultura tecno-mediática}

Asistimos hoy a un precipitado avance de la digitalización de diferentes órdenes de la vida en donde las formas de interpelación y de reconocimiento de los sujetos se modifican sustancialmente. Este nuevo contexto se hace necesario repensar la tensión escuela-medios, casi dos décadas después de uno de los textos que más ha marcado el campo de comunicación / educación, como es Cultura escolar / cultura mediática (2000) de Jorge Huergo y de Belén Fernández. En dicha, obra los autores afirmaban:

(a)

La cultura escolar comprende un conjunto de prácticas, de saberes y de representaciones producidas y reproducidas a partir de la institución escolar. Pero también incluye las modalidades de la comunicación y la transmisión de saberes para poder actuar socialmente (más allá de la escuela) que operan de acuerdo con la lógica escolar. En este sentido, la cultura escolar es una forma de producción, transmisión y reproducción que tiende a la organización racional de la vida social cotidiana. La cultura escolar, entonces, transforma desde adentro la cotidianeidad social, imprimiendo en ella formas de distribución, de disciplinamiento y de control de prácticas, de saberes y de representaciones aún más allá de los ámbitos identificados como la institución escolar (p. 47).

Nos preguntamos si, en este nuevo contexto de digitalización de la cultura, la escuela sigue operando esta transformación de la cotidianeidad y, en todo caso con qué fuerza. Si abordamos el problema educativo en su dimensión institucional, como artefacto central de la reproducción cultural ocurrido en buena parte de los siglos XIX y XX, reconocemos un conjunto de prácticas que exceden lo escolar pero que se desprenden de ellas. Es decir no solo contenidos prescriptos, sino dinámicas comunicacionales que configuran un curriculum oculto (lo que la escuela enseña desde su estilo institucional) y un curriculum nulo (lo que la escuela no enseña) [Coscarelli, 2001]. 
Ya tenemos una primera mirada sobre elementos que son claves para repensar las dinámicas áulicas. Revisamos los conceptos vertidos por Huergo y Fernández (2000):

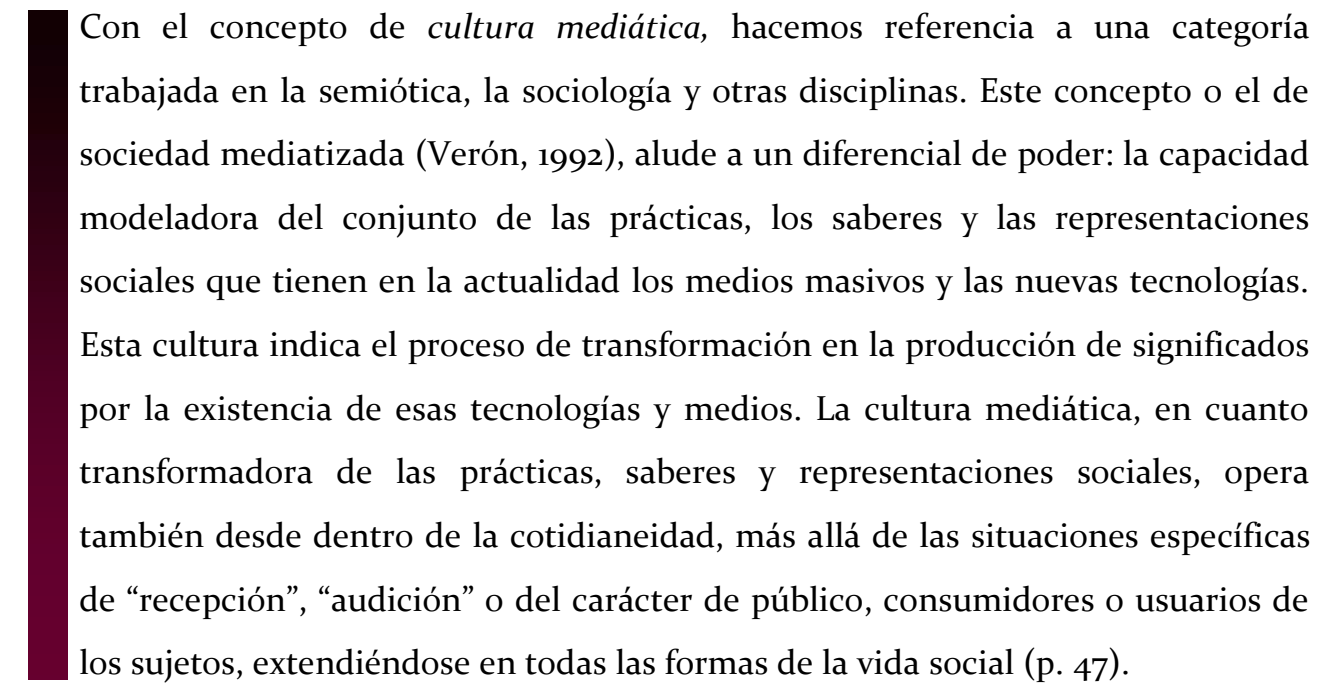

Es preciso destacar la transformación en la producción de significados, es decir, en los modos de configurar los sentidos sociales y advertir que esa capacidad modeladora del conjunto de prácticas, saberes y representaciones, que se expande en nuestra cotidianeidad, hoy cobra características particulares y sobre todo dinámicas comunicacionales que exceden la novedad.

El discurso tecno-mediático, circulante en un entorno caracterizado por plataformas o, como las llama Carlos Scolari (2018), interfaces, sufre modificaciones sustanciales al entrar de la mano de las multipantallas en nuestra cotidianeidad, a la vez que se transforma en un elemento modelizante.

Este elemento, que está integrado en la definición dada por Huergo y Fernandez (2000) es clave, ya que lo significativo de la cultura mediática entonces y más aún ahora, es que no solamente reconfigura la producción social de sentidos, sino que también y en el mismo movimiento, forma sujetos.

Este tipo de discurso hoy, con la expansión de las redes sociales, interpela centralmente desde la imagen, con una fuerte carga emocional, alude a nuestros deseos y está en muchos casos diseñado para captar ese bien escaso que anteriormente detallábamos: nuestra atención. 
Aníbal Ford ve en este desplazamiento una puesta en escena, en las culturas electrónicas, de cuestiones propias de las culturas orales: primacía de lo concreto por sobre lo abstracto, lo no verbal, lo kinésico y lo proxémico, de lo facial y lo espacial. De allí que las estrategias cognitivas de las culturas urbanas de la sociedad de los mass media tienen más que ver con estructuras orales, emotivas, intuitivas del hemisferio cerebral derecho, que con las estrategias escriturales del izquierdo (Ford, 1994). Los medios y las nuevas tecnologías provocan nuevas formas de conocimiento a la manera de una pedagogía perpetua, no recortada, organizada y controlada por la escuela (McLaren, 1992) [Huergo \& Fernandez, 2000, p. 53].

Este tipo de interpelación, producida por el mercado (pero también por la política y por otros actores que batallan en la escena discursiva), posee hoy una potencia nunca antes vista. Puede llegar en cualquier momento, a casi cualquier lugar (en los grandes centros urbanos ya no queda un rincón sin $4 \mathrm{G}$ ), y nos azota en la soledad de nuestras micropantallas adosadas permanentemente. Y este fenómeno que no dejamos de describir de todas las formas posibles, porque es aún inabarcable en toda su dimensión, es clave cuando hablamos de la captación de la atención de nuestros educandos.

Si las formas de interpelación del discurso escolar conservan las características lineales del siglo XIX, como ya lo marcara Jesús Martín-Barbero (2017), del palimpsesto, no podrán interpelar a quienes vienen siendo modelados en la cultura tecno-mediática, que ya incluso deja lejos aquel hipertexto desconectado de internet al que se aludía.

\section{Actualizando una mirada de la cultura tecno-mediática}

A continuación, realizaremos una síntesis compleja y profunda sobre las características de este nuevo ecosistema mediático que integre perspectivas comunicacionales, culturales, economicistas e informáticas, en una serie de elementos que hoy nos resultan clave para actualizar la tensión entre la cultura escolar y la cultura (tecno) mediática.

Repensar los modelos de comunicación hoy, no se trata solo de analizar la conjunción multilenguaje, sino de revisar una codificación específica que intenta llamar nuestra atención continuamente. Entonces los conjuntos textuales con los cuales hoy como sujetos estamos en vinculación, tienen algunas características que podemos sintetizar de la siguiente manera y sobre los cuales debemos prestar especial atención: 
1. Son producidos en el marco de una escasez de la atención humana y por lo tanto apelan a diferentes estrategias con el fin de llegar a interpelarnos.

2. Cargan con el potencial del multilenguaje, la instantaneidad, la rapidez, la facilidad de reproducción (copio, pego, reenvío), la comodidad, la primacía de lo audiovisual, la desterritorialización, el trabajo multitareas y la fragmentación entre otros.

3. Son producidos en muchos casos con un grado de segmentación cada vez más grande, ya que la posibilidad de llegar por la vía de las redes sociales permite organizar en extremo el conjunto de nuestros destinatarios en pequeños subconjuntos para cada discurso y por lo tanto alcanzar cada vez mayores grados de eficacia, pasando de un discurso masivo y amplio a uno restringido y segmentado, hecho a medida.

4. Apelan mucho más a lo emocional que a la razón. Las nuevas tendencias en el campo de las neurociencias habilitaron una línea de producción discursiva que no intenta convencer, sino emocionar (Ferrés Prats, 2015).

5. Están mediados por algoritmos que se organizan de formas complejas sobre la base del procesamiento de un volumen inédito de información que permite resultados anteriormente imposibles, ya que la conjunción de nuevos procesadores con bases de datos interconectados, hacen del Big Data uno de los elementos distintivos de nuestra era.

Un elemento que podemos destacar aquí fruto de este nuevo ecosistema mediático es la necesidad de repensar el proceso de interpelación y reconocimiento planteado por Rosa Nidia Buenfil Burgos (1993) y retomado por Huergo (1999), si no debemos partir previamente de la necesidad de llamar la atención de los sujetos con los cuales vamos a trabajar en educación. Esto implica no solo disponer estrategias pedagógicas y temáticas, sino también propuestas que recuperen la dimensión comunicacional como un elemento clave.

Así, este tipo de ecosistema comunicativo nos obliga a repensar entonces de qué manera podemos interpelar a nuestros estudiantes, como sujetos configurados en esta nueva cultura tecno-mediática (fruto del proceso de digitalización de la cultura que antes describimos), con los que nos debemos el desafío de concitar su atención y a quienes debemos hoy más que nunca reconocer su universo vocabular para, desde allí, prealimentar nuestras acciones estratégicas (Huergo, 2006). 
El elemento central de esta reflexión tiene que ver con repensar las estrategias educativas, es decir, los modos de interpelación de nuestros educandos, las formas de construcción de una cultura escolar que sea arrancada del siglo XIX en el cual se quedó detenida para que pueda dialogar con el mundo contemporáneo. Si las formas de la comunicación social están sufriendo un cambio en su digitalización, las formas en la enseñanza deberán abordar esta problemática no por una cuestión de aparatos, sino de prácticas culturales que ya son cotidianas en nuestros estudiantes.

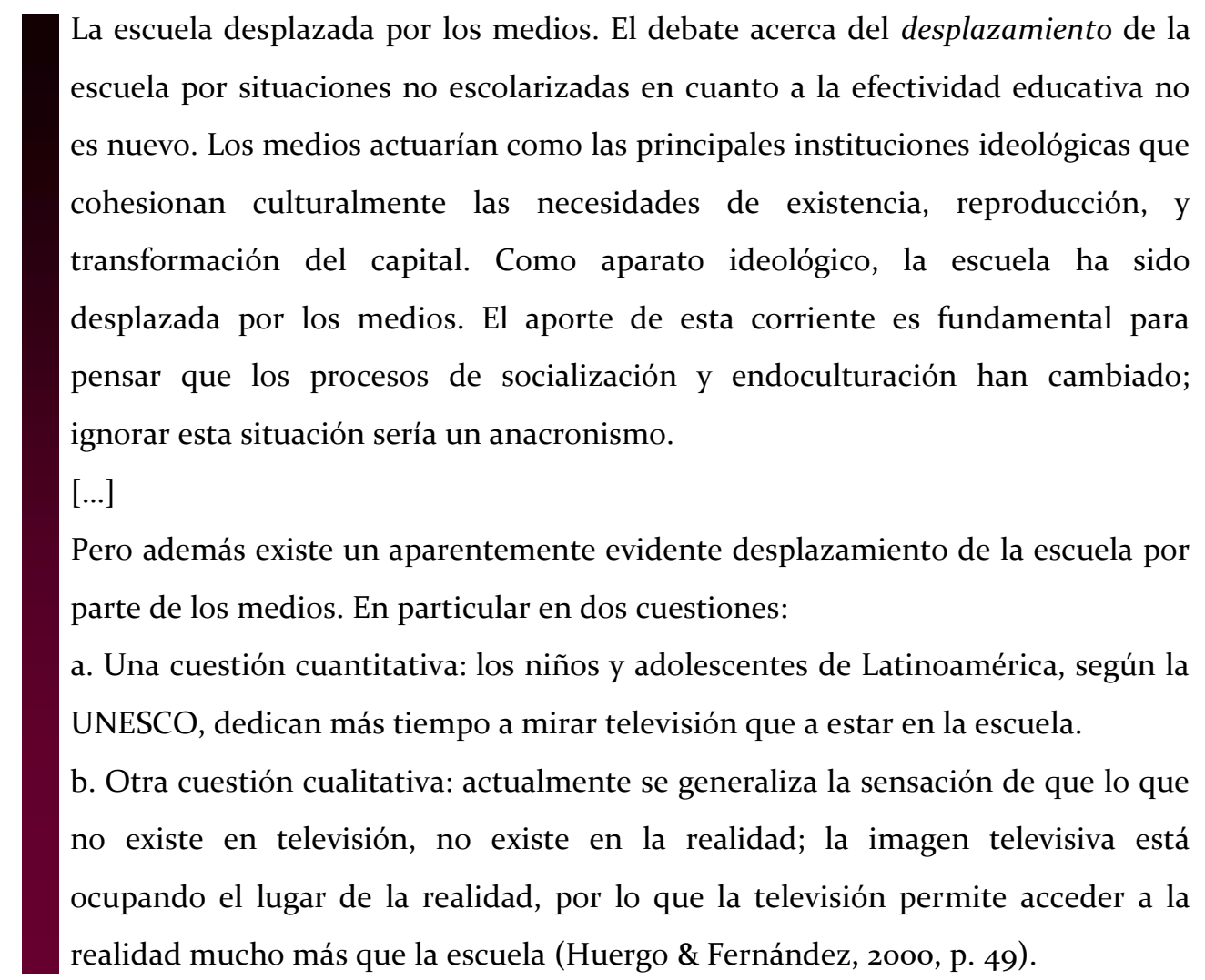

Más allá de los desplazamientos mencionados ya con extrema lucidez en el año 2000 por los autores, hoy debemos sumar sin duda la complejización del panorama con la consolidación de las redes sociales como medios de información privilegiados para los más jóvenes, las horas incontables que pasan conectados, y la construcción de la realidad en la era de la posverdad.

Si continuamos con la perspectiva mencionada, y sumamos estudios sobre tipos de actividades que se realizan en la web, como por ejemplo el de COM Score para América Latina: 
Estos datos dejan en evidencia que los mayores usos de estas tecnologías se vinculan con «Entretenimiento», «Redes sociales», «Servicios», «Portales», «Búsqueda / navegación», categorías distantes de aquellas actividades que promueven explícitamente la enseñanza y el aprendizaje. En términos de mediación cultural, son estas apropiaciones las que estarían jugando un papel preponderante en los contenidos pero también en las formas de recibir y de percibir la información y el conocimiento, en los modos de interactuar con ellos y de posicionarnos en el marco de otros actores sociales (Martin, 2017, p. 11).

Es decir que la afirmación sobre la mediación que realizan los entornos mediáticotecnológicos con el mundo, permitiéndonos acceder a la realidad mucho más que la escuela, se vuelve cada vez más potente y recobra sentido en la era de las multipantallas (a la carta).

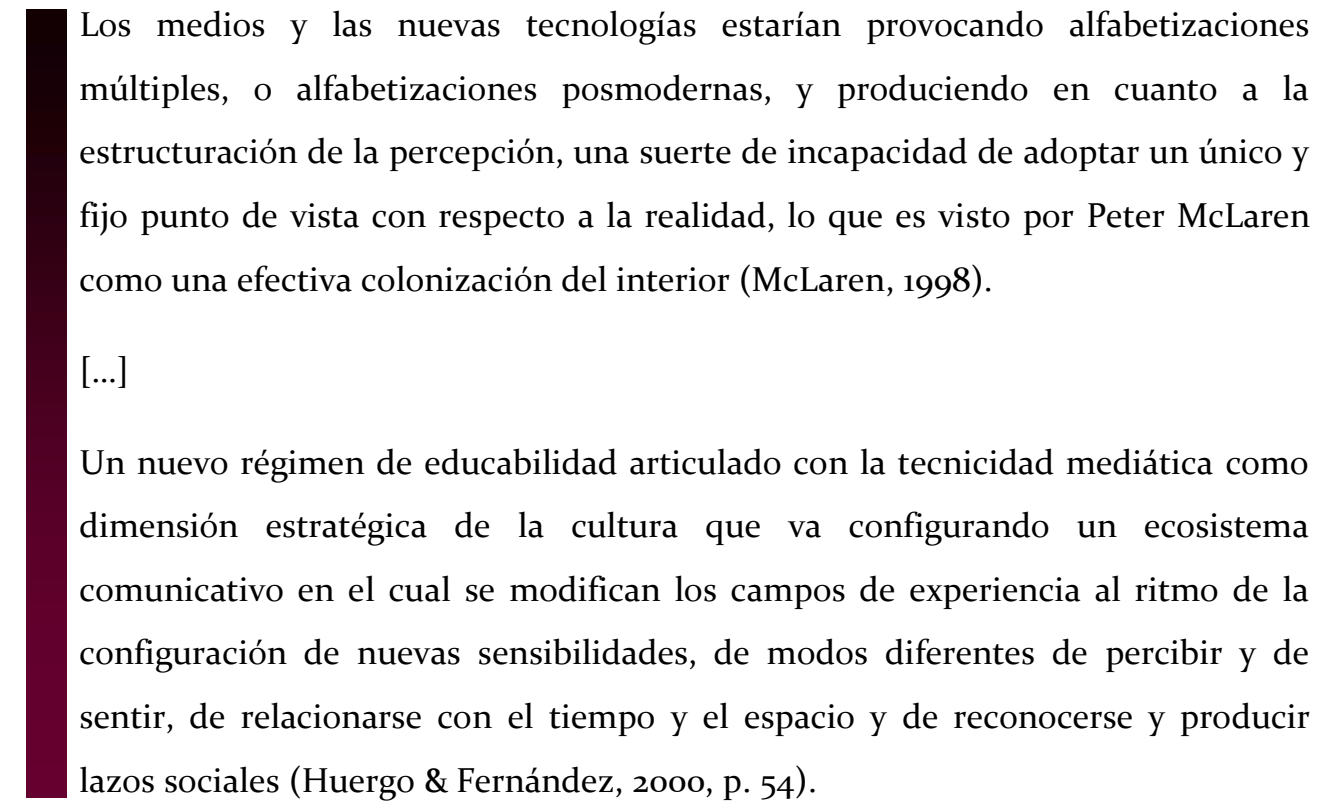

Dos décadas después de las afirmaciones de Peter McLaren (1998) retomadas por Huergo y Fernández (2000), seguimos sin la posibilidad de encontrar horizontes concretos de trabajo para reestructurar uno de los sistemas de socialización que con todas sus debilidades continúa siendo central y estratégico en las sociedades contemporáneas. 


\section{Una continuidad de los mapas nocturnos}

Una de las características del pensamiento complejo es la necesidad de recorrer diferentes capas del fenómeno y desde allí ir configurando posibles articulaciones entre elementos de distintos niveles, y entre aquellos que desde dentro de un mismo nivel se encuentran aparentemente desconectados.

No tenemos aquí recetas ni propuestas acabadas, pero una de las posibilidades que otorga un trabajo de estas características, ensayístico y sin pretensiones de consolidar respuestas pero sí de dar pistas y horizontes posibles, es de construir guías que pueden orientar las formas de repensar la arquitectura escolar tanto material como simbólica a partir del eje concreto que aquí se plantea de la reconfiguración de la cultura.

De esta manera se hace necesario proponer una serie de elementos que consideramos centrales a la hora de debatir posibles transformaciones del sistema escolar que dialogan con el presente de nuestra educación en vinculación con:

- El problema no es una cuestión de aparatos sino de reconocer la digitalización de la cultura.

- La incorporación de una perspectiva en la cual las interpelaciones incorporen la sensibilidad emocional como parte de la estrategia de aprendizaje.

- La necesidad del rediseño institucional y de reestructuración de las formas del poder que allí habitan.

- La modificación de las prácticas cotidianas escolares y las lógicas de organización curricular.

- El tipo de saberes necesarios en este nuevo contexto.

- Las formas comunicacionales que dentro de las instituciones escolares deben habitar.

Por ello a continuación diferenciaremos elementos que en la práctica se encuentran articulados, que son parte de la trama cotidiana de la educación actual. 
1. No es cuestión de incorporar aparatos sino de reconocer cómo la digitalización de la cultura constituye subjetivamente a los sujetos con los que vamos a trabajar.

Este es un primer enunciado que necesitamos reiterar. Aunque ya dicho anteriormente de otras formas, no debemos centrarnos en las lógicas tecnológicas, sino en las formas discursivas.

Entonces lo que se debe modificar es el tipo de sentido que se produce en el aula, más allá de si esto se realiza con computadoras, celulares, tabletas, u ordenadores cuánticos, lo más importante sigue siendo reconocer el universo vocabular de los sujetos (Freire, [1968] 2005), y desde allí, hacer el aquí de nuestros procesos pedagógicos.

Esto pone necesariamente el punto de partida en el educando y la configuración que como sujeto trae al ingresar al aula, fruto de las interpelaciones del discurso tecnomediático, y que nos desafía a repensar estrategias que de una forma u otra deben dialogar con él, ya que podemos presuponer que, si no, con la potencia de lo que afuera de la escuela acontece, corremos el grave riesgo de quedar completamente relegados como educadores, sin capacidad real de incidencia.

Y aunque esta afirmación no puede ser contrastada, sin embargo es preciso enunciarla con urgencia, ya que si la escuela o, mejor dicho, la cultura escolar pierde la posibilidad de formar sujetos, el mercado en este contexto hará el resto. Y allí aún es válida la tensión planteada por Néstor García Canclini (1995) entre la producción de consumidores y la formación de ciudadanos.

Perder la posibilidad de interpelar a los estudiantes, no solo reafirmaría las hipótesis más fatalistas que se animan a decir que las instituciones escolares así como están ya de poco sirven, sino que perderemos una de las pocas trincheras culturales desde las cuales aún es posible dar batalla a esta era del capitalismo de plataformas (Srnicek, 2018).

El capitalismo se volcó hacia los datos como un modo de mantener el crecimiento económico y la vitalidad de cara al inerte sector de la producción. En el siglo XXI, sobre la base de cambios en las tecnologías digitales, los datos se han vuelto cada vez más centrales para las empresas y su relación con trabajadores, clientes y otros capitalistas. La plataforma emergió como un nuevo modelo de negocios, capaz de extraer y controlar una inmensa cantidad de datos, y con este cambio hemos visto el ascenso de grandes compañías monopólicas. Hoy en día el capitalismo de las economías de altos y medianos ingresos está dominado cada vez más por estas compañías (Srnicek, 2018, p. 40). 
Es decir que nos encontramos ante un escenario en el cual el sistema escolar va modificándose y las grandes corporaciones mundiales que sostienen el desarrollo del sistema de medios, en muchos casos son quienes, como se explicó previamente, se encargan de estructurar las nuevas redes de socialización que buscan retenernos, no necesariamente para comunicarnos, sino para monetizar nuestro tiempo de exposición y transformarlo en ganancias.

2. Configuraciones discursivas que no apelen a la emoción, en sistemas educativos dialógicos, no logran interpelaciones profundas y duraderas.

Como se verá en la entrevista a Joan Ferrés, los sistemas educativos basaron en parte el aprendizaje en emociones negativas a partir de un miedo que con el correr de los años fue pasando del pánico que puede crear el castigo físico al terror que implica en un joven adolescente perder su marco de referencia al repetir y ser expulsado de la institución en la cual está.

El dispositivo pedagógico fundado sobre la base del disciplinamiento (de los cuerpos y de las mentes), tuvo como aliado principal un sistema de premios y castigos en las escuelas. Desde la violencia física hasta la simbólica, la meritocracia, la movilización de emociones negativas como el miedo tanto a represalias dentro de las instituciones escolares como en las familias ante un error o fracaso, motorizaron durante siglos el aprendizaje.

Pero lo que sí aquí nos llama la atención es la necesidad de poner foco en un elemento que es central. En los últimos años, la modificación de los sistemas escolares y el descenso de la capacidad punitiva de las instituciones educativas, de sus directivos y docentes, se debe suplir ese elemento que motorizó fuertemente el aprendizaje por otros que desde lo positivo nutran a los sujetos.

Si se me permite un diagnóstico simplificador, se podría decir que la capacidad de influencia de la que disfrutaban en otras épocas instituciones dedicadas a la comunicación persuasiva, como la escuela o la iglesia fue debido en buena medida a su habilidad para utilizar en beneficio propio las emociones negativas: el miedo al palo [...]. Y que en buena medida su fracaso en la actualidad se explica por su incapacidad para utilizar en su beneficio las emociones positivas para sustituir el palo por la zanahoria, es decir, por su capacidad para convertir sus productos en objeto de deseo. Sin emoción del signo que sea, no hay movilización (Ferrés Prats, 2015, p. 43). 
Y no debemos tener prurito en hablar de las emociones, ya que desde América Latina, nuestra tradición principal centrada en una pedagogía de la Esperanza, nos ubica en el plano de la sensibilidad históricamente relegada a la razón y que hoy pareciera que los discursos dominantes nos la arrebatan dejándonos su herencia de la razón moderna y quitándonos uno de los elementos claves que caracterizaron la educación en nuestra región.

Las huellas de la producción latinoamericana en comunicación / educación si hay algo que ha marcado es el impulso de un pensamiento situado que recupera a los sujetos en sus contextos, en sus lecturas de su propia realidad a partir de sus modos de ver el mundo y reescribirlo. Nada de eso ha sido despojado del arte de nombrar y de intervenir en lo que Paulo Freire denominó la dialéctica de los procesos; si bien allí sigue persistiendo la lógica de la razón como necesidad, la dimensión sensible y afectiva adquiere carácter político y transformador. El propio Freire reconoció que en su obra originaria Pedagogía del oprimido ([1968] 2005) muchas perspectivas no habían sido incluidas y que por el contrario en pedagogía de la esperanza lo retoma: las emociones, las sensibilidades y las perspectivas nacidas de nuevos movimientos sociales como el de las mujeres.

La relación entre cultura mediática y cultura escolar hace parte de un desafío que puede retomar esa voluntad de emancipación y perspectivas más holística que no separa sujeto de objeto, teoría de práctica, cuerpo y alma y tampoco, razón de emoción. Lo planteaban los griegos, pero también los planteaban los mayas en sus propias cosmogonías.

Así afirmamos que, de la misma manera en que las pantallas se vinculan con lo emocional (Ferrés Prats, 2015), nuestras estrategias educativas también deben hacerlo.

3. El rediseño institucional es una urgencia

Recuperar la discusión sobre las formas organizacionales es clave en este contexto. Debemos animarnos a indagar posibilidades y repensar esquemas naturalizados que al calor de la revolución industrial y de la necesidad de consolidar mano de obra fueron sedimentando una cultura escolar que lejos hoy está de dialogar con el mundo contemporáneo y que en parte también por ello encuentra serias limitaciones para contener a los sujetos que aloja dentro. 
La

La escuela en su versión tradicional está interpelada por el carácter y la celeridad de los cambios tecnológicos, económicos y políticos que desbordan los acotados límites escolares y disciplinares y conmueven la vida social en sus distintas facetas. Estos rasgos epocales se instalan en nuestra realidad latinoamericana en que distintas problemáticas acuciantes — pobreza, desocupación, deterioro del medio ambiente, marginación, democratización de la sociedad civil— requieren respuestas superadoras [...].

Las tecnologías de la información y la revolución producida en las comunicaciones han acrecentado en una magnitud sin precedentes el caudal disponible de conocimientos. Al mismo tiempo se han modificado también las formas de percepción y las estrategias de producción y adquisición de los mismos. Existe dificultad en el plano general de la institución educativa para superar sus códigos culturales asentados en sus orígenes modernos, tanto en valores como en los medios a través de los que ejerce su accionar. Se ha producido un desplazamiento de la cultura impresa por la visual [...].

La innovación informática ha contribuido a la globalización aumentando la celeridad de los cambios y el acceso a la información. Requiere poner en juego capacidades de discernimiento ante las infinitas fuentes documentales provistas por la virtualidad. Todavía no se tienen datos fehacientes de su impacto, aunque entre otros cambios se evidencian modificaciones en la escritura, emergencia de códigos lingüísticos (el chateo), ciertas metodologías de composición de trabajos de corte y pegue y un modelo de atención flotante y dispersa (Coscarelli, 2010, p. 3).

Esto implica que estamos ante un corrimiento del sentido de lo escolar, que ya lleva como mínimo una década siendo diagnosticado, pero que en muchos casos no se suele reconocer la necesidad profunda de retomar el cruce entre las modificaciones socioculturales que están aconteciendo, con las particularidades de América Latina, lo que requiere una mirada atenta al contexto actual global, pero profundamente situada y que reconozca las particularidades de un territorio como el nuestro, con sus limitaciones y potencialidades.

(

Más tarde, en el siglo XX, el pedagogo cordobés Saúl Taborda (1885-1943) dirá que las instituciones imitadas cargan con conflictos que les dieron origen y que son propios de otros contextos, por eso fracasan o no dan respuestas adecuadas o satisfactorias a los problemas de nuestros pueblos. La invitación de don Simón [Rodríguez] es provocativa: "Inventamos o erramos"; y en tierra de pobreza e injusticia no podemos darnos el lujo de errar (Huergo, 2015, p. 132). 
El desafío de hoy que ya planteaban Saúl Taborda y Simón Rodríguez se vuelve central, ya que las instituciones están trasplantadas no solo de lugar, teniendo en cuenta que la modernidad europea centralmente creó el sistema escolar como lo conocemos; sino también en tiempo. Instituciones creadas al calor de la revolución industrial (Puiggrós, 2003), para formar un proletariado que pudiera hacerse cargo como mano de obra calificada de los puestos de trabajo que se generaban, o ciudadanos que accedieran a una cultura común que, fruto de las múltiples migraciones, debía generarse, quedan obsoletas en el panorama que estamos viendo crecer. Si no las repensamos, si no imaginamos, si no inventamos, estamos condenados a errar.

La cultura escolar, como dijimos, comprende un conjunto de prácticas, saberes y representaciones producidas y reproducidas a partir de la institución escolar e incluye también las modalidades de la comunicación y la transmisión de saberes. Entonces allí podemos identificar diferentes elementos en los que debemos detenernos a pensar, organizar, y analizar posibilidades.

\section{Las prácticas}

Paralelamente a lo anterior, consideramos necesario revisar, reconsiderar nuestras prácticas, debemos reorientar las acciones cotidianas, los ritos que actualizamos cada mañana al entrar o cada tarde al salir de la escuela, no para modificarlos necesariamente, sino para situarlos en un nuevo contexto.

Desnaturalizar todos aquellos elementos que hoy están integrados en las prácticas cotidianas es fundamental. Si en el siglo XXI seguimos formando niños, por un lado, niñas por el otro, y todo esto ubicados del más bajo al más alto, no necesariamente debemos dejar de hacerlo, pero por lo menos revisar una práctica que, por lo menos podríamos caracterizarla de sexista.

Así con las estructuras de asignaturas, la rotación, sobre todo en la escuela secundaria, de docentes y de contenidos, el lugar del cuerpo dormido ante una racionalidad que lo aplasta, las lecturas descontextualizadas y sobre todo el tipo de saberes que se exige queden fuera de la escuela y que hoy diferentes académicos e investigadores están reconociendo como habilidades que muchos niños y jóvenes poseen y que no ingresan al ámbito escolar. 
Un ejemplo clave en esta línea es el trabajo en el proyecto Transmedia Literacy, en el que se indagan dos preguntas centrales hoy: ¿qué están haciendo los adolescentes con los medios? Y ¿cómo aprendieron a hacer esas cosas?

Para responder a estas dos preguntas, se diseñó una estrategia metodológica que involucró a más de 50 investigadores de diez instituciones en ocho países y en cuya instancia de cierre y de sistematización tuve la oportunidad de participar, en enero de 2018, en Barcelona, en la Universidad Pompeu Fabra, fruto de una estancia de investigación realizada bajo la coordinación de los doctores Joan Ferrés Prats y Carlos Scolari.

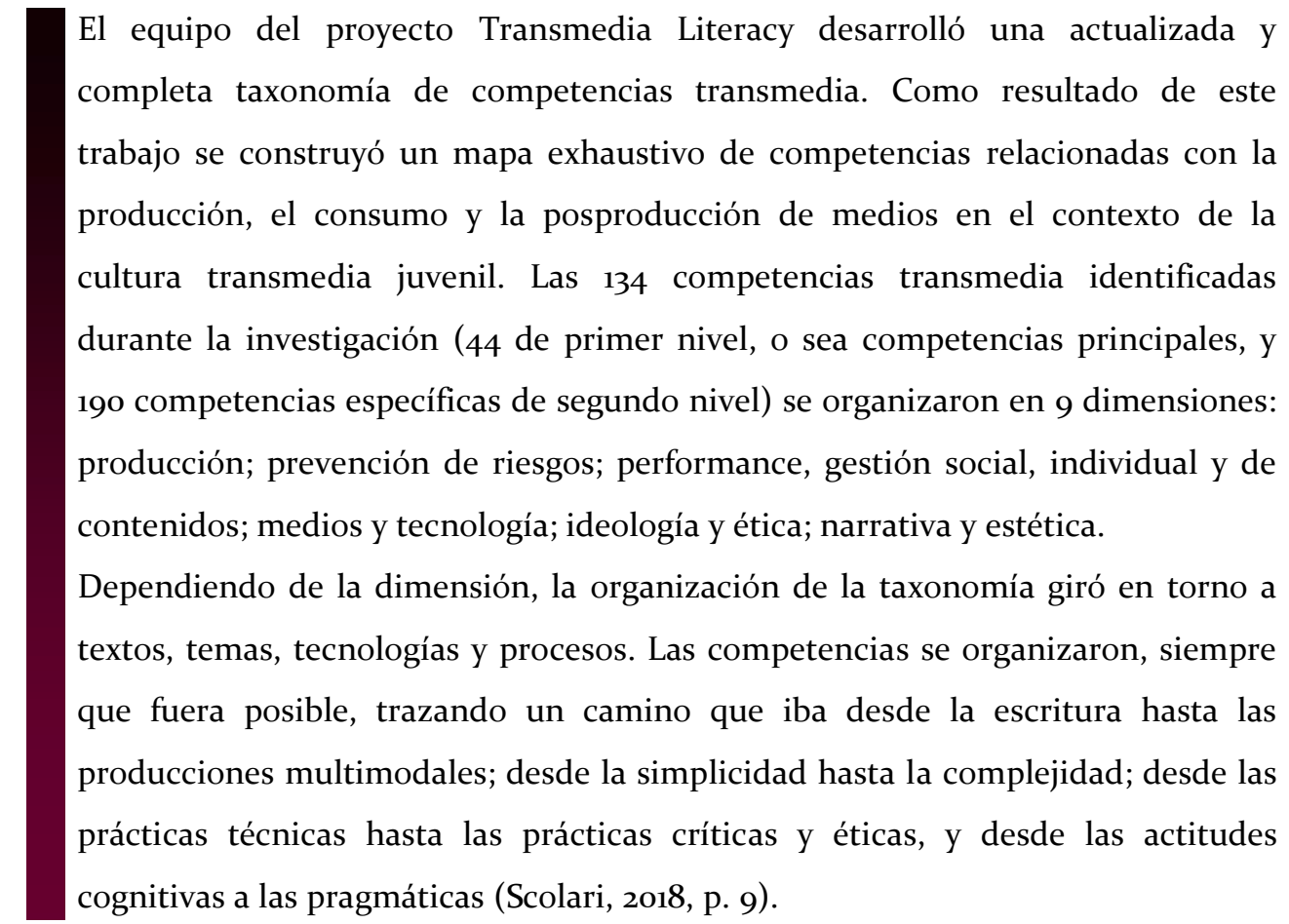

Esta mirada se posa centralmente en el aprendizaje de los adolescentes de aquello que podemos denominar educación no formal, pero que es cada vez más importante dentro de la vida de los jóvenes. Más allá de las críticas constantes realizadas a los sistemas de análisis de competencias, no es este el objetivo del trabajo realizado por el equipo, ya que en este caso no es el aprendizaje por competencias el sentido propuesto, sino justamente el reconocimiento y la sistematización de prácticas y habilidades que hoy poseen muchos de los sujetos que ingresan al sistema educativo y que deben dejar fuera porque no se los reconoce como valiosos para ser puestos en funcionamiento dentro de las dinámicas escolares. 


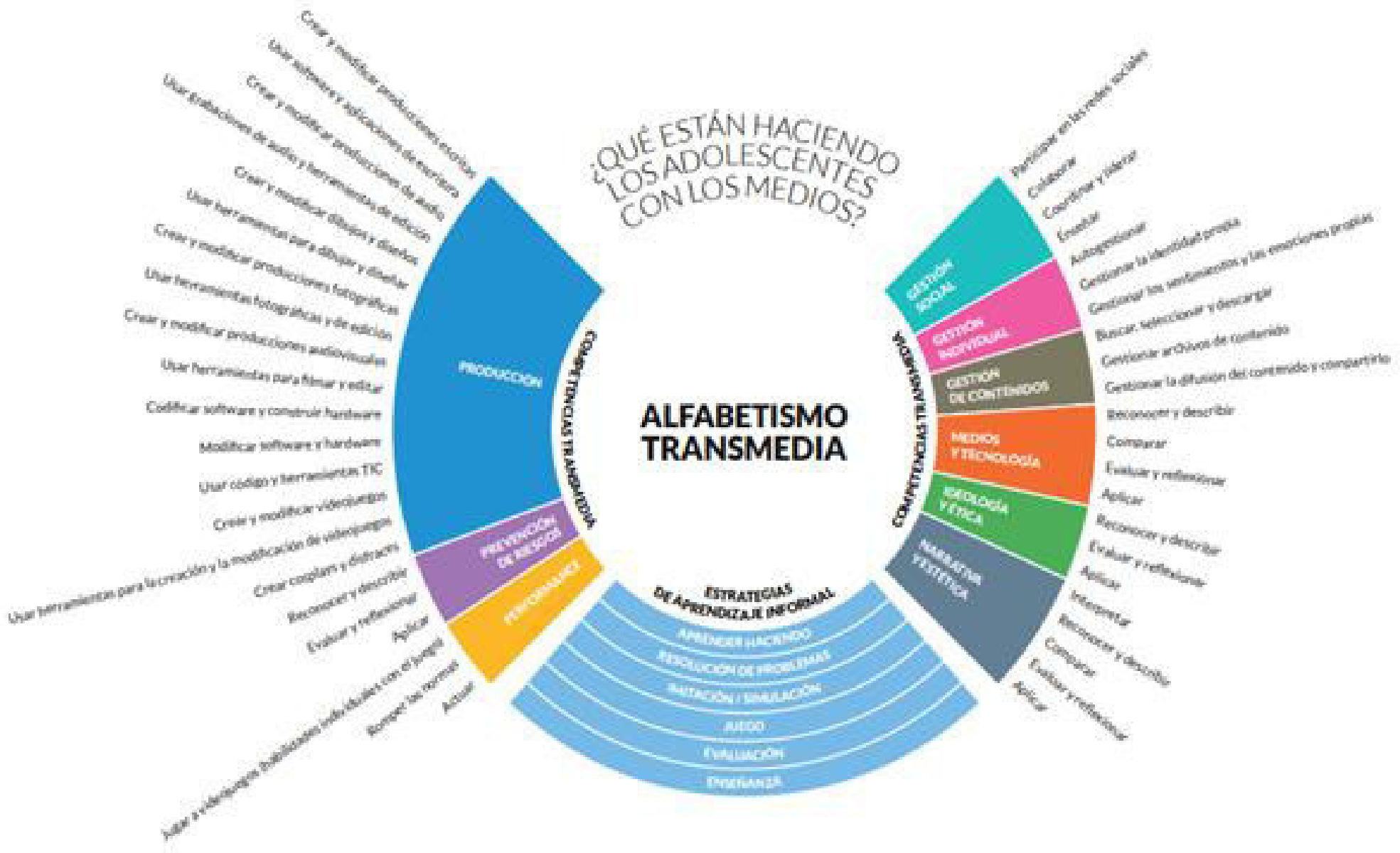

Alfabetismo transmedia (Scolari, 2018, p. 9).

Es decir que más allá del peso del término "competencias" para el campo pedagógico, aquí la búsqueda de estas nuevas habilidades juveniles posee como horizonte el reconocimiento del mundo cultural de los sujetos con los cuales vamos a trabajar.

Esta investigación, entre muchas otras, nos muestra la necesidad de repensar qué tipo de prácticas habilitamos en las aulas, cómo reestructuramos las dinámicas de trabajo y de qué manera nos dejamos atravesar como docentes por este nuevo saber hacer que poseen muchos de los jóvenes y con los cuales debemos consolidar nuevas estrategias de encuentro y de intervención. 


\section{Los saberes}

Debemos reconsiderar también los contenidos que brindamos tanto a través del curriculum, en los elementos que en él surgen manifiestos, como de aquello que se transmiten en lo no dicho y en lo oculto (Coscarelli, 2001). Es decir que al momento de reflexionar sobre los saberes, necesitamos recuperar también la dimensión en la cual el conocimiento se formaliza, se constituye en documento público, y desde allí organiza, al menos en parte la tarea docente. Es por ello que los contenidos curriculares, son un elemento clave de discusión ya que si podemos inferir que la información está disponible con una facilidad nunca antes vista, parte de los contenidos de la educación deben ser rediscutidos.

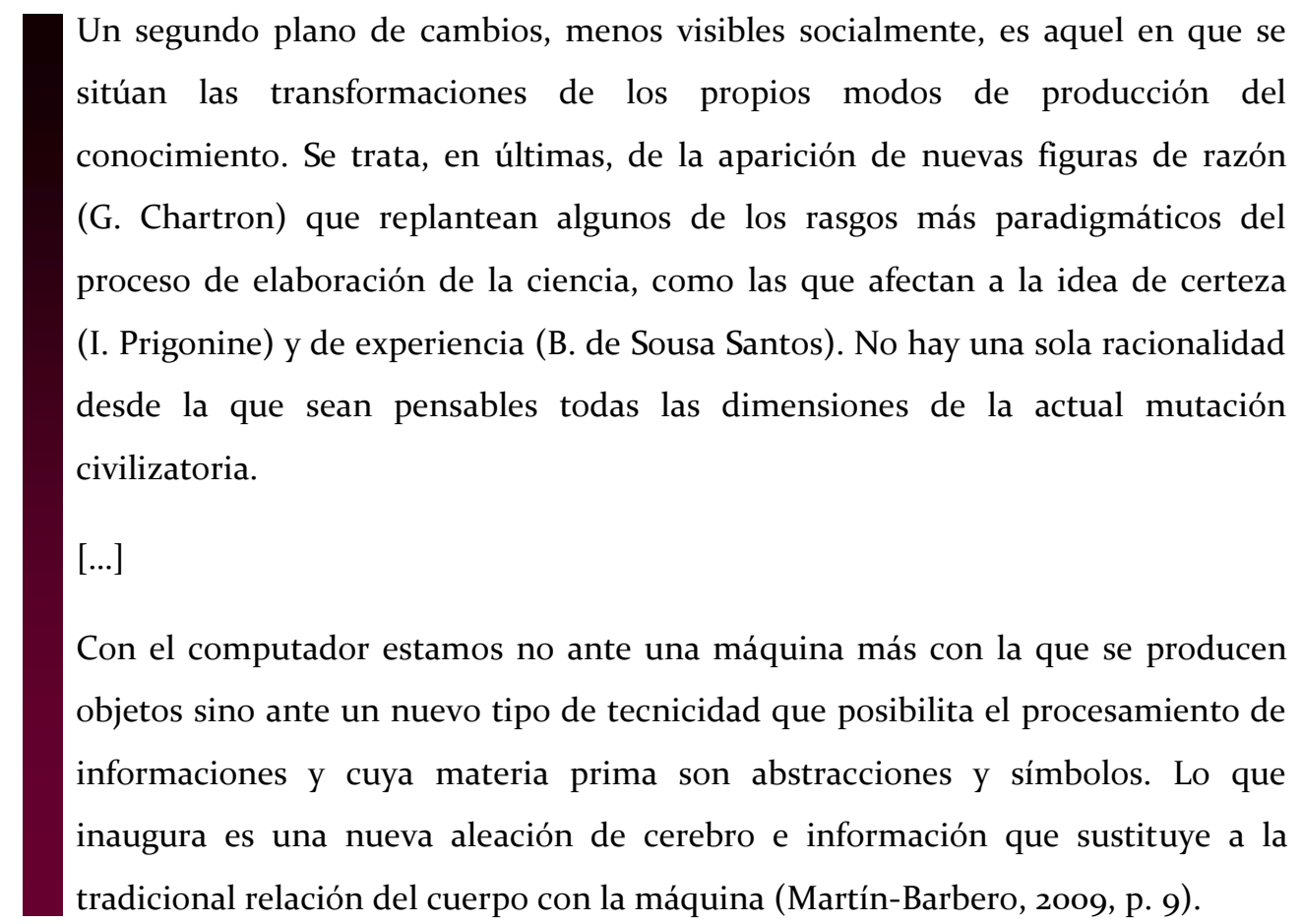

En esta afirmación de Martín-Barbero (2009), encontramos la posibilidad de reconocer que el tipo de contenidos que durante décadas llenó las horas de trabajo en el aula, tal y como se viene desarrollando comienza a perder sentido. El compendio de datos específicos en la mayoría de los casos está a un clic de distancia, ordenado y organizado con diferentes lógicas de acceso y por lo tanto lo que se deben intentar son procesos de producción de razonamiento complejo, de miradas críticas del mundo y no de un tipo de saber enciclopédico, en la actualidad completamente irrelevante. Para poder producir 
escenas educativas que logren integrar esta "nueva aleación de cerebro e información", necesitamos reconocer las formas en las cuales hoy la cultura se inscribe en una nueva arquitectura simbólica, comprender profundamente las dinámicas que le son propias y desde allí, evidenciadas las nuevas reglas de juego, plantear estrategias que permitan interpelar a unos sujetos que hoy ya son parte de este proceso en muchos casos desde su llegada al mundo.

Los proyectos o diseños curriculares, deben hacer este esfuerzo por integrar de manera transversal estas nuevas lógicas, no ligadas a unas asignaturas o campos de conocimiento en sí, sino como parte de un nuevo sensorium o universo vocabular, que como educadores debemos reconocer.

Estamos ante un nuevo tipo de racionalidad y por lo tanto dar las claves para que las grandes mayorías logren ingresar en este nuevo escenario, es un debate urgente que debemos tomar, sin miedo a equivocarnos, ya que la certeza única que tenemos por el momento es que no podemos en un mundo que en pocos años cambió radicalmente y lo seguirá haciendo cada vez más, es continuar como si nada sucediera, haciendo lo que más cómodo nos queda, que es repetir lo anterior.

6. La modalidad de comunicación y la producción de saberes:

Aquí nos encontramos con un punto que es el que quizás también está profundamente imbricado con los anteriores, pero consideramos necesario destacarlo. Si algo cambia, como vimos en la sociedad contemporánea, esas son las formas de comunicación social (hipermediadas), y por lo tanto el tipo de producción de sentidos que se construya en el trabajo educativo debe considerar este fenómeno.

Una de las más claras señales de la hondura del cambio en las relaciones entre
cultura, tecnología y comunicación, se halla en la reintegración cultural de la
dimensión separada y minusvalorada por la racionalidad dominante en
Occidente desde la invención de la escritura y el discurso lógico, esto es la del
mundo de los sonidos y las imágenes relegado al ámbito de las emociones y las
expresiones. Al trabajar interactivamente con sonidos, imágenes y textos escritos,
el hipertexto hibrida la densidad simbólica con la abstracción numérica haciendo 
reencontrarse las dos, hasta ahora "opuestas", partes del cerebro. De ahí que de mediador universal del saber, el número esté pasando a ser mediación técnica del hacer estético, lo que a su vez revela el paso de la primacía sensorio-motriz a la sensorio-simbólica (Martín-Barbero, 2009, p. 9).

La nueva relación entre cultura, tecnología y comunicación conecta cotidianamente a los sujetos a través del hipertexto que incorpora imagen y sonido: junto con la palabra escrita, la racionalidad emocional, es decir aquellos elementos que antes estaban por fuera de muchos ámbitos, que ahora se integran y por lo tanto al incorporarlos en la escuela debemos tener en claro que estamos trabajando un tipo de discurso, de tipo narrativo desde y sobre una cultura en la cual lo estrictamente intelectual no alcanza, porque las emociones son parte de los conjuntos textuales desde los cuales a los sujetos cotidianamente se los interpela desde medios y tecnologías de la comunicación y con ello debemos aprender a trabajar.

Muchos ámbitos ya lo manejan y con especial finura: la publicidad antes que ninguno, luego parte del discurso político, las narrativas audiovisuales de las series, pero el discurso escolar aún no ha encontrado una narrativa que contenga esta nueva lógica. Quizás lo más cercano a esto sea la necesidad de repensar el curriculum, ya no solo como un texto escrito que propone una didáctica áulica, sino una forma de curriculum transmedial que incorpore estos diferentes elementos que aquí Martín-Barbero (2009) claramente desarrolla.

\footnotetext{
Estamos, pues, ante un segundo proceso de cambio mucho más radical aún. Me refiero a los nuevos modos de producción de conocimiento, y más específicamente a la, ya apuntada, nueva relación entre lo sensible y lo inteligible. Ahí está la lucidez de Castells ligando la mutación digital a la superación definitiva de la separación entre los dos lóbulos del cerebro: el de la razón argumental y el de la emoción pasional; ¡que no por mera casualidad resulta ser el del arte! (Martín-Barbero, 2009, p. 11).
}

Está claro que cuando hacemos referencia a la incorporación de ciertos elementos vinculados a la sensibilidad o a las emociones, no caemos en la trampa de reducir al sujeto educativo a un ser que debe aprender a gestionar sus emociones para ser más operativo en un mundo plagado de injusticias e incertidumbre, sino que apelamos a la necesidad de salir de la dicotomía razón / emoción, hoy ampliamente superada desde el campo comunicacional pero que aún en términos pedagógico sigue operando. 


\section{A modo de síntesis}

Para complementar y actualizar una tensión cada vez más notable entre la cultura escolar y la cultura (tecno) mediática, se hizo necesario poner algunos elementos de manifiesto comenzando por una afirmación clave como la que nos remite a que el problema no es una cuestión de aparatos sino de reconocimiento de la digitalización de la cultura, hecho sobre el cual tanto Huergo (1999) como Martín-Barbero (2009) ya nos alertaban pero que hoy se hace más necesario que nunca recuperar dada la invasión de artefactos electrónicos en la vida cotidiana.

Avanzamos en la necesidad de incorporar una perspectiva en la cual las interpelaciones incorporen la sensibilidad emocional como parte de la estrategia de aprendizaje, no solo por considerar que la razón y la emoción son indisociables, sino por reconocer también que el tipo de comunicación hipermediada de hoy, compone una serie de discursos (tecno) mediáticos, apelan de esta forma y allí lo escolar no puede desconocer su relevancia.

Paralelamente abordamos la necesidad del rediseño institucional y de reestructuración de las formas del poder que allí habitan, repensando la modificación de las prácticas cotidianas escolares y las lógicas de organización curricular en donde debemos encontrar integrada la convergencia tecnológica como elemento transversal a partir de considerar que la escuela no puede aislarse de una nueva arquitectura simbólica que la atraviesa.

En esta línea, el tipo de saberes necesarios en este nuevo contexto desafía las lógicas enciclopédicas que dieron sustento desde su nacimiento al proyecto educativo moderno, y llama a la necesidad de reestructurar formas comunicacionales unidireccionales y lineales que dentro de las instituciones escolares habitan.

Por lo tanto, este ensayo entonces, tiene como objetivo movilizar elementos que desde hace más de veinte años están en debate pero que aún sigue siendo necesario analizar por la profundidad de los cambios y sobre todo por la inferencia de la potencia aún mayor de lo que está por venir.

Consideramos necesario entonces repensar, revisar y valorar las instituciones escolares, y para eso apartarnos de la idea de que son completamente inútiles, pero profundizar la mirada sobre la incipiente necesidad de cambios cada vez más profundos. En esta línea acordamos con lo propuesta por Inés Dussel (2014): 
Es en este contexto que considero que las utopías post-escolares como la de Ken Robinson son no solo cortas y simplistas, sino también peligrosas en sus implicancias éticas y políticas. Y creo que la teoría curricular debería aportar a pensar otras formas del texto curricular que insistan sobre la complejidad, la distancia y la dificultad, y también sobre la necesidad de mantener abierta una conversación sobre qué es lo común, elementos que vienen de la tradición del curriculum moderno y que no habría que hacer a un lado con ligereza.

$[\ldots]$

Frente a la proliferación de los archivos, frente a la individualización de las pantallas, frente al reinado del yo, y también —en tono más optimista — frente al enorme despliegue de energías creativas, de canales de comunicación y de posibilidades de expresión, el curriculum escolar podría seguir operando como un nodo de encuentro y de organización de ese mundo, no ya centrado en los contenidos más votados por la presión de las industrias culturales o por fugaces climas sociales, sino mediado - y asumiendo los riesgos de toda mediación- por decisiones éticas y políticas con otros plazos y otros alcances. La escuela sigue siendo uno de los pocos espacios donde la idea de "lo público" es central, y sospecho que esa idea no debería ser abandonada tan rápidamente sin tener más en claro qué viene a reemplazarla (p. 23).

Por lo tanto, cuando retomamos la tensión entre la cultura escolar y la cultura tecnomediática, no podemos sino llamar la atención respecto de todo lo que la primera está perdiendo cada vez más rápidamente por sobre la segunda, específicamente en cuanto a la capacidad de interpelar a los sujetos y desde allí lograr que estos se reconozcan en un proceso transformador.

La conjunción de las tecnologías disponibles, con técnicas basadas en la movilización de las emociones y un repertorio discursivo nunca antes disponible, hacen que hoy nos encontremos ante una inminente crisis del sentido de lo educativo dentro de las instituciones escolares y que desde allí perdamos potencia en la capacidad de recrear, como lo señala Dussel (2014), lo común, lo público, elementos que cada vez más son puestos en tensión en la actualidad.

Paralelamente, parte del horizonte posible de abordaje de esta problemática puede tener que ver también con conocer qué están haciendo los adolescentes con los medios, y preguntarnos qué estamos haciendo quienes somos responsables de instituciones educativas con los sujetos que las habitan cotidianamente. Y acto seguido, ver no solo 
qué hacemos nosotros con ellos, sino qué hacen los niños, jóvenes y adultos que en el mundo de hoy cada vez son más demandados a educarse permanentemente y se encuentran con ámbitos alejados de sus prácticas, de sus saberes y de sus representaciones.

En este contexto, religar aquello que hoy parece distante entre el universo vocabular de los educandos y el horizonte de las instituciones escolares es urgente, porque los riesgos si no, son demasiado altos. Si no se interpela lo educativo con un sentido basado en los derechos humanos, la justicia social y el horizonte puesto en acompañar el salto que como humanidad estamos viviendo en favor de acortar brechas hoy cada vez más visibles, el mercado hará lo propio y educará para sí.

Y en esta línea, el problema no es de incorporación de aparatos e innovaciones ni de capacitación tecnológica, sino de transformación cultural. El problema es empezar por comprender que los acontecimientos comunicativos mediados por dispositivos técnicos se insertan en un dinamismo permanente que responde a exigencias y procesos sociales, produciendo modos de comunicación, reestructuraciones de las formas de percepción y transformación de las acciones, las creencias y la imaginación colectiva.

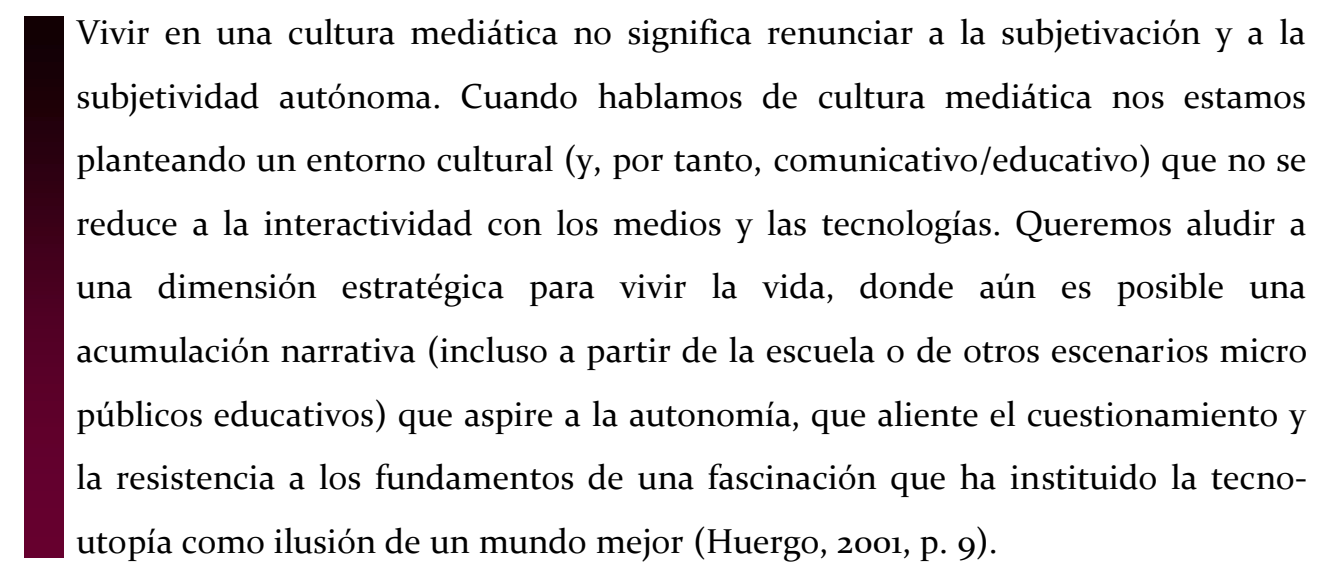

Es por ello que para reconstituir la potencia de una institución central de la modernidad pero también en las estrategias de proyectos emancipatorios, animarnos a debatir y a analizar en extremo el sentido de lo educativo hoy y como correlato el de las instituciones escolares es clave, porque si no estamos ante el enorme riesgo de que la pérdida de capacidad de interpelar de las instituciones escolares deje liberado el camino a un mercado que en la era de las multipantallas y de las hipermediaciones avanza y ocupa cada vez más el lugar de consolidación de la subjetivación. 


\section{Referencias}

Buenfil Burgos, R. N. (1993). Análisis de discurso y educación. Documentos

DIE 26. Ciudad de México, México: Instituto Politécnico Nacional.

Coscarelli, R. (2001). Algunas consideraciones acerca del curriculum (ficha de cátedra). La Plata, Argentina: Facultad de Humanidades y Ciencias de la Educación, Universidad Nacional de La Plata.

Coscarelli, R. (2010). Los cambios del Curriculum ante los retos de los cambios tecnológicos, económicos y políticos. (ficha de cátedra). La Plata, Argentina: Facultad de Humanidades y Ciencias de la Educación, Universidad Nacional de La Plata.

Dussel, I. (2014) ¿Es el curriculum escolar relevante en la cultura digital? Debates y desafíos sobre la autoridad cultural contemporánea. Archivos Analíticos de Políticas Educativas, 22(24). http://dx.doi.org/10.14507/epaa.v22n24.2014

Ferres Prats, J. (2015). Las pantallas y el cerebro emocional. Barcelona, España: Gedisa.

Freire, P. [1968] (2005). Pedagogía del oprimido. Ciudad de México, México: Siglo XXI.

García Canclini, N. (1995). Consumidores y ciudadanos. Conflictos multiculturales de la globalización. Ciudad de México, México: Grijalbo.

Huergo, J. (2001). Desbordes y conflictos entre la cultura escolar y la cultura mediática. Nómadas, (15), 88-10o. Recuperado de www.redalyc.org/pdf/1051/105117927008.pdf

Huergo, J. (2006). Comunicación y educación: aproximaciones. Recuperado de https://comeduc.blogspot.com/2006/o4/jorge-huergo-comunicacin-yeducacin.html

Huergo, J. (2015). La educación y la vida. La Plata, Argentina: Ediciones de Periodismo y Comunicación. 
Huergo, J. y Fernández, M. B. (2000). Cultura escolar y Cultura mediática / Intersecciones. Colombia, Bogotá: Universidad Pedagógica Nacional

Martin, M. V. (2017). ¿Consumidores o sujetos de derecho? La educación, entre las TIC y las TEP. Apuntes de comunicación, educación y discurso, (2), eoog. https://doi.org/10.24215/25252046eoog

Martín-Barbero, J. (2009). Cuando la tecnología deja de ser una ayuda didáctica para convertirse en mediación cultural. Teoría de la Educación. Educación y Cultura en la Sociedad de la Información, 10(1), 19-31. Recuperado de http://www.redalyc.org/articulo.oa?id=201018023002

McLaren, P. (1998). Multiculturalismo revolucionario. Pedagogías de disensión para el nuevo milenio. Ciudad de México, México: Siglo XXI.

Puiggrós, A. (2003). Qué pasó en la educación. Breve historia desde la conquista hasta el presente. Ciudad Autónoma de Buenos Aires, Argentina: Galerna.

Scolari, C. (2018). Alfabetismo transmedia en la nueva ecología de los medios.

Libro blanco. Recuperado de

http://www.codajic.org/sites/www.codajic.org/files/Alfabetismo\%2oTransmedia\% 20.\%20Scolari o.pdf

Srnicek, N. (2018). Capitalismo de plataformas (Trad. Aldo Giacometti). Ciudad Autónoma de Buenos Aires, Argentina: Caja Negra. 


\section{Una aproximación a la tensión entre racionalidad / sensibilidad Diálogos con Joan Ferrés Prats}

Hay una concepción de lo emocional en la comunicación, y en ella se anudan las tradiciones más profundas de las perspectivas latinoamericanas con elementos que hoy encontramos diseminados por múltiples campos del conocimiento fruto de un proceso de rebiologización de las ciencias sociales, junto con la llegada de nuevas formas de analizar la reacción que como sujetos tenemos a diferentes estímulos, relevando procesos electroquímicos que suceden en nuestros cerebros.

El debate está abierto nuevamente y remite a épocas lombrosianas, pero también recupera un elemento clave de nuestras tradiciones como es la posibilidad de salir de la dicotomía entre la razón y la emoción, una más asociada a la cultura letrada y otra a la cultura popular, tensión que conlleva un profundo impacto en los procesos educativos.

\footnotetext{
El problema del saber no es más que el asunto de un andamiaje ideológico para sostener el nuevo diseño, que se basa en el saber frío, lógico y racional de los varones. Desde allí, tal vez, debamos empezar a comprender por qué las culturas populares han sido asimiladas a la sensibilidad y la irracionalidad (Huergo, 2015, p. 49).

$[\ldots]$

La presión por ser alguien va configurando un sentido preferente sobre la práctica educativa, que ha sido internalizado constituido como deber ser de la educación en general, que implica un rechazo, una desconfianza o una impugnación y sanción hacia todo aquello que provenga del vector emocional y de sus dioses (estigmatizados como demonios, degradaciones, peligros, deformaciones). [Huergo, 2015, p. 46].
} 
Así nos encontramos en este momento entre el rechazo a perspectivas provenientes del campo de las neurociencias que invaden la pedagogía con una intención de imponer la necesidad de aprender a gestionar las emociones en el aula, con la recuperación de aquello que dentro del orden de lo no racional, siempre estuvo presente en las matrices de América Latina.

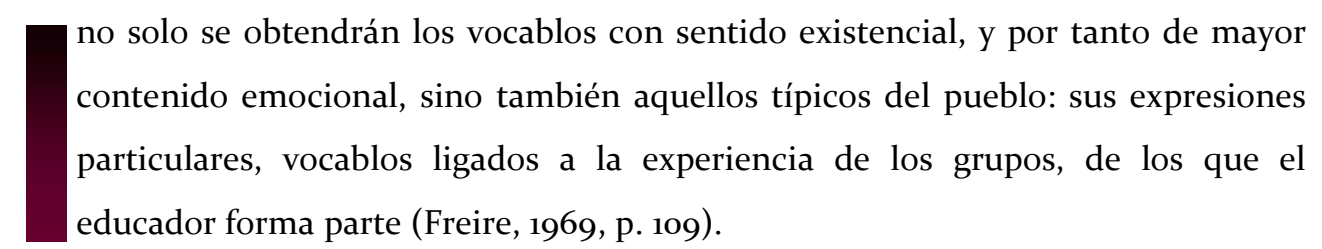

Por todo ello, consideramos necesario avanzar en esta línea como parte de la construcción de mapas nocturnos en los cuales no existen recorridos pre trazados y así nos encontramos con un eje imposible de soslayar como es el de la emoción en los procesos de comunicación / educación. Los ensayos hasta aquí son una mixtura entre escritura y reflexión que forman una búsqueda comprensiva de la cultura digital y su implicancia en procesos que también poseen una dimensión clave en la sensibilidad, sea por la apelación que realizan los discurso tecno mediáticos en este sentido, o por la necesidad de recuperarla en la educación. En ese camino apelamos nuevamente a la entrevista en profundidad como parte de la producción de conocimiento que sigue la huella del diálogo de saberes, al mismo tiempo que es expresión de reconocimientos de trayectorias que pueden contribuir a complementar un recorrido complejo, muchas veces desviado y al mismo tiempo productivo de aprendizaje.

Es por ello que se incorpora una conversación desplegada en reiterados encuentros con el Dr. Joan Ferrés Prats, en la estancia de investigación doctoral realizada en la Universidad Pompeu Fabra, Barcelona, a inicios de 2018.

Bajo la coordinación conjunta de Ferrés Prats y de Carlos Scolari, se iniciaba un trabajo que apuntaba a la problematización de la relación de los medios y las tecnologías con la educación. En las conversaciones con Ferrés Prats, nos encontramos con que estaba desarrollando paralelamente a sus trabajos, ampliamente reconocidos desde los años ochenta, investigaciones sobre la relación entre las pantallas y el cerebro emocional.

Allí, al escuchar primeramente los argumentos sobre los cuales basa las afirmaciones que realiza fueron múltiples las tensiones y las resistencias al enfoque que propone, pero cada conversación, con el correr de los días fue enriqueciendo una mirada que mediada 
por una cantidad de bibliografía significativa que se me fue acercando, más las charlas y la revisión de conferencias dictadas por Ferrés Prats y otros autores en esta línea, fueron construyendo la certeza de que la complejidad del tema requería de avanzar en una perspectiva ensayística sobre el problema de la convergencia tecnológica como fenómeno cultural, teniendo en cuenta una mira que aunque no acordemos con ella quizás en todas sus propuestas, obliga a reflexionar y suma en la agenda temática un elemento que es clave como el de la sensibilidad.

\section{Diálogos con Joan Ferrés}

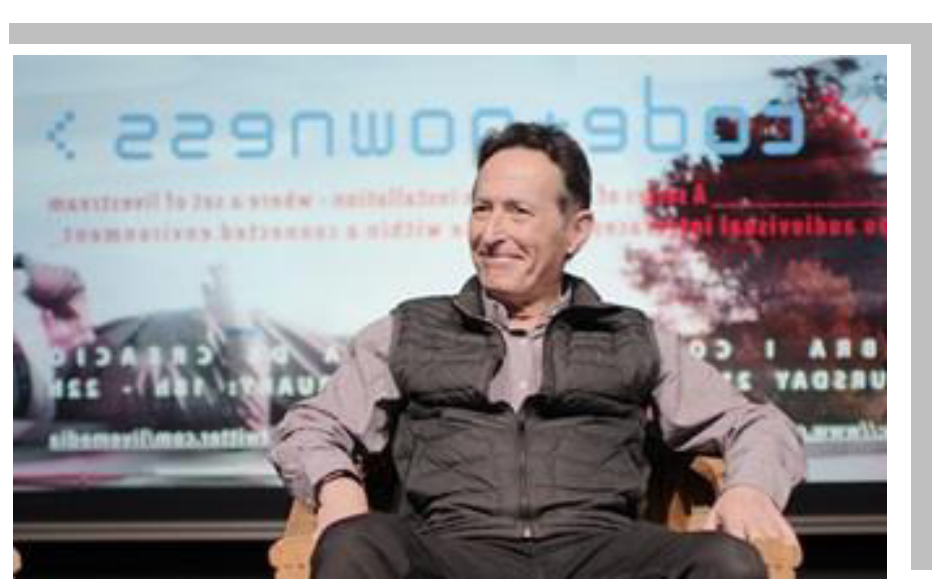

El Dr. Joan Ferrés i Prats es doctor en Ciencias de la Información y maestro. Ha sido profesor de Enseñanza Secundaria. Actualmente es Profesor en los Estudios de Comunicación Audiovisual de la Universidad Pompeu Fabra de Barcelona.

Especialista en Comunicación Audiovisual y Educación, trabaja de manera preferente en los ámbitos de la competencia mediática, de la relación entre competencia mediática y competencia emocional y de la búsqueda de un nuevo estilo en la comunicación educativa y cultural.

Entre sus últimas publicaciones destacan La educación como industria del deseo. Un nuevo estilo comunicativo (Gedisa, 2008) y Las pantallas y el cerebro emocional (Gedisa, 2014).

Ha sido Investigador Principal en diversas investigaciones sobre el grado de competencia mediática de la ciudadanía española y por lo tanto se transforma en un referente y una voz autorizada que a continuación, con una síntesis consideramos necesario integrar, para ensayan una vez sobre la digitalización de la cultura, y en este caso sus implicancias en lo emocional. 
Siendo un referente en el campo, sobre todo desde la perspectiva del impacto de los medios audiovisuales en los procesos de formación de sujetos, ¿en qué sentido considera que cambia el ecosistema comunicacional a partir de la existencia de nuevos medios y tecnologías?

JF: No recuerdo ahora qué autor es pero decía que no es que estamos en una época de cambio, sino en un cambio de época. De cierta radicalidad. Desde el momento en el que se utiliza la palabra "ecosistema" ya significa que cualquiera de los elementos modifica el resto.

Recuerdo que hace unos años, cuando empezaba, utilizaba el ejemplo de que si tú estuvieras en un entorno rural en lo más perdido, y te compras un coche, la única manera de sacarle rendimiento como coche es cambiando todo el ecosistema. Si no hay gasolineras, si no hay vías no puedes sacar provecho. En los cambios tan radicales de tecnología, o cambia todo el ecosistema o el carro no funciona, y tienes que vivir de caballos.

Y eso en buena medida es lo que está pasando en el mundo de la escuela que cambia uno de los elementos del ecosistema, que es la nueva tecnología, pero se le obliga a hacer las funciones que hacía a la antigua, sin cambiar los otros y la obliga a hacer las funciones que hacía a la antigua. Como si fuese el coche haciendo las funciones del carro de caballo: no le estás sacando ningún provecho, por una incapacidad de darle la vuelta a todo.

Entonces, a partir de ahí lo que se me ocurre es que uno de los elementos del ecosistema que no ha cambiado, para darle cierta radicalidad a mi posición, es que estábamos siendo muy conscientes de lo que suponen las nuevas tecnologías y las nuevas prácticas comunicativas y no estamos siendo nada conscientes de los cambios que hubo en cuanto al conocimiento científico sobre cómo funciona la mente de las personas que interactúan con esa tecnología.

¿Cómo cree que la reproducción de las pantallas afecta a los jóvenes y a los más niños? ¿Cómo predispone su posición ante el conocimiento o sus "formas de ser y estar en el mundo“, diría Freire? 
JF: Creo que transforma el ecosistema de una manera radical. Antes los medios eran únicos y estaban circunscriptos a un espacio y a un tiempo. Cuando yo era pequeño, los domingos por la tarde iba a un cine de mi pueblo. Sabía que había dos horas, dos horas no en realidad, porque veía dos películas cada domingo por la tarde. Pero había que ir al cine junto a los del colegio, junto a los que querían. Luego había un sitio donde podías ver la tele, y en unos tiempos determinados. Ahora evidentemente la pantalla la llevas en el bolsillo, y cualquier tipo de espectáculo. Cuando era pequeño iba una vez por mes al circo; ahora evidentemente, cualquier tipo de espectáculo lo tienes en el bolsillo, en cualquier espacio y a cualquier horario.

Por otro lado la disponibilidad de información está a un clic de distancia, por lo tanto, hay una transformación radical. Desde el punto de vista de la comunicación, desde el punto de vista del acceso a la información, al conocimiento y al entretenimiento.

Tal vez nos hemos alegrado mucho con la entrada de las TIC en la educación y hablamos de la escuela como soporte y como expresión de la sociedad y del conocimiento, pero lo que estamos teniendo muy poco en cuenta es que, en general, a los niños y a los jóvenes lo que les atrae es otro tipo de información, no la que nos interesa a nosotros.

Paralelamente, una cosa es que la información esté disponible y otra cosa, que los niños y jóvenes quieran acceder a ella. Y también las maneras de las que se quiere acceder, en buena medida, a la mayor parte de nuestros jóvenes, y gran parte de adultos, a quienes lo que les interesa es la opción del entretenimiento y de acceso a otras formas e informaciones, que muchas veces tienen más que ver con los hobbies, con los intereses y pasiones de cada uno. Por ese lado esos son los hábitos, lo que da el aspecto de conectividad. Y afecta a los dos ámbitos, los entretenimientos más compartidos. Los chicos juegan con los videojuegos y usan simultáneamente el teléfono, mostrando que es accesible el conocimiento compartido más allá de espacio y de tiempo, como por otro lado el trabajo colaborativo en la generación de nuevos conocimientos, y por lo tanto las posibilidades son increíbles.

\section{¿Qué tipos de cambios cree que se pueden observar entonces hoy?}

De entrada se me ocurre que el acceso a las pantallas fuera del aula, en relación con lo de la alienación emocional, las pantallas funcionan como espejo en el sentido que ponen de manifiesto, que es lo que me mueve. Es decir, fuera del aula la persona, yo hablo solo de 
niños y jóvenes, pero en general, cualquier persona que se acerque a algún tipo de pantalla está poniendo de manifiesto sus intereses donde están sus intereses, tanto si lo que hace es consumir programas basura, o informaciones basura, o entretenimiento basura, como si lo que hace es generar conocimiento.

Lo que le apasiona, en cualquier caso es una expresión. Es decir ese acceso tecnológico y acceso al conocimiento y a mensajes de conocimiento, hace que se pueda llegar a satisfacer cualquier tipo de deseo. Basta decir qué tipo de pantallas mirás para decir quién eres.

Termina siendo un reflejo, un espejo. Yo le digo a mi mujer, cuando hace zapping, que no sé cómo hace para que los programas de deportes ni aparezcan. Antes de que aparezcan, ha cambiado. Es una habilidad, bueno algo similar ocurre en este punto. Y en cambio en el mundo académico, generalmente pasa lo evidentemente opuesto. Los contenidos vienen impuestos y entonces hay que poner la pantalla, lo cual pone de manifiesto el proceso inverso, a mi modo de ver. Lo que hay que hacer es generar la emoción para que haya aprendizaje. Sabiendo que lo que nos mueven son emociones, entonces lo que hay que conseguir es que lo que pretendemos que sea objeto de conocimiento, u objeto de aprendizaje, sea objeto de deseo. Es decir, invertir la situación.

El secreto es que lo que pretendemos que sea objeto de conocimiento u objeto de aprendizaje se convierta primero en objeto de deseo.

\section{Por cómo se ha estudiado, entonces, ¿la reacción de los sujetos el aprendizaje se da si hay algún tipo de emoción, negativa o positiva?}

Es que está comprobado, y por mucho que nos duela. Aristóteles decía que la educación es la educación del deseo. Por esto que de algún modo, tampoco sería nuevo. Pero es decir, como personas por la búsqueda del instinto de vida, y la búsqueda con calidad. Por lo tanto la búsqueda de satisfacer deseos y evitar el dolor y todo lo que representa una amenaza. En ese sentido, tanto desde un punto de vista estrictamente biológico, como el modo de que funcionará el método de aprendizaje de la letra con sangre entra, y cómo puede generar deseo. Y eso diríamos desde la ciencia está demostrado las dos variantes, lo que pasa es que tú tienes que priorizar: o estudias para evitar el palo, el suspenso, la riña, o estudias porque aquello te satisface para tener una buena nota. Una vez sabido 
que nos movemos por deseo, en positivo o en negativo, lo ideal creo que es aprender a convertir el objeto de conocimiento en objeto de deseo. Es decir, potenciar la situación de lo que ocurre fuera del aula. Si fuera del aula yo solo me aproximo a eso que me satisface, al nivel que sea, desde los deseos más primarios hasta aquellos que han sido educados muy superior, con una complejidad superior, pues lo que hay que hacer, es conseguir sintonizar, unos grandes contenidos con los deseos de los estudiantes. Para que así, ese proceso se repita de la misma manera.

Podemos entonces continuando con esta línea de reflexión, suponer que a partir de que el rol docente está cada vez más humanizado, con la supresión de los castigos físicos primero y luego de muchos dispositivos como sanciones o amonestaciones, entraríamos en una etapa en el que sistema educativo desecha "la letra con sangre entra" y como otra opción no le queda, si le interesa interpelar a los sujetos, debe buscar desde la movilización de emociones positivas el punto de partida de una educación transformadora.

Estoy dejando al mismo nivel opciones, desde un punto de vista neurocientífico. Por lo tanto estoy descontando que no sé si es ahí o no.

En conferencias a veces explico y aquí hago una simplificación, pero ¿cuáles son las dos grandes instituciones tradicionales, instituciones sociales, más potentes con fuerza socializadora durante los últimos siglos? La escuela y la Iglesia. Las dos han utilizado durante siglos sistemas represivos, la pedagogía represiva de castigos y amenazas en el otro. O físicamente, incluso represivas. Hay un cuadro de Goya, "La letra con sangre entra”, precisamente, y se ve a un alumno con los pantalones bajados y el profesor que le está dando azotes y hay otro estudiante que se está subiendo los pantalones. Entonces, por suerte, las dos instituciones han sido capaces de eliminar ese tipo de prácticas, pero no han sido capaces de sustituir buena parte de su fracaso social, de haber perdido la relevancia social que tenían como fuerza socializadora... Se debe a la incapacidad de sustituir el palo por la zanahoria. Es decir, o hay palo o hay zanahoria. Como mecanismo. O la evitación de la emoción es negativa, o el deseo de la emoción es positivo. Y entonces yo me apunto al deseo. Neurológicamente, vamos por un lado o por el otro. Y a mí que, es el eterno problema, es que si renuncias al sistema del palo, hay que suprimir el otro. 
Desde el lugar docente, ¿qué estrategias le debemos incorporar a nuestras prácticas pedagógicas a partir del saber de las neurociencias, que conocimos en los últimos años, y cómo ingresan las emociones en este escenario?

JF: Una metáfora que utilizo mucho y logré darle la vuelta es la metáfora del navegante, que tiene un punto en común con la que te acabo de decir antes, la del publicitario. La estrategia del navegante se basa en dos pasos: primero, saber para dónde soplan los vientos, y luego debe ser capaz de regularlos y de gestionarlos según el objetivo al que quiera llegar. Conecta con lo de antes en el sentido de que si nosotros no somos buenos navegantes, cuando el viento que sopla no es el que nos gusta no sabremos cómo resolverlo. El navegante no dice: "yo tengo que ir hacia allá", y "yo tengo que ir hacia el otro lado". Los navegantes no se quejan del viento, si eres un buen navegante, lo que tienes que hacer es detectar y gestionar. Detectar para qué lado deben ir las velas, y como tal, para aprovechar la fuerza del viento, sople para donde sople. Esa capacidad de sintonía, ante cualquier contenido, pero descubriendo hacia dónde soplan los vientos.

Hay otro relato que utilizo, que es el de Avicena. Es sobre un Rey que está estucado, que lo único que lo mueve es ser sacrificado por lo tanto, dice si lo único que nos mueve son las emociones...

Avicena es un filósofo y tiene esa habilidad en descubrir qué le mueve, fijate que ese es un caso más extremo porque lo único que lo mueve es la razón de ser sacrificado. Una emoción patológica, autodestructiva. Yo le puedo decir con discursos, pero lo único que lo mueve es eso. La habilidad de Avicena es que lo único que lo mueve es ser sacrificado. ¿Cómo he podido gestionar una emoción negativa? Es lo que han logrado esos médicos, filósofos y demás, el descubrir qué le mueve y la habilidad para gestionar. Porque el problema es que a veces tienen la habilidad para sintonizar pero no para gestionar.

Vemos el anuncio de Claudia Shiffer, el anuncio te impactó, jugó con tus emociones pero si no ha logrado canalizar hacia donde ibas, ha fracasado. Por lo tanto esa doble estrategia de decir: "yo tengo que llegar a ese tipo de contenido de tipo procedimental, o actitudinal" pero lo que le mueve va esa línea pero opuesta ¿Cómo puedo yo captar qué le mueve? Sea colectivo o individual, que tengo y luego cómo lo gestiono para darle vuelta a la situación. 
Me contaban en la escuela Plus, en Chile hace tres semanas, de un maestro. En la escuela Plus trabajan con DirecTV y un maestro de Matemáticas. Les pide un partido entero del Barcelona y dice bueno, yo estoy convencido de que el Barcelona es el equipo que mejor triangula del mundo. Entonces agarró el partido y fue buscando aquellos fragmentos en los que había una buena triangulación. Si era reconocible, con jugadores como Messi, Iniesta, jugadores muy reconocibles y entonces trabajó la triangulación a partir de fragmentos del partido. Serían ejemplos para ver, bueno, cómo hago en el campo tan árido y tan poco atractivo de las matemáticas, algo que les mueva.

Por lo tanto podemos afirmar siguiendo lo que se plantea que incorporar las emociones, no es solo una cuestión filosófica o política, sino que es también una cuestión técnica. Nuestro desafío como docentes es que el estudiante se movilice, que aprenda y por lo tanto podríamos decir que sean positivas o negativas, ¿sin emoción no hay aprendizaje?

JF: Exactamente. Desde hace unos años tenemos la oportunidad de conocernos a nosotros mismos a través de un tipo de ciencia que logra a través de experimentación contrastar resultados que en muchos casos surgen de teorías o campos del conocimiento diferentes. El avance sobre el análisis de los procesos electroquímicos que se desarrollan en el cerebro, permite contrastar y analizar mucho de lo que en otros campos como el de la pedagogía, la psicología o la comunicación se viene trabajando desde hace tiempo.

Hasta ahora había tendencias en esos campos basadas en la experiencia pero evidentemente sin un sustrato de cómo funcionaba el cerebro.

En mi caso, paralelamente, puedo dar la impresión porque uno ha descubierto muchas cosas desde la neurociencia de sacralizar nuevamente un saber pero allí creo que corremos también un gran riesgo.

Creo que hoy nada que tenga que ver con lo humano se puede hacer sin tener en cuenta la neurociencia y nada se puede solo desde la neurociencia. Esto no anula nada de lo otro, yo creo que es un valor extraordinario que tenemos para añadir a toda la riqueza que tenemos acumulada. 
Desde allí podemos construir mayores fundamentos sobre el rol docente y afirmar que no podemos ser reemplazados por máquinas, ya que ellas pueden reproducir contenidos pero nunca desplegar emociones compartidas, aquello que Freire repetía incansablemente sobre la necesidad del encuentro con el otro. Esto se puede explicar desde cincuenta teorías distintas, pero hay un elemento fundamental para sumar a la explicación. Entiendo que cuando uno encuentra conocimientos más profundos le permiten argumentar de una manera más fundamentada aquello que en muchos casos ya conocía.

Consideramos necesario abrir un espacio de debate como señala Ferrés Prats, sobre un nuevo conocimiento que fruto del despliegue de tecnologías de análisis de procesos biológicos, pueden aportar al campo de las ciencias sociales en general, pero al de comunicación / educación en particular. Recuperar la sensibilidad en los procesos de formación de sujetos y de producción social de sentidos es clave ya que atraviesa las tradiciones más profundas del campo América Latina, en donde podemos encontrar perspectivas críticas, para reconsiderar el lugar de la emoción.

Allí encontramos una clara distinción entre posiciones planteadas que recuperan lo emocional desde una mirada tecnicista, vinculada a la gestión de las emociones y a su posible utilización, elementos que no podemos dejar de lado pero que desde nuestras tradiciones son abordados de manera diferente, haciendo foco en la sensibilidad relacional, en su centralidad en procesos de emancipación y en la recuperación de las experiencias previas para su resignificación como instancia clave en la educación.

Así en la búsqueda de un continente que logre rodear la complejidad de la digitalización de la cultura, sumamos el debate aquí abierto y los elementos ensayados. Es necesario considerar que las multipantallas despliegan conjuntos textuales que interpelan construidos sobre todo con una perspectiva emocional para ser cada vez más efectivos y eficientes, y desde allí hay un sujeto expuesto casi cotidianamente a sentirse amenazado por la presencia de un otro, como se ve en la campaña por el No en el Brexit en Gran Bretaña, en la cual fue clave la atemorización de los votantes por la inmigración.

Pero también, nos reencontramos con una necesaria articulación entre la razón y la sensibilidad, en la tensión histórica entre la cultura popular y la cultura letrada, hoy todo ello entremezclado ya que en este nuevo contexto de digitalización de la cultura, son elementos estratégicos tanto en los procesos de dominación como en aquellos que siguen promoviendo la emancipación. 


\section{Referencias}

Freire, P. (1989). La educación como práctica de la libertad. Ciudad Autónoma de Buenos Aires, Argentina: Siglo XXI.

Huergo, J. (2015). La educación y la vida. La Plata, Argentina: Ediciones de Periodismo y Comunicación. 


\section{Formación de sujetos y tecnologías}

Como ya lo señalaron Jorge Huergo y Belén Fernández (200o) —siguiendo a Jesús Martín-Barbero ([1987] 1997)—, la utilización de las nuevas tecnologías es más una cuestión de "mediaciones" que de "medios". Por eso, empecemos por despejar el temor instalado de que las nuevas tecnologías podrían reemplazar al docente, al modo como los robots están reemplazando a los obreros en las fábricas de automóviles. Es cierto que así como la revolución industrial vino a reemplazar la fuerza física, la "convergencia tecnológica” ayuda a gestionar — con más rapidez y eficacia - muchas funciones mentales. Pero la escuela no es (o no debiera ser) semejante a una ensambladora de autopartes ni sus funciones deberían agotarse en el acoplamiento de datos o en su procesamiento estadístico. Es más, tampoco debería ser la encargada de satisfacer las caprichosas demandas de un Mercado mundial que pretende hacer desaparecer las culturas para instalar en los niños y jóvenes la única lógica de la especulación económica y financiera, que los convierta en consumidores/consumidos.

De lo que se trata, como venimos afirmando en cada ensayo, es de terminar de tomar conciencia de que merced a las nuevas tecnologías ha cambiado la percepción del mundo. El tiempo se ha relativizado y por lo tanto hay que aprender a "darse tiempo" y a "darle tiempo" al otro; a valorar los procesos como partes del resultado. Es decir que se hacen necesarias nuevas habilidades, sobre todo actitudinales y procedimentales, ya que las informaciones están al alcance de la mano.

También es necesario reconocer que ya no se lee solo según la lógica escritural del libro (secuencia textual de izquierda a derecha y de arriba hacia abajo), ni en soporte de papel sino desde múltiples pantallas y múltiples estímulos sonoros, visuales, cinéticos, escriturales y por lo tanto hay que incorporar otras técnicas de lectura y escritura: videos, emoticones, producciones multimediales, memes, videojuegos, experiencias de realidad aumentada, inmersiva, donde los múltiples planos de la realidad que hoy la tecnología permite puedan estar configurando parte del aprendizaje y dialogando con las formas en las cuales cada vez más sujetos se forman hoy fuera de la escuela. 
Y aunque en este caso por momentos será el niño o el joven quien asuma el rol de enseñar al docente cómo instalar una aplicación o acceder a las múltiples pantallas, leer en simultáneo, desde diferentes direcciones, esto no descalifica ni reemplaza al maestro. Al contrario, le da ese nuevo rol de enseñar a enseñar, explicándole las dificultades del aprender y valorándolo como interlocutor válido en un proceso de producción (co-producción) de conocimientos.

Podemos admitir que por un momento haya que dejar de lado las computadoras o los celulares para aprender lo que ellos no permiten aprender e incluso para corregir hábitos indeseados que ellos puedan provocar. Enseñar sobre ciberseguridad, grooming, sobre la estrategia de las plataformas para retenernos dentro en una era en donde la atención humana es escasa y se monetiza, sobre las diferentes formas de adicción que generan, sobre los riesgos, los malos usos y posibles perjuicios.

Pero antes es preciso reconocer que las actuales tecnologías de la comunicación — por cierto, ya instaladas en la cotidianidad de una inmensa cantidad de niños y jóvenes que cursan en nuestras escuelas- han operado un cambio cultural en la sociedad actual, una de cuyas características es la de haber adquirido una nueva "sensorialidad" donde los límites entre lo posible, lo deseado, lo real, lo efímero, lo inmediato, lo lejano, lo creíble, lo verdadero, no están tan claros como cuando podían enseñarse desde la lógica lineal de la lecto-escritura.

Y este cambio en el sensorium de nuestra época interpela en primer lugar a los decisores de políticas educativas para que, a través de la escuela, se minimicen las grietas entre los que tienen y los que no tienen oportunidades de acceder a una parte sustantiva de esta cultura, lo cual no puede reducirse solamente a comprarle una computadora a cada niño, ni a desplegar una vidriera de maravillosos aparatos en las escuelas, aunque sin duda ese debe ser un punto de partida.

Es por eso que nos parece fundamental destacar las transformaciones sociales y culturales que hoy las tecnologías están generando y su impacto en la formación de los sujetos desde un abordaje de las formas de interpelación que las multipantallas poseen en la configuración de la subjetividad de jóvenes y niños, para luego reconocer el fenómeno de modificación en los sujetos y abordar también algunos elementos de la incorporación de tecnologías en el aula. 


\section{La relevancia formativa de las multipantallas}

Para comenzar este apartado es necesario definir a qué hacemos referencia cuando hablamos de formación. Jorge Huergo (22/04/2007), retoma una serie de autores que problematizan este concepto. En este sentido, recupera a Ricardo Nassif (1958), quien sostenía que "la formación es la culminación del proceso educativo: la conformación personal del ser en el desarrollo de su forma propia, que tamiza todo lo que pasa a través suyo", y a Edward Thompson (1989) quien, en cambio, visualizaba a la formación como "un proceso activo y un producto siempre inacabado que se debe tanto a la acción como al condicionamiento". De este modo, para Huergo (22/04/2007), "existiría, pues, una mediación donde los condicionamientos producen la acción, pero la acción incide en los condicionamientos" (en línea).

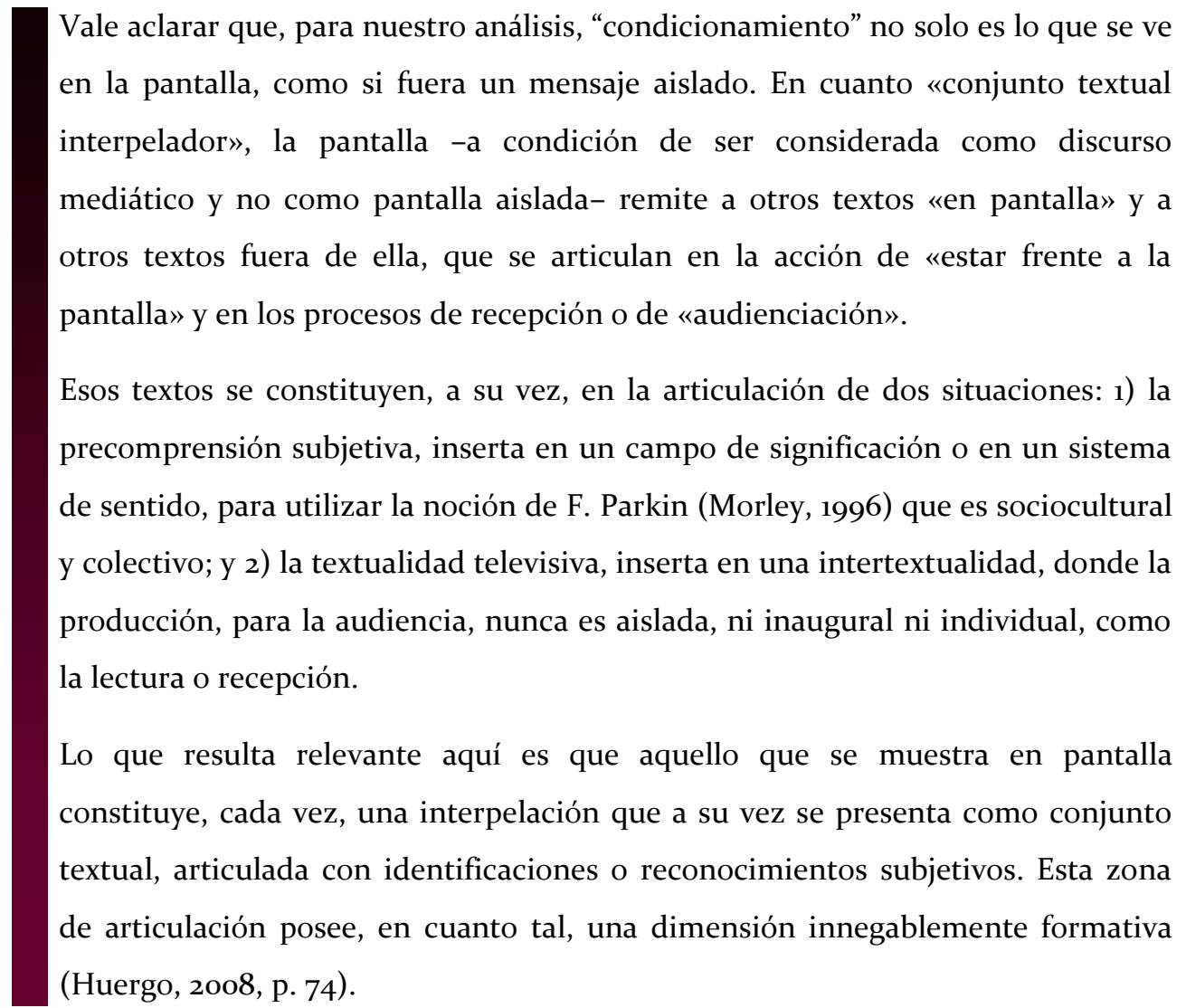

Desde la posibilidad que plantea Huergo (2008) de conceptualizar de qué manera los medios en general y la televisión en particular forman, hoy debemos forzar estas definiciones y ampliarlas para abarcar aquello que no podemos dejar de visibilizar que es la profunda capacidad de interpelación que poseen los discursos hipermediados por TIC. 
Por ello, para comprender la relevancia formativa de las multipantallas, retomaremos la categoría anteriormente explicitada de lo "educativo" que propone la pedagoga mexicana Rosa Nidia Buenfil Burgos (1993). Allí, en cierto modo, la clave comunicacional de lo educativo está en la “interpelación”. A propósito, Michel Pècheux (2005) señala que en la figura de la interpelación es donde se vincula el problema de la producción del significado con el de la constitución del sujeto. Dicho de otro modo, donde la evidencia del significado hace evidente al sujeto.

Entonces, podemos decir que es en el juego de interpelaciones y reconocimientos en el que se constituye el sujeto y que hoy las nuevas formas de la cultura digitalizada, hipermediada, hacen cada vez más necesarias concepciones que permitan formalizar qué hay de educativo en todo esto.

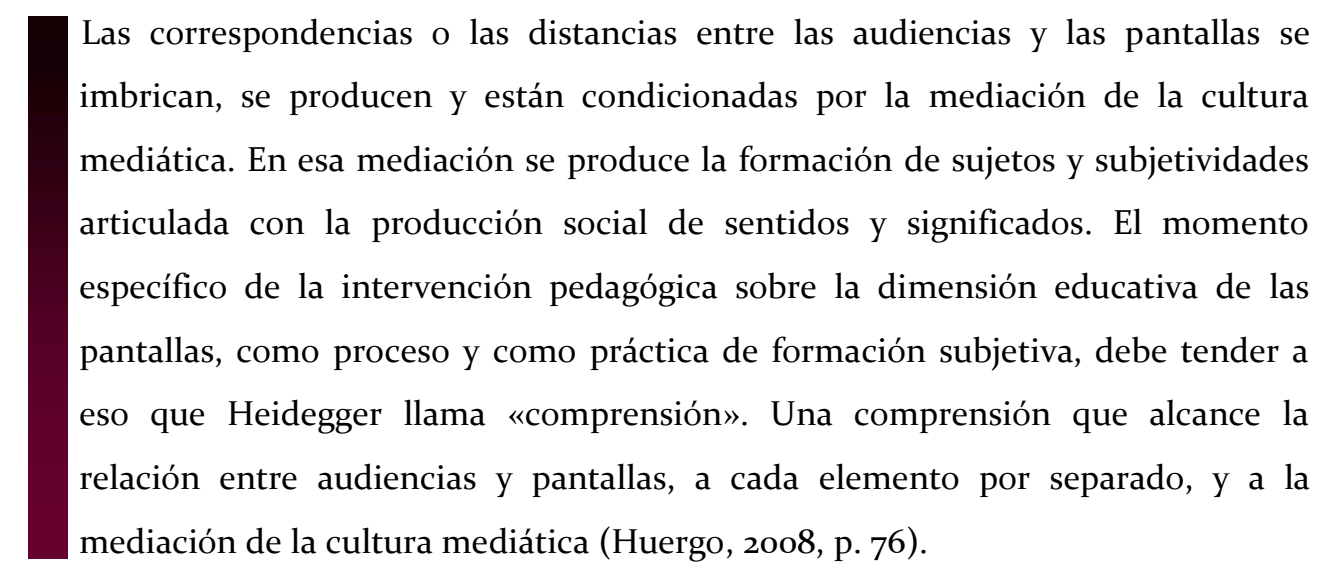

La citada dimensión se refiere al reconocimiento de las transformaciones culturales y está vinculada a las hipermediaciones tecnológicas en la vida cotidiana, como un elemento que forma sujetos y configura prácticas culturales que, al estar articuladas con la propia cotidianeidad, poseen una dimensión educativa por fuera de las instituciones escolares. Como ya dijimos, esta relevancia requiere ser reconocida y profundizada, si nos ubicamos en una posición en la cual el conocimiento de las prácticas y los saberes previos de los sujetos supone una dimensión estratégica desde la cual abordar los procesos educativos en los contextos actuales, o más concretamente si consideramos que el reconocimiento del universo vocabular de los sujetos es el punto de partida para cualquier proceso pedagógico (Freire, [1968] 2005).

Es preciso actualizar este concepto, es decir que hoy para comprender con quiénes nos encontramos a la hora de trabajar en establecimientos educativos, sobre todo dirigidos a jóvenes y niños, para lograr "hacer del allí del otro mi aquí", como decía Freire ([1968] 
2005), debemos comprender la profundidad del fenómeno, la relación de los sujetos con estas multipantallas, las hipermediaciones que se dan y cómo hoy podemos arriesgarnos a decir que el propio concepto de lo humano se está modificando.

Si pensamos en un horizonte político sobre el tema, podemos afirmar que

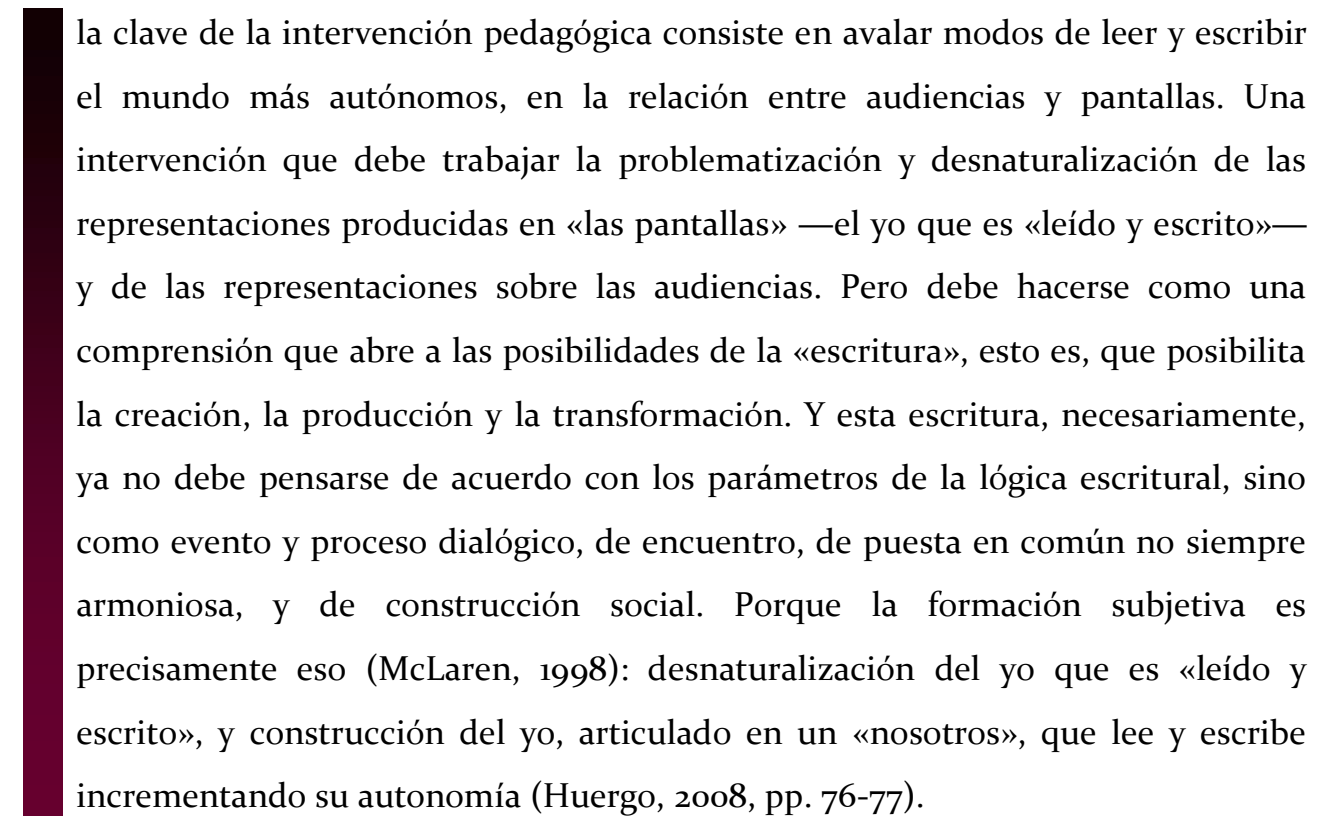

\section{La didáctica mediada por TIC}

La segunda dimensión, que es necesario reponer luego de analizar de qué manera este nuevo escenario forma sujetos y por lo tanto debemos reconocer, se refiere a una didáctica mediada por las TIC y parte de la necesidad de repensar la enseñanza y sobre todo el vínculo docente-alumno, a partir de la disposición de una gama de recursos tecnológico-mediáticos que habilitan nuevas escenas educativas posibles. En muchos casos, estas se manifiestan en el escenario del aula, a partir de nuevas configuraciones y cambios en las relaciones de poder donde los y las jóvenes son portadores de saberes que desafían el estatuto y la legitimidad del "saber" de los docentes. Así, pueden recrearse nuevas posibilidades pedagógicas y didácticas para los distintos niveles de enseñanza y las diversas lógicas disciplinares. También implica desafíos en la formación a partir de la disponibilidad de una multiplicidad de diferentes asistentes y recursos tecnológicocomunicacionales que permitirán visibilizar herramientas que promuevan procesos educativos desde una perspectiva integral. 
Esos recursos tecnológicos constituyen un medio que se vale de la tecnología para cumplir con su propósito pedagógico. Pueden ser tangibles — una computadora, un cañón, una tablet - o intangibles — un sistema, una aplicación virtual, un video o un audio- Asimismo se encuentran los recursos lineales: texto, imágenes, infografías y los recursos interactivos / colaborativos, como las wikis y las aulas virtuales, que a su vez pueden incluir a una serie de recursos lineales e interactivos/colaborativos.

Pero como dice Edith Litwin (2005):

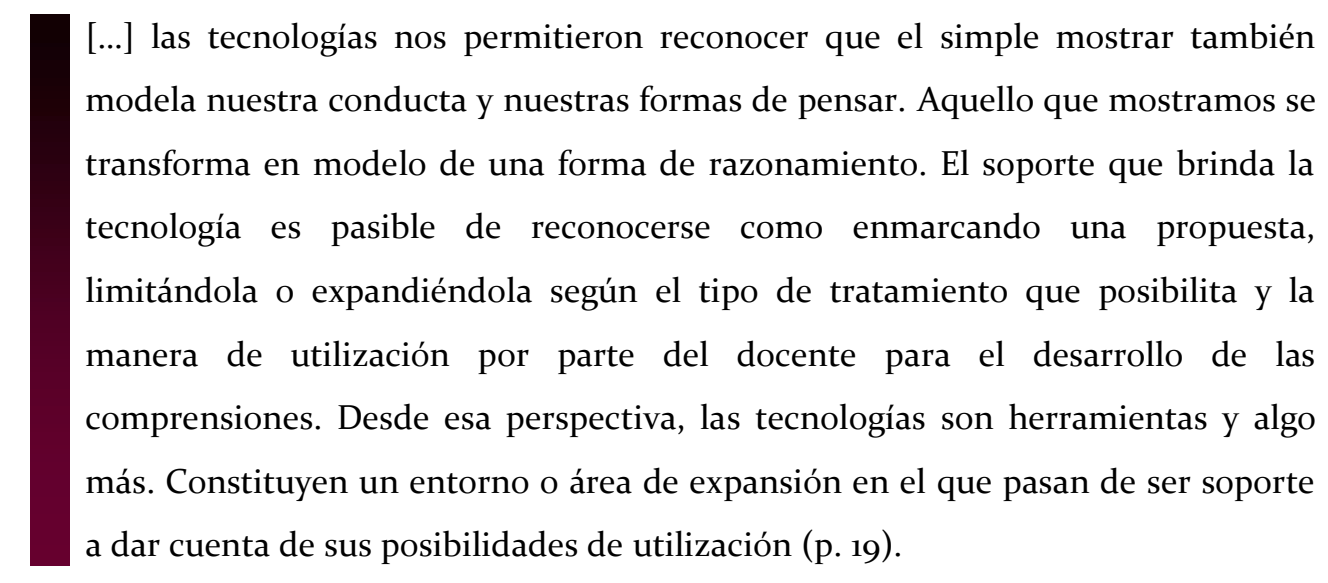

El factor de modelaje de la cultura y su producción sociohistórica entonces, deviene en matriz de constitución de los sujetos y sus modos de comprensión y producción social, del sistema educativo y de realización de los procesos de enseñanza aprendizaje, es decir se transforma en otra clave para reconocer que la digitalización de la cultura es un elemento performativo.

Paralelamente, es necesario desarrollar una reflexión profunda desde una perspectiva crítica que trabaje sobre las potencialidades de estos medios y tecnologías, en los que Huergo (2007) reconoce cuatro elementos clave:

En primer lugar, la interactividad y la ruptura de la linealidad (y la secuencialidad) del "conocimiento escolarizado"; aquí está la posibilidad de apostar a la construcción del texto y el hipertexto de manera interactiva o colectiva.

En segundo lugar, la conectividad y la inteligencia colectiva, en cuanto apertura a vínculos (links) con otras mentes y con otros cuerpos vivos. La misma estructura hipertextual significa un acceso y un recorrido interactivo a cualquier contenido o a cualquier conocimiento desde cualquier parte, rompiendo los encorsetamientos espacio-temporales de la escolarización. 
En tercer lugar, [...] el aprendizaje no está tan sometido a los controles de la "racionalidad escolarizadora” y permite la emergencia y puesta en escena de las diversas subjetividades.

En cuarto lugar, el hipertexto [...] potencia el pensamiento relacional o asociativo; permite la integración significativa de múltiples conocimientos; avala el crecimiento de la autonomía del estudiante en el proceso de aprendizaje y posibilita una perspectiva multimedial o polifónica (p. 19).

Estos elementos son centrales para disponer una polifonía de movimientos en los cuales la interactividad, la ruptura de secuencialidad, la conectividad, la inteligencia colectiva, la salida de los controles de la racionalidad escolarizadora, junto con el pensamiento relacional y asociativo, permitan disponer otros modelos, otros mundos posibles de la educación. Nuevas arquitecturas escolares que acompañen las nuevas arquitecturas simbólicas que hoy están desarrollándose cada vez con mayor velocidad.

\section{Las funciones de la tecnología}

Avanzamos un paso más entonces y recuperamos en los estudios didácticos el reconocimiento de una tríada conformada por el docente, los estudiantes y el contenido. Allí es posible identificar una serie de vínculos y entretejidos que dan cuenta de la manera en que se construye el conocimiento tradicional y también en esa misma tríada podríamos identificar tres usos diferentes de las tecnologías; según el lugar que se le asigne al docente, según la concepción del sujeto de aprendizaje que se asuma y según el sentido con el que se entiende el contenido en la enseñanza (Litwin, 2005).

En primer lugar, podríamos referirnos a un sistema clásico de información en el que el vínculo docente-alumno se entiende a partir de considerar al primero como proveedor de información, y al segundo, como un usuario consumidor. Aquí la incorporación de las tecnologías pasa a desempeñar un papel preponderante, en tanto asegura la provisión de información actualizada. Este enfoque básico varía según la edad de los estudiantes, sus posibilidades de autonomía, sus intereses y la facilidad que se tenga para acceder a las nuevas tecnologías de la información. Es clave el papel que asuma el estudiante para romper esta visión en tanto no considera intereses personales, desafíos cognitivos y alcances o disposición de las tecnologías. 
Un segundo uso parte de entender a las tecnologías como herramientas que ponen a disposición de los estudiantes contenidos que resultan inasequibles en la clase del docente, en sus exposiciones, representaciones o modos explicativos. En estos casos, la tecnología amplía el alcance de la clase. Son los docentes quienes preparan esos usos, los ofrecen a sus estudiantes y los integran a las actividades del aula. Es clave aquí el papel que los docentes asignan a las tecnologías.

En tercer lugar, podemos concebir a los estudiantes como sujetos del conocimiento que necesitan tener a su disposición ofertas variadas para favorecer el proceso de formación que mejor se adapte a sus necesidades, sus intereses o sus posibilidades. Las tecnologías pueden poner a su disposición múltiples opciones. Pueden integrarse en proyectos que permiten también propuestas comunicacionales alternativas para la construcción del conocimiento y alienten el trabajo en grupo y en colaboración.

Estos tres enfoques se hacen más complejos y se entrecruzan cuando reconocemos diferentes dimensiones y variables, tanto en los actos de conocimiento como en las maneras en que se asume la profesión docente, o según los análisis político-ideológicos que permiten identificar los diseños curriculares o las propuestas de trabajo que se llevan a cabo en las escuelas. Resulta necesario admitir que el estudio de las funciones que les caben a las tecnologías en relación con la enseñanza no se presta hoy simplemente a una enumeración de usos posibles. La utilización de aquellas en un proyecto educativo enmarca un modelo pedagógico en el que se seleccionaron contenidos culturales y se modelaron estrategias cognitivas. En su conjunto, como plantea Litwin (2005), deberían promover la equidad, la inclusión social, el desarrollo personal y académico de los alumnos, propiciar la comunicación y brindar a la comunidad educativa acceso a información actualizada.

En este sentido, un uso adecuado de la tecnología en la enseñanza requiere del desarrollo de un conocimiento complejo y contextualizado, para su debida integración con lo pedagógico y lo disciplinar. Esta idea está presente en el marco conceptual denominado Conocimiento Tecnológico Pedagógico Disciplinar, conocido como ТРАСК (sigla en inglés de technological pedagogical content knowledge), que se ha expandido en diversos espacios de formación docente. 
En el TPACK se identifican como componentes centrales: conocimiento de contenido, pedagogía y tecnología, los cuales se presentan aisladamente, pero el TPACK también presenta la relación entre estos factores: conocimiento pedagógico del contenido, conocimiento tecnológico del contenido, conocimiento tecnológico-pedagógico y conocimiento tecno-pedagógico del contenido.

Por lo tanto, los elementos primarios, la intersección dos a dos y la intersección de los tres elementos conforman las siete dimensiones del TPACK, como se puede observar en la siguiente imagen:

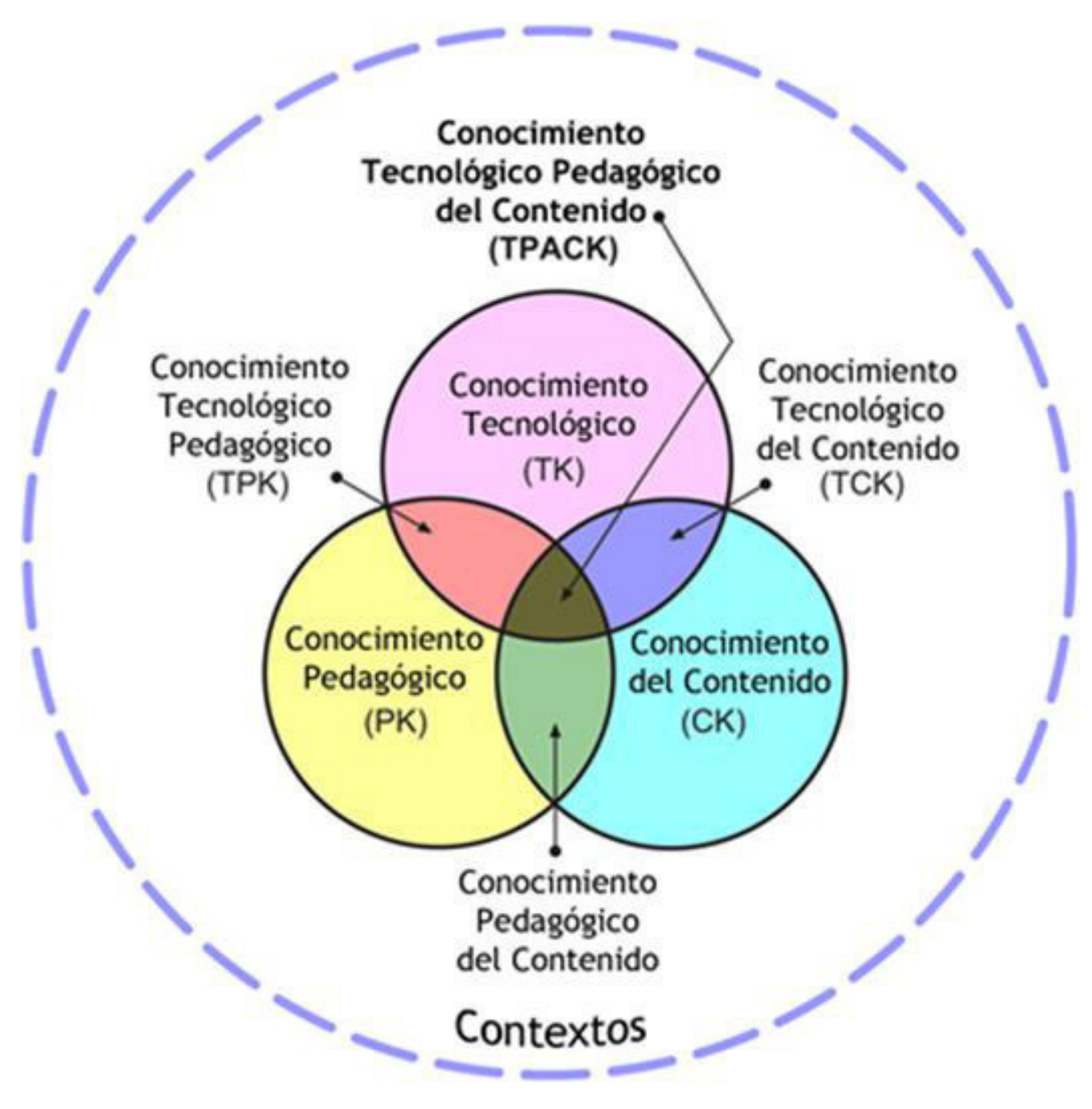


La utilización de la tecnología en el proceso de aprendizaje, entonces, requiere, al menos, de crear, de mantener y de restablecer un equilibrio dinámico entre los componentes del TPACK, ya que el contenido, la pedagogía y la tecnología en los contextos de enseñanza tienen roles individuales y en conjunto.

Por otro lado, para pensar la didáctica mediada por TIC es necesario poner en tensión el mito de que la computadora puede reemplazar al docente (Negroponte, 1997). El riesgo que conlleva este mito es la persistencia de la idea de un ciclo que "siempre sigue de la misma manera: con un limitado uso en clase, lo que conlleva una desilusión y recriminaciones entre políticos, reformadores y docentes. Las declaradas mejoras, entendidas en general como incrementos en los logros de aprendizaje, no se constatan en los estudios empíricos" (Maggio, 2012).

Esto se puede relacionar con formas de inclusión de las TIC en las prácticas de la enseñanza. Por un lado están las inclusiones efectivas, donde la incorporación se produce por otras razones que no son las del docente preocupado por la enseñanza, sino que responde a la disponibilidad de la tecnología, a su aura de modernidad o a una moda. La tecnología está pero podría no estar. Al contrario, una inclusión genuina alcanza su mejor expresión en la propuesta didáctica cuando emula en este plano de la práctica el entramado de los desarrollos tecnológicos en los procesos de producción del conocimiento, en el campo al que esté refiriendo.

En este sentido, Marina Maggio (2012) denomina el modelo 1 a 1 (un alumno, una computadora). Estas experiencias son muy diversas, como también lo han sido sus objetivos y sus grados de desarrollo. Podemos señalar una serie de iniciativas muy valorables para América Latina, como el Plan Ceibal en Uruguay, Enlaces en Chile, Proyecto Huascarán en Perú, Programa Computadoras para Educar en Colombia, Programa integral Conéctate en El Salvador, Escuelas del Futuro en Guatemala o el Plan de Inclusión Digital Educativa y Conectar Igualdad en la Argentina, entre otros. Todos ellos dan muestras de la existencia de políticas que buscan acompañar estas transformaciones, sumarlas al mundo de la escuela y orientarlas en una dirección determinada (Dussel, 2011).

En el momento del diseño de estas políticas, la primera preocupación hace a la inclusión digital, y tiene que ver con reducir la brecha entre sectores sociales y entre generaciones, en el acceso y el uso que se hace de las llamadas nuevas tecnologías. El desafío es la articulación entre políticas de inclusión y políticas educativas en relación con: 
- Dónde, cuándo y quiénes se harán cargo de la introducción de estas nuevas tecnologías en el aula.

- La vinculación de dos lógicas y modos de configuración del conocimiento muy diferentes.

- La inversión en infraestructura (requisito necesario pero no suficiente en el campo de las TIC).

Entonces, no estamos solamente ante un problema de inversión sino también ante una mutación simbólica y cultural, que involucra las bases sobre las que se construye la institución escolar (Dussel \& Quevedo, 2010): hoy es necesario reconocer que nuestras mentes y en especial las de los niños y jóvenes están atravesadas por entornos tecnológicos que soportan comunicaciones, relaciones, consumos culturales y entretenimiento. Cuando no hacemos este reconocimiento, se genera un vacío entre los modos como nuestros alumnos conocen y pueden aprender y nuestras propuestas para favorecer que ello ocurra. Este vacío es cognitivo cuando no reconocemos el carácter de los procesos que tienen lugar efectivamente; es cultural, cuando no entendemos a nuestros alumnos como sujetos y miembros de culturas particulares; y, finalmente, es pedagógico, cuando construimos y llevamos adelante propuestas que en lugar de suscitar lazos con esos sujetos sociales, cognitivos y culturales, caen en el vacío propio de la falta de reconocimiento de sus modos de pensar, de conocer, de relacionarse, de interactuar y, por ende, de aprender (Maggio, 2012).

Si la inclusión genuina como categoría teórica tenía sentido epistemológico en las investigaciones, el reconocimiento de lo que los niños y los jóvenes, que son nuestros alumnos, experimentan con la tecnología, tiene un sentido cultural. Efectuar los dos reconocimientos y crear propuestas pedagógicas que incluyan ambos sentidos —epistemológico y cultural — son algunos de los mayores desafíos de la docencia en los escenarios de la contemporaneidad.

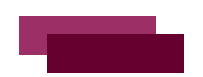




\section{Referencias}

Buenfil Burgos, R. N. (1993). Análisis de discurso y educación. Documentos

DIE 26. Ciudad de México, México: Instituto Politécnico Nacional.

Dussel, I. (2011). Aprender y enseñar en la cultura digital. Ciudad Autónoma de Buenos Aires, Argentina: Santillana.

Dussel, I. y Quevedo, L. A. (2010). VI Foro Latinoamericano de Educación;

Educación y nuevas tecnologías: los desafíos pedagógicos ante el mundo digital.

Ciudad Autónoma de Buenos Aires, Argentina: Santillana.

Freire, P. [1968] (2005). Pedagogía del oprimido. Ciudad de México, México: Siglo XXI.

Huergo, J. y Fernández, M. B. (200o). Cultura escolar y cultura mediática / Intersecciones. Bogotá, Colombia: Universidad Pedagógica Nacional.

Huergo, J. (22 de abril de 2007). Breve apunte sobre Formación [entrada de blog]. Recuperado de http://comeduc.blogspot.com/2007/o4/formacin.html

Huergo, J. (2007). Los medios y tecnologías en educación. Ciudad Autónoma de Buenos Aires, Argentina: Ministerio de Educación, Ciencia y Tecnología.

Recuperado de

http://repositorio.educacion.gov.ar:8o8o/dspace/handle/123456789/95679

Huergo, J. (2008). La relevancia formativa de las pantallas. Comunicar, 15(30), 73-77. Recuperado de http://sedici.unlp.edu.ar/handle/10915/29447

Litwin, E. (Comp.) (2005). La tecnología educativa en el debate didáctico.

En Tecnologías educativas en tiempos de internet. Ciudad Autónoma de Buenos Aires, Argentina: Amorrortu.

Maggio, M. (2012). Enriquecer la enseñanza. Los ambientes con alta disposición tecnológica como oportunidad. Ciudad Autónoma de Buenos Aires, Argentina: Paidós. 
Martin, V. y Vestfrid, P. (2015). La aventura de innovar con TIC : aportes conceptuales, experiencias y propuestas. La Plata, Argentina: Ediciones de Periodismo y Comunicación. Recuperado de https://perio.unlp.edu.ar/sites/default/files/la aventura de innovar con tic.pdf Martín-Barbero, J. [1987] (1997). De los medios a las mediaciones. Bogotá, Colombia: Gustavo Gili.

Negroponte, N. (1995). Ser digital. Nueva York: Estados Unidos: Alfred A. Knopf.

Pècheux, M. (2005). El mecanismo del reconocimiento ideológico. En S. Zizek (Comp.), Ideología. Un mapa de la cuestión (pp. 157-167). Ciudad Autónoma de Buenos Aires, Argentina: Fondo de Cultura Económica. 


\section{Políticas de inclusión digital en escuelas}

En línea con lo presentado hasta aquí, consideramos necesario retomar una experiencia realizada en el marco de la Universidad Nacional de La Plata, desde la cual se analizó el impacto de dos políticas públicas centrales para lo abordado en esta tesis: el plan Conectar Igualdad y Mi TV Digital.

Esto es clave ya que no podemos dejar de analizar aquellas políticas públicas que intentaron entrar de lleno en terreno de la convergencia tecnológica y que, reconociendo la complejidad del panorama, ensayaron una respuesta que hoy debemos recuperar en un contexto de achicamiento de lo público y restauración conservadora. Lo central aquí es poder revisar parte del proceso y desde allí con una mirada crítica sobre todo proveniente del paso del tiempo y de la revisión de los programas de entrega de una computadora para cada niño, analizar aquellos elementos que en futuras políticas que restituyan lo público deben estar presentes pero reconfigurados.

Conectar Igualdad fue el nombre de un programa surgido como iniciativa del Poder Ejecutivo Nacional argentino, lanzado en 2010 por la entonces presidenta Cristina Fernández de Kirchner mediante la firma del Decreto 459/10. La iniciativa estuvo enfocada en recuperar y en valorizar la educación pública, con el fin de reducir las brechas digital, educativa y social en el territorio argentino. Se trató de una política de Estado en la que intervinieron la Presidencia de Nación, la Administración Nacional de Seguridad Social (ANSES), la Jefatura de Gabinete de Ministros, el Ministerio de Educación y el Ministerio de Planificación Federal, Inversión Pública y Servicios.

Entre los años 2010 y 2015 se entregaron cinco millones y medio de computadoras, y se construyeron 1.428 aulas digitales en toda la Argentina.

El programa consistió en la entrega en todo el país de computadoras subportátiles tipo Classmate PC a todos los/as estudiantes y las/os docentes de establecimientos públicos de educación secundaria, especial y de formación docente. Adicionalmente, el programa 
desarrolló contenidos digitales utilizables en distintas propuestas didácticas y trabajó en los procesos de formación docente, con la intención de transformar modelos, procesos y paradigmas de aprendizaje y de enseñanza.

Conectar Igualdad contempló tanto el uso de las portátiles en el ámbito escolar como en el hogar, buscando un impacto a nivel social que trascendiera el ámbito educativo. De esta manera, el programa tuvo como objetivo alfabetizar a la sociedad en las tecnologías de la información y la comunicación, democratizando el acceso a los recursos tecnológicos y a la información, sin discriminación social, económica ni espacial, llegando a todo el país, como se señalaba en el portal www.conectarigualdad.gob.ar que se encuentra fuera de línea desde el cierre de esta política, en 2018.

Es necesario destacar que el programa fue acompañado no solo por las capacitaciones que desde allí se realizaron sino también por la Especialización Docente en Educación y TIC que desde el Instituto Nacional de Formación docente, dependiente del Ministerio de Educación de la Nación, llegó a más de cuatrocientos mil inscriptos.

Paralelamente, el Estado Nacional, a través del Plan Operativo de Acceso Mi TV Digital, trabajó para que todos y todas los/as argentinos/as tuvieran igualdad de oportunidades en el acceso a la Televisión Digital Terrestre (TDT) abierta, libre y gratuita, procurando el acceso al equipo receptor necesario para ver la TDT, sin costo para aquellos ciudadanos e instituciones que presentaran riesgos de exclusión durante el proceso de transición tecnológica.

La distribución de receptores tuvo carácter procesual y estuvo sujeta al avance de las obras de infraestructura que el gobierno nacional llevó adelante para expandir el área de cobertura de la señal de TDT entre 2010 y 2015.

Los beneficiarios del Plan Operativo de Acceso fueron:

- Establecimientos estatales que tuvieran por finalidad y/o función el desarrollo de actividades sociales, culturales, educativas y/o de promoción de contenidos audiovisuales.

- Organizaciones sociales tales como asociaciones civiles sin fines de lucro, fundaciones o cooperativas, que tuvieran por objeto el desarrollo de actividades sociales, culturales, educativas y/o de promoción de contenidos audiovisuales.

- Hogares: titulares con asignaciones, pensiones u otras coberturas estatales. ${ }^{10}$

10 Información que estaba disponible en el portal www.mitvdigital.gob.ar antes de su cierre, en 2017. 
Esta articulación de políticas públicas con otras como el programa Polos y Nodos Audiovisuales en articulación con universidades nacionales, el desarrollo de la Televisión Digital Abierta (TDA), la creación del Banco de Contenidos Universales Audiovisuales (BACUA), la producción del portal Contenidos Digitales Abiertos (CDA) y la creación de los canales de televisión Pakapaka y Encuentro, fueron marcando el rumbo de diferentes trabajos de investigación que abordaban una agenda pública que estaba intentando revolucionar el campo comunicacional y el educativo, muchas veces en conjunto.

Es por ello que en ese contexto se formuló una propuesta de análisis en el proyecto de Investigación "Políticas públicas de Inclusión tecnológico/Digital. Procesos formativos en escuelas públicas de la provincia de Buenos Aires: TV digital y Conectar Igualdad", que se desarrolló durante el bienio 2014-2016 en el Centro de Investigación y Desarrollo en Medios, Industrias Culturales y Televisión (CEID-TV), radicado en la Facultad de Periodismo y Comunicación Social de la UNLP.

La investigación, que resultó financiada luego de ser seleccionada en el programa Consenso del Sur del ministerio de Educación de la Nación, fue dirigida por el Dr. Leonardo González y codirigida por mí, como corresponsable general del proceso, pero centralmente también a cargo del diseño metodológico y del trabajo de campo realizado.

Allí se avanzó en un relevamiento sobre la llegada y el uso de las políticas públicas digitales del Conectar Igualdad y el Programa Mi TV Digital en las escuelas secundarias públicas de la ciudad de La Plata y alrededores: Berisso, Ensenada, Brandsen, Verónica y Pipinas. El relevamiento comprendió Escuelas Secundarias Básica, Escuelas de Educación Media, Escuelas Rurales, Escuelas Técnicas, Escuelas Agropecuarias y Escuelas de Educación Especial, ubicadas en diferentes zonas geográficas de dichos distritos.

Esta investigación fue diagramada en dos etapas: la primera, de carácter cuantitativo, dio cuenta de los alcances concretos de la política pública, es decir, de en qué medida las políticas llegaban concretamente a las escuelas según el propio relato de sus directivos; y la segunda, de carácter cualitativo, se focalizó en la producción de conocimiento y tomó como base las experiencias generadas en las escuelas a partir del uso de las netbooks del Conectar Igualdad y del Programa Mi TV Digital. 
El valor de este trabajo radica en que permitió sintetizar el recorrido realizado en 2014, para proponer aquí los resultados que integran la mirada general de la tesis respecto de los programas 1 a 1 como el Conectar Igualdad, que en su momento fueron estratégicos, pero sobre los cuales hoy se hace necesario reflexionar.

En función de los objetivos planteados en la investigación, el acercamiento inicial se realizó telefónicamente dialogando con los/as directivos/as de las escuelas. Este primer registro, que permitió la construcción de la variable cuantitativa, facilitó también el segundo análisis de carácter cualitativo a partir de entrevistas y de observaciones en aquellas instituciones que habilitaron la continuidad del diálogo a través de una visita.

La selección de las escuelas para esa posterior etapa de análisis cualitativo se produjo, como expusimos anteriormente, a partir de la habilitación de las instituciones a la visita, pero también por medio de una selección intencional de las experiencias producidas en las instituciones. De manera que intentamos generar un segundo encuentro en aquellas escuelas adonde habían llegado las netbooks del Conectar Igualdad y desde las cuales se había solicitado el Programa Mi TV Digital.

El siguiente mapa clarifica territorialmente el alcance de la muestra:

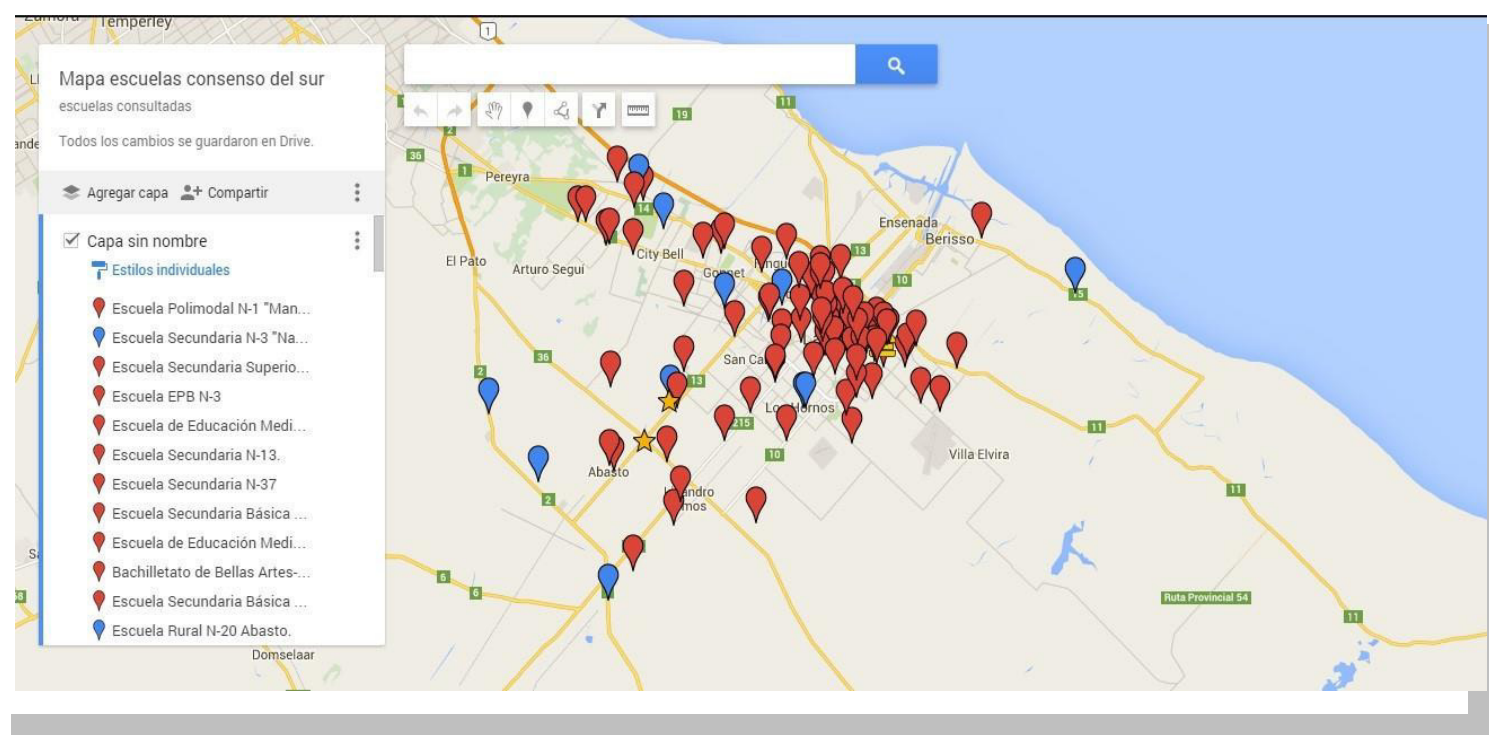

Mapa de escuelas relevadas en la ciudad de La Plata por tipo y modalidad Fuente: elaboración propia 


\section{Datos Generales}

\section{Escuelas y Políticas Públicas}

\begin{tabular}{|l|l|l|}
\hline \multicolumn{1}{|c|}{ TIPO DE ESCUELA } & Conectar Igualdad & Mi TV ditigal \\
\hline $\mathbf{1 0 4}$ Secundarias Provinciales & $\mathbf{9 3}$ & $\mathbf{8}$ \\
\hline $\mathbf{2 1}$ Escuelas Especiales & $\mathbf{2 0}$ & $\mathbf{0}$ \\
\hline $\mathbf{1 3}$ Escuelas Técnicas & $\mathbf{1 3}$ & $\mathbf{3}$ \\
\hline $\mathbf{7}$ Escuelas Rurales & $\mathbf{7}$ & $\mathbf{3}$ \\
\hline $\mathbf{2}$ Escuelas Municipales & $\mathbf{0}$ & $\mathbf{0}$ \\
\hline $\mathbf{1}$ Bachillerato & $\mathbf{1}$ & $\mathbf{0}$ \\
\hline
\end{tabular}

\section{Conectar Igualdad (CI) ${ }^{11}$}

Del total del registro (148), 134 escuelas recibieron las computadoras del Programa Conectar Igualdad.

\section{$\mathrm{Cl}$ en Escuelas de La Plata, Berisso y Brandsen}

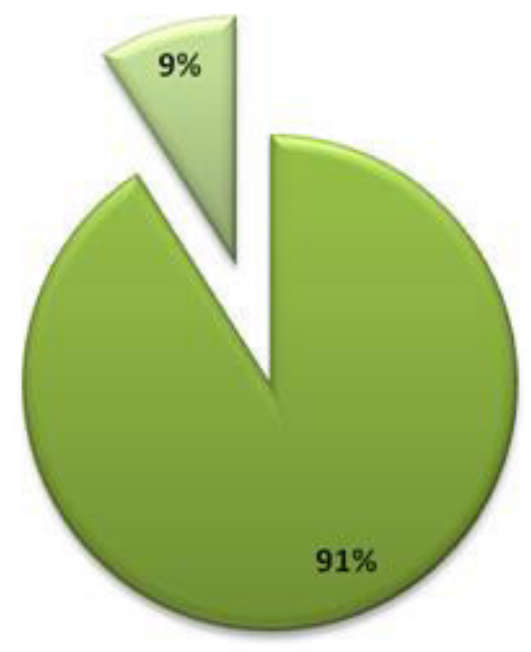

11 La totalidad de los gráficos que se reproducen en este ensayo fueron elaborados por el autor en el marco del proyecto de investigación "Políticas públicas de Inclusión tecnológico/digital. Procesos formativos en escuelas públicas de la provincia de Buenos Aires: TV digital y Conectar Igualdad”. 


\section{Llegada de las netbooks a las escuelas}

Solo en dos instituciones los/as directivos desconocen el año de llegada de las computadoras del CI.

\begin{tabular}{|l|l|}
\hline AÑo & \multicolumn{1}{c|}{ ESCUELAS } \\
\hline 2008 & $\mathbf{1}$ (Escuela Técnica N. ${ }^{\circ}$ 2 $^{\text {"República de Italia") }}$ \\
\hline 2009 & $\mathbf{1}$ (Escuela de Educación Técnica N. ${ }^{\circ}$ 4) \\
\hline 2010 & $\mathbf{8}$ \\
\hline 2011 & $\mathbf{1 2}$ \\
\hline 2012 & $\mathbf{6 6}$ \\
\hline 2013 & $\mathbf{3 4}$ \\
\hline 2014 & $\mathbf{1 0}$ \\
\hline
\end{tabular}

\section{¿En qué año llegaron las Netbook a la escuela?}

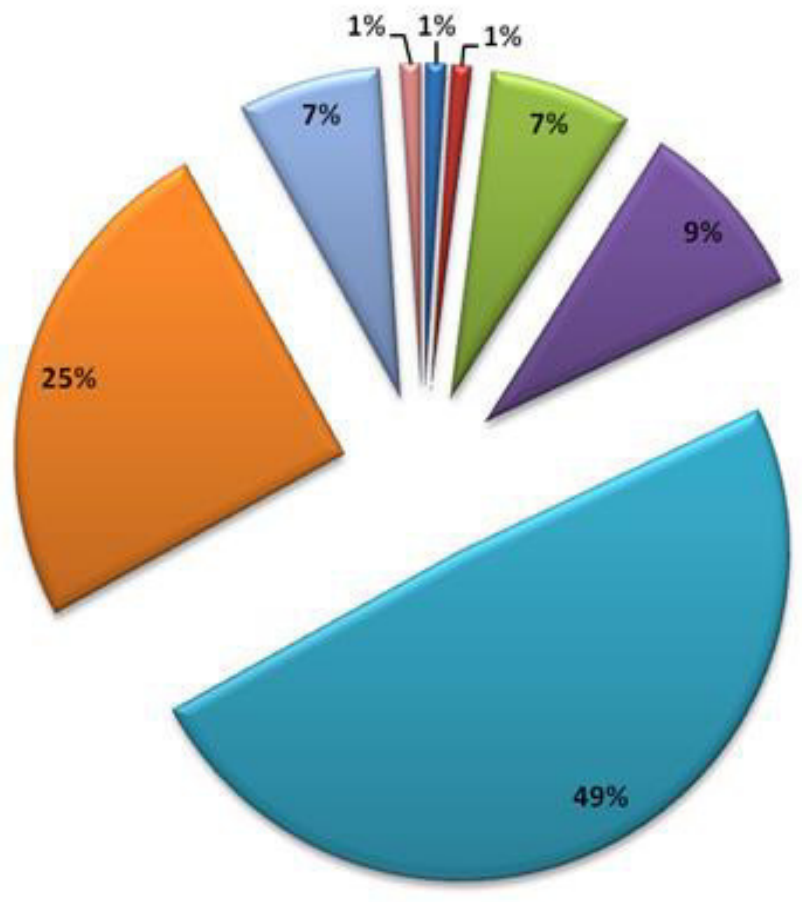

\section{Servicio de Intranet}

Las netbooks del CI se conectan entre sí con un sistema de Intranet: en 129 escuelas del total de los establecimientos con CI (134), Intranet funciona eficientemente. En cinco instituciones con netbooks del CI los directivos afirman "no tener sistema". 


\section{Intranet en las escuelas con $\mathrm{Cl}$}

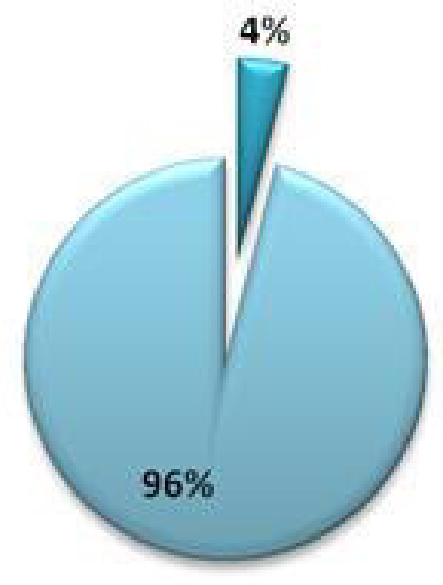

Sin sistema

$\triangle$ Intranet

\section{Reparación de las máquinas}

Del total de escuelas CI (134), 129 directivos afirmó que el servicio técnico arreglaba las máquinas. Cuando estas eventualmente se descomponían, hubo en las escuelas personal a cargo del polo tecnológico que, en general, se encargaba de reparar las computadoras. Cuando el arreglo excedía las habilidades del personal, las máquinas eran enviadas, vía correo argentino, al servicio técnico del CI retornando a la institución aproximadamente tres meses después.

\section{Arreglo de las Net en las escuelas}

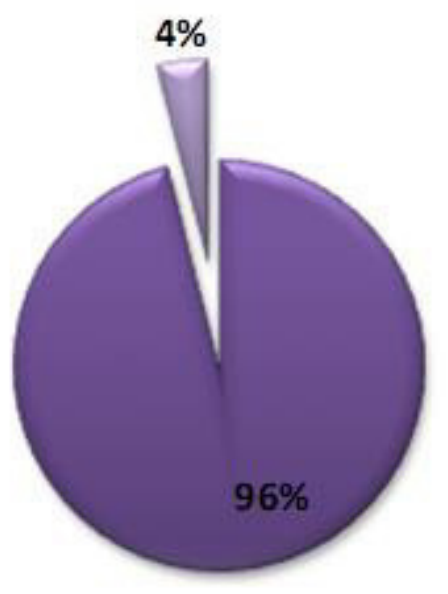




\section{Capacitación a los/las docentes}

En 109 escuelas CI (134), sus directivos afirmaron que los docentes necesitaban capacitación para el manejo de los programas de las computadoras.

\section{Necesidad de capacitación para docentes}

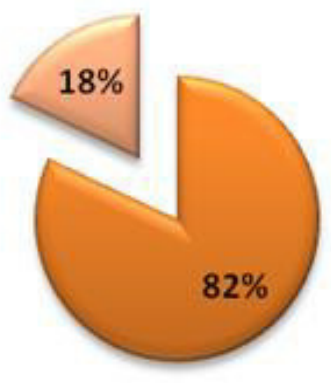

\section{Usos dentro del aula}

En 95 casos, los/las directivos/as desconocían las asignaturas y el uso que se les da a las máquinas dentro del aula.

En 41 casos supieron describir en qué asignaturas eran utilizadas, las principales fueron las siguientes:

\section{Asignaturas}

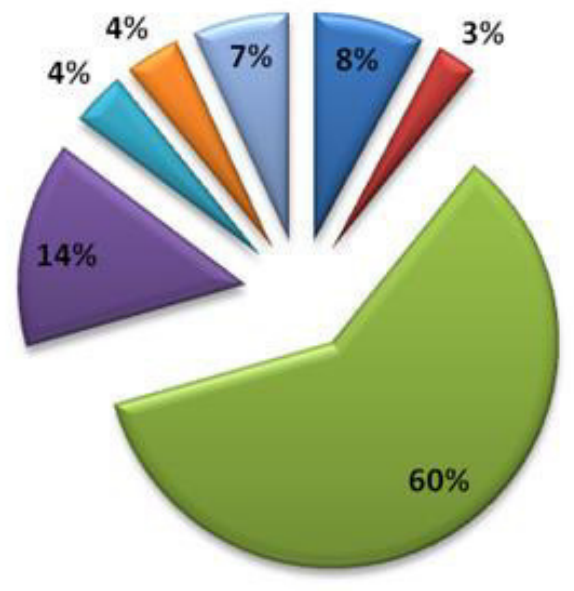

Giencias Naturales

日inglés

No sabe

Gécnicas

Matemática

본 Lengua

$\square$ Ciencias Sociales 


\section{Usos por fuera del aula}

Directivos de 120 escuelas afirmaron que las netbooks son utilizadas por los/las estudiantes y por los/las docentes fuera del aula "para uso personal y capacitaciones".

En 13 de las instituciones que poseen el CI manifestaron no saber sobre su uso por fuera del aula.

\section{Uso de las Net fuera del aula}

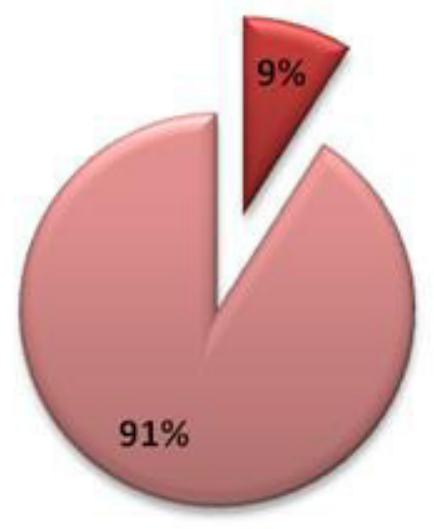

No sabe

ⓤso personal y capacitaciones

\section{Internet en las escuelas}

En 119 instituciones, del total de 148, tenían conexión a Internet.

De ellas, 118 eran clientes de Cablevisión/Fibertel y solo una tenía una conexión municipal.

La empresa ofrecía a través de sus políticas de Responsabilidad Social Empresaria (RSE) conectividad sin cargo y cable a través del "Programa de Inclusión Puente Digital Cablevisión”.

La mayoría solicitó la política de RSE, otras pagaron el servicio como particulares. 


\section{Internet en las escuelas}

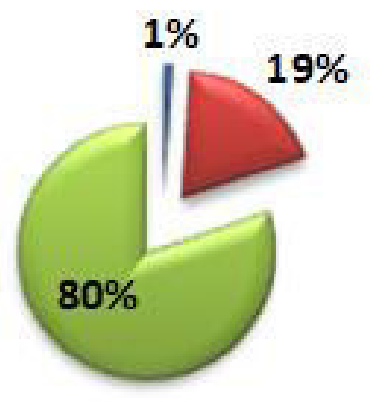

Municipal

No tiene

Fibertel

\section{Programa Mi TV Digital}

En 14 escuelas de las 148 relevadas solicitaron la antena y el decodificador del Programa Mi TV Digital.

En tres escuelas de esas 14 no tenían señal de la TDA.

\section{Mi Tv Digital en las escuelas}

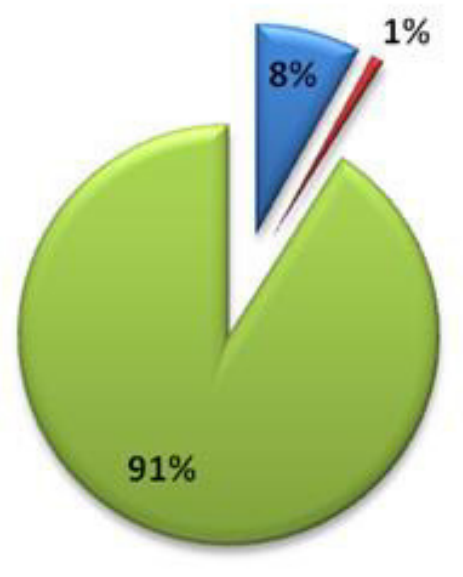

घ Mi Tv Digital con señal

घ Mi Tv Digital sin señal

$\square$ No tiene 
Conocimiento de la política pública

138 directivos, de las 148 escuelas consultadas, conocían la existencia del Programa Mi TV Digital.

En 133 casos dijeron saber cómo solicitarla, pero solo 14 escuelas contaban con el Programa Mi TV.

\section{Sobre el conocimiento de la Política Pública}

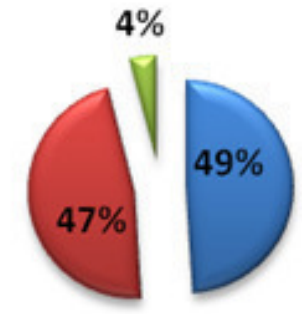

La conocen

四 Saben cómo solicitarla

$\square$ No la conocen

\section{Presencia de televisores}

136 escuelas de las 148 encuestadas disponían de televisores.

\section{Tv en las escuelas}

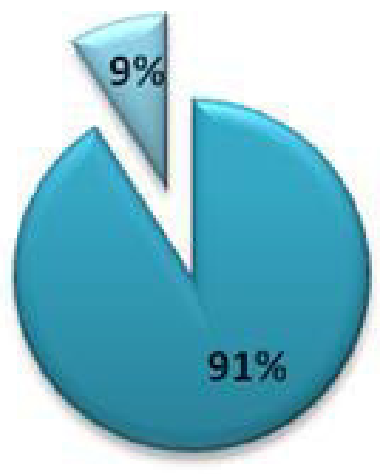


En 130 casos los televisores estaban en el aula y se utilizaban para reproducir materiales editados por los/las docentes (series, películas, documentales).

En cuatro casos en la dirección utilizando el cable y en dos casos en la biblioteca.

\section{¿Dónde está la TV?}

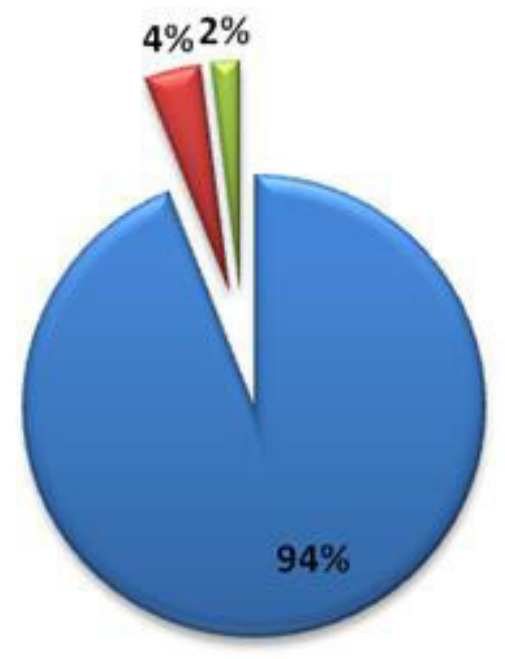

En el aula, materiales enlatados

En la Dirección, con cable

$\triangle$ En la biblioteca

\section{Cable en las escuelas}

De las 136 escuelas con televisión, 129 tenían Internet de Fibertel, de modo que también disponían de Cablevisión.

\section{Cable en las escuelas}

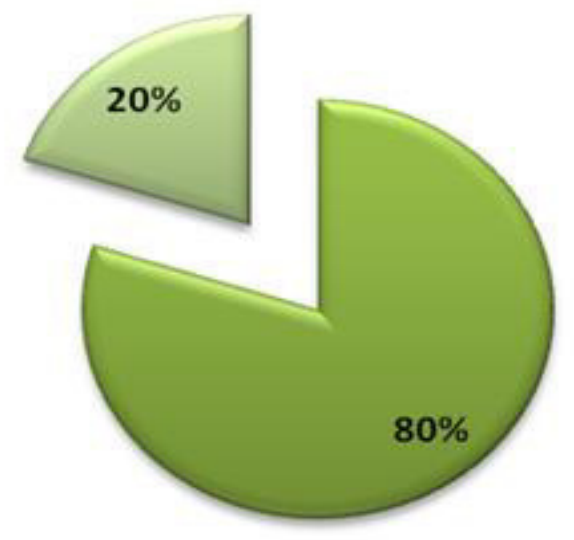

$\square$ Cablevisión

$\triangle$ No 


\section{¿Cómo se mira televisión en las escuelas?}

Según los datos expuestos, $91 \%$ de las escuelas tenía televisión y 80\% contaba con televisión por cable. Sin embargo, en la mayoría de los establecimientos el cable no estaba conectado a la televisión y la televisión estaba en las aulas, pero generalmente desenchufada.

Los televisores se encontraron mayormente en el salón para vehiculizar materiales editados por los docentes, como series, películas y documentales.

En 125 escuelas, sus directivos afirmaron que los/as estudiantes miraban televisión en la escuela mediante la netbook del CI. ¿Pero cómo lo hacían?

Todas las netbooks del CI venían equipadas con contenidos televisivos: Contenidos Digitales Abiertos, Canal Encuentro, etc.

A partir de 2013, las computadoras del CI traían incorporadas la antena de la TDA que permitía ver televisión en vivo. En 41 instituciones las netbooks eran 2013/2014, pero solo seis escuelas poseían el Programa Mi TV Digital y cuatro señal de la TDA, y recordemos que en 119 escuelas, que poseían CI, había Internet.

\section{TV en la Netbook}

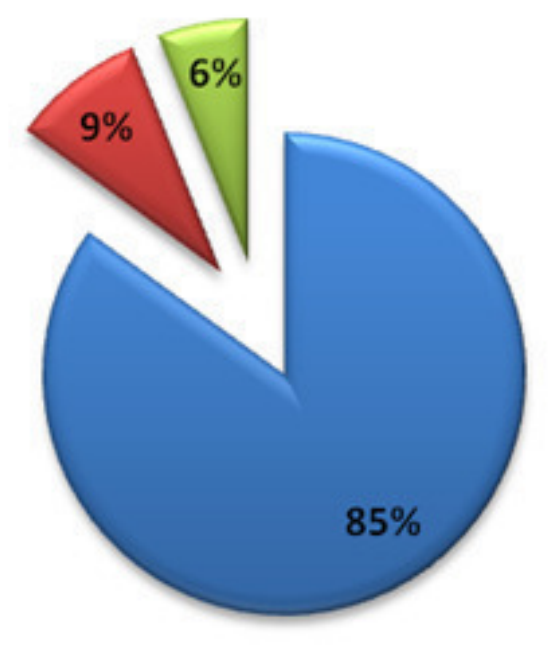

Internet

Mi TV Digital

Mi TV Digital $+\mathrm{Cl}$ con antena 
A modo de síntesis, existen diferentes modos de ver televisión: en diferido, series, youtube, en vivo, etc. Los contenidos que venían con la netbook (CDA, documentales, serie Horizontes, etc.) podían verse en todas las computadoras del CI, con o sin antena. En tanto, televisión en vivo, videos, redes sociales y otros contenidos televisivos no diagramados por CI podían mirarse en el $85 \%$ por Internet.

Es fundamental, aquí, recuperar una de las tensiones que podemos encontrar entre las políticas de inclusión digital desarrolladas y el debate sobre la convergencia tecnológica como fenómeno cultural. Es necesario considerar que la evaluación realizada en 2014, con la posterior relectura realizada para esta tesis, otorga una perspectiva que en principio puede desplegar una serie de análisis críticos tanto sobre el Conectar Igualdad como sobre el programa Mi TV digital, que lejos de inhabilitar la potencia de lo realizado, lo reivindica pero sobre todo para aprender de los errores, en su mayoría provenientes de lo sumamente complejo del contexto.

Hay una confusión que encontramos en las políticas públicas desarrolladas, que tiene que ver con la incorporación de tecnologías en el aula, con el objetivo de reducir la brecha digital, es decir, de incluir socialmente a través de una netbook a quienes no tenían acceso a ella en el mundo digital. Pero considerar que esto puede mejorar el rendimiento escolar, en un sistema que desde su federalización en 1993 sin los recursos correspondientes no logra salir de una aguda crisis, es subestimar drásticamente los problemas de la escuela y sobreestimar la potencia de los aparatos.

Paralelamente el desarrollo y la exploración de nuevos formatos de consumo audiovisual, con la posibilidad de entrada de una nueva televisión en la escuela y en las netbooks del Conectar, fue un modo de ensayar alternativas en un contexto en el cual todo el sistema de producción audiovisual se encontraba en expansión hacia nuevas plataformas. Quizás allí podamos pensar que lo que faltó por un lado es tiempo y por el otro la potencia que competidores de la talla de Netflix o el monopolio Cablevisión-Multicanal, lograron desplegar para ganar una batalla clave como es la de la disputa por la atención humana.

La digitalización de la cultura es un proceso que se encuentra en pleno despliegue y desarrollo, por lo que la articulación de políticas públicas que intenten torcer con las inercias del mercado será sumamente compleja y requerirán de una profunda concepción del contexto, presupuestos elevados y sobre todo de tiempo para configurar cambios que por corresponder a lo más profundo de las formas culturales son lentos y precisan de múltiples estrategias comunicacionales y educativas. 


\section{Algunas experiencias escolares}

La Escuela Secundaria Básica (ESB) N. ${ }^{\circ} 78$ está ubicada en la localidad de Melchor Romero, a dos cuadras del Hospital Neuropsiquiátrico de la ciudad de La Plata, provincia de Buenos Aires. En la zona se hallan dos establecimientos más, uno con Modalidad Agraria y el otro, Técnico Profesional. La institución cuenta con la Orientación en Comunicación, y tiene una matrícula de 400 alumnos, aproximadamente.

Su vicedirectora, Andrea De la Iglesia, nos comentaba que las netbooks comenzaron a llegar al establecimiento a partir de 2010, con la antigua gestión. Cuando asumió en el 2012, tanto ella como la directora actual regularizaron todas las que faltaban y actualmente están al día.

Desde su perspectiva, la implementación de esta política "fue bárbara. Después criticaremos el cómo, de dónde, etc.". La docente cree que es una herramienta que actualmente tanto los profesores como los estudiantes tienen, y que el problema radica en el no saber cómo utilizarla de algunos docentes. Nos decía que el mayor conflicto es "el problema generacional de que el profesor lo sabe todo. Los chicos se sienten menos vulnerables frente al "no sé", y un profesor puede no saber".

A su vez, plantea que para ponerse a trabajar solamente con las net, hay que empezar de cero, "tirar todas las carpetas, y lamentablemente no tenemos capacitaciones en servicio que sirvan". Y agrega: "Nosotros tenemos suerte de contar con gente que sabe usarla, y que busca, trae, prepara, pero no hemos tenido un tiempo suficiente para sentarnos y trabajar todos en conjunto". Asimismo, plantea que desde la dirección y con algunos docentes tienen la intención de generar reuniones con todo el personal para fomentar este tema. Por último, comentaba que llevar a cabo esto les sería de suma utilidad, por ejemplo, para los Proyectos Flexibles, destinados a "adolescentes embarazadas, alumnos que son papás o trabajadores".

Con el ingreso de las net a la escuela, hubo un cambio tanto en las dinámicas de las aulas como en la manera de dar clases. A su vez, a través de talleres con los alumnos sobre el uso responsable de las máquinas, pudieron abordar temáticas como la violencia.

De la Iglesia relataba que "hay muchos profes a los que en primer lugar hay que enseñarles a usarlas y a su vez muchos niños y niñas que es la primera vez que están en contacto con una computadora”. Frente a esto, desde el establecimiento, decidieron comenzar con la primaria "enseñándoles a buscar información, [...] la bibliotecaria hizo 
un blog, donde los chicos se comunican con ella, les busca material... es una forma de llevarlos a ellos a que puedan crear herramientas para ir buscando distintas informaciones".

Paralelamente, en el ciclo superior y con algunos profesores "ya las utilizan con la especificidad de la materia”. La vicedirectora contaba el caso de la materia Práctica del Lenguaje, donde la docente a través del uso de sinónimos y adjetivos, "les propuso hacer una presentación en la compu, de quién era la persona describiéndose la cara. Tuvieron que realizarla, pero teniendo en cuenta que no se podían ver y los compañeros iban escuchando, las Net abiertas, a ver quién era el que estaba hablando. Realmente fue un trabajo de mucho tiempo, y ellos no se dan cuenta de lo que lograron".

Esto implica que es innegable la alteración de las prácticas educativas que genera al menos en este caso la entrada de las netbooks en la escuela, en términos de formas de organización del aula y de abordaje de contenidos específicos curriculares. Las tecnologías, despliegan procesos pedagógicos desatan procesos de subjetivación y nuevas formas de socialidad. Es decir que podemos considerar que estas experiencias aquí mencionadas reafirman la concepción de la necesidad de recuperar el mundo cultural de los sujetos, hoy hipermediado, y desde allí construir estrategias de interpelación que puedan hacer sentido y transformar las rutinas de la educación.

Por otro lado, y en relación con los contenidos audiovisuales que los docentes utilizan en sus clases, De la Iglesia relataba que "muchos de los materiales son de canal Encuentro o distintos programas que se utilizan pedagógicamente". A su vez, comentaba que armaron una sala de video que funciona en la biblioteca del establecimiento donde tanto los docentes como los estudiantes pueden ver los materiales para cada una de sus clases.

Con respecto a los contenidos, la vicedirectora contaba que, por ejemplo, cuando organizaron el acto del 20 de junio, trajeron un programa de Encuentro sobre Manuel Belgrano donde se mostraba qué opinaba la gente. "Abrimos el juego y sumamos a los chicos para preguntarles qué opinaban ellos". A su vez, explicaba que "en todos los actos tratamos de trabajar junto a los chicos con los materiales audiovisuales que nos van llegando desde el Ministerio".

Como mencionamos anteriormente, aquí recuperamos la potencia de las producciones educativas realizadas desde Pakapaka y Encuentro, señales dependientes del Ministerio de Educación de La Nación, que consolidaron otras formas de abordaje de contenidos específicos, que desde el eduentretenimiento y la cultura digital lograron integrarse en las rutinas escolares. 
La Escuela Técnica N. ${ }^{\circ}$ "Albert Thomas", está ubicada en la calle 1 entre 57 y 58, dentro del casco histórico de La Plata, en el ingreso al bosque platense, en una zona de grandes instituciones educativas. Es un edificio muy grande de construcción antigua, que alberga a 1.500 estudiantes en cinco Orientaciones: Industrial, Electrónica, Construcción, Electromecánica e Industrias de Procesos. Su director, Sergio Figueredo, a quien entrevistamos, nos aportó las siguientes impresiones.

Sobre el Conectar Igualdad manifestó: "Nos llegaron las computadoras por primera vez en el año 2010 y fueron llegando consecutivamente todos los años. Las usan tanto en el ciclo básico como en el superior. En el superior las usan más por el tema de los programas que se utilizan en cada especialidad. En Electrónica, Química, Construcción, se cargan programas nuevos. De igual forma los profesores traen los contenidos en un pen drive, así por ejemplo, las computadoras son usadas igual”.

Esto nos habla del compromiso de algunos docentes con el uso de las computadoras como capital fundamental en el aprendizaje de los estudiantes, además de la especial utilidad que en las escuelas técnicas tiene la computadora con la utilización de programas especiales.

"En los recreos se la pasan jugando al Counter Strike, usando redes sociales, etc. Las compus son de los chicos, se las llevan a sus casas y las traen todos los días para utilizarlas en clase", señaló el director del establecimiento.

Figueredo nos habló, también, de la necesidad de "poder poner internet en toda la escuela para poder manejar mayor cantidad de contenidos”. Actualmente, a través de la cooperadora, se abona el servicio de Fibertel 6 megas: "Antes había un mega y no alcanzaba para un colegio como este".

Las escuelas técnicas en lo que refiere a la capacitación de los docentes y a la reparación de las máquinas poseen una ventaja: sus profesores, al tener profesiones afines al uso de las computadoras, en general no necesitan capacitaciones. "Sucede que en el ciclo básico la mayoría de los docentes maneja el tema de las computadoras y en ciclo superior más aún porque son ingenieros, arquitectos, etc. y la parte de dibujo la manejan ellos”.

Y sobre las reparaciones, indicó: "Si el daño es en el sistema se reparan acá mismo; si tiene que ver con roturas físicas se tienen que enviar para ser reparadas; por este camino tardan entre uno o dos meses". 
La escuela posee instalaciones tecnológicas de última generación: "Tenemos una red interna, el piso tecnológico funciona muy bien”. Tienen una sala de informática muy completa, computadoras de última generación, internet acorde a la amplitud de los espacios y una pantalla gigante en un salón muy grande conectado a Mi TV Digital. Este dispositivo "fue preparado especialmente para el Mundial. Allí transmitimos los partidos de Argentina cuando coincidían con los horarios de clase”.

Los docentes no utilizan el programa Mi TV digital para ver tele en las computadoras. En las compus se miran videos de la CDA o material llevado por los/las docentes. "Se usa mucho en Historia y Geografía, en el básico. Por ejemplo, los videos de Felipe Pigna en Historia".

La escuela, tal vez por su especialidad, tiene una excelente predisposición al uso de tecnologías.

También entrevistamos a la vicedirectora, Diana Vázquez, docente de Electrónica. Diana tiene unos 55 años, cerca de 35 años de profesión y dice lo siguiente acerca de las computadoras del Conectar: "Me parecen perfectas, están muy bien. Son fundamentales. Te permiten dar clases dinámicas, a ellos (los estudiantes) les facilita el tomar apuntes".

Diana es profesora de Lenguaje Electrónico y Sistema de Comunicaciones. "Los chicos elaboran todo en la computadora, porque sería muy denso tomar nota a mano. Así que hacen las tareas y me las envían por correo electrónico. Por mi parte, la información que yo tengo y la bibliografía también se las mando por correo", señaló.

Diana también nos contó que en sus materias sin computadora prácticamente no pueden trabajar: "Nosotros utilizamos un programa de Diseño gráfico, de diseño de circuitos electrónicos; se trata de un diseño asistido con computadora. Este del que te hablo es un programa de Conectar que utilizo mucho, aunque también usamos programas complejos que no vienen con la compu, así que les doy una consigna, vamos trabajando y nos ayudamos".

Y finalizó diciendo: "Los chicos tienen una muy buena predisposición. El trabajar con las computadoras les da otra motivación. Si bien usan las computadoras para trabajar en clase, a la vez utilizan las redes sociales. Siempre llevan y traen las computadoras. En caso que no las tengan, doy la clase en la sala de Informática porque no podemos trabajar sin la herramienta". 
La relación del equipamiento entregado desde el Plan Conectar Igualdad y Mi Tv Digital, con la educación técnico profesional es contundente y no es casual que esta modalidad escolar sea de las que primeramente recibieron todo el denominado piso tecnológico. La articulación de una enseñanza específica con las herramientas correspondientes es otra de las claves que debemos destacar. Formar sujetos en entornos que se correspondan con los horizontes de inserción laboral, en este caso técnicos electromecánicos, eléctricos, electrónicos, mecánicos, etc., afianza lo que se releva sobre el final como motivación de los estudiantes pero que en realidad se logra a partir de la percepción de la pertinencia entre campo del conocimiento abordado, herramientas utilizadas y horizonte profesional.

La Escuela Secundaria Básica (ESB) N. 49 está ubicada en la localidad de Abasto, partido de La Plata, sobre la ruta 36 a la altura del Km 45. En el mismo edificio funcionan el Jardín de Infantes y una cooperativa de trabajo escolar llamada "Amasando futuros". Actualmente cuenta con una matrícula de 249 alumnos, y posee como orientaciones Economía y gestión y Educación Física.

El director del establecimiento, Marcos Rosenfeld, nos contaba que las netbooks comenzaron a llegar a partir del 2013 de manera consecutiva. En relación al uso dentro de las aulas, relataba que "hubo muchos intentos de uso, porque se frustran en el medio por distintos motivos o a medias un grupo las usa, el otro la tiene rota, etc. Igual una profe demostró que si quiere, si está convencida, lo logra”.

La docente de Arte daba clases en sexto año, donde tenía 18 alumnos. Su intención era trabajar el lenguaje multimedial y la animación, pero que cada estudiante pueda hacerlo con una computadora. Por esta razón, y a través de la gestión que hicieron el Director junto con el Encargado de Medios de Apoyo Técnico-Pedagógico (EMATP) habilitaron las máquinas que les hacían falta para poder llevar adelante el trabajo. Rosenfeld nos relataba que "le llevó cuatro clases que se centralice el trabajo y que cada chico tenga su compu, costó, en el medio hubo paros, fueron más de cuatro clases, pero hizo un trabajo muy lindo multimedial y de animación".

Por otro lado, el director se propone desde el establecimiento que se trabaje de forma colaborativa y colectiva entre los diferentes docentes junto a los estudiantes. De esta manera, la profesora de Plástica junto con el docente de Arte elaboraron un trabajo donde les propusieron a los chicos "una serie de poemas latinoamericanos propios del 
contenido que tienen que trabajar. Pusieron sobre la mesa 120 poemas, los chicos leyeron uno por uno, trabajamos en forma comunitaria, en formato de taller (como institución nos proponemos que esas prácticas se institucionalicen un poco más). Cuesta, hay que romper un montón de estructuras sobre todo con los profes, y se llegó a elaborar dos ejemplares en papel con encuadernación, con ilustraciones hechas por los chicos con serigrafía y todo ese trabajo lo hicieron los chicos por medio de las Net, las impresoras de la escuela, escanearon y encuadernaron".

Frente a esta experiencia, Rosenfeld comentaba que el objetivo para este ciclo lectivo es que los chicos digitalicen esas producciones. A través de este proyecto trabajaron "el profe de literatura y de plástica en un programa de forma paralela y pusieron en práctica no solo una técnica de ilustración, como la serigrafía, sino que después usaron las tecnologías como para poder terminar el producto y ahora se proyecta usarlas para tenerlas también digitalizadas y que se usen en otras escuelas".

Por otro lado, el director nos contaba que en la escuela no tienen cable, pero que al venir las netbooks con la antena de la TDA, los chicos ven programas desde ahí. A su vez, esto posibilitó que "en la época del Mundial las usaran para mirar los partidos. Entonces eso permitió que no hubiera ausentismos". Asimismo, en el establecimiento cuentan con tres televisores que son utilizados frecuentemente por los docentes sobre todo cuando dan contenidos específicos que pasan películas o programas, y muchos de ellos "sobre todo de sociales, trabajan con contenidos de canal Encuentro y los traen en sus compus para que los chicos los vean".

El director remarca que cuando comenzaron a llegar las netbooks no se dictó ninguna capacitación que les enseñara a los docentes a utilizarlas, y que eso dificultó en muchos casos que se comenzaran a generar actividades con ellas. Por esta razón, Rosenfeld decidió ponerse "en contacto con una profe de exactas de otra escuela, y va a venir a darnos dos módulos para capacitar a las profes de esa área y después buscar un referente que pueda brindarles los conocimientos del uso".

En relación con las políticas públicas de inclusión, el docente plantea que "hay dos cosas que cambiaron: los recreos los hicieron más tranquilos... Algunos escuchan música, otros juegan a los jueguitos. Y la otra es que en el aula pasa lo contrario. Para mí no es una computadora, es una herramienta de trabajo". 
A su vez, considera que "para trabajar en la mayoría de los lugares tienen que saber utilizarlas. Entonces jugando, dibujando, aprenden a hacerlo. Por eso, uno a veces contextualiza los contenidos como para que de determinada forma se den otros con otras herramientas para un objetivo: prepararlos como ciudadanos, para un trabajo, para los estudios superiores".

Estas apreciaciones suman nuevamente la necesidad de revalorizar la entrada de dispositivos tecnológicos, que en muchos casos por falta de resistencia y de capacitación no siempre impactan desplegando todo el potencial que poseen para alterar las dinámicas escolares. Pero de todas formas con proyectos diferentes y alternativas a la didáctica tradicional se visibilizan elementos que tanto docentes como autoridades recuperan y valoran notablemente.

Quizás aquí también sea necesario destacar que aunque fue masiva la entrega de netbooks y la entrada de Mi Tv Digital, es necesario dar continuidad y reforzar durante mucho tiempo las estrategias para que realmente los cambios sean profundos, significativos y recuperen todo el potencial de la cultura digital.

\section{A modo de síntesis}

Según el relevamiento realizado en esta investigación, 91\% de las escuelas consultadas recibió las computadoras del Conectar Igualdad, dato que acompaña las cifras oficiales que afirman que la política Conectar Igualdad, hasta diciembre de 2014, distribuyó en La Plata 6o.969 netbooks en 143 escuelas.

La principal distribución de las máquinas se realizó en 2012, cuando se repartió casi 50\% de las netbooks que hoy pertenecen a los/las estudiantes y a las/los docentes de la escuela secundaria pública. Estas computadoras no poseen la antena de la TV Digital Abierta.

Con respecto al funcionamiento de las máquinas, repasemos dos variables: Intranet (conexión intrasistema) funciona eficientemente en $96 \%$ de los casos consultados. En relación con el mantenimiento de las computadoras que sufren roturas, la proporción es idéntica: $96 \%$ de los/las directivos/as asegura que las máquinas son reparadas.

Estos datos conforman un contrapunto al supuesto con el cual llegamos a las escuelas: un imaginario negativo respecto al funcionamiento y el mantenimiento de las máquinas. 
Sin embargo, en relación con la capacitación de las/los docentes, quienes son los/las encargados/as de guiar los procesos educativos áulicos, el relevamiento confirmó la sospecha: según los/las directivos/as, en $82 \%$ de las escuelas consultadas las/los docentes necesitan capacitación.

Es importante resaltar que desde el gobierno nacional se generaron capacitaciones subvencionadas para docentes, es decir el Estado Nacional les pagó a las/los docentes para que asistan a las capacitaciones. El Estado Provincial, por el contrario, no ha acompañado suficientemente este proceso.

Es importante remarcar que las netbooks también llegan para los/las docentes y que las computadoras son utilizadas para cuestiones personales y/o capacitaciones. El espíritu de la política pública es la distribución de netbooks para la inclusión digital, y esto no es solo aprender programas contables en matemática o mapas de geografía en el aula, también es para las prácticas cotidianas de la vida: las capacitaciones, las redes sociales, la escritura de trabajos y de cartas, la televisión, el diario, las películas y la radio, tanto de las/los docentes como de los/las alumnos/as.

En este sentido, según los/las directivos del 91\% de las escuelas consultadas, las compus fueron utilizadas para "uso personal" en la institución, por fuera del contrato de enseñanza-aprendizaje que tiene lugar en el aula.

Respecto del uso de las netbooks dentro del aula, los talleres en Escuelas Técnicas llevan la delantera. Si bien 6o\% de las/los directivos no saben qué hacen con las compus en el aula ni en qué materias las utilizan, generalmente en los establecimientos técnicos tienen una relación más cotidiana con las tecnologías, por ejemplo todas las escuelas técnicas relevadas (13 de 148) poseen Conectar Igualdad, funciona bien la Intranet e Internet, tres de ellas cuentan con Mi TV Digital y todas poseen televisor en la escuela.

Respecto al servicio de Internet en las escuelas, nos hemos encontrado con un dato políticamente fuerte: $82 \%$ de las escuelas consultadas poseen Internet. De estas, $99 \%$ son clientes de Fibertel/Cablevisión. Una eficaz política de Responsabilidad Social Empresaria cubre casi la totalidad de las escuelas que poseen Internet.

Dos cuestiones a tener en cuenta: por un acuerdo político económico, el entonces intendente de la ciudad de La Plata, Pablo Bruera, no permitía el ingreso de otras empresas que le disputaran la hegemonía a la empresa Fibertel/Cablevisión del Grupo Clarín. Un ejemplo de este acuerdo es la negativa a la habilitación para operar del Grupo 
mendocino Telecentro. A cambio, Cablevisión/Fibertel ofrecía el servicio de Internet y cable de manera gratuita a las escuelas públicas, afianzando por medio de esta política de comunicación externa su legitimidad y su estatus empresarial. ${ }^{12}$

Con respecto al Programa Mi TV Digital solo 14 escuelas, lo que representa $9 \%$ del total de establecimientos consultados, ha solicitado el Programa. Es, claramente, un resultado negativo para la política pública. Incluso, en tres de esas 14 escuelas no hay señal de la TDA.

Creemos que un dato fundamental sobre estos números es la estrategia de recepción de Mi TV Digital. A diferencia del Conectar Igualdad, que llega a las escuelas como un derecho al acceso tecnológico/digital de los/las estudiantes y de las/los docentes; el Programa Mi TV digital debe ser solicitado por las escuelas mediante un formulario en línea.

Creemos que esta estrategia de recepción es equivocada, pues históricamente la escuela rechazó la televisión por considerar que su contenido no era educativo. De modo que esperar a que los/las directivos soliciten la política pública no es una buena metodología para la democratización del programa. Incluso, en algunos casos aseguraron que los contenidos de Mi TV Digital eran los contenidos de La Cámpora que vienen a colonizar la escuela.

La mayor cantidad de solicitudes de Mi TV Digital se produjo en vísperas del Mundial de Fútbol Brasil 2014.

En $32 \%$ de las escuelas consultadas, las netbooks son 2013-2014, por lo que poseen la antena que capta la señal de la TDA, pero solo 6\% de esas escuelas tiene señal de la TDA.

Un dato llamativo es que las 14 escuelas que poseen Mi TV Digital tienen también Conectar Igualdad y en todas funciona eficientemente la Intranet. A su vez, 11 también tienen Internet, mientras que 12 no poseen Internet, tampoco Conectar Igualdad ni el Programa Mi TV Digital.

Veamos, entonces, la relación de la escuela con la televisión:

- 91\% de los establecimientos recibió televisores. De ellos, 80\% cuenta con televisión por Cable (sin embargo, este dato no supone que esa televisión se use ni mucho menos que se analicen los contenidos en clase).

- En 93\% de los casos la televisión está en las aulas pero sin el cable; eventualmente se transmiten videos y documentales preseleccionados por los/las docentes. 
- Según las/los directivos, los/las estudiantes miran televisión por la netbook, al margen de la propuesta curricular formal. La pregunta es cómo lo hacen.

De esta forma, podemos afirmar también que un complemento importante para las políticas mencionadas que favorezca la inclusión y que disminuya la brecha digital se relaciona con democratizar el acceso a Internet.

Igualmente, esto no invalida en lo más mínimo lo realizado; creemos que la distribución material de las máquinas es una política fundamental y prioritaria, es decir lógicamente antes de Internet es importante que estén las computadoras; y tampoco negar los procesos actuales como la conquista de la soberanía energética a través de la creación de Arsat, pero creemos que las computadoras del Conectar Igualdad con Internet en las escuelas inauguran un sinfín de potencialidades, por eso también es importante en función de esta idea disolver los monopolios de la comunicación.

Las políticas de derrame del Grupo Clarín no pueden protagonizar el sentido del Conectar Igualdad en las escuelas públicas.

Internet es hoy la conexión vital de toda organización, incluso para ver televisión. La convergencia digital que se estipula para 2019, sumada a la direccionalidad del capital hacia Internet, abona la idea de que el cable tal como lo conocemos ahora, desaparecerá. La televisión se verá más por Internet que por su soporte tradicional, al igual que la radio. Por ello, celebramos la democratización de las computadoras del Conectar Igualdad, los decodificadores y las antenas del Programa Mi TV Digital, pero insistimos en la lucha contra los monopolios y la democratización de Internet.

Sobre todo, reivindicamos el programa Conectar Igualdad como algo que era necesario hacer —e, incluso, imprescindible y urgente-, para disminuir la brecha social que se produce cuando un niño no tiene la posibilidad de acceder al tren de la historia y se siente marginado en el andén. Pero, al mismo tiempo, pensamos que ese programa debió ser acompañado con estrategias de formación, más allá de las desplegadas desde el Instituto Nacional de Formación Docente, del Ministerio de Educación de La Nación, con la Especialización Docente en Educación y TIC que cursaron más de cuatrocientos mil docentes, dando un fuerte acompañamiento a las escuelas, sumando otras formas de capacitación y, sobre todo, luego de que fuera cerrado el programa en 2017, a tiempo para su fortalecimiento, evaluación y redireccionamiento en relación con los resultados obtenidos. 
La clausura del programa y su reemplazo por políticas autodenominadas modernizadoras que solo conciben la tecnología desde la conectividad y no mediante el equipamiento, dan por tierra lo realizado sin reemplazarlas por alternativas seriamente planificadas. Esta visión hace parte de un desprecio por la inversión pública y la noción de Estado como garante de derecho. Antes bien, entiende que el Estado es un garante del sector privado cuyos servicios de alto costo y los avances tecnológicos pueden ser sostenidos por usuarios en condiciones para afrontar este tipo de necesidades cubriéndolas por sus propios medios.

En este sentido, las grandes mayorías sociales más que un problema de exclusión lo que viven es un proceso de pauperización y condena a la subalternidad cultural, educativa. El esfuerzo realizado entre 2010 y 2017 , favorable para la democracia, la justicia social y la igualdad se ve de este modo afectado, pero sobre todas las cosas es condenar a la desigualdad a un sector sustantivo de la sociedad. La nueva gestión de gobierno iniciada en 2015 habilita el relato moderno que deja a más de la mitad de los argentinos y de las argentinas sin posibilidades de idear formas de uso y apropiación de las tecnologías y de participar de la toma de decisiones respecto de la sociedad en la que quiere vivir que cada día más se encuentra hipermediada.

Podemos afirmar, incluso, que mientras las visiones tecnocráticas invierten cada vez más en robótica, informática avanzada e interfaces educativas, una visión neoliberal de la educación que la considera un gasto achica costos, incluso, contradiciendo en muchos casos lo que desde las perspectivas pedagógicas liberales se suele promover.

Es necesario recuperar estos programas, aprender de ellos, desarmarlos y repensarlos al calor de lo que el contexto actual de digitalización de la cultura comienza a mostrar, ya que la seriedad y el profesionalismo con el que se desarrollaron las políticas públicas aquí analizadas así lo ameritan, sobre todo, si queremos recuperar la potencia de las instituciones educativas desde lo que por algunos breves años se logró implementar. 


\section{Encuentro y Pakapaka Experiencias que marcan la historia}

Dentro del campo de comunicación / educación, la tradición de abordaje de los medios educativos es central y está en su matriz de surgimiento, sobre todo en América Latina. Experiencias como las de Radio Sutatenza, en Colombia, o las de Radios Educativas Mineras, en Bolivia (Villamayor, 2014), fueron centrales para el desarrollo de una reflexión profunda y certera sobre la capacidad de interpelación que poseían estas tecnologías y sus implicancias en los procesos de subjetivación.

Es por ello que necesitamos reconocer dos casos excepcionales que en la Argentina dieron luz al surgimiento de una televisión educativa, no comercial, que buscó construir ciudadanía e interpelar sin una lógica comercial.

Canal Encuentro, primero, y Pakapaka, después, dos señales televisivas dependientes del Ministerio de Educación de la Nación, nacieron al calor de nuevas concepciones sobre lo comunicacional y su necesaria implicancia en la educación. Debemos hacer referencia entonces a dos canales que rompen con la lógica del mercado, gracias a una fuerte inversión pública, y dan lugar a esos otros relatos que en el mundo de la comunicación fueron posibles de la mano de la Ley 26.522 de Servicios de Comunicación Audiovisual (LSCA), de 2009, y de los cuales es fundamental aprender para volver a imaginar.

En el contexto que venimos narrando, donde la cultura se hace digital, es fundamental repensar cómo desde las políticas públicas comunicacionales / educativas es posible intervenir en escenarios de disputa por las formas de reconfiguración de lo social.

La televisión argentina no solo revolucionó por su formato digital, sino que incorporó nuevos contenidos que desafiaban saberes establecidos a partir de marzo de 2007 con la creación de Canal Encuentro. A partir de allí, convergieron de diferentes formas proyectos que vinculaban de manera novedosa las funciones tradicionales de la televisión: entretener, educar e informar. 
En este punto, los sentidos formativos orientados a lo pedagógico comenzaron a tener más protagonismo a partir de la sanción de la LSCA, y luego con la creación de la TDA, ${ }^{13}$ ambas en 2009, como el marco en el cual se configuraron nuevas reglas de juego para el mercado comunicacional, junto a relatos democratizadores que condujeron a pensar la televisión como un espacio participativo y de construcción ciudadana (Villamayor, 2011). Es por ello que es necesario reconfigurar marcos de interpretación de la dimensión formativa de los medios de comunicación en general y de la televisión en particular, que nos permitan pensar estrategias en el contexto de la convergencia, pero que no se realicen en el vacío sino retomando procesos extraordinariamente significativos y que quizás no fueron lo suficientemente valorados en su tiempo.

Paralelamente, es necesario decir que ambas señales abordaron con contundencia la propuesta de núcleos de producción que derivaron en múltiples plataformas. Incluso con el caso de la dirección de convergencia de Pakapaka, se puede establecer una perspectiva de vanguardia en la propuesta y en las formas de construcción de múltiples relatos, destinados a soportes diversificados que en muchos casos rompieron incluso en su momento las lógicas del hacer televisión.

\section{El edu-entretenimiento}

Para hablar de televisión, partamos brevemente de un concepto muy simple pero que también es de carácter ordenador para presentar un análisis de las señales mencionadas.

La conceptualización de edu-entretenimiento (E-E), o su reducción edutenimiento, no evoca un solo significado, como suele suceder en estos casos; más bien remite según el contexto a diversas acepciones. En este sentido, cada una de las definiciones enfatiza una etapa de la conceptualización, de forma tal que se han generado debates y discusiones en todo el mundo, expandiendo de ese modo el concepto original, a saber: un neologismo derivado del inglés edutertaiment, referido a espectáculos, shows, eventos, programas de radio y televisión que en su propuesta, fundamentación, programación y forma presentan contenido educativo a través del entretenimiento (Gonzalez, Pauloni \& Codoni, 2016).

13 Para una detalle del proceso de la TDA, ver en el libro compilado por la Dra. Silvina Pauloni, Tv digital : un diálogo entre disciplinas y multipantallas (2013), los capítulos: "TV Digital, un nuevo modelo cultural”, de Osvaldo Mario Nemirovsci, y “Contextos y conceptos sobre la TV”, de Silvina Pauloni y Sebastián Novomisky. 
En la variedad de definiciones del término, la noción de Singhal (1990) es la de disponer de contenido educativo en los mensajes mediáticos de entretenimiento. Parafraseando a Wallden (2004), edu-entretenimiento son programas que utilizan diversos medios para incorporar mensajes educativos de forma entretenida, o sea, que educan entreteniendo (Marcos Américo, 2015). Por otra parte, Belén Mainer Blanco (2006) lo define como un producto que además de entretener, potencia la maduración del ser humano pues afecta al cambio de comportamiento del saber, al intelecto, al desarrollo motor, a lo afectivo y a lo social. De manera más generalizada, para Tufte (2004) el edu-entretenimiento consiste en la utilización de formatos mediáticos y comunicacionales de entretenimiento con fines educativos, que puede abarcar desde el uso del teatro y conciertos musicales hasta radio/telenovelas. El mencionado autor junto con Obregon (2008) establecen una cronología de la génesis del concepto a partir de productos audiovisuales destinados a niñas y niños como "Popeye, el marino" (EE.UU., 1934), "The Archers" (UK, década del cincuenta), "Simplemente María" (Perú, 1969), novelas de Miguel Sabido (México, a partir de 1970) y el desarrollo del E-E como estrategia en shows, radionovelas, programas de televisión, aplicaciones para computadoras y videojuegos (Pauloni, Novomisky, Codoni \& Gómez, 2016, pp. 48-49).

En esta línea, las producciones pueden considerarse educativas si se tiene en cuenta su contexto histórico y cultural; por ejemplo, las novelas latinoamericanas como la peruana "Simplemente María", distribuida y reversionada en distintos países a partir del original argentino de Celia Alcántara, plantea cierto empoderamiento de la mujer en el mundo del trabajo y la planificación familiar. Estos tópicos fueron retomados en otras telenovelas del continente.

Un ícono fundacional del edu-entretenimiento es el programa "Sesame Street" (conocido en Latinoamérica como "Plaza Sésamo") que fue estrenado en la televisión pública norteamericana NET (actual PBS, Public Broadcasting Service) en 1969, con 37 temporadas y distribuida en 120 países. En este escenario, muñecos animados creados por Jim Henson enseñaban a los niños nociones de lectura, matemática, los colores, números, días de la semana, y aspectos básicos de la vida social como cruzar la calle o la higiene personal. 
Hacia una complejización del concepto, Thomas Tufte (2004) señala que los procesos de edu-entretenimiento se dan en tres generaciones: la primera está relacionada con el mercadeo social y la planificación familiar, enfocada a los cambios de conducta individual, donde son expertos quienes se encargan de los contenidos y la producción de los mensajes; la segunda incorpora y valora la participación de la comunidad en el proceso y combina el uso de medios con el aporte de organizaciones; la tercera se ocupa de la identificación de los problemas y el desarrollo de capacidades para resolverlos, integrando herramientas de debate e incidencia en políticas públicas.

Estas últimas corrientes se pueden vincular con el pensamiento de Paulo Freire (Tufte, 2004), desde un enfoque comunitario de diálogo que piensa a la comunicación de manera horizontal y ya no como mera transmisión de información. Mediante formas de educación no formal se valen de nuevos formatos y lenguajes, articulando procesos de empoderamiento de las comunidades a través de una pedagogía que promueve la empatía, el reconocimiento de las diferencias y el respeto por el otro, en el fortalecimiento del tejido social. A su vez, estas producciones plantean la formulación de preguntas que alientan la reflexión y el debate en distintos espacios. De esta manera suelen utilizarse en diferentes contextos de la educación formal o no formal.

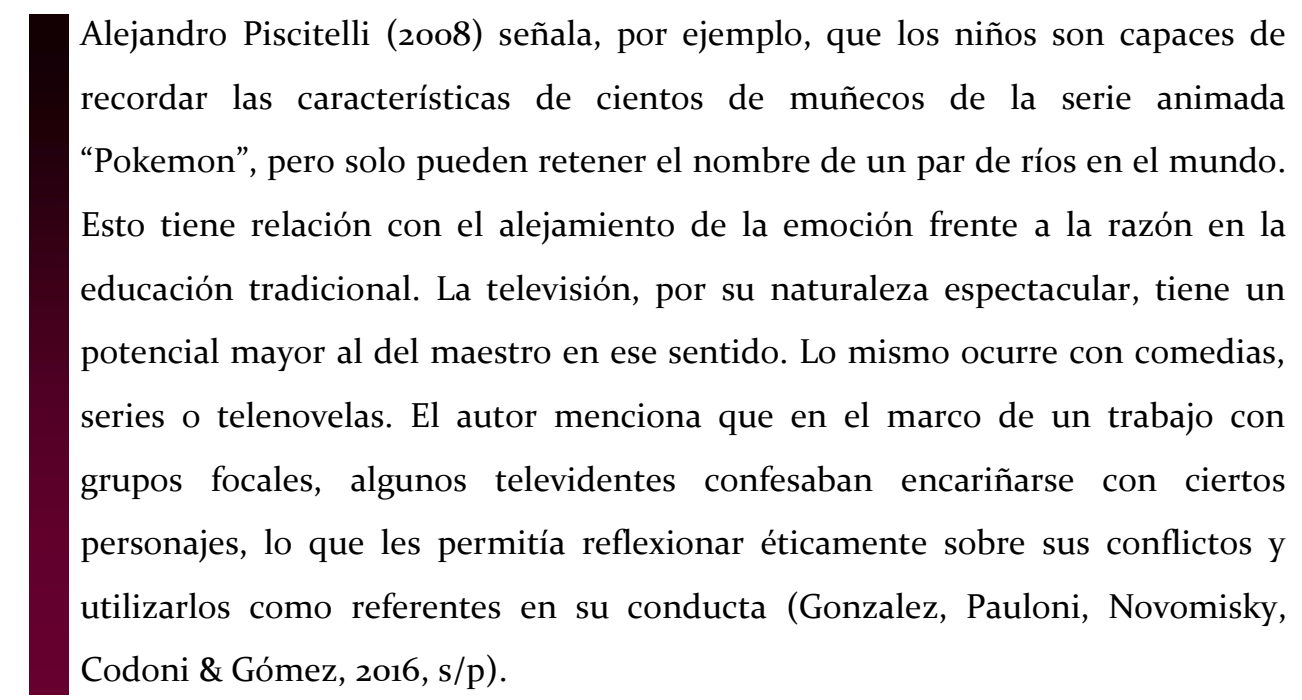

Por eso, "el entretenimiento se convierte en un modo de educarse también en la medida en que se consumen valores y significaciones, que pretenden articular simbólica, afectiva y racionalmente" (Quiroz, 1984, p. 98). Más que la aprehensión de datos por parte del televidente —al modo de la educación bancaria_, la televisión puede proponer los insumos simbólicos para la construcción del propio mundo. 
Este enfoque del edu-entretenimiento es considerado de importancia especialmente en el contexto de la relación entre globalización y modernidad, con los consecuentes sentimientos de incertidumbre y subjetividades inestables que se producen en esta trama, como caracteriza Arjun Appadurai ([1996] 2001). En las coyunturas locales, estas formas de edu-entretenimiento se volvieron útiles en el paradigma de la comunicación que tenía como principios el acceso abierto a los medios y el reconocimiento de las diferencias en un marco de diálogo y respeto por el otro, de manera que se pudiera articular las voces de los grupos sociales antes relegados y promover la movilización para la reconstrucción del tejido social. Además, en la actualidad el creciente uso de las TIC se fusiona con las prácticas del edu-entretenimiento, no solo en las distintas etapas de producción sino también en las relaciones de interacción.

Entonces, el concepto que aquí presentamos tiene que ver con dar cuenta de una mirada educativa sobre los procesos de comunicación social, especialmente enfocados en este caso en la televisión, pero que por el contexto en el que se dieron, derivaron en una lógica de multipantallas.

\section{Sobre Educ.ar S.E.}

Para conocer el origen de las señales Pakapaka y Encuentro, debemos rastrear al menos brevemente el recorrido de un espacio estratégico, que fue tomando diferentes lugares desde su creación, hasta que en 2003 logró articular una potencia fundamental como para sostener desde allí procesos de relevancia como los que estamos mencionando.

Educ.ar es una Sociedad del Estado creada por el ministerio de Educación de la Nación en septiembre de 2000, durante la presidencia de Fernando de la Rúa, mediante fondos de la fundación Varsavsky. Fernando, el hijo del expresidente, fue el impulsor y el director ejecutivo del portal, cuyos fines iniciales incluían conectar a las 40.000 escuelas del país, el desarrollo de contenidos y la capacitación docente. Durante sus primeros años no se avanzó demasiado en cuanto a los objetivos planteados, ya que según el plan original debían conectarse unas 7.00o escuelas hacia fines de 2001 pero solo se abrieron licitaciones para unas 5.000 (San Martín, 28/06/2003).

Durante la presidencia de Eduardo Duhalde, con Graciela Giannettasio como ministra de Educación, se buscaron inversiones de empresas privadas y la asociación con universidades y gobiernos locales para la conectividad en las escuelas. Sin embargo, Educ.ar se mantuvo sin grandes cambios. 
En julio de 2003, bajo la presidencia de Néstor Kirchner, el proyecto fue relanzado con financiación del Banco Interamericano de Desarrollo (BID). El ministro de Educación, Daniel Filmus, planeaba que cuando llegaran los fondos podrían completar la conectividad de las escuelas, potenciar la educación de adultos, impulsar la producción de contenidos regionales en el país y la capacitación docente (San Martín, 28/o6/2003).

En 2006, la Ley 26.206 de Educación Nacional le otorgó a Educ.ar un papel fundamental en la ejecución de políticas públicas para la integración de las TIC. En esta nueva etapa, el portal Educ.ar es pensado como un espacio de acción y de intercambio más que como un reservorio de recursos digitales, si bien se pueden encontrar:

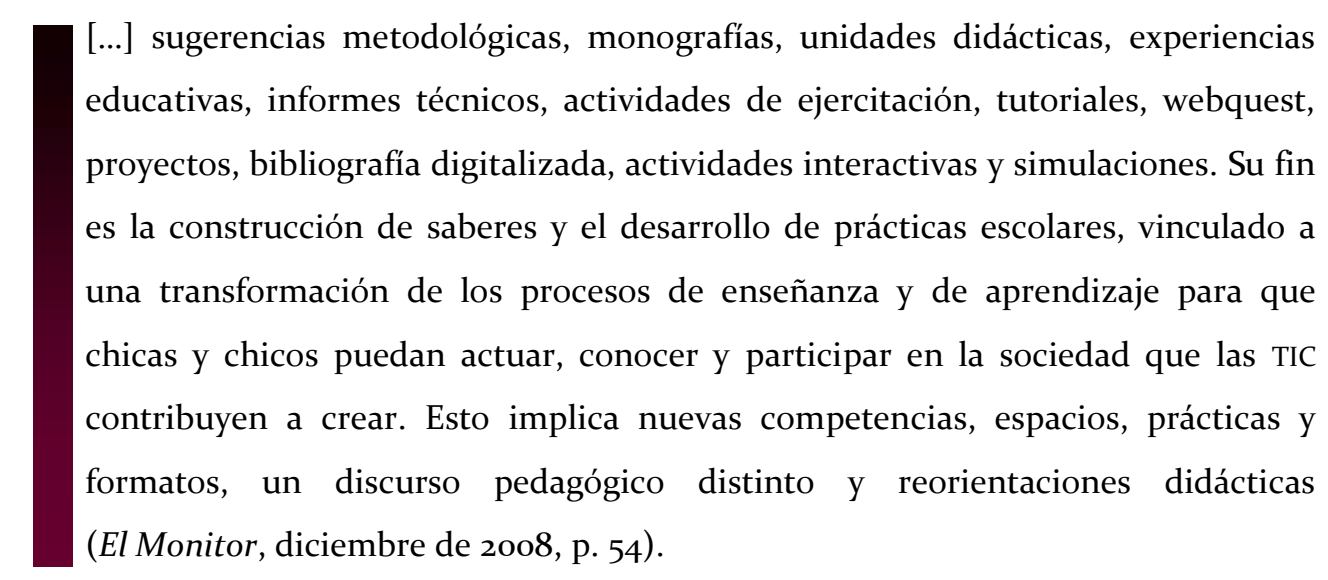

En este sentido, a través del portal, el docente podía buscar recursos para el armado de las clases, organizarlos y recomendarlos, realizar capacitaciones y acceder a información sobre novedades del ámbito educativo y tecnológico. Así, Educ.ar constituyó un lugar de circulación y producción de saberes, donde cabe resaltar la posibilidad de participar activamente en una comunidad de docentes, de aprender en compañía de otros, de experiencias y proyectos compartidos.

Finalmente, desde allí se logra un hito fundamental que es la creación del primer canal de televisión del mundo dependiente de un ministerio de educación nacional, en marzo de 2007. La señal Encuentro, desde sus inicios plantea el objetivo más importante del proyecto de Educ.ar, que fue crear un espacio multimedia e interactivo a partir de la convergencia entre la televisión e Internet. Desde sus comienzos, la señal se ha desarrollado al mismo tiempo desde ambas plataformas, para brindar herramientas que expanden las posibilidades y competencias (El Monitor, diciembre de 2008). 
Todo este desarrollo, de diferentes maneras y con ritmo acelerado, continuó hasta diciembre de 2015. A pocos días del cambio de gobierno en la Argentina, pudo verse un giro radical en la posición respecto de la comunicación (que luego también se vería en relación con lo educativo), cuando cinco días después de asumir el nuevo presidente modificò la LSCA redimensionando, sobre todo, su sentido de democratización de voces y de desconcentración de medios (La Nación, o4/o1/2016).

\section{Canal Encuentro}

Canal Encuentro nace de la mano de Tristán Bauer, reconocido cineasta y documentalista, que toma el desafío de hacer otra televisión. Se crea en mayo de 2005 y empieza a transmitir en marzo de 2007 por Cablevisión, antes de la creación de la TDA, como una señal de cable. No se trata de un canal cultural sino educativo, por más que los antecedentes que toma como base fueran de canales culturales. Su objetivo responde al hecho de haber sido gestado como un canal del ministerio de Educación, Ciencia y Tecnología de la Nación, a través del Decreto 533, de 2005, posteriormente reconocido por la Ley 26.206 de Educación Nacional, lo que constituye un hecho de avanzada.

Encuentro funcionaba en el marco de una Sociedad del Estado que es Educ.ar, como ya se dijo, creada por decreto en 2005 y reconocida en 2006 por la Ley de Educación Nacional 26.206. El ministro de Educación Daniel Filmus fue quien avanzó en crear una señal educativa y relanzó el portal Educ.ar con el propósito de que el canal estuviera bajo su órbita. Por otro lado, el portal permitía potenciar la relación entre la televisión e Internet, pues la convergencia tecnológica ya se avizoraba como un tema central para la educación. Pero por sobre todo enmarcaba al canal dentro de la televisión educativa. (Corte, 2016).

Los preparativos para el armado de la señal datan de 2004, cuando en el Área de Prensa del ministerio de Educación se crea el Programa de Medios Audiovisuales. Paralelamente, Bauer coordinaba una investigación en la Universidad Nacional de San Martín que derivó en el informe "Proyecto multimedio educativo" (Corte, 2016).

Desde un comienzo, la idea fue que Encuentro se convirtiera en un canal de aire en el mediano plazo. Tanto los sucesivos directores como los ministros de educación manifestaron este objetivo en distintas oportunidades, pues el concepto de canal público 
entraba en contradicción con el hecho que para visualizarlo durante los primeros años se requiriera estar suscripto al cable. La Resolución 1831 del COMFER, de 2006, dispuso que los licenciatarios de los servicios complementarios de radiodifusión debían transmitir la señal dentro de los primeros 15 lugares de sus grillas. A la red de 1.400 cableoperadores se sumaban las franjas horarias en distintos canales locales de televisión abierta y la Televisión Pública (Canal 7) de aire y alcance nacional. En 2010, la implementación de la TDA permitió visualizar Encuentro de manera gratuita, aunque aún queda mucho trabajo para que la televisión digital tenga la masividad de la televisión de aire. Por su parte, se suman los contenidos de la señal en Internet (Gonzalez \& Novomisky, 2012).

Definido como un servicio público de comunicación, se trata de un canal federal con contenidos de todas las regiones del país y algunas producciones del exterior, cedidos por instituciones públicas y privadas, universidades y programas nacionales e internacionales. La producción propia se realiza a través del sistema de producción delegada. La señal, dirigida a todo el público, constituye una importante herramienta para la comunidad educativa. En relación con este enfoque, una de sus características sobresalientes es la ausencia de publicidad.

Desde el propio canal se definen como objetivos: contribuir a la equidad en el acceso al conocimiento para todos los habitantes de la Argentina y los países de la región, brindar a las escuelas contenidos televisivos / multimedia y ofrecer herramientas innovadoras para facilitar y mejorar los procesos educativos.

Como ya se indicó, la señal se inscribe dentro de la televisión educativa por gestarse como un canal del ministerio de Educación de la Nación, como una herramienta más en pos de la igualdad y la calidad educativa. Aun cuando en 2008 Bauer deja la dirección del canal para asumir como presidente del Sistema Nacional de Medios Públicos, desecha la idea de que Encuentro pase a depender del nuevo organismo. Así permanece bajo la órbita del ministerio, parte de su propia génesis (Corte, 2016).

Por su parte, para la comprensión de la perspectiva educativa que ha caracterizado a Encuentro es útil retomar la categorización que hace Julio Cabrero Almenara (1994) sobre los productos audiovisuales con intención pedagógica. Por un lado está la televisión cultural, que tiene como objetivos la divulgación y el entretenimiento, con el diseño de la TV comercial. Algunos formatos clásicos para estos fines son las noticias, entrevistas e informes especiales. Los primeros ejemplos en la Argentina son Charlas con Federico García Sanchiz (1952) y Primer plano literario (1953) [Panaccio, 2010]. 
Una segunda categoría está constituida por la televisión educativa, que tiene un interés formativo que va por fuera del sistema educativo formal, con el propósito de influir sobre el conocimiento, las actitudes y los valores del espectador. Como parte de sus primeros exponentes en el país, se encuentran ciclos que contribuyeron a la construcción del rol de la mujer como ama de casa, esposa y madre: Petrona C. de Gandulfo (1951); Lecciones de dibujo y modelaje; Clases de belleza; Manualidades; Señora, sea práctica (1952) y Telecocina Pulqui (1953). También entran aquí los programas religiosos como los de los padres Capriotti, conductor de Entre Nosotros, y Moledo, de Hoja de Ruta (1952). Otros casos fueron los concursos de preguntas y respuestas, como Admiral paga, que premiaba el descifrado de refranes populares, o el famoso Odol pregunta (1956). Asimismo, se encuentran dentro de esta categoría los programas sobre salud como Cuide su salud (1954). La concientización política también tuvo lugar en espacios como Plan quinquenal (1953) o La libertad de la enseñanza (1958), que acompañó el conflicto por la educación superior laica o libre (Panaccio, 2010).

Por último, la televisión escolar emula al sistema educativo formal, con metas similares, desde el nivel primario hasta cursos de actualización universitarios. Es por esto que sus principios de producción tienen su origen en la didáctica y las teorías del aprendizaje. Entre los primeros programas de este tipo en la televisión argentina se encuentran Telescuela rural (1958), Cómo discar números telefónicos (1952), Hablemos inglés y Hable francés (1953), Primera telescuela técnica (1963) y Escuela para padres (1966), durante el primer año de Canal 2.

Si bien el proyecto original de Encuentro estaba orientado a la tercera categoría, con la incorporación de Bauer fue virando hacia el primer y segundo enfoque. Todo lo que se hiciera debía ser utilizable en un escenario escolar, pues el destinatario prioritario era el sistema educativo. Pero además debía ser atractivo para el gran público, por tratarse de televisión. Finalmente, se observa la predominancia de la televisión educativa por sobre una de corte cultural (Corte, 2016).

Durante sus primeros tiempos se destacaron los programas de Jorge Ginzburg, uno de los hombres más populares de la Argentina, que tenían un formato híbrido entre documentales y programas de entrevistas. Bauer tenía la capacidad de tomar figuras muy reconocidas y populares, ubicarlas en un lugar distinto, y hacerlas jugar en un registro diferente al acostumbrado. Desde los comienzos del canal, se destacaron envíos como Proyecto G, Filosofía aquí y ahora, Diálogos con Laclau, El interior de la memoria, Horizontes y $\mathrm{MP}_{3}$, entre otros. 
Por su parte, no hay hasta el momento estudios pormenorizados sobre las grillas de programación, contenidos y ejes temáticos, a partir de 2016 y en relación con los años anteriores. Sin embargo, en general, se observa una continuidad en el perfil de la propuesta.

Si bien existe un debate sobre las audiencias y el nivel de encendido de Encuentro, el caso difiere del de otros canales generalistas de la grilla de la TDA, por tratarse de un canal del ministerio de Educación de la Nación, que se ve en tiempo real pero que también tiene otros dispositivos de entrada. Por un lado están los contenidos en Internet y, por otro, las acciones y soportes materiales distribuidos directamente por el ministerio de Educación. En ambos casos se observa el propósito educativo, no obstante, en la segunda modalidad se presenta de forma más directa.

Algo que hizo Encuentro fue introducirse en las escuelas, tanto en la educación primaria, secundaria y universitaria, donde se utilizan materiales del canal. Por ejemplo, a partir del Programa Conectar Igualdad, la señal aportó contenidos audiovisuales para las netbooks distribuidas entre los alumnos de escuelas secundarias.

Otra de las iniciativas fueron los paquetes que, bajo el nombre de Colecciones, incluían una serie de DVD más un CD de navegación para maestros y estudiantes. Abordaban diferentes temáticas dedicadas a algún programa o una temática específica a través de distintas producciones del canal. Asimismo, a los materiales se sumaba la capacitación de los docentes en encuentros y talleres, para su abordaje en las clases y cuestiones específicas como, por ejemplo, el lenguaje audiovisual. Según Tamara Smerling (2015) las colecciones se distribuyeron en $\mathbf{2 2 . 0 0 0}$ escuelas primarias, 10.000 secundarias y en una gran cantidad de colegios de gestión social o parroquial del territorio nacional (Corte, 2016).

Por ejemplo, en un estudio de Ana Abramowski y Belén Igarzábal (2012) se muestrearon 22 escuelas bonaerenses —once del Programa Integral para la Igualdad Educativa (PIIE), dos rurales, dos FinEs y siete escuelas medias de diferentes modalidades-. En las instituciones, sus docentes y directivos destacaron aspectos como su carácter dinámico, la posibilidad de interpelación mediante un recurso cercano a la cultura de los chicos, que sirva como disparador, cierre o refuerzo de conceptos; la posibilidad de romper con la rutina y dar un cambio a la dinámica de la clase, sumar otros puntos de vista y acercar otras realidades, los ejemplos cercanos a la vida cotidiana de los alumnos que generan una sensación de "proximidad", la confianza en el tratamiento que realiza el canal sobre las temáticas y la duración de los materiales (de media hora) que deja margen a una introducción o trabajo posterior durante la misma jornada. 
Por otro lado, se valoró la presencia de conductores claros, didácticos y que generen “cercanía” y no así los casos en los que se utilizaba un lenguaje demasiado técnico (Abramowski \& Igarzábal, 2012). Aquí cabe recordar la distinción entre televisión cultural, educativa y escolar, y que Encuentro es una señal que tiene características de las dos primeras, inclinándose por el segundo modelo desde su gestación como canal del ministerio de Educación de la Nación. Por lo tanto, estará ajeno a la lógica de una teleclase. Distinto es el caso de la serie para las escuelas rurales Horizontes o la colección para escuelas técnicas - producida por Encuentro y por el Instituto Nacional de Educación Tecnológica-, donde se tratan contenidos curriculares.

Por su parte, a partir de sus observaciones, las autoras de los materiales no tienen problemas para incluirse y acomodarse en las prácticas escolares habituales. (Abramowski \& Igarzábal, 2012). No obstante, en los casos en que la apropiación se vio dificultada se debió a dinámicas arraigadas en las instituciones educativas:

[...] guardar bajo llave, hacer copias, cuidar los originales, miedo al extravío, rotura, robo y/o la pérdida, dan cuenta de una práctica escolar que excede a los audiovisuales, que es cierta tendencia al 'atesoramiento' que pone el valor de las cosas no tanto en el uso como en la preservación. En este punto, los DVD son absorbidos por una lógica propia de la cultura escolar (Abramowski \& Igarzábal, 2012, p. 18).

Otro aspecto fue la falta de estrategias sistemáticas de difusión por parte de directivos y bibliotecarios. En este sentido, eran los propios docentes los que facilitaban la circulación a partir de motivaciones individuales y el "boca a boca". En algunos casos bajaban el material desde el portal de canal sin saber que en su establecimiento se encontraba el material. Aún de esta forma surgían otros inconvenientes como la falta de competencias a la hora de manejar tecnologías. En este sentido, se evidencia como importante un acompañamiento a nivel del Estado.

Por otro lado, como ya se dijo, un caso destacable es el de la serie Horizontes, la primera de este tipo de producciones con contenidos curriculares de nivel secundario, pensada para las escuelas rurales y dividida en cuatro ejes: Ciencias Sociales, Ciencias Naturales, Matemática y Lengua, con contenidos según el año de curso, más un DVD general de artes visuales. La serie también fue lanzada en DVD y entregada a las 3.500 escuelas rurales que tiene la Argentina - a través de programas como PROMER (Programa de Mejoramiento de Escuelas Rurales) — y a diferentes establecimientos públicos del país, junto con el equipamiento necesario para su proyección. 
En Horizontes, Ernestina Pais presentaba los temas y era el contrapunto del personaje del Profe, que representaba el lugar del saber, validando el contenido. Abramowski e Igarzabal (2012) señalan como un valor destacado por los docentes la interpelación que generan los conductores en el vínculo que establecen con los alumnos, a partir del lenguaje apelativo. En el caso de esta producción se estima cómo la conductora logra que el programa sea entretenido y simple, sumado al hecho de ser una persona conocida, que genera empatía con los alumnos.

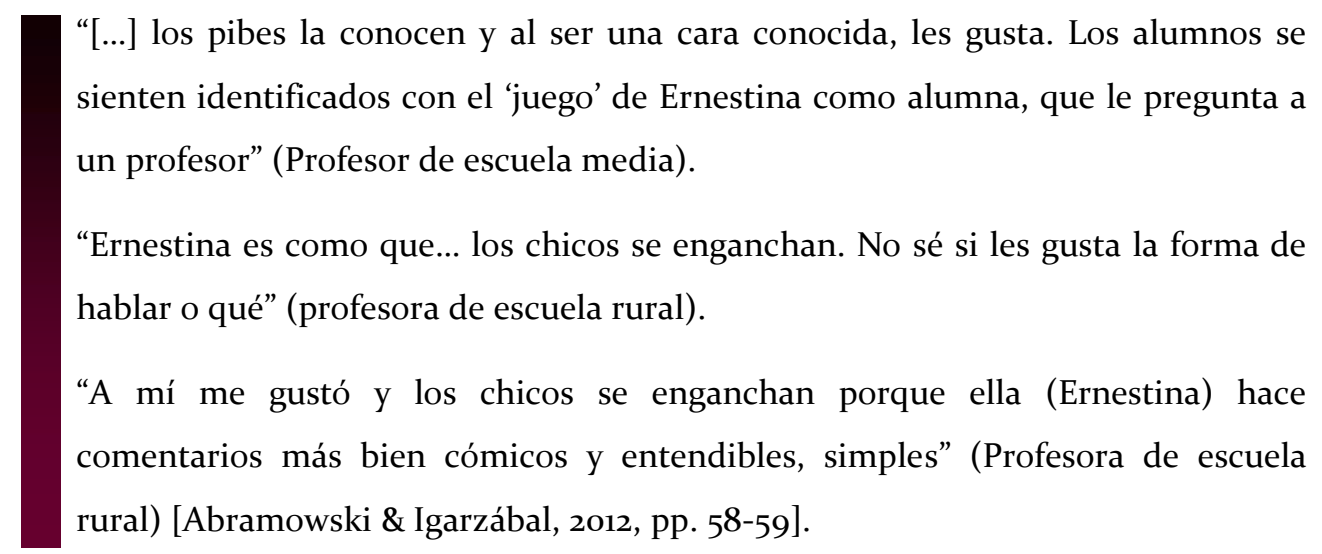

Otro ejemplo es el paquete de la serie documental Mejor hablar de ciertas cosas, sobre cuestiones vinculadas a los adolescentes, entre ellas la sexualidad. Algo a destacar es que no trata contenidos curriculares de una materia, sino transversales a la secundaria a partir de la Ley 26.15o Programa Nacional de Educación Sexual Integral. Está planteada a partir de la recuperación de la experiencia de chicos y chicas con la narración de Gastón Pauls, que es una voz con llegada en los jóvenes; una figura que valida mucho más que cualquier otro adulto.

El programa se estructura a partir de generar la identificación de los alumnos con los protagonistas de la serie, lejos de los estereotipos del joven exitoso o peligroso que construyen los medios. Rescata la voz de los jóvenes y acerca su realidad cotidiana a la escuela para poder reflexionar. Así, los chicos pueden verse a ellos mismos o a sus amigos. Y por otro lado, le sirve al docente para involucrarse con temáticas relacionadas con las juventudes, con las diferentes maneras de ser joven. Además, permite tratar temáticas que pueden no ser fáciles de trabajar en el aula, generalmente abordadas dentro de la asignatura Construcción Ciudadana. 
Trabajé "Mejor Hablar de Ciertas Cosas", los temas de sexualidad adolescente, paco, HIV, drogas y obesidad. Para tratar el tema del paco también les mostré a los alumnos la película "Paco" [...] "Mejor hablar de ciertas cosas" es muy bueno, mis alumnos se matan de risa con las caras que pone Gastón Pauls cuando encara un tema en forma pausada e inclinando la cabeza. La puntuación que le daría es 10/10" (Profesor de escuela media).

... el contenido es muy piola, es muy buena la mirada, son las voces de los pibes interpelados, la problemática adolescente, madres adolescentes, tribus, tabaco. Todos respetan el mismo formato, la voz de los adolescentes, por lo tanto los pibes prestan atención... está el tema de la identidad, no es moralista, plantea la situación y da información y te deja un terreno para seguir profundizando" (Profesor de escuela media).

La conducción de Gastón Pauls ayuda a que sus alumnos se interesen en el DVD porque instala un tema. Lo más relevante de estos programas es la voz de los pibes, son mis alumnos, los veo reflejados, usan la misma ropa, hablan igual, tienen las mismas características, no son los pibes de "Casi Ángeles" (Profesor de escuela media).

[...] ayudan a la formación docente y a la mirada que tienen sobre los pibes... que atareados por las cuestiones del trabajo tan adversas a veces somos reproductores del 'no se puede, a los pibes no les interesa nada' y se cae en un mensaje derrotista. Esto ayuda al docente y al alumno" (Profesor de escuela media) [Abramowski \& Igarzábal, 2012, p. 77].

\section{Encuentro en la web}

Con respecto a la presencia del canal en Internet, esta pasó por varias instancias, desde formar parte del portal Educ.ar, desde donde podían descargarse contenidos hasta tener su propio sitio, en principio, con la grilla de programación, foros y adaptaciones de los programas para su uso en el aula. Actualmente, en el sitio se pueden ver y descargar contenidos y material para las clases además de la posibilidad de visualizar la transmisión en directo.

Asimismo, el canal tiene presencia en redes sociales como Youtube, Facebook y Twitter. Además, otra forma de acceso era el portal Conectate, creado en 2012, que permitía descargar contenidos tanto de Encuentro como de Pakapaka, Educ.ar y el Programa Conectar Igualdad (Corte, 2016). 
En cuanto al sitio web de Encuentro, en la parte superior de cada página se encuentra una serie de íconos: Inicio, Catálogo, Grilla, En vivo, En el aula, Transmedia y Efemérides.

Un caso particular es el de los contenidos que presenta En el aula. Una vez que se ingresa, bajo el título Todas las guías para el aula, se halla una serie de materiales con consignas sugeridas para que los docentes trabajen los programas y temáticas abordados por Encuentro. Debajo de las solapas Categorías y Ordenar por se encuentra una explicación sobre el propósito de este material: "Descubrí, descargá y usá estas guías en tus clases. Nuestras guías para docentes proponen actividades teóricas y prácticas para aplicar el contenido de Canal Encuentro de manera productiva en clase. Generadas por expertos en educación y chequeadas por especialistas, estas guías son una excelente herramienta para el trabajo diario de profesores y maestros".

Debajo hay once páginas de contenido audiovisual. El enlace a cada material posee como diseño una imagen, el título y el comienzo de la sinopsis, que se puede terminar de leer si se ingresa. Debajo se encuentra el nombre del nivel educativo sugerido, que en los contenidos observados corresponde a secundaria. Para ingresar a la guía se puede cliquear en la imagen, en el título o en Ver más. Una vez allí, al lado de nivel se suma como etiqueta la temática a tratar. Cada uno de estos archivos, en formato PDF, puede ser descargado, impreso o compartido.

Cabe mencionar los contenidos agrupados en Transmedia, también denominados en otras páginas del sitio como Producciones Interactivas. Allí se alojan cuatro materiales. 1 primero que aparece, en tamaño destacado, se titula Arturo Illia. Fragmentos de una República. Se trata de un e-book de entrevistas a familiares, colaboradores cercanos y testigos directos de aquellos años. Se puede descargar, imprimir y compartir.

En este sentido, el portal de Encuentro posee características crossmedia y transmedia. Por una lado permite la reproducción del material audiovisual sin variantes pero además, a través de En el aula y Transmedia permite ir más allá de un camino trazado y dar rienda a la autonomía narrativa, que tiene su máximo exponente en las experiencias particulares de cada docente con el grupo de alumnos si contemplamos a Encuentro como un gran proyecto que articula estos distintos espacios.

Podemos destacar la presencia de contenidos diseñados mediante la investigación y el apoyo de educadores y curricularistas, donde el ministerio de Educación, a través de Educ.ar, se pone a trabajar de la mano de otros actores incluido el sector privado, como sucede con las productoras. Estos son algunos de los aspectos que Tufte (2004) señala 
como importantes en la evaluación de los aportes de las producciones de eduentretenimiento, que pueden tener un impacto directo o con un potencial a largo plazo, tal es el caso de las colecciones de DVD entregados en las escuelas, como parte de la relación entre la señal y el sistema de educación formal, una de las características que el autor subraya a la hora de valorar los contenidos.

Si bien algunos de los programas del canal responden más a la categoría de televisión cultural, como ya se dijo, su orientación y su proyecto original ubican a Encuentro dentro de la televisión educativa. El tipo de producción también oscila entre la segunda y tercera generación del eduentretenimiento.

La relación con lo popular, cómo determinados elementos son narrados en un producto de eduentretenimiento también es un factor importante para analizar la calidad de los contenidos. Por ejemplo, esta serie muestra a un grupo de jóvenes de una escuela pública que viven las mismas cosas que pueden ocurrirles a otros chicos y chicas. No se trata de la juventud angelada o exitosa de las producciones para adolescentes, ni del estereotipo de joven peligroso, varón y pobre que se muestra en los medios. El programa se acerca a los modos de hablar, de vestir, de ser de las y los jóvenes para poder interpelarlos.

Esta es una modalidad que no solo se vio en este programa sino también en otras producciones destinadas al público juvenil, como Presentes (Encuentro, 2012 y 2015) y Los pibes del puente (TV Pública, 2012). Pero en el caso de Mejor hablar de ciertas cosas, el proyecto se articula con el Programa Nacional de Educación Sexual Integral (Ley 26.150) que implica su abordaje en todas las escuelas públicas del país. Algunos capítulos de la serie trataban sobre las temáticas contempladas.

De esta manera, la Ley 26.150 junto con la Ley de Servicios de Comunicación Audiovisual 26.522, que se para en el paradigma que contempla a la comunicación como un derecho humano, más una serie de políticas públicas como la introducción de las computadoras en las escuelas con el Programa Conectar Igualdad, hacen que este tipo de iniciativas no queden aisladas sino en el marco de políticas más integrales.

Este tipo de alcance a gran escala, la incorporación de las temáticas en la agenda pública, el aporte del Estado y otras organizaciones es lo que caracteriza a las producciones del eduentretenimiento de tercera generación. En este caso no fue la producción el disparador de estas transformaciones sino parte de las estrategias de procesos que se venían consolidando. Aun así cabe considerar a este ejemplo de eduentretenimiento dentro de esta categoría, por la forma en que retoma las ideas de Freire, por el 
econocimiento que hace de ese otro que concibe como sujeto y busca interpelar, en la propuesta de diálogo, como sentido que se plantea en la narrativa pero que también se propone desde el trabajo en el aula.

\section{Pakapaka}

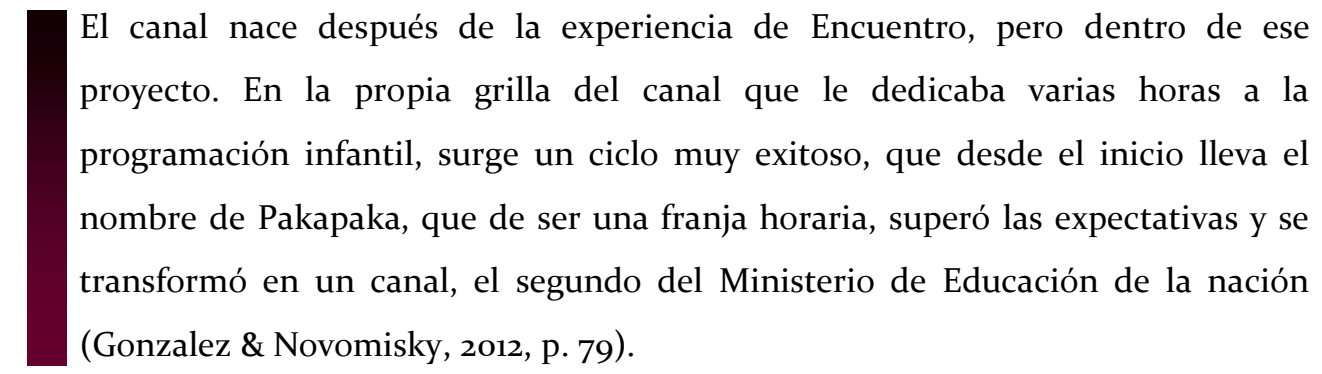

Es el primer canal para niños realizado íntegramente en la Argentina y por el Estado Nacional. En su origen fue la franja infantil de Canal Encuentro, con tres horas de duración y un buen encendido. En 2010, pasò a ser una señal independiente, por la TDA.

Ya desde su nombre (juego de las escondidas, en quechua) se sitúa en un lugar distinto. El spot de lanzamiento condensa el lugar desde donde se posiciona el canal, qué infancia piensa pero también qué infancia muestra. La clave no solo está en qué niño imagina como espectador sino qué niño busca para representar. La estética también avanza en ese camino. Los chicos encuentran en Pakapaka algo con lo cual se pueden sentir representados. No se muestran todos niños rubios que hablan con acento neutro, que en realidad es un acento del mercado para aplanar un territorio muy vasto y poder hacer circular una determinada cantidad de contenidos.

Así, el valor no está solo en lo que se piensa sino en lo que se muestra, porque es ahí donde se construyen representaciones de la infancia. Pakapaka, como el resto de los canales, construye una representación, pero en este caso, de nuestras infancias, de los chicos jugando en la calle, los chicos del norte, del sur o de la provincia de Buenos Aires.

En esta línea, rompe con la homogeneidad de las demás señales infantiles, que son en su mayoría norteamericanas y que transmiten 24 horas al día: Disney Channel (con cuatro canales diferentes), Discovery Kids, Cartoon Network, Nikelodeon y el reciente Baby TV, que solo pueden ser vistos desde los sistemas pagos. En este sentido, Pakapaka vino a llenar un área de vacancia muy grande, una demanda que existía en relación a esta carencia, que se realizó desde el Estado pero también desde la misma sociedad. 
Además, los canales privados presentan una segmentación en franjas etarias que está vinculada no solo al tipo de contenido al que puede atender un niño sino al tipo de consumo que pueda hacer. Por lo tanto, se segmenta para dar lugar a una publicidad definida que tiene un destinatario también definido entre determinadas edades.

Pakapaka tiene otra característica muy importante que es no contener publicidad comercial. Sí posee cortes con referencias a la programación propia. Eso es una política pública, pues no hay ninguna manera de sostener un canal sino es desde el Estado o con publicidad. Y esto le da otra dinámica; la posibilidad de no romper su manera de interpelar cada seis u ocho minutos con otro discurso muy distinto, rupturista. Además, los enlatados de las publicidades no representan a nuestros niños. La publicidad también construye una representación de la infancia.

Lo importante es que los niños puedan ver cosas que tengan que ver con su propio mundo, porque eso los ayuda a problematizar su cotidianeidad. De eso se trata cuando se habla de interpelar a un niño o a un joven: que pueda pensarse situado y que el producto contribuya con su construcción de ciudadanía.

\section{Pakapaka en un contexto de multipantallas}

Como recupera Carolina Di Palma (2017), directora del área de convergencia tecnológica de Pakapaka, en su tesis de maestría:

\footnotetext{
El proyecto de Convergencia de la nueva señal PKPK se estructuró en torno al concepto del juego. El objetivo fue proponerles a las nuevas generaciones entornos digitales en los que pudieran jugar, explorar y descubrir. Creíamos que los espacios digitales tenían un gran potencial para promover experiencias de juego, experimentación, imaginación y que los espacios interactivos podían fortalecer y ampliar las posibilidades de protagonismo y participación, desarrollando sus potencialidades creativas.

A su vez, pensábamos que los juegos promovían nuevas relaciones y acercamientos a la programación de la señal. En los juegos que desarrollamos las actividades fueron interactivas, lo que implicaba que los chicxs se enfrentaran a un reto y tomaran decisiones que tenían efectos sobre lo que sucedía en la pantalla, permitiendo reflexionar sobre sus decisiones y reconsiderarlas para desarrollar nuevas estrategias de producción de contenidos. Otra característica de los juegos fue que incluyeron la posibilidad de ser resueltos a través de diferentes
} 
estrategias, la adaptación a diferentes edades y capacidades así como a la de habilitar jugadores individuales o múltiples, permitiendo el ensayo y error, fomentando que jueguen repetidas veces y en distintos momentos.

La filosofía del juego proponía una puerta de entrada diferente al aprendizaje. Los procesos actuales de enseñanza y aprendizaje, mediados por las TIC, poseen tendencias y características específicas diferentes a las características de estos procesos en la Modernidad. Algunas de estas características específicas en el aprendizaje contemporáneo nos mostraban una tendencia hacia el aprendizaje no formal, la experimentación a través del ensayo y error, la exploración, los recorridos no lineales, la exploración, la inmersión, la colaboración con otros.

Los nuevos medios permitían poner en marcha operaciones cognitivas vinculadas a la memoria y el recuerdo, poner a prueba hipótesis, predecir y planificar estratégicamente, establecer diálogo con los demás, realizar actividades multialfabetizadas o hipermediales, interpretar entornos tridimensionales, leer y escribir texto en pantalla y fuera de ella (meta e híper textual) y procesar información auditiva. Los contenidos serían parte fundamental del proyecto de convergencia pero se abordarían, en consonancia con la filosofía de la señal, desde la imaginación, la interactividad y la exploración (p. 56).

Es por eso que hasta el día de hoy, al ingresar al sitio web de Pakapaka, en la página de inicio, se destaca el logo del canal en grandes letras, acompañado por algunos personajes. Debajo se encuentra una grilla horizontal con los personajes del canal. Se puede recorrer y cliquear sobre los dibujos para acceder de una forma simple a una lista de videos y canciones relacionados. Una vez abierta, se puede modificar la opción de visualizado con los íconos del margen superior derechos Todo, Videos y Canciones, siempre con una propuesta atractiva y que invita a la interacción.

Debajo de la grilla de personajes del inicio hay dos recuadros de gran tamaño: uno abre la sección de aplicaciones para teléfonos móviles. El otro cuadro destaca el noticiero de Pakapaka, Alta Noticia, al que se puede acceder desde allí, ya comenzando a desplegar opciones de usos diferentes y en múltiples plataformas,

Por ello, se puede observar en la parte superior de cada página una serie de íconos denominados Videos, Juegos, Audios, Aplicaciones, En vivo y Horarios. Las tres primeras opciones despliegan una lista de contenidos que pueden reordenarse mediante un ícono con dos flechas, ubicado en el margen superior derecho. Como se ve, existen muchas formas o caminos para acceder a los contenidos. 
En la esquina superior derecha están los enlaces a Twitter, Facebook y el canal de Youtube de Pakapaka, articulando con redes sociales el proyecto y reconectando con otras plataformas los contenidos disponibles. Estos íconos se reiteran en la parte inferior de la página, junto a Contacto, Institucional, Condiciones de uso, Presentación de proyectos e Información para proveedores, dando un lugar preferencial con dos entradas diferentes a la relación con las redes sociales
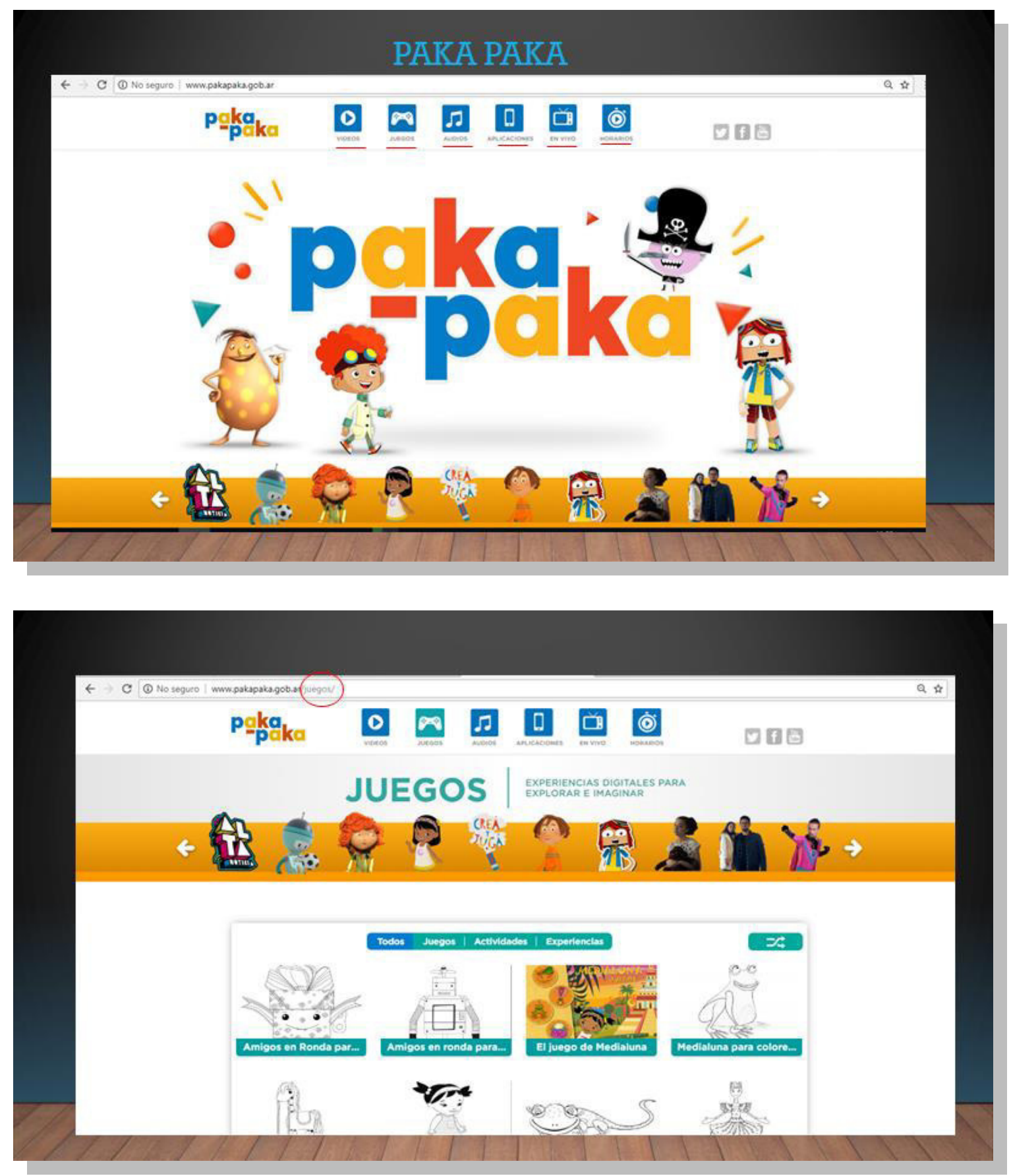

Home y sección Juegos en el sitio web del canal Pakapaka

Fuente: http://www.pakapaka.gob.ar/ 
Por otro lado, en Juegos se despliegan diferentes opciones, divididas en tres categorías: actividades, juegos y experiencias, todas con personajes del canal. En cada una de estas pantallas se puede ver la cantidad de veces que se ha jugado o descargado. La primera categoría permite descargar, imprimir y compartir. Algunos ejemplos son dibujos para colorear, posters, recortables para cumpleaños, títeres, caretas, figuritas recortables, juegos de mesa, crucigramas, muñecos para armar, entre muchos otros. Por su parte, en Experiencias, chicos y chicas pueden armar una torta de cumpleaños personalizada, dibujar sobre vidrios empañados mediante un software que toma imagen y voz con la cámara web de la computadora, jugar con la fuerza de gravedad, crear ritmos con Las goteras musicales, entre otras opciones.

El ícono Aplicaciones permite acceder a Google Play o App Store para descargar en forma gratuita las apps que ofrece el sitio de Pakapaka u otras de los mismos desarrolladores. Aquí se encuentra, por ejemplo, La asombrosa clase de Zamba sobre San Martín, disponible desde Google Play. Desde allí se puede hacer un breve recorrido por las diferentes pantallas de la aplicación, descargarla, darle una puntuación de hasta cinco estrellas y dejar un comentario.

Se trata de un libro interactivo desarrollado para niños y niñas de 5 a 10 años. Aquí Zamba invita a chicas y a chicos a hacer un viaje al pasado, a jugar con distintos personajes y a aprender sobre la historia argentina y latinoamericana. Sus páginas recorren Yapeyú, el Combate de San Lorenzo, el cruce de los Andes, el desembarco en Perú y la reunión del Libertador con su par Simón Bolívar. Se suma una trivia, una sopa de letras y un juego de figuras como final del camino.

Otra aplicación es ¡Piedra libre, Medialuna!, un cuento interactivo basado en la serie Medialuna y las noches mágicas, sugerido para niños y niñas de entre 2 a 7 años, que pueden escuchar la narración o leer de forma autónoma, jugar con las distintas propuestas interactivas, recorrer escenarios, mover elementos y encontrar los personajes escondidos. Para descargarla se puede ingresar a Google Play y App Store.

También desde Google Play se puede bajar Laboratorio de Superhéroes, basado en la serie homónima, que permite diseñar personajes, ponerles voz y música, crear una historia animada, guardarla y compartirla. Además, la página de Aplicaciones anticipa la App de Pakapaka —que estará próximamente disponible para Android y el sistema IOS (Iphone IOS, compatible con IPod Touch y IPad)—, desde la cual se podrán mirar los videos, escuchar los cuentos y las canciones, conocer la programación y las novedades de canal. 
En este sentido, se puede decir que la sección Juegos y Aplicaciones constituye el ejemplo más claro de la convergencia entre múltiples pantallas. En rigor, todo el portal de Pakapaka es transmedia. Distintos lenguajes, texto, audio, imagen y video, confluyen y circulan a través de distintos dispositivos: la compu, la televisión y el celular. Incluso reaparece el papel como un soporte muy especial en la primera infancia, cuando se trata de recortar y de colorear a los personajes de Pakapaka. Las historias desarrolladas para el canal se expanden en juegos, apps y papel. Las canciones cobran autonomía en diferentes contextos. Los chicos y las chicas son los/as verdaderos/as protagonistas.

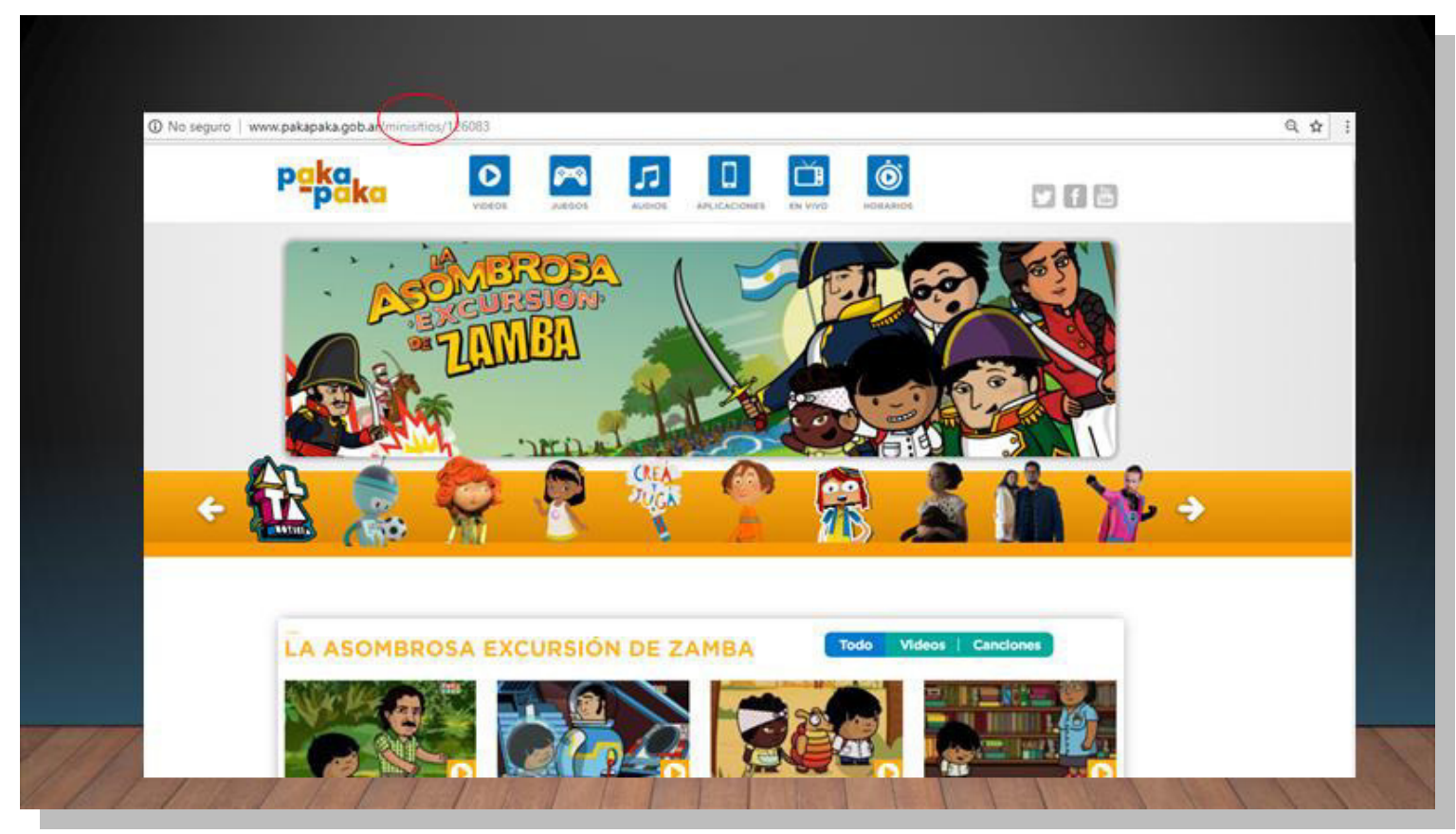

La asombrosa excursión de Zamba en el sitio web del canal Pakapaka Fuente: http://www.pakapaka.gob.ar/

En cuanto a las narrativas, en general todos los envíos plantean valores positivos, aunque algunos se destacan por sobre otros. Ejemplos son Medialuna y las noches mágicas, donde prevalece la diversidad y la identidad de Latinoamérica, a través de una pequeña de Locoto, un pueblo ficticio con reminiscencias de pueblos originarios; o Amigos, una seria animada sobre un grupo de chicos que viven en una ciudad del interior del país. Sin dudas, el caso más paradigmático es La asombrosa excursión de Zamba, que hace foco en la identidad nacional, el ejercicio de la ciudadanía, el reconocimiento y la promoción de los derechos humanos. 
Por su parte, si consideramos a todo el portal de Pakapaka como un producto transmedia, debemos advertir que contiene elementos con distintos enfoques sobre el eduentretenimiento pero que en el conjunto tienen una identidad y una escala de impacto, que lo posiciona como un producto de eduentretenimiento de tercera generación.

Estas narrativas no se quedan en la pequeña escala sino que alcanzan una circulación a través de un canal de televisión e Internet, a partir de una política de Estado, de una ley nacional como la LSCA y una serie de medidas contempladas para fortalecer la producción de contenidos nacionales con una perspectiva federal. Con el despliegue de la TDA, es destacable lo que significa estar presente en todos los rincones del país. Se trata entonces de procesos a nivel macro que ponen en el centro la concepción de la comunicación como derecho humano y la educación desde el mundo cultural del otro.

\section{Zamba transmedia: el potencial de la convergencia y las narrativas transmedia en el eduentretenimiento de tercera generación}

Una de las cuestiones fundamentales para pensar productos educativos es reconocer a la convergencia como fenómeno de la cultura, que forma parte del mundo cultural del otro, y justamente estos aspectos tienen que estar desde el nacimiento de los proyectos, como productos transmediales, para interpelar a los chicos desde múltiples espacios.

Estos productos tienen una capacidad de impacto mucho mayor, pues además de promover la interactividad, de generar otras cosas, la posibilidad de que el niño con aquello que conoce pueda indagar otras cuestiones supone que hay una mirada estratégica en términos de presencia del producto. Pero el desafío que no se debe perder de vista es pensar qué tipo de interpelación y de relación queremos construir y para qué: queremos que la persona se mueva de producto en producto y se fidelice como audiencia o queremos generar otra cosa.

En esta línea, La asombrosa excursión de Zamba se puede considerar un producto transmedia por varios aspectos. Uno de ellos son las canciones, que pueden funcionar de forma autónoma. Otros derivados son los juegos relacionados. También, en articulación con la Universidad Nacional de La Plata, se editó el libro El asombroso libro de Zamba en las Islas Malvinas (2015), que es distinto al episodio. Tiene una línea de tiempo y un objetivo intencionalmente más educativo sobre contenidos específicos. Se centra en contenidos específicos, aunque recupera la estética del capítulo para televisión. 


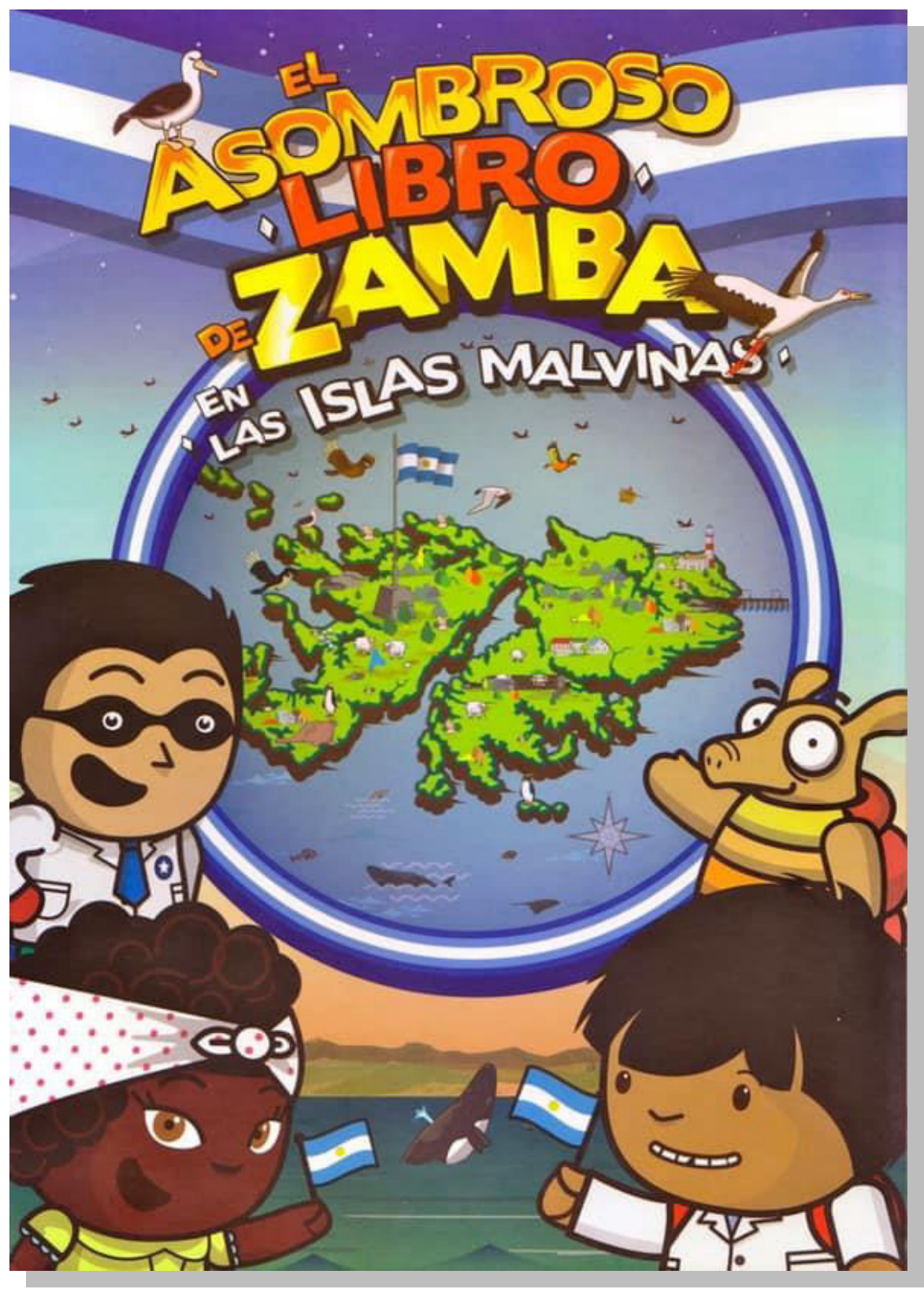

Libro sobre la serie infantil producida por el Ministerio de Educación

de la Nación y el canal Pakapaka editado por la Universidad Nacional de La Plata

Un caso para reflexionar es el de otro producto relacionado con Zamba, como son los muñecos de Juana Azurduy, San Martín o Belgrano. La gestación del proyecto de Zamba tiene características particulares que hacen que la reproducción y diversificación de productos no copie el modelo del mercado, porque en todos ellos nunca dejan de estar presentes la Historia argentina, los valores de la soberanía y de la patria, la humanización de nuestros próceres. Es por eso que como marca, no implica solo el fetiche de un muñeco, porque transmite valores distintos a los de otros productos. Tiene lógicas que comparte con el mercado pero con rupturas significativas. 
En este sentido, es significativo el lugar donde se pueden adquirir los productos, como ferias, festivales, algunos centros culturales y unos pocos locales, sumado a la simpleza de los muñecos, que consisten en siluetas hechas en tela serigrafiada con un relleno. También marca una línea el hecho de que sean artículos producidos por cooperativas del ámbito de la economía solidaria. Por ejemplo, La Maqueta es responsable de los estampados. Es integrante de redes de comercialización y de trabajo, como la Red Textil, desde donde se articula la producción, de modo que distintas cooperativas se encargan diferentes tareas. El desarrollo de una marca, aunque aquí no sea en el sentido estricto del mercado, constituye un potencial apreciado para las producciones de eduentretenimiento de tercera generación (Tufte, 2004).

\section{A modo de conclusión}

Pakapaka y Encuentro son dos modelos de los cuales no solo debemos aprender sobre cómo se puede hacer una televisión educativa, de calidad, entretenida y que logre interpelar a las audiencias, sino también como formatos de producción multiplataforma con algunas lógicas transmedia. Todo ello, desarrollado desde el Estado con una fuerte inversión pública, nos permite pensar que otra comunicación / educación es posible y que las transformaciones profundas que venimos describiendo en esta tesis pueden ser abordadas desde lógicas que no solo respondan al mercado, sino que también apuesten a la construcción de la ciudadanía.

Viendo incluso las producciones, las tradiciones latinoamericanas pueden aportar miradas profundas y atentas, que acompañen con la potencia de nuevos dispositivos y formatos de interpelación estrategias para "hacer del allí del otro mi aqui", en el siglo XXI.

Por otro lado, tenemos que la construcción de las identidades en los tiempos actuales ha sufrido grandes transformaciones, a partir de la relación entre lo nacional, regional y local. En su constitución entran en juego múltiples adscripciones que integran elementos identitarios tanto locales como globales. Es entonces que productos del eduentretenimiento como Zamba cobran especial importancia en la construcción / reconstrucción de la identidad nacional, al volver una historia individual al plano público, priorizando el lenguaje propio como lo expresaba la LSCA. 
Así, visibilizar a los diferentes actores nacionales es una manera de reconocerlos. El hecho de mostrar en Zamba a distintos personajes, diversos, es en cierta medida darles voz. De esta manera, la reconstrucción del tejido social, ese sentimiento de cohesión, de Nación, puede promover una sensibilización de la sociedad que cristalice en la defensa de sus propios derechos.

Zamba, como quizás el mejor ejemplo de lo que venimos describiendo, viene a ser en parte la síntesis de una propuesta que pensó la comunicación como un derecho humano y la educación desde el mundo cultural del otro. La diferencia substancial entre un dibujo que pretende con una estrategia conductista fomentar una respuesta a partir de un determinado estímulo, choca aquí con una posición sobre la historia, un niño que hace y habla de los hechos y no es narrado por otros (adultos).

El lugar en el cual se reconoce una toma de posición es claro: Zamba posee una postura profunda, palpable y respetable, que a diferencia de otras producciones -que desde el clásico Para leer al Pato Donald (Dorfam \& Mattelart, [1971] 2001) hasta aquí sabemos que todos los dibujos animados poseen - se oculta y se anula como si fuera esa neutralidad del español, no neutro, por supuesto, sino necesario para consolidar un mercado regional en América Latina.

Por ello, consideramos hoy que la revisión del edu-entretenimiento, en un contexto de multipantallas y en donde los más chicos consumen cada vez más y de diferentes formas producciones infantiles es clave, no solo por su dimensión ideológica como denunciaran Ariel Dorfam y Armand Mattelart ([1971] 2001) en los años setenta, sino porque la penetración en la actualidad es tanto mayor que la conceptualización de estos medios como educativos ya no es discutible. No podemos negar la diferencia radical entre la interpelación a un sujeto como consumidor y la que se realiza al sujeto como ciudadano; son dos polos opuestos que nos pueden servir de guía para el análisis del campo audiovisual, en un contexto de transformaciones y la experiencia argentina en ello, durante casi una década, posee un potencial que no podemos dejar de recuperar.

Como mencionamos al inicio, tanto en Radio Sutatenza como en las Radios Mineras de Bolivia existía una concepción de sistema educativo en la cual las tecnologías eran parte del modo de pensar la formación. En esta perspectiva de la educación popular, los medios son constitutivos de los procesos de interpelación y de reconfiguración de la subjetividad. 
El Estado en estos casos y en los vistos en la Argentina configura otros modos de modelización de la sociedad, propone formas alternativas de configuración de lo social, a partir de núcleos de producción de tramas discursivas audiovisuales y tecnológicas que abonan otra mirada de la comunicación y de lo educativo. Una perspectiva que consiste en disputar la producción social de sentidos en el terreno de lo público, de unos relatos por sobre otros.

Esto implica que es posible pensar un sistema de comunicación pública en donde los medios sean parte también de una estrategia de comunicación / educación, incorporando la dimensión formativa en una innovación discursiva que consolida otro horizonte posible al de la concentración mediática y de voces. Así, el despliegue de géneros y estilos diversos, con ficción, animaciones, documentales, series y otros formatos sobre soportes como apps, mini sitios webs o narrativas transmedias, son puestos en relación a una estrategia general en donde la trama comunicacional es indisociable de un proyecto de emancipación. 


\section{Referencias}

Abramowski, A. e Igarzábal, B. (2012). Uso y apropiación de las producciones de Canal Encuentro en las escuelas bonaerenses. En A. Abramowski, B. Igarzábal, R. P. Carbonatto, M. Mobilia, y E. Tenti Fanfani (Coords.), Cuadernos de Investigación \#1. Los docentes bonaerenses. Las políticas educativas vistas desde el aula (pp. 12-21). La Plata, Argentina: UNIPE.

Appadurai, A. [1996] (2001). La Modernidad desbordada: dimensiones culturales de la globalización. Ciudad Autónoma de Buenos Aires, Argentina: Tricle.

Cabrero Almenara, J. (1994). Retomando un medio. La televisión educativa. Presentado en CMIDE-SAV: I Jornadas sobre Medios de Comunicación, Recursos y Materiales para la Mejora Educativa, Sevilla, Universidad de Sevilla. Recuperado de http://linamariapatricia.tripod.com/convergencia/118.pdf

Corte, M. (2016). Reflexiones en torno al propósito educativo de Canal Encuentro. Question, 1(51).Recuperado de https://perio.unlp.edu.ar/ojs/index.php/question/article/view/3403

Decreto 533 (2005). Programas de televisión educativa y multimediales. Recuperado de http://servicios.infoleg.gob.ar/infolegInternet/anexos/105000-109999/106542/norma.htm

Di Palma, C. (2017). Interpelación y reconocimiento de la cultura mediática en la convergencia digital pública infantil. Nuevos sentidos político-estratégicos del campo Comunicación / Educación para ampliar horizontes de significación en la era de la onda cuadrada (Tesis de maestría). Recuperado de http://www.ondacuadrada.com

Dorfam, A. y Mattelart, A. (1971) (2001). Para leer al Pato Donald. Ciudad Autónoma de Buenos Aires, Argentina: Siglo XXI.

El asombroso libro de Zamba en las Islas Malvinas (2015). La Plata, Argentina: Edulp.

El Monitor (diciembre 2008). Un espacio para la transformación educativa. La función del portal educ.ar, pp. 52-55. Recuperado de http://www.me.gov.ar/monitor/nroo/pdf/monitorı.pdf 
González, L. y Novomisky, S. (2012). La televisión digital en Argentina. Cambios políticos, tecnológicos y económicos. Miradas desde una perspectiva federal. El caso del canal para niños Pakapaka. En M. Souza, P. Cabello y C. Del Valle (Eds.), Medios, edades y Cultura (pp. 71-87). Santiago de Chile, Chile: Ediciones Universidad de La Frontera.

González, L., Pauloni, S. y Codoni, M. F. (2016). De dónde viene y hacia dónde va la televisión educativa, cultural y pública en la Argentina. Oficios Terrestres, (34), 24-36. Recuperado de http://perio.unlp.edu.ar/ojs/index.php/oficiosterrestres

González, L., Pauloni, S., Novomisky, S., Codoni, M. F. y Gómez, A. J. (2016). Perspectivas para pensar contenidos educativos infantiles. El concepto eduentretenimiento en la televisión Digital Argentina. Actas de Periodismo y Comunicación, 2(1). Recuperado de https://perio.unlp.edu.ar/ojs/index.php/actas/article/view/4014

La Nación (4 de enero de 2016). Oficial: el DNU de Macri que modifica aspectos centrales de la ley de medios y elimina la Afsca. Recuperado de https://www.lanacion.com.ar/politica/el-gobierno-publico-el-dnu-que-modificala-ley-de-medios-y-elimina-la-afsca-nid1859236

Ley Nacional 26.150 (2006). Programa Nacional de Educación Sexual Integral. Recuperado de http://servicios.infoleg.gob.ar/infolegInternet/anexos/1200oo124999/121222/norma.htm

Ley Nacional 26.206 (2006). Ley de Educación Nacional.

Recuperado de http://servicios.infoleg.gob.ar/infolegInternet/anexos/1200oo124999/123542/norma.htm

Ley Nacional 26.522 (2009). Servicios de comunicación audiovisual. Recuperado de http://servicios.infoleg.gob.ar/infolegInternet/anexos/155000159999/158649/norma.htm

Nemirovsci, O. M. (2013). TV Digital, un nuevo modelo cultural. En S. Pauloni (Comp.), Tv digital. Un diálogo entre disciplinas y multipantallas (pp. 13-32).

La Plata, Argentina: Ediciones de Periodismo y Comunicación.

Pauloni, S. (Comp.) (2013). Tv digital. Un diálogo entre disciplinas y multipantallas. La Plata, Argentina: Ediciones de Periodismo y Comunicación. 
Pauloni, S. y Novomisky, S. (2013). Contextos y conceptos sobre la TV.

En S. Pauloni (Comp.), Tv digital. Un diálogo entre disciplinas y multipantallas (pp. 62-85). La Plata, Argentina: Ediciones de Periodismo y Comunicación.

Pauloni, S., Novomisky, S., Codoni, M. F. y Gómez, A. J. (2016). Argentina.

Televisión educativa: nuevos debates y formatos. En S. Novomisky y M. Américo (Comps.), Convergencia. Medios, tecnologías y educación en la era digital (pp. 47-72). La Plata, Argentina: Edulp. Recuperado de http://sedici.unlp.edu.ar/bitstream/handle/10915/55418/Documento completo .p df-PDFA.pdf? sequence $=3 \&$ isAllowed $=y$

Panaccio, M. (marzo 2010). Los primeros pasos de la TV educativa. El Monitor, pp. 52-53. Recuperado de http://www.me.gov.ar/monitor/nroo/pdf/monitor24.pdf

Quiroz, M. T. (1984). Los medios: ¿una escuela paralela? Lima, Perú: Centro de Investigación en Comunicación Social de la Universidad de Lima (CICOSUL).

Resolución 1831 (2006). Comité Federal de Radiodifusión.

San Martín, R. (28 de junio de 2003). Nueva apuesta al portal Educ.ar. La Nación. Sección Cultura. Recuperado de http://www.lanacion.com.ar/507247-nuevaapuesta-al-portal-educar

Smerling, T. (2015). La otra pantalla: educación, cultura y televisión. 2005 -2015. Una década de Canal Encuentro, Pakapaka y las nuevas señales educativas. Ciudad Autónoma de Buenos Aires, Argentina: Ediciones educ.ar.

Tufte, T. (2004). Eduentretenimiento en la comunicación para el vih/sida más allá del mercadeo, hacia el empoderamiento (Trad. Tanya Escamilla). Investigación $\mathcal{E}$ Desarrollo, 12(1), 24-43. Recuperado de http://www.redalyc.org/articulo.oa?id=26800102

Villamayor, C. (2011). La subjetividad oxidada (apunte de cátedra). Facultad de Periodismo y Comunicación Social, Universidad Nacional de La Plata. Recuperado de http://amarcargentina.org/wp-content/uploads/2011/11/La-subjetividadoxidada Villamayor.pdf

Villamayor, C. (2014). Disrupción, comunicación y emancipación. Oficios Terrestres, (31), 49-59. Recuperado de https://perio.unlp.edu.ar/ojs/index.php/oficiosterrestres/article/view/2438 


\section{Netflix: el sueño es mi mayor enemigo}

Durante una parte importante del siglo XX y hasta comienzos del siglo XXI, La televisión fue uno de los medios de comunicación masivos por excelencia. Al decir de Omar Rincón (2006), la televisión gusta, entretiene, genera conversación social.

Pero lo que vemos en la actualidad es que, en medio de tantas opciones de interpelación al televidente, asoma un modelo diferente de producción audiovisual que, sin ser televisión ni cine, pero sumando todo eso y mucho más, está cambiando las lógicas no solo de producción y de circulación audiovisual, sino también de consumo, acaparando la atención de las audiencias.

Mario Carlón y Carlos Scolari reflexionaban ya en 2009:

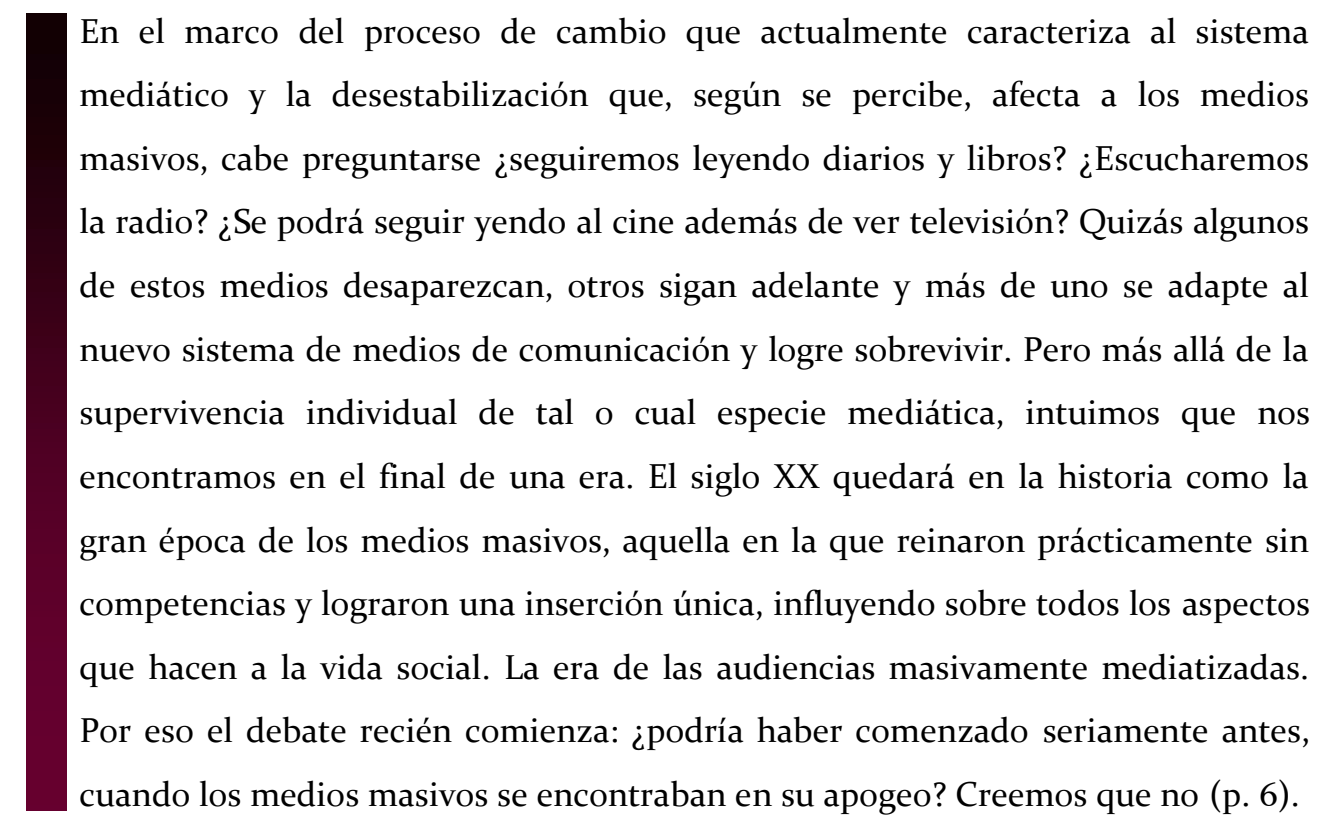

Tan solo una década después, esta nueva era llegó, plataformas mediáticas de streeming con transmisión por Internet sin necesidad de descarga, fueron surgiendo cada vez con más fuerza hasta ser hoy una realidad innegable dentro del mundo audiovisual que 
compite firmemente con los contenidos que tradicionalmente estaban alojados en la televisión como películas, series, realities, documentales, animaciones y hasta en algunos casos programas de política y de actualidad.

Y en esta línea tenemos que recuperar concepciones que desde la posibilidad de analizar la televisión, nos van a permitir incorporar las miradas tradicionales a nuevos objetos y así no perder el enorme aporte de los estudios culturales, la economía política de medios y las miradas latinoamericanas sobre el campo, para luego poder ir sumando nuevos y diferentes elementos para rodear el fenómeno de una de las plataformas paradigmáticas de esta era como lo es Netflix.

\section{Nuestra histórica relación con la pantalla}

Antes que nada hay que analizar el lugar que tuvo la televisión en nuestra sociedad. En este sentido, parafraseando a Rincón (2005), casi todos somos hijos de la tele, al menos hasta hace algunos años, por lo que sin la televisión no podríamos vivir porque ella es necesaria para la vida, ya que genera conversación social, mucha cotidianidad simbólica y mundos paralelos para gozar y para imaginar.

La televisión gusta, ayuda a las personas a vivir, a distraerse y a entender el mundo. Formó parte fundamental de la vida diaria, de las formas de construir el símbolo y de nuestras maneras de crear comunidades de sentido. De ahí que aparezca en nuestras vidas como un actor indispensable con todas las resignificaciones y las expansiones que fue encontrando. Puesto que "la pantalla ya no se llena de meras imágenes y sonidos, sino de formas culturales, deseos colectivos, necesidades sociales, expectativas educativas, rituales de la identidad; la tele se convirtió en la institución social y cultural más importante de nuestras sociedades" (Rincón, 2005, p. 11-12).

Pensemos, por ejemplo, en el sentido que cobraba hasta hace pocos años la televisión, a través de una pregunta simple como la que plantea Dominique Wolton (200o): ¿ ¿Para qué servía la TV? Para reunir individuos y público que están separados por todo lo demás, y por otro lado para ofrecerles la posibilidad de participar individualmente en una actividad colectiva" (p. 120). Y este elemento hoy podría seguir vigente, ya que las series y los programas que encontramos alojados en nuevas plataformas reordenan gustos y formas de leer el mundo, pero siguen tejiendo una conversación común en sociedades cada vez más hiperfragmentadas. 
En definitiva, aquí encontramos una alianza particular que, aunque con modificaciones, se sigue estableciendo entre el individuo y la comunidad que hace de esta tecnología una actividad cada vez más constitutiva de la sociedad contemporánea. La televisión sirve para hablar, es una formidable herramienta de comunicación entre los individuos. Lo más importante no es lo que han visto, sino el hecho de hablar de ello. La televisión es, pues, un objeto de conversación, y eso se está modificando radicalmente en el tipo de plataforma, o mejor dicho interfaz (Scolari, 2018), en el que el proceso de recepción se desarrolla como veremos en breve.

\section{Reconfiguración del campo audiovisual}

Este escenario comienza a reestructurarse completamente con la aparición de las plataformas de video bajo demanda, que fueron cobrando cada vez más protagonismo, hasta llegar a la consolidación de Netflix, como el fenómeno audiovisual de carácter mundial (o al menos de casi todo occidente), que irrumpió en los últimos años y está modificando sustancialmente las formas de consumir televisión.

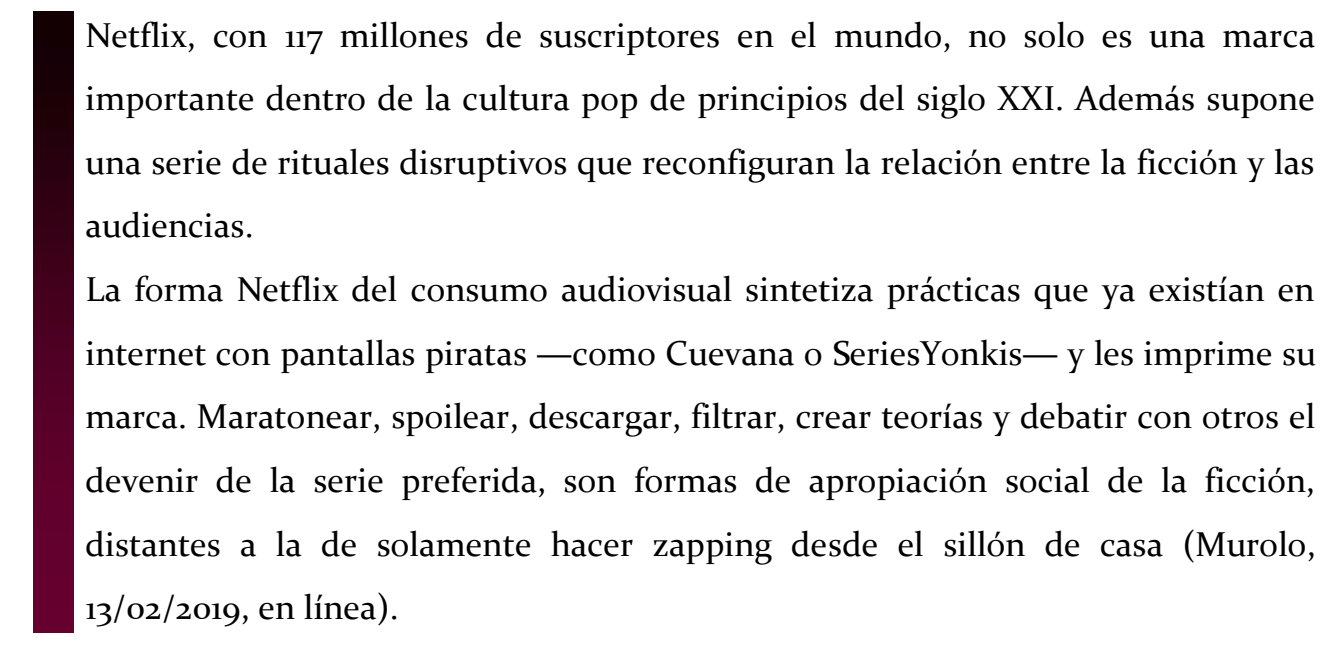

Y este fenómeno avanza de una manera profunda modificando las características que los medios tradicionales durante más de medio siglo consolidaron en las audiencias con la centralidad en la emisión en vivo, la unificación de gustos en franjas horarias, el consumo masificado y la ritualización del tiempo alrededor de estrenos, a punto tal de ubicarse hoy por encima de todos ellos. 
La historia de esta plataforma se remonta al 4 de abril de 1998, cuando comienza como una empresa emergente en California, con una propuesta: alquilar una película por unos pocos dólares más envío a través de su plataforma de comercio electrónico y un sobre rojo con un DVD que llegaba a tu casilla de correo. Después de siete días, podía ser devuelta por correo en el mismo paquete, una idea que el fundador de la empresa tomó del fastidio que le generaba que le cobraran un recargo por día en los videoclubes tradicionales de alquiler de películas.

Con el correr del tiempo, sosteniendo la marca y fusionando la tecnología de Silicon Valley con Hollywood, Netflix se convirtió, paralelamente, en una tienda virtual y en un servicio de transmisión que hoy está revolucionando completamente la industria audiovisual. Al momento de redactar este ensayo, Netflix posee 120 millones de suscriptores en casi todos los países del mundo (190 aproximadamente) y se proyecta que para 2023 llegue a los 200 millones (Ramsey, 16/05/2018).

Por otra parte, en la actualidad es más que conocida y trabajada la dinámica de consumo maratónico de series:

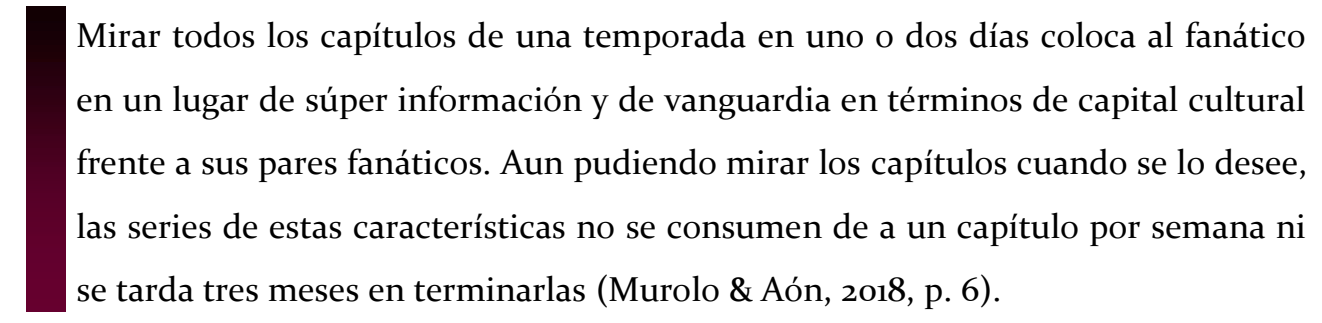

Pero, paralelamente a la reconfiguración de las formas en las cuales como sujetos nos vinculamos con estos productos de una manera compulsiva, que quizás también tiene que ver con el espíritu de época de expoliación al máximo en el menor tiempo posible de lo que sea que se cruce en el camino, lo más llamativo hoy pasa por la intromisión de Netflix en el mundo mucho más complejo y competitivo como el del cine.

En 2018, bajo la dirección de Scott Stuber, quien coordina la división de cine, promovieron el estreno de 86 películas de producción propia, frente a las 61 del año anterior, superando a los cuatro grandes estudios cinematográficos de Hollywood. Este movimiento se produce a medida que este gigante del streaming está aumentando el número de sus series de televisión originales y sus películas, una de las cuales, "Roma", 
obtuvo diez nominaciones a los premios Oscar, rompiendo una nueva barrera y sumando a lo que comenzó como un catálogo de películas on line el prestigio de pasar a ser una de las productoras audiovisuales más importantes del planeta.

Y este camino se consolidó con el ingresó a la Motion Pictures Association of America (MPAA) como miembro pleno. La MPAA, integrada hasta hace poco por seis grandes estudios de Hollywood (Walt Disney, Metro-Goldwyn-Mayer, Paramount Pictures, 2oth Century Fox, Universal Studios y Warner Bros), es el organismo no gubernamental que defiende los intereses de los productores de cine estadounidenses en todo el mundo. Es decir, la MPAA regula todas las relaciones importantes del cine; y en su seno se dan acuerdos para estrenar y difundir, así como se establecen políticas para, por ejemplo, luchar contra la piratería o pelear fechas de estreno en el resto del mundo. Ambas cosas — piratería y simultaneidad de estrenos- están vinculadas. La MPAA protege los intereses comerciales del cine de Hollywood en todo el mundo.

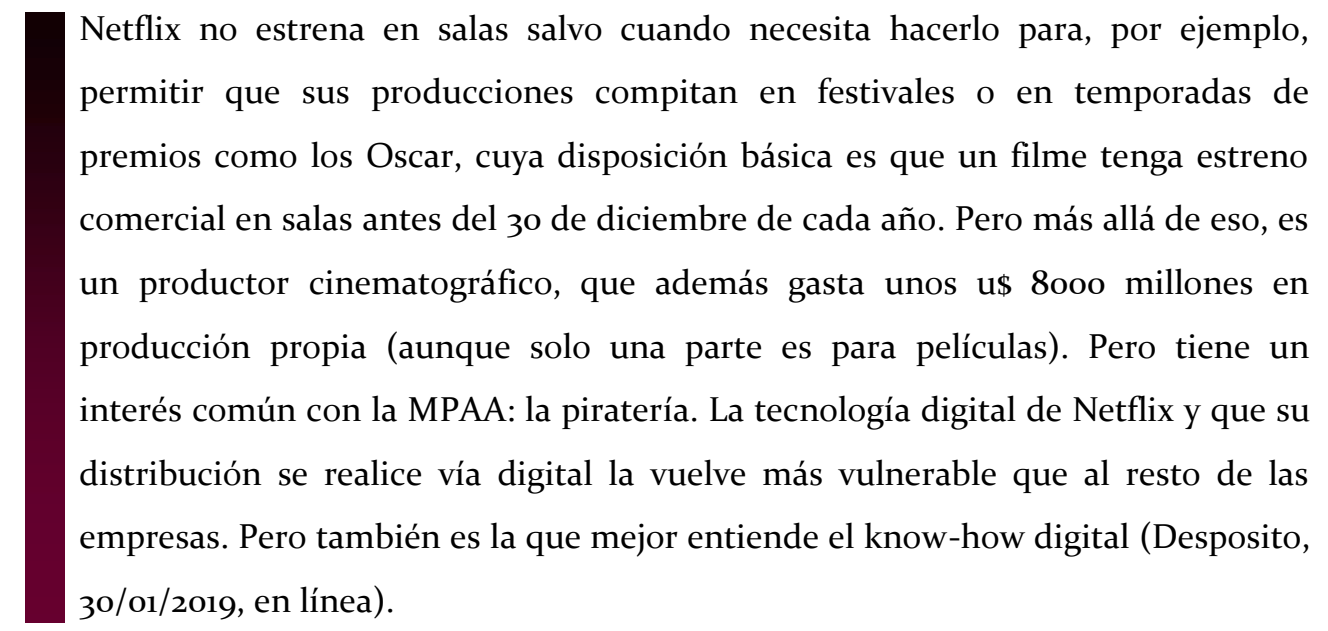

\section{El límite}

En este marco, cualquier persona podría pensar que las principales amenazas a las que enfrenta Netflix día tras día (son) Disney, Warner, HBO o Amazon Video. Sin embargo, la respuesta de Reed Hastings, CEO de Netflix, ha sido muy diferente.

\footnotetext{
(En Amazon) están haciendo una gran programación, y seguirán haciéndola, pero no estoy seguro de que eso nos afecte a nosotros porque el mercado es muy grande. Pensad sobre ello: cuando ves una serie de Netflix y te enganchas, te quedas hasta tarde viéndola. Realmente, y al final, estamos compitiendo con el sueño (PlaySeries, 19/04/2017, en línea).
} 
Esta polémica frase fue retomada por Netflix US, para ser tuiteada con aún más contundencia: "Sleep is my greatest enemy" (el sueño es mi mayor enemigo) y, por lo tanto, también el límite de quienes en algún momento debemos dormir.

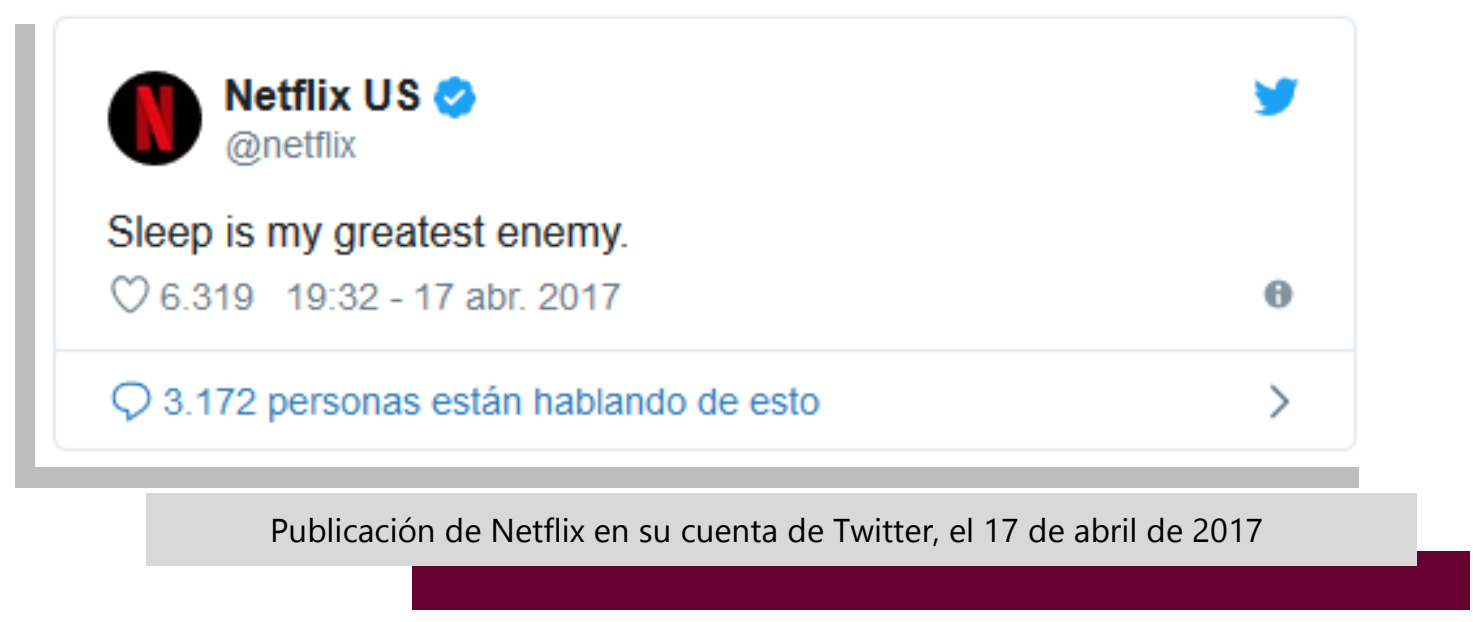

Hay, por ende, un elemento que nuevamente hace necesario salir de las condiciones de producción y ubicar el análisis en las condiciones de recepción y en las limitaciones que como humanos poseemos.

Esta frase, muy efectiva en términos de desprecio por la competencia, esconde un elemento que es explicable con un concepto que surge en los años setenta y que con el correr del tiempo fue ganando relevancia, aunque aún no se encuentra ubicado en el centro del debate en el campo de la comunicación y es central para poder avanzar en la descripción del contexto en el que nos encontramos: el concepto de economía de la atención.

Aquí, sumamos un elemento que necesariamente debe aportar de manera central en los estudios de comunicación, ya que por primera vez en la historia la capacidad como sujetos de atender a los múltiples discursos disponibles que insisten en interpelarnos es una de las principales limitaciones para que el sistema se desarrolle y crezca. Podemos ver una determinada cantidad de horas pantallas, luego debemos al menos dormir. En el resto de los momentos de nuestras vidas, cada vez más estamos conectados y mediados por dispositivos electrónicos que absorben nuestra fuerza laboral, nuestra necesidad de esparcimiento, nuestros deseos de vinculación con otros tipos de pulsiones que como humanos desplegamos hacia el entorno y que la digitalización de la cultura va canalizando aceleradamente para convertirse en poco tiempo en el mediador estructural entre los sujetos entre ellos y con el mundo. 
Esto se asienta en tres premisas simples pero que es necesario enunciar:

- Sobreabundancia de información con una oferta gigantesca y en muchos casos gratuita o de bajo costo de nuevas producciones.

- Tiempo escaso de los receptores por la condición vital de ser un sujeto que puede consumir limitadamente discursos tecno mediáticos.

- Múltiples mensajes distribuidos por una variedad cada vez mayor de plataformas que al unísono pugnan por interpelar a los sujetos.

La economía de la atención, representa un cambio de paradigma en la forma de entender la comunicación humana. Esta idea surge ante la abundancia y accesibilidad de la información, dando como consecuencia que se considere la atención humana como un bien escaso (Sociología y redes sociales, 06/04/2010, en línea).

En 1971, Herbert Simon, premio nobel de economía, construye este concepto hasta llegar a proponer que se trata de un modelo económico emergente en la era digital. Recordemos que Simon hace referencia a que el exceso de información convierte la atención humana en un bien escaso que es necesario distribuir eficientemente entre la abundancia de informaciones disponibles (Sociología y redes sociales, (o6/o4/2010, en línea).

La relación que tenemos con las multipantallas es un elemento central de la vida contemporánea, que no solo llegó para quedarse sino que se profundiza cada minuto que pasa. Esto es clave para pensar la relación que como sujetos, portadores hoy de un capital finito, tenemos de poder atender a las múltiples formas en que se nos interpela, siendo parte de un problema como bien señalan desde Netflix, ya que en algún momento debemos por ejemplo dormir.

\footnotetext{
Michael Goldhaber va más lejos al colocar la atención en la base de las necesidades humanas. Desde el bebé cuya supervivencia depende de que sea capaz de atraer la atención de los adultos, hasta el vendedor que intenta captar la atención de los consumidores, todo el mundo necesita que le presten atención para sobrevivir.

La atención es una fuerza conductora que permite lograr efectos en los demás, permite acceder a sus conciencias para transmitir nuestro mensaje. 
En la era digital, el crecimiento exponencial de la información disponible, la facilidad de acceso ilimitado y la popularización de los medios de generar información permiten pensar en el paso de una economía basada en el intercambio de dinero a una economía basada en el intercambio de atención. El intercambio de dinero seguirá presente, pero se guiará por los flujos de redistribución de la atención, especialmente a través de la Red (Sociología y redes sociales, 06/04/2010, en línea).

Esta perspectiva la podemos encontrar parcialmente ratificada en esos segundos que por mirar un video o por escuchar una canción Youtube o Spotify nos piden a cambio al mirar una publicidad que se inserta.

Así, parte de las características de la comunicación on-line que hacen que este concepto tome importancia son, por un lado, el aumento de la facilidad para generar contenidos y la comunicación cotidiana mediada por mensajes, y por otro lado, la existencia de información activa, es decir, programas informáticos que operan sobre la información haciéndola accesible, ordenándola, estructurándola, falsificándola o reproduciéndola con alguna finalidad especifica.

Es evidente que la reciente (y muy creciente) digitalización de la mayoría de los
procesos comunicativos que se realizan en las sociedades postindustriales
provoca un crecimiento exponencial de los datos, que deben ser asimilados,
clasificados, comparados, monitorizados. Es una tarea cada vez más ardua que
provoca que la atención sea uno de los bienes más escasos de este nuevo
paradigma.
Si hasta hace unos años, con audiencias monoplataforma y cautivas, era posible
gestionar audiencias cautivas, hoy la promiscuidad es una constante. Atraer la
atención de las audiencias, cautivar su confianza, generar interés continuado y
convencer es la estrategia adecuada (Velilla, 15/o1/201/, en línea).

En este marco es en el que Netflix se ha ganado un lugar central en occidente y es por ello que es necesario analizarlo. La economía de la atención, nos sirve como marco interpretativo del contexto de extrema competencia en el que esta nueva plataforma se abre lugar, pero también nos permite reconocer cuál es su principal desafío, en un momento en el que con la apertura de oficinas de producción primero en España y luego en México, Netflix apoya en América Latina parte de sus expectativas de crecimiento y con ello su cada vez más poderosa incidencia en la conformación de la subjetividad de quienes habitamos esta región. 


\section{Nuevas formas de leer}

Para avanzar un paso más allá en el análisis de una plataforma que vincula estrategias de construcción de narrativas seriales consolidadas para ser devoradas bajo formas maratónicas, junto con algoritmos que ajustan el final de un capítulo con el otro, el principio de una serie con otra y así sucesivamente en un loop infinito, caracterizan uno de los fenómenos audiovisuales más importantes de esta época, continuamos desentramando para analizarla desde miradas económicas, mediáticas, organizacionales y culturales, permite adentrarnos en uno de los sistemas más disruptivos del ecosistema mediático y que está trastocando de fondo reglas que durante años fueron estables en el mundo del audiovisual.

Netflix se ubica en lo que podemos denominar "postbroadcasting: un espacio central en el ecosistema de las mediatizaciones sociales en el que están en tensión intercambios networking con intercambios broadcasting” (Fernández, 2016, p. 72). Esto implica insertarse entre un modelo de transmisión masiva y lineal con una única fuente y múltiples receptores y uno de comunicación en red vinculado a la forma de funcionamiento de internet. De esta forma Netflix no trabaja completamente ni en un modelo ni el otro, sino sobre la base de una plataforma mediática que fruto de la convergencia tecnológica logra reestructurar sobre una arquitectura informática una nueva modalidad de distribución y consumo de material audiovisual.

Jorge Carrión, en una nota en el New York Times, publicada en febrero de 2019, propone:

Spotify, YouTube, Vimeo, Netflix, HBO, Amazon, SoundCloud, iTunes, App Store, Filmin o Storytel son algunas de las grandes marcas culturales de nuestra época. Algunas de ellas tienen incluso el poder de incipientes mitos.

Su influencia en nuestros modos de consumo cultural está siendo superlativa. Aunque se articulen como archivos de archivos (de canciones, podcasts, discos, vídeos, películas, series, libros o audiolibros) su impacto va mucho más allá de la posible producción y de la decisiva distribución. Han ido imponiendo nuevos mecanismos de lectura, como el canal, la lista de reproducción, la app, las recomendaciones, el play automático del siguiente capítulo, la superproducción cinematográfica que no se estrena en cines o el lanzamiento de toda una temporada de una serie (eliminando de paso su serialidad). 

inteligencias colectivas, tanto humanas como matemáticas (Carrión, 10/02/2019, en línea).

Y es así que la primera gran característica que destacamos es justamente la que Carrión (2019) llama nuevas formas de leer. En un cruce entre producciones audiovisuales de diferente género, estilo y duración, con mecanismos automatizados de recolección de datos, procesamiento y recomendación automatizada a partir de la compactación de los gustos de cada usuario por parte de una inteligencia artificial que coordina los movimientos no solo temporales, sino incluso el tipo de imágenes que veremos como recomendación de cada producción (existen 14 tapas posibles para cada producción de netflix, pero según los gustos de cada usuario, la misma serie o película será presentada con un actor masculino, una mujer, una escena de sexo o un paisaje al amanecer).

En la misma nota, Carrión (2019) afirma que para analizar estas plataformas debemos

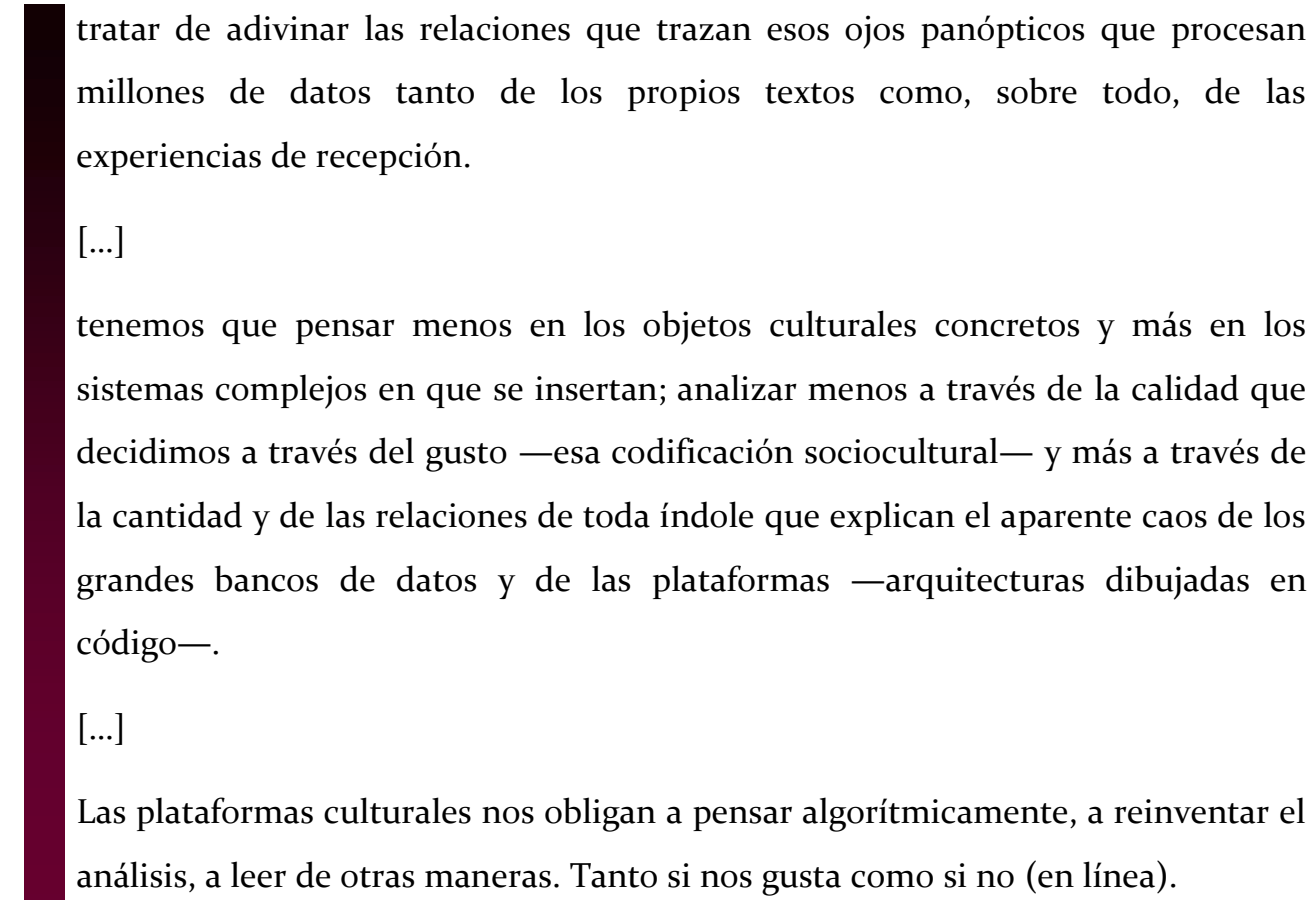

Así, para profundizar sobre el fenómeno de Netflix, se deben hacer esfuerzos analíticos poniendo en diálogo diferentes campos del conocimiento, adoptando otras lógicas como las que del despliegue de algoritmos proviene, sumar elementos del campo comunicacional de los estudios de medios, la historia formal de la empresa pero sobre todo, el contexto de digitalización de la cultura en el que esta plataforma audiovisual, 
aparece como uno de los emergentes principales de época y que inexorablemente debemos destacar para seguir rodeando la problemática de la digitalización de la cultura y su impacto en la configuración de nuestra subjetividad.

Las plataformas y sus algoritmos han llegado para quedarse, son un espacio
donde se expresa todo tipo de conflictos y sería un gran error político negar su
existencia o plantearse un repliegue ("me voy de Facebook"). ¿Cuántos de esos
colegas que levantan las banderas del "malestar en la cibercultura” están
dispuestos a abandonar las redes sociales, los servicios de Gmail o Whatsapp, o
dejar de mirar series en Netflix? Más que quedarnos lagrimeando porque
"Facebook sabe todo de nosotros" o "Netflix diseña series a partir de los
algoritmos", lo más productivo es comprender cómo funcionan estos espacios y
activar otros espacios o usos dentro (y fuera) de ellos (Scolari, 19/05/2019, en
línea).

Recordemos que la aparición de formas de leer el mundo, parafraseando a Freire, desde las propuestas de Scolari y de Carrión (2009), son un elemento clave en la conformación de prácticas culturales que modifican nuestra percepción, nuestro sensorium y por lo tanto hay un punto en que son y deben ser consideradas como pedagógicas ya que forman al sujeto contemporáneo en unos modos de consumo novedosos con los cuales otros procesos de la vida cotidiana deben dialogar.

El tipo de contenidos propuestos desde esta plataforma, los sentidos producidos, los mundos imaginados, las construcciones del futuro (centrales en la narrativa de Netflix) y muchos elementos más que corresponden al análisis discursivo y a la crítica cultural no pueden desconocerse en su dimensión performativa.

\footnotetext{
En la década del ochenta Eliseo Verón (1984) distinguió una sociedad mediática (moderna) de una sociedad mediatizada (posmoderna). En la sociedad mediática los medios pusieron en juego una estrategia del orden de la representación e intentan funcionar como "espejos" de lo real: quisieron representar lo que acontecía en la vida social. En una sociedad mediatizada los medios masivos asumieron su capacidad para construir los acontecimientos y, por ende, la realidad como fenómeno compartido (Carlón, 2017, p. 3).
} 
Este elemento es complementado con un fenómeno en el cual los sujetos dejamos de estar con los medios, a pasar a estar en los medios, allí trabajamos, nos relacionamos, vivimos experiencias de diversa índole y por supuesto nos formamos. En este sentido, la diferencia substancial es que la sociedad mediatizada, se construye en ese continuum on/off line en el cual lo real y lo virtual están articulados de tal manera que son indisociables en la experiencia vital de ser y de estar en este mundo.

La estructuración de la sociedad se juega cada vez más en procesos que son de orden simbólicos que conjugan la digitalización, la convergencia y la interactividad como elementos fundamentales de la hipermediación.

Es necesario pensar las hipermediaciones en las prácticas cotidianas, como señala Scolari (2008) quien retoma los planteamientos mediacionales expuestos por Jesús MartínBarbero en los ochenta. Para una teoría sobre la nueva realidad comunicativa mediada por las TIC, el autor plantea la importancia de pasar del análisis de los llamados nuevos medios digitales (los objetos) al de las hipermediaciones (los procesos). Así, a la mayor cantidad de medios y de sujetos se suma la trama de reenvíos e hibridaciones que la tecnología digital, al reducir todas las textualidades a una masa de bits, permite articular dentro del ecosistema mediático. En este sentido es que podemos pensar el concepto como un fenómeno de relaciones.

Para profundizar este abordaje retomamos las conceptualizaciones sobre convergencia, lo que implica a su vez los cambios tecnológicos, industriales, culturales y sociales en la circulación de los medios en nuestra cultura. Entre las ideas comunes a las que se refiere el término figuran el flujo de contenidos a través de múltiples plataformas mediáticas tanto como la volatilidad de las audiencias que no están sujetas a un medio o dispositivo sino más bien a la propuesta de entretenimiento que desean.

En términos más generales, la convergencia mediática designa una situación en la que coexisten múltiples sistemas mediáticos y en la que los contenidos mediáticos discurren con fluidez a través de ellos. El concepto se entiende aquí como un proceso o una serie de intersecciones entre diferentes sistemas mediáticos y no como una relación fija (Jenkins, 2006).

Entonces, la convergencia tecnológica como fenómeno cultural modifica las prácticas individuales y sociales. La cultura distintivamente internalizada en forma de habitus (Bourdieu [1980] (2007)) en las identidades de los sujetos se actualiza en las prácticas 
culturales. La industria cultural en la era de las TIC se reconfigura en el momento de la reproducción de la cultura y, sobre todo, en sus formas de circulación y de consumo. Esto es clave para reconocer a los niños y jóvenes de hoy.

Los contenidos de entretenimiento no son lo único que fluye a través de las múltiples plataformas mediáticas. Nuestras vidas, relaciones, recuerdos, fantasías y deseos también fluyen por los canales de los medios (Scolari, 2013).

\section{Consideraciones finales}

Este ensayo responde, centralmente, al objetivo inicial de esta tesis que está puesto en conmover al lector con el impacto que este nuevo ecosistema tecno mediático está generando en nuestra sociedad y de qué manera las nuevas arquitecturas informáticas que soportan interfaces como Netflix, configuran procesos de subjetivación que van mucho más allá del hecho en sí de consumir un producto audiovisual, sino que son una parte central y estratégica del proceso de digitalización de la cultura.

Por lo tanto, aquí se podría haber tomado para ejemplificar lo que se presenta otra plataforma, como Youtube, porque en realidad de lo que aquí se trata es de ver con contundencia, los elementos que están en un lugar claramente identificables como fruto del paso de un formato de comunicación masiva a un modelo de cultura digital.

En el campo de comunicación / educación, como ya se mencionó, la tensión cultura escolar - cultura mediática vuelve a parecer aquí pero ya no solo vinculada a elementos generales, sino a la posibilidad de contrastar parte del proceso de disputa por la atención humana, como un elemento clave en la batalla por la hegemonía actual. Es decir, que debemos también repensar estas plataformas mediáticas, en su vinculación con la configuración de poder y en la formación de sujetos y subjetividades.

Esto implica poder ver como paradigmáticos, algunos procesos como el de Netflix, que afectan la televisión, el cine, las formas de distribución, de consumo audiovisual o simplemente como dijimos, de leer el mundo.

No es el objetivo del ensayo desplegar elementos que son ampliamente profundizados por Jose Van Dijck, Carlos Scolari, Henry Jenkins o José Luis Fernández entre otros, sino más bien articularlo con un sistema de pensamiento complejo que posibilite en el entramado construido, ver los límites de lo que sucede en términos de socialidad es 
decir, recuperar las formas en que la configuración de la subjetividad hoy se despliega en un marco en el que muchos de los fenómenos mediáticos que fueron característicos de décadas atrás están dando paso a estos nuevos emergentes y desde allí, preguntarnos por lo educativo de estos procesos, ya que como afirmamos a lo largo de toda esta tesis, uno de los grandes desafíos del futuro será sostener la tensión entre el discurso (tecno) mediático que crece, se fortalece y se diversifica día a día, y el discurso escolar que aún no logra configurarse para poder interpelar a los sujetos que hoy habitan en su espacio en el marco de una socialidad conectada (Van Dijck, 2016). 


\section{Referencias}

Bourdieu, P. [1980] (2007). El sentido práctico (Trad. Ariel Dilon). Madrid, España: Taurus.

Carlón, M. (2017). Documento teórico metodológico (apunte de cátedra). Semiótica de redes, Facultad de Ciencias Sociales, Universidad de Buenos Aires.

Carlón, M. y Scolari, C. (2009). El fin de los medios masivos. Ciudad Autónoma de Buenos Aires, Argentina: La Crujía.

Carrión, J. (10 de febrero de 2019). Las plataformas transforman nuestros modos de leer. Recuperado de https://www.nytimes.com/es/2019/o2/10/cultura-plataformasamazon-netflix/

Desposito, L. (30 de enero de 2019). Netflix ingresa a la Motion Pictures Association of America. Recuperado de https://www.baenegocios.com/espectaculo/Netflix-ingresa-a-la-Motion-PicturesAssociation-of-America-20190129-0068.html

Fernández, J. L. (2016). Plataformas mediáticas y niveles de análisis. Inmediaciones de la comunicación, (11), 71-96. Recuperado de https://revistas.ort.edu.uy/inmediaciones-de-la-comunicacion/article/view/2618

Jenkins, H. (2006). Convergence culture: la cultura de la convergencia de los medios de comunicación. Madrid, España: Paidós.

Murolo, L. (13/02/2019). ¿Por qué Netflix? Recuperado de https://www.pagina12.com.ar/174666-por-que-netflix

Murolo, L. y Aon, L. (2018). Maratón en Netflix. House of cards, entre la narrativa de la televisión y la web. Tram[p]as de la comunicación y la cultura, (82), eo23. https://doi.org/10.24215/2314xeo23

PlaySeries (19 de abril de 2017). El gran competidor de Netflix es el sueño. Recuperado de https://www.abc.es/play/series/noticias/abci-gran-competidornetflix-sueno-201704192030 noticia.html 
Ramsey, C. (16 de mayo de 2018). Netflix to reach 201 million subscribers by 2023.

Recuperado de https://www.tvbeurope.com/data-centre/netflix-to-reach-201million-subscribers-by-2023

Rincón, O. (Comp.) (2005). Televisión pública: del consumidor al ciudadano.

Ciudad Autónoma de Buenos Aires, Argentina: La Crujía.

Rincón, O. (2006). Narrativas mediáticas. Barcelona, España: Gedisa.

Scolari, C. (2008). Hipermediaciones. Elementos para una Teoría de la Comunicación Digital Interactiva. Barcelona, España: Gedisa.

Scolari, C. (2013). Narrativas transmedia. Cuando todos los medios cuentan. Barcelona, España: Planeta.

Scolari, C. (19 de mayo de 2019).La guerra de las plataformas (III). Recuperado de https://hipermediaciones.com/2019/05/19/la-guerra-de-las-plataformas-iii

Sociología y redes sociales (06/04/2010). Economía de la atención III - Análisis del concepto de Michael Goldhaber. Recuperado de http://sociologiayredessociales.com/2010/o4/economia-de-la-atencion-iii-analisisdel-concepto-de-michael-goldhaber/

Velilla, J. (15 de enero de 2010). Economía de la atención: "la abundancia de la información da lugar a la pobreza de la atención". Recuperado de http://www.javiervelilla.es/wordpress/2010/o1/15/economia-de-la-atencion-laabundancia-de-la-informacion-da-lugar-a-la-pobreza-de-la-atencion/

Van Dijck, J. (2016). La cultura de la conectividad. Una historia crítica de las redes sociales (Trad. Hugo Salas). Ciudad Autónoma de Buenos Aires, Argentina: Siglo XXI.

Wolton, D. (2000). Internet, ¿y después? Una teoría crítica de los nuevos medios de comunicación. Barcelona, España: Gedisa. 


\title{
Un final, a riesgo de equivocarnos
}

\author{
Aquello que es complejo recupera, por una parte, el mundo empírico, \\ la incertidumbre, la incapacidad de lograr la certeza, de formular una ley eterna \\ y, por el otro, la incapacidad de evitar contradicciones.
} Edgar Morin y otros (2003)

Hasta aquí, hemos avanzado en un recorrido que da cuenta, por una parte, de fenómenos concretos, que se encuentran efectivamente sucediendo más allá de las posibles interpretaciones que de ellos hagamos, en donde lo educativo y lo comunicacional se imbrican en un proceso de reconfiguración al estar directamente afectados por la digitalización de la cultura. Allí, en ese devenir, es en donde se hace imposible consolidar certezas, formular leyes eternas y evitar las contradicciones que, seguramente, a lo largo del trabajo habrán quedado evidenciadas.

La incerteza como método de trabajo permite avanzar en una conjunción de elementos que son fruto de un movimiento epistemológico que reemplaza las hipótesis y las contrastaciones de unas determinadas afirmaciones, por mapas nocturnos en los cuales salimos a buscar sin saber siempre qué es lo que encontraremos, hacia dónde nos derivará el siguiente recorrido y de qué forma se irá configurando una cartografía posible que nos dé la posibilidad de navegar, al menos, una parte del revuelto mar de la convergencia. Pero el esfuerzo por sostener estas tensiones sobre la perspectiva de un conocimiento inacabado, difuso, es también uno de los pilares en el que encontramos una fortaleza mayor de este escrito.

Realizar un recuento de lo acontecido constituye también una instancia de aprendizaje. En el mito del eterno retorno apelamos a una visión circular sobre lo visto y escrito en el tiempo que nos permite repensar lo realizado, reelaborar, volviendo hacia atrás en un bucle inacabado, donde hay un principio del tiempo y un fin, que vuelve a generar a su vez un principio. Sin voluntad de sostener una visión cíclica del tiempo, porque no se 
trata de ciclos ni de nuevas combinaciones en instancias posibles, sino de que los mismos acontecimientos se repiten. Sin embargo, para nosotros en el retorno se ve la variación y la emergencia de nuevos saberes.

En su obra La gaya ciencia (1882), Friedrich Nietzsche plantea que no solo son los acontecimientos los que se reiteran, sino también los pensamientos, los sentimientos y las ideas, vez tras vez, en una repetición infinita e incansable, que para nosotros se configura, en la recuperación de lo elaborado, también en una instancia formativa.

Presentar perspectivas que en muchos casos son antagónicas, como las provenientes de campos del conocimiento como el de las neurociencias y las que son fruto de las matrices de nuestra América Latina, donde se recuperan dimensiones clave como la emoción y la sensibilidad; el intentar poner en relación medios educativos de la talla de Canal Encuentro y de Pakapaka con la complejidad de las plataformas mediáticas de hoy como es el caso de Netflix; tensar una cultura escolar con una cultura (tecno) mediática, sabiendo que una no debe salir de atrás de la otra pero paralelamente que tampoco puede desconocerla; reconceptualizar las formas de circulación del poder y la configuración de hegemonías, no solo a partir de las relaciones sociales, sino del sensorium con el cual percibimos el mundo, son elementos que fueron conformando una matriz de análisis de la convergencia como proceso epistémico, técnico y cultural.

En nuestras indagaciones no hay respuestas acabadas sino más bien obstáculos y dificultades que responden al modo de comprender y de realizar un análisis de estas características sobre fenómenos multidimensionales que habilitan repensar en la actualidad la articulación entre comunicación / cultura / educación.

La convergencia tecnológica afecta las subjetividades y las identidades sociales que requieren una atención detenida y un reconocimiento. Perder la capacidad de reconocer esos procesos nos resta posibilidades de intervenir sobre ellos y, por lo tanto, de modificarlos. Si consideramos que la dimensión estratégica del campo de comunicación / educación justamente se ubica en su carácter político, este elemento es clave para devolverle su horizonte transformador.

Así, dejar en evidencia lo que sucede permite recuperar en un momento de gran incertidumbre algo del diagnóstico necesario para cualquier proceso de planificación y de gestión que integre una intencionalidad transformadora, como sucede históricamente desde el campo de comunicación / educación. 
Y allí nos ubicamos, en recuperar su dimensión como espacio estratégico no solo para analizar las prácticas educativo comunicacionales, sino para imaginar mundos posibles, para repensar procesos emancipatorios y para aportar desde las tramas históricas que nos constituyen posibles respuestas a las preguntas que un mundo convergente nos desafía a realizarnos.

Avanzamos en un contexto en el cual se nos incita a reflexionar sobre el lugar de la escuela como último espacio de la Nación (Puiggrós, 23/05/2019) o como última plataforma de la Patria (Puiggrós, 30/05/2019), donde se produce aquella filiación que teje en una trama invisible el fruto de la historia, de los procesos y de las luchas que nos anteceden, una subjetividad compartida que articula el ser colectivo y configura en parte la ciudadanía. En ella debemos reencontrarnos, porque así lo requiere la posibilidad de sostener una construcción en la que el ser individual, la meritocracia y el aislamiento queden relegados ante proyectos de una construcción común.

En las notas de Pedagogía de la esperanza. Un reencuentro con la Pedagogía del oprimido (1992), Ana María Araújo escribe que la posibilidad de orientarse hacia una utopía histórica o un sueño posible requiere de un conocimiento preciso de las múltiples situaciones que podrían interponerse como barreras que deben ser vencidas a nivel existencial, social e histórico. Esas barreras son las que Paulo Freire ([1992] 2008) identifica como "situaciones límite", que se pueden interpretar o como obstáculos que no se pueden o no se quieren superar o como algo que se sabe que existe y que es necesario trascender.

Ese momento de trascendencia del obstáculo, ese momento en el que se hace presente en nuestra conciencia la posibilidad de superar esa barrera, es el origen y el fundamento de la esperanza. Ese momento de cambio de conciencia supone, según Freire ([1992] 2008), al menos una condición necesaria: la de convertir aquella situación, que inicialmente concebíamos como una resistencia que se nos oponía, en objeto de conocimiento. Solo entonces, estas "situaciones límites" pueden ser sobrepasadas a través de "actos límites" que se dirigen, simultáneamente a la "superación y a la negación de lo dado" (Freire, ([1992] 2008), p. 234). Es decir, esta superación requiere de la certeza de que lo que se nos opone no es una cualidad óntica de la existencia sino el resultado de ciertas condiciones históricas que la determinan. 
En el momento en que los sujetos perciben ya no más como "frontera entre el ser y la nada, sino como una frontera entre el ser y el más ser", se hacen cada vez más críticos en su acción ligada a aquella percepción. Percepción en la que se encuentra implícito el inédito viable como algo definido a cuya concreción se dirigirá su acción (Freire, [1968] (2005), p. 126).

Por ello, necesitamos considerar la situación actual desde una perspectiva entre la esperanza y la desesperanza, entre el ser y la nada, y el ser y el ser más. Nos encontramos ante una situación límite, por lo que necesariamente debemos acudir al inédito viable. A esta instancia a la que Freire ([1992] 2008) nos desafiaba a ir, recuperando las tramas de nuestra historia y la complejidad del escenario, por vías que aún no han sido exploradas pero que por ello no dejan de ser una opción históricamente posible.

La cultura digital realiza una nueva arquitectura simbólica, que reconfigura la relación entre los sujetos, las prácticas y los saberes a partir de la programación matemática de sistemas informáticos que procesan a velocidades sobrehumanas cada vez más información.

Así como la Escuela de Frankfurt copiaba en el siglo XX las formas de reproducción del capital, y así denominaban "era de la reproductibilidad técnica" a este modelo útil para describir lo que fue el inicio de la cultura masiva y el desarrollo de los medios de comunicación, hoy nos encontramos en una nueva etapa que aún no muestra el lugar al cual nos puede arrojar.

Si la cultura se digitaliza, y por lo tanto se modifica profundamente, los elementos que históricamente anudamos a ella como son los de la comunicación y la educación, ambos impensables por fuera de la misma, se van a ver afectados en diversas formas, y sin lugar a dudas, sustancialmente transformados.

En nuestro recorrido hay cuatro nudos problemáticos que, vistos desde el paradigma de la complejidad, poseen su propio desarrollo interno, pero a su vez se relaciona con los demás y en esa articulación también se ven modificados.

El primer nudo es el elemento central de esta tesis que tiene que ver con afirmar que el proceso de digitalización de la cultura es una nueva forma en que se va reestructurando el campo simbólico, no solo por la mediación tecnológica sino por la internalización de procesos hipermediados en los sujetos, que luego son actualizadas en sus prácticas 
cotidianas muchas veces no mediadas. Esta situación base posee una doble derivación fundamental para analizar las formas de interpelación a los sujetos, es decir que se ubica en el tipo de procesos comunicacionales que hoy encontramos para repensar, por un lado, lo mediático y, por el otro, los procesos de formación.

El segundo nudo, entonces, se ubica en las problemáticas educativas, en la reconfiguración de la subjetividad de los sujetos a partir de este contexto y desde allí la necesidad de reconocerlos para lograr construir tanto dinámicas áulicas, instituciones, diseños curriculares y marcos normativos que, fruto de la historia, reconozcan transversalmente que una nueva revolución aconteció y que las respuestas anteriores hoy dejan de tener cada vez más sentido y, sobre todo, eficacia y funcionalidad.

El tercer nudo, proveniente del nuevo ecosistema mediático, necesita permitirnos reconocer qué cambios se generan hoy en los sujetos en su acople constante a las micro y macro pantallas, cómo los discursos que apelan a la emoción se enredan en estas lógicas, y de qué manera las plataformas nos intentan retener dentro, para monetizar uno de los nuevos bienes escasos hoy por excelencia: la atención humana.

Finalmente, el cuarto y último nudo corresponde a poder sincerarnos desde el campo académico y reconocer cada vez más la imposibilidad de abordaje de los fenómenos aquí mencionados desde una disciplina en particular. Así como se comienzan a fundar en diferentes lugares del planeta espacios dedicados a problematizar por ejemplo la Inteligencia Artificial, con profesionales de las más diversas áreas del saber y con los más variados conocimientos técnicos, necesitamos desde el sur avanzar en esta línea y potenciar nuestras tradiciones un paso más, buscando responder a estos nuevos interrogantes. Para ello, el paradigma de la complejidad es una mirada epistemológica necesaria, que habilita la articulación transdisciplinaria, pero aún no sabemos qué otros elementos debemos construir para poder tomar seria y fuertemente una transformación tan profunda como la que hasta aquí se analizó. Hemos pasado de un televisor en el centro del comedor hace cincuenta años, a estar literalmente conectados a un smartphone y todo este escenario abierto e inacabado también posee algún grado de estabilidad que podemos enunciar.

La digitalización de la cultura posee un grado de afectación profundo en la vida cotidiana y altera las más profundas estructuras de socialización de los sujetos; como dijimos, allí se produce un encuentro entre las prácticas culturales cotidianas y una nueva arquitectura de algoritmos programados para procesar parte de nuestras vidas en un 
novedoso repertorio de experiencias vitales que Ana Brizet Ramírez Cabanzo (2014) da en llamar "temporalidades online-offline" (s/p), que se despliegan ya sin interrupción y estructurando una realidad que carga dentro de sí misma la virtualidad como un modo más de relación con los otros y con el mundo.

La posibilidad que posee lo digital de modelizar paulatinamente la cultura y su producción sociohistórica deviene en matriz de constitución de los sujetos y de sus modos de comprensión y de producción social, transformando la digitalización de la cultura en un elemento performativo.

Al decir de José Van Dijck (2016), “hacer social la red' en realidad significa 'hacer técnica la socialidad” (p. 30). Esta socialidad tecnológicamente codificada convierte las actividades de las personas en fenómenos formales, gestionables y manipulables, lo que permite a las plataformas dirigir la socialidad de las rutinas cotidianas de los usuarios. Sobre la base de este conocimiento íntimo y detallado de los deseos y los gustos de las personas, las plataformas desarrollan herramientas pensadas para crear y para conducir necesidades específicas.

Podemos decir, entonces, que los análisis de información que se realizan en los llamados Big Data no están relevando elementos aislados de los sujetos y de las comunidades, sino que se puede afirmar, de manera contundente, que llegamos a un estadio en el cual lo que empieza a ser aprehensible son las matrices culturales que configuran las identidades (individuales y colectivas) y, por lo tanto, la combinación de los diferentes rasgos que las componen (gustos, miedos, deseos, consumos, repulsiones, etc.). Esto permite, en la actualidad, configurar estrategias que apelan decididamente sobre sujetos (individuales y colectivos) que pueden ser micro políticamente interpelados para tal o cual finalidad, con altos grados de afectación y con la posibilidad de predecir su accionar con un nivel de certeza hasta hoy insospechado.

Entonces, la capacidad de los algoritmos de relevar las matrices de identidad y de reconocer sus características principales habilita a que los procesos comunicacionales hipermediados sean, como dijimos, profundamente performativos.

Esto sucede ya que, al abrirse la posibilidad de construir una interpelación, desde un discurso microtecnológicamente diseñado, se produce, en muchos casos, no solo un proceso comunicacional sino también un hecho educativo, pedagógico, a partir del cual se modifican las prácticas de los sujetos en relación con la propuesta planteada. Es por ello que debemos refinar una mirada que pareciera retomar las viejas nociones de falta 
de libertad del receptor, ampliamente debatidas en los años ochenta, y que hoy es necesario recuperar, con mayor finura y delicadeza en el análisis, ya que las herramientas para configurar los conjuntos textuales (multimediales, emocionales y multipantallas algorítmicamente diseñados) habilitan la configuración de mensajes con una capacidad contundente de afectación.

\section{Prospectivas posibles}

Mucho se escucha sobre lo que debemos hacer, para dónde ir, qué medidas tomar, pero mientras más indagamos en el fenómeno, más nos damos cuenta de que aún el principal problema es tomar dimensión de lo que está sucediendo, para abordar un proceso que, al decir de muchos de los autores mencionados (Sibilia, 2009; Sadin, 2017), atenta contra la existencia misma del ser humano tal y como lo conocemos.

Es por ello que este trabajo es de carácter ensayístico y exploratorio, ya que no posee una intención programática lineal ni tampoco pretende resolver problemas específicos, aunque sí ser un aporte concreto en pos de mucho de lo que se debe abordar.

Pero si atamos algunos cabos sueltos, como el descubrimiento cada vez más certero de la poca incidencia de lo racional en nuestra toma de decisiones, sumado a las nuevas posibilidades de interpelación de las audiencias que poseen las multipantallas, podemos asumir que quienes dominan hoy algunos campos técnicos de conocimiento, que se apoyan en estas premisas y en los soportes disponibles, ya gestionan, es decir planifican, ejecutan y consiguen resultados en un mundo que existe pero que todavía en muchos de los espacios intelectuales y académicos nos cuesta ver. Donde algunos hoy, fruto de avances científicos y transformaciones tecnológicas, despliegan profesiones que permiten gestionar emociones a escala masiva con fines electorales o comerciales, otros aún estamos debatiendo si el fenómeno existe o no, como si pudiéramos tapar el sol con las manos.

Esto es central, también como dijimos, en los procesos educativos. Allí, la tríada docente, estudiante e institución formadora se ve alterada de diferente forma y, por supuesto, en todas sus articulaciones posibles: estudiantes que son formados en el mundo contemporáneo interpelados por conjuntos textuales complejos, audiovisuales, diseñados para movilizar emociones, se enfrentan a discursos escolares racionales, diseñados para movilizar emociones, se enfrentan a discursos escolares racionales, lineales, con lógicas del palimpsesto en épocas del hipertexto (Martín-Barbero, 2017). 
En esta tesis hemos recorrido algunos interrogantes clave, reuniendo miradas dispersas como pueden ser las de expertos en informática, comunicadores, sociólogos, filósofos y educadores, entre otros, recuperando investigaciones y trabajos realizados sobre el campo mediático y el educativo, que de diferentes formas aporten a construir un corpus que permita conmover a quienes lean, con el simple objetivo de movilizar para tomar cartas en un asunto que ya está en juego, pero para el que en muchos casos aún ni siquiera nos hemos sentado a la mesa dispuestos a participar.

Los doce ensayos en busca de una narrativa piden respuestas situadas, que recuperen nuestra voz, y es por ello que aquí se trabajó para la comprensión de cambios tecnológicos, sociales y políticos desatados en el entramado global, que hoy ya son de larga data si nos remitimos a su origen bélico en una actualidad densa y profusa. Parece tratarse de otro salto civilizatorio en puerta que no se está viendo ni reconociendo pero que exige dejar de mirar el árbol para reconocer la existencia de un bosque detrás. Tal vez nunca como hasta ahora tuvimos las comodidades de las que ahora gozamos pero tampoco hemos aceptado como ahora las desigualdades injustas que dejan personas en situación de exclusión completa.

La interpelación está dispuesta y se hace imperiosa para reconocer los silencios y las voces de América latina. ¿Serán esas respuestas justo lo que necesitamos? Es imposible saberlo, pero como decía Simón Rodríguez: “O inventamos, o erramos”.

El estatuto del saber se encuentra en discusión, las formas de ser y de estar en el mundo se modifican y los aprendizajes acontecen en la interseccionalidad, en el lugar de cruce de matrices culturales en donde la convergencia digital hace parte de la construcción social de las identidades. Salir de miradas tecnofóbicas nos permite comprender que las multiplataformas en la era del algoritmo reestructuran el pensamiento no solo en relación con el campo de comunicación / educación sino también en la comprensión y en el desarrollo de las ciencias sociales, donde se requiere cada vez más la presencia de las diversas disciplinas, su capacidad de diálogo y su complementariedad.

Indagar en esta línea abre la posibilidad de preguntarnos: ¿podemos dejar de lado que los cuerpos comienzan a estar intervenidos por dispositivos que se acoplan a ellos cotidianamente para cosas tan importantes como medir la glucemia o monitorear funciones cardiacas, sin suponer tal vez que esta no es una excepción, sino una forma que comienza a aparecer? ¿Podemos pensar que los formatos de enseñanza de las instituciones modernas tienen sentido en este escenario? ¿Hasta cuándo vamos a esperar 
para modificar las escuelas, cuánto tiempo más tendremos para problematizar la política con las nuevas reglas establecidas? ¿Podemos abandonar la producción de mensajes en la lógica multiplataforma como magistralmente comenzaban a hacerlo Pakapaka y Encuentro? ¿Hay alguna chance de no pensar cómo será nuestro próximo Conectar Igualdad? ¿Podemos no pensar que Facebook posee en Occidente la mayor base de datos de la historia, que no solo contiene nuestros rostros o lugares visitados, sino nuestros más profundos deseos, sueños y anhelos y que alguien con esa información puede producir conocimiento y desde allí buscar interpelación?

¿Podemos imaginar cuando formamos futuros docentes qué tipo de institución educativa van a pisar en veinte años cuando estén comenzando su plenitud laboral? ¿Podemos imaginar con qué niños, niñas y jóvenes van a trabajar?

Claramente, aquí ensayamos, provocamos, inundamos de preguntas una tesis doctoral que puede abonar esta búsqueda de una nueva narrativa. Somos conscientes del límite de mucho de lo que hemos planteado porque cuando se desarman estructuras muchas veces se corre el riesgo de que lo que se rearme en realidad responda a otros intereses, pero no alcanza hoy la pulsión de lo instituido, debemos ir por lo instituyente y avanzar.

En una reflexión como la que aquí se desarrolló, demostrando los límites de la comunicación masiva y el surgimiento de otro ecosistema mediático, problematizando la cultura escolar, sentando bases epistemológicas y justificando por qué las tradiciones del campo de comunicación / educación no alcanzan para abordar los objetos y las preguntas que les son propias, debemos darnos el permiso de ensanchar los horizontes y de ir a buscar a tientas algunas respuestas para poder continuar.

El riesgo, como mencionamos, es enorme, es quedarnos fuera, que decidan por nosotros y que otros le den forma a un futuro incierto pero que demanda una participación en su configuración. La imposibilidad de intervenir en un escenario de transformación como el que hoy se encuentra aconteciendo, cerrando la posibilidad de construir horizontes posibles en los cuales las lógicas establecidas no sean las únicas posibles, demanda el esfuerzo analítico, pero también la acción política.

La posibilidad de tener resueltas de forma automatizada algunas de las necesidades productivas básicas como humanos, nos pone ante la disyuntiva, desde hace años, de qué será de aquellos que no logren articularse con el mundo del trabajo. Según un informe de la consultora Accenture (2015), 37\% del total de empleo privado de la Argentina podría ser automatizado casi por completo en los próximos quince años. La transformación, 
según la compañía, "deberá involucrar por igual a todas las empresas, sin distinción de tamaño y a trabajadores de todas las edades" (p. 5), en un proceso local pero que sigue una tendencia mundial.

Tal vez esto nos permita desentendernos del trabajo como modelo productivo para reproducir el capital y nos posibilite ir a una visión del trabajo mucho más vinculada a lo que es la mediación del ser humano para transformar el mundo, como lo expresa Foucault (1990), y las máquinas se dediquen a reproducir el capital mientras nosotros vivimos libres para hacer otras cosas. Siguiendo esa línea de pensamiento, nos encontramos ante una dicotomía en la cual podemos imaginar un sobrante importante de humanos en el mundo, ya que si el trabajo remunerado y productivo como lo conocemos desaparece en una gran parte, qué pasará con quienes no lo posean.

¿Necesariamente tendremos que trabajar para reproducir el capital o si hay quien lo haga por nosotros tendremos muchas otras cosas a las que dedicarnos? Podría ser una suerte de narrativa — no tan utópica - del sur, donde ya no tuviéramos que competir, ni la necesidad de batallar por la supervivencia. Y si se trata de proponer nuevas representaciones para una nueva narrativa, quizás podamos recuperar la dicotomía que enuncia Rodolfo Kusch (2000) para América latina entre el mero estar y el ser alguien.

Pero, claramente, el gran problema es salir de la matriz ganadores / perdedores, explotadores / explotados, incluidos / excluidos en la que nos ubicamos y retomar la propuesta del Buen Vivir, o Sumak Kawsay en Quechua, como paradigma de las culturas originarias que dentro de nuestra región crece con fuerza. Tan distinto puede ser un modo como otro, según se logre ir configurando como horizonte de posibilidad.

Quizás estemos en los albores de que algo o de que alguien pueda cumplir las tareas básicas para que el hombre subsista en condiciones muy favorables (tener comida, vestimenta, vivienda, salud), y entonces podamos simplemente recuperar también a uno de los pensadores que funda la filosofía en Occidente. Aristóteles anunciaba: "Si las lanzaderas tejiesen por sí mismas, si el arco tocase solo la cítara, los empresarios prescindirían de los operarios, y los señores, de los esclavos".

Es por ello que doce ensayos en busca de una narrativa es como un pedido, una demanda que expresa la necesidad de proponer voces, una voz y que suene, se haga oír a pesar del ruido, de la distracción entre las múltiples pantallas y que no quede acá, que resuene, para que juntos configuremos una narrativa nueva que nos dé condiciones de posibilidad, de libertad, de futuro. Un mundo donde quepan todos los mundos. 


\section{Referencias}

Accenture (2015). El futuro del trabajo en Argentina. Recuperado de https://www.accenture.com/ acnmedia/PDF-5/Accenture-El-Futuro-Del-TrabajoEn-Argentina-POV.pdf\#zoom=50

Araújo, A. M. (1992). Notas. En P. Freire, Pedagogía de la esperanza. Un reencuentro con la Pedagogía del oprimido. Ciudad Autónoma de Buenos Aires, Argentina: Siglo XXI.

Aristóteles (1988). Política. Madrid, España: Gredos.

Foucault, M. (1990). Tecnologías del yo y otros textos afines. Barcelona, España: Paidós.

Freire, P. [1968] (2005). Pedagogía del oprimido. Ciudad de México, México:

Siglo XXI.

Freire, P. [1992] (2008). Pedagogía de la esperanza. Ciudad Autónoma de Buenos Aires, Argentina: Siglo XXI.

Kusch, R. (2000). Geocultura del hombre americano. En Obras completas, tomo 3. Rosario, Argentina: Fundación Ross.

Martín-Barbero, J. (2017). Jóvenes: entre el palimpsesto y el hipertexto.

Barcelona, España: Nuevos emprendimientos editoriales.

Nietzsche, F. [1882] (2016). La gaya ciencia. Madrid, España: Tecnos.

Puiggrós, A. (23 de mayo de 2019). Conferencia de presentación de la Cátedra Libre Paulo Freire. Facultad de Humanidades y Ciencias de la Educación, Universidad Nacional de La Plata.

Puiggrós, A. (30 de mayo de 2019). La escuela, plataforma de la patria. Página/12. Recuperado de https://www.pagina12.com.ar/197070-la-escuela-plataforma-de-lapatria 
Ramírez Cabanzo, A. B. (diciembre de 2014). Una mirada a las tecnicidades mediáticas de las infancias en Bogotá - Colombia, en clave de etnografía multisituada Trabajo presentado en las VIII Jornadas de Sociología de la UNLP. Ensenada, Argentina. Recuperado de http://www.memoria.fahce.unlp.edu.ar/trab eventos/ev.4794/ev.4794.pdf

Sibilia, P. (2009). El hombre postorgánico. Cuerpo, subjetividad y tecnologías digitales. Ciudad Autónoma de Buenos Aires, Argentina: Fondo de Cultura Económica.

Sadin, E. (2017). La humanidad aumentada. La administración digital del mundo. Ciudad Autónoma de Buenos Aires, Argentina: Caja Negra.

Van Dijck, J. (2016). La cultura de la conectividad. Una historia crítica de las redes sociales (Trad. Hugo Salas). Ciudad Autónoma de Buenos Aires, Argentina: Siglo XXI. 


\section{Referencias}

Abramowski, A. e Igarzábal, B. (2012). Uso y apropiación de las producciones

de Canal Encuentro en las escuelas bonaerenses. En A. Abramowski, B. Igarzábal,

R. P. Carbonatto, M. Mobilia, y E. Tenti Fanfani (Coords.), Cuadernos de

Investigación \#1. Los docentes bonaerenses. Las políticas educativas vistas desde

el aula (pp. 12-21). La Plata, Argentina: UNIPE.

Accenture (2015). El futuro del trabajo en Argentina. Recuperado de

https://www.accenture.com/ acnmedia/PDF-5/Accenture-El-Futuro-Del-TrabajoEn-Argentina-POV.pdf\#zoom $=50$

Appadurai, A. [1996] (2001). La Modernidad desbordada: dimensiones culturales de la globalización. Ciudad Autónoma de Buenos Aires, Argentina: Tricle.

Araújo, A. M. (1992). Notas. En P. Freire, Pedagogía de la esperanza. Un reencuentro con la Pedagogía del oprimido. Ciudad Autónoma de Buenos Aires, Argentina: Siglo XXI.

Arciniegas, G. (1979). Nuestra América es un ensayo. Latinoamérica.

Cuadernos de cultura latinoamericana, (53). Ciudad de México, México:

Universidad Nacional Autónoma de México.

Aristóteles (1988). Política. Madrid, España: Gredos.

Asociación de Docentes de Informática y Computación de la República

Argentina (ADICRA) (s/f). ¿De qué hablamos cuando hablamos de Informática?

Recuperado de http://adicra.org.ar/informatica/

Bajtín, M. [1982] (1998). Estética de la creación verbal. Ciudad de México, México: Siglo XXI.

Benjamin, W. (1982). Discursos interrumpidos. Madrid, España: Taurus. 
Borchardt, M. y Roggi, I. (2017). Ciencias de la Computación en los Sistemas Educativos de América Latina. Recuperado de http://eduteka.icesi.edu.co/pdfdir/siteal-cienciascomputacion.pdf

Borelli, J. (10 de junio de 2018). Natalia Zuazo: “Hay que politizar la tecnología: pensar para qué la queremos". Tiempo Argentino. Recuperado de https://www.tiempoar.com.ar/nota/natalia-zuazo-hay-que-politizar-la-tecnologiapensar-para-que-la-queremos

Bourdieu, P. [1980] (2007). El sentido práctico (Trad. Ariel Dilon). Madrid, España: Taurus.

Buenfil Burgos, R. N. (1993). Análisis de discurso y educación. Documentos DIE 26. Ciudad de México, México: Instituto Politécnico Nacional.

Cabrero Almenara, J. (1994). Retomando un medio. La televisión educativa. Presentado en CMIDE-SAV: I Jornadas sobre Medios de Comunicación, Recursos y Materiales para la Mejora Educativa, Sevilla, Universidad de Sevilla. Recuperado de http://linamariapatricia.tripod.com/convergencia/118.pdf

Carlón, M. (2017). Documento teórico metodológico (apunte de cátedra). Semiótica de redes, Facultad de Ciencias Sociales, Universidad de Buenos Aires.

Carlón, M. y Scolari, C. (2009). El fin de los medios masivos. Ciudad Autónoma de Buenos Aires, Argentina: La Crujía.

Carrión, J. (1o de febrero de 2019). Las plataformas transforman nuestros modos de leer. Recuperado de https://www.nytimes.com/es/2019/02/10/cultura-plataformasamazon-netflix/

Corte, M. (2016). Reflexiones en torno al propósito educativo de Canal Encuentro. Question, 1(51).Recuperado de https://perio.unlp.edu.ar/ojs/index.php/question/article/view/3403

Coscarelli, R. (2001). Algunas consideraciones acerca del curriculum (ficha de cátedra). La Plata, Argentina: Facultad de Humanidades y Ciencias de la Educación, Universidad Nacional de La Plata. 
Coscarelli, R. (2010). Los cambios del Curriculum ante los retos de los cambios tecnológicos, económicos y políticos. (ficha de cátedra). La Plata, Argentina: Facultad de Humanidades y Ciencias de la Educación, Universidad Nacional de La Plata.

De Sousa Santos, B. (2018). Construyendo las Epistemologías del Sur: para un pensamiento alternativo de alternativas. Ciudad Autónoma de Buenos Aires, Argentina: Consejo Latinoamericano de Ciencias Sociales (CLACSO).

Recuperado de http://biblioteca.clacso.edu.ar/clacso/se/20181203040213/Antologia Boaventura V ol1.pdf

Decreto 533 (2005). Programas de televisión educativa y multimediales. Recuperado de http://servicios.infoleg.gob.ar/infolegInternet/anexos/105000109999/106542/norma.htm

Deleuze, G. (2018). Diferencia y repetición. Ciudad Autónoma de Buenos Aires, Argentina: Amorrortu.

Desposito, L. (30 de enero de 2019). Netflix ingresa a la Motion Pictures Association of America. Recuperado de https://www.baenegocios.com/espectaculo/Netflixingresa-a-la-Motion-Pictures-Association-of-America-20190129-0068.html

Di Palma, C. (2017). Interpelación y reconocimiento de la cultura mediática en la convergencia digital pública infantil. Nuevos sentidos político-estratégicos del campo Comunicación / Educación para ampliar horizontes de significación en la era de la onda cuadrada (Tesis de maestría). Recuperado de http://www.ondacuadrada.com

Díaz, E. y Heler, M. [1987] (1999). El conocimiento científico. Hacia una visión crítica de la ciencia. Ciudad Autónoma de Buenos Aires, Argentina: Eudeba.

Dorfam, A. y Mattelart, A. (1971) (2001). Para leer al Pato Donald. Ciudad Autónoma de Buenos Aires, Argentina: Siglo XXI.

Dussel, I. (2011). Aprender y enseñar en la cultura digital. Ciudad Autónoma de Buenos Aires, Argentina: Santillana. 
Dussel, I. (2014) ¿Es el curriculum escolar relevante en la cultura digital? Debates y desafíos sobre la autoridad cultural contemporánea. Archivos Analíticos de Políticas Educativas, 22(24). http://dx.doi.org/10.14507/epaa.v22n24.2014

Dussel, I. y Quevedo, L. A. (2010). VI Foro Latinoamericano de Educación; Educación y nuevas tecnologías: los desafíos pedagógicos ante el mundo digital. Ciudad Autónoma de Buenos Aires, Argentina: Santillana.

El asombroso libro de Zamba en las Islas Malvinas (2015). La Plata, Argentina: Edulp.

El Monitor (diciembre 2008). Un espacio para la transformación educativa. La función del portal educ.ar, pp. 52-55. Recuperado de http://www.me.gov.ar/monitor/nroo/pdf/monitorı.pdf

Fernández, J. L. (2016). Plataformas mediáticas y niveles de análisis. Inmediaciones de la comunicación, (11), 71-96. Recuperado de https://revistas.ort.edu.uy/inmediaciones-de-la-comunicacion/article/view/2618

Ferres Prats, J. (2015). Las pantallas y el cerebro emocional. Barcelona, España: Gedisa.

Foucault, M. [1969] (2003). La arqueología del saber (Trad. A. Garzón del Camino). Ciudad Autónoma de Buenos Aires, Argentina: Siglo XXI.

Foucault, M. (1979). Historia de la sexualidad. 1. La voluntad del saber. Ciudad Autónoma de Buenos Aires, Argentina: Siglo XXI.

Foucault, M. (1990). Tecnologías del yo y otros textos afines. Barcelona, España: Paidós.

Freire, P. [1968] (2005). Pedagogía del oprimido. Ciudad de México, México: Siglo XXI.

Freire, P. (1989). La educación como práctica de la libertad. Ciudad Autónoma de Buenos Aires, Argentina: Siglo XXI.

Freire, P. [1992] (2008). Pedagogía de la esperanza. Ciudad Autónoma de Buenos Aires, Argentina: Siglo XXI.

Freire, P. [1996] (2004). Pedagogía de la autonomía. Saberes necesarios para la práctica educativa. Ciudad Autónoma de Buenos Aires, Argentina: Siglo XXI. 
García, R. (2007). Sistemas complejos. Conceptos, método y fundamentación epistemológica de la investigación interdisciplinaria. Madrid, España: Gedisa.

García Canclini, N. (1995). Consumidores y ciudadanos. Conflictos multiculturales de la globalización. Ciudad de México, México: Grijalbo.

Giménez, G. (1997). Materiales para una nueva teoría de las identidades sociales. Frontera Norte, 9(18), 9-28. Recuperado de https://fronteranorte.colef.mx/index.php/fronteranorte/article/viewFile/1441/891

González, A. (1 de julio de 2014). ¿Qué es Machine Learning? CleverData. Recuperado de https://cleverdata.io/que-es-machine-learning-big-data

González, L. y Novomisky, S. (2012). La televisión digital en Argentina. Cambios políticos, tecnológicos y económicos. Miradas desde una perspectiva federal.

El caso del canal para niños Pakapaka. En M. Souza, P. Cabello y C. Del Valle (Eds.), Medios, edades y Cultura (pp. 71-87). Santiago de Chile, Chile: Ediciones Universidad de La Frontera.

González, L., Pauloni, S. y Codoni, M. F. (2016). De dónde viene y hacia dónde va la televisión educativa, cultural y pública en la Argentina. Oficios Terrestres, (34), 24-36. Recuperado de http://perio.unlp.edu.ar/ojs/index.php/oficiosterrestres

González, L., Pauloni, S., Novomisky, S., Codoni, M. F. y Gómez, A. J. (2016). Perspectivas para pensar contenidos educativos infantiles. El concepto eduentretenimiento en la televisión Digital Argentina. Actas de Periodismo y Comunicación, 2(1). Recuperado de https://perio.unlp.edu.ar/ojs/index.php/actas/article/view/4014

González Frígoli, M. y Racioppe, B. (2015). Investigación y formación en comunicación en los nuevos territorios digitales. Oficios Terrestres, (33), 39-49. Recuperado de https://perio.unlp.edu.ar/ojs/index.php/oficiosterrestres/article/view/2634

Gramsci, A. (1986). El materialismo histórico y la filosofía de B. Croce. Ciudad de México, México: Juan Pablos Editor.

Hall, S. [1996] (2003). Introducción: ¿quién necesita 'identidad'? En S. Hall y P. du Gay (Comps.), Cuestiones de identidad cultural (pp. 13-39) (Trad. Horacio Pons). Ciudad Autónoma de Buenos Aires, Argentina: Amorrortu. 
Huergo, J. (2001). Desbordes y conflictos entre la cultura escolar y la cultura mediática. Nómadas, (15), 88-100. Recuperado de www.redalyc.org/pdf/1051/105117927008.pdf

Huergo, J. (2005). Hacia una genealogía de Comunicación/Educación. Rastreo de algunos anclajes político-culturales. La Plata, Argentina: Ediciones de Periodismo y Comunicación.

Huergo, J. (2005). Hegemonía, un concepto clave para comprender la comunicación (ficha de cátedra). La Plata, Argentina: Facultad de Periodismo y Comunicación Social, Universidad Nacional de La Plata.

Huergo, J. (2006). Comunicación y educación: aproximaciones. Recuperado de https://comeduc.blogspot.com/2006/o4/jorge-huergo-comunicacin-yeducacin.html

Huergo, J. (15 de abril de 2007). Espacios discursivos. Lo educativo, las culturas y lo político. Recuperado de http://comeduc.blogspot.com/2007/o4/jorge-huergoespacios-discursivos-lo.html

Huergo, J. (22 de abril de 2007). Breve apunte sobre Formación [entrada de blog]. Recuperado de http://comeduc.blogspot.com/2007/o4/formacin.html

Huergo, J. (2007). Los medios y tecnologías en educación. Ciudad Autónoma de Buenos Aires, Argentina: Ministerio de Educación, Ciencia y Tecnología. Recuperado de http://repositorio.educacion.gov.ar:8o8o/dspace/handle/123456789/95679

Huergo, J. (2008). La relevancia formativa de las pantallas. Comunicar, 15(30), 73-77. Recuperado de http://sedici.unlp.edu.ar/handle/10915/29447

Huergo, J. (2013). Mapas y viajes por el campo de comunicación / educación. Tram(p)as de la comunicación y la cultura, (75), 19-30. Recuperado de https://perio.unlp.edu.ar/catedras/system/files/1 huergo trampas 75 .pdf

Huergo, J. (2015). La educación y la vida. La Plata, Argentina: Ediciones de Periodismo y Comunicación.

Huergo, J. y Fernández, M. B. (2000). Cultura escolar y cultura mediática / Intersecciones. Bogotá, Colombia: Universidad Pedagógica Nacional. 
Huergo, J. y Morawicki, K. (2008). El sentido de la "experiencia social".

La Plata, Argentina: Dirección General de Cultura y Educación.

Idárraga Franco, H. F. (2009). Sensorium e Internet. Una aproximación al fenómeno tecnológico desde la obra de Walter Benjamin (tesis de maestría). Recuperado de https://repository.javeriana.edu.co/handle/10554/238

Jaimovich, D. (5 de julio de 2018). Algoritmos racistas, machistas y extremistas: ¿se necesita enseñarles ética a los robots? Recuperado de https://www.infobae.com/america/tecno/2018/07/05/algoritmos-racistasmachistas-y-extremistas-se-necesita-ensenarles-etica-a-los-robots/

Jenkins, H. (2006). Convergence culture: la cultura de la convergencia de los medios de comunicación. Madrid, España: Paidós.

Jiménez, J. (3 de diciembre de 2015). ¿Pueden ser racistas los algoritmos? Recuperado de https://www.xataka.com/robotica-e-ia/pueden-ser-racistas-los-algoritmos

Kaplan, A. y Haenlein, M. (2019). Siri, Siri in my Hand, who's the Fairest in the Land? On the Interpretations, Illustrations and Implications of Artificial Intelligence. Business Horizons, 62(1), 15-25. https://doi.org/10.1016/j.bushor.2018.08.004

Kusch, R. (2000). Geocultura del hombre americano. En Obras completas, tomo 3. Rosario, Argentina: Fundación Ross.

La Nación (4 de enero de 2016). Oficial: el DNU de Macri que modifica aspectos centrales de la ley de medios y elimina la Afsca. Recuperado de https://www.lanacion.com.ar/politica/el-gobierno-publico-el-dnu-que-modificala-ley-de-medios-y-elimina-la-afsca-nid1859236

Laclau, E. y Mouffe, C. (1987) Hegemonía y estrategia socialista. Hacia una radicalización de la democracia, Madrid, España: Siglo XXI.

Larrosa, J. (2003). El ensayo y la escritura académica. Propuesta educativa, 12(26), 34-40.

Ley Nacional 26.150 (2006). Programa Nacional de Educación Sexual Integral.

Recuperado de http://servicios.infoleg.gob.ar/infolegInternet/anexos/12000o124999/121222/norma.htm 
Ley Nacional 26.206 (2006). Ley de Educación Nacional.

Recuperado de http://servicios.infoleg.gob.ar/infolegInternet/anexos/120000124999/123542/norma.htm

Ley Nacional 26.522 (2009). Servicios de comunicación audiovisual.

Recuperado de http://servicios.infoleg.gob.ar/infolegInternet/anexos/155000159999/158649/norma.htm

Litwin, E. (Comp.) (2005). La tecnología educativa en el debate didáctico.

En Tecnologías educativas en tiempos de internet. Ciudad Autónoma de Buenos Aires, Argentina: Amorrortu.

Maggio, M. (2012). Enriquecer la enseñanza. Los ambientes con alta disposición tecnológica como oportunidad. Ciudad Autónoma de Buenos Aires, Argentina: Paidós.

Martin, M. V. (2017). ¿Consumidores o sujetos de derecho? La educación, entre las TIC y las TEP. Apuntes de comunicación, educación y discurso, (2), eoog. https://doi.org/10.24215/25252046eoog

Martin, V. y Vestfrid, P. (2015). La aventura de innovar con TIC : aportes conceptuales, experiencias y propuestas. La Plata, Argentina: Ediciones de Periodismo y Comunicación. Recuperado de https://perio.unlp.edu.ar/sites/default/files/la aventura de innovar con tic.pdf

Martín-Barbero, J. [1987] (1997). De los medios a las mediaciones. Bogotá, Colombia: Gustavo Gili.

Martín-Barbero, J. (1989). Procesos de comunicación y matrices de cultura. Itinerario para salir de la razón dualista. Ciudad de México, México:

FELAFACS / G. Gili.

Martín-Barbero, J. (2001). Los oficios del comunicador. Renglones, revista del ITESO, (48). Recuperado de https://rei.iteso.mx/handle/11117/480

Martín-Barbero, J. (2009a). Cuando la tecnología deja de ser una ayuda didáctica para convertirse en mediación cultural. Teoría de la Educación. Educación y Cultura en la Sociedad de la Información, 10(1), 19-31. Recuperado de http://www.redalyc.org/articulo.oa?id=201018023002 
Martín-Barbero, J. (2009b). Culturas y comunicación globalizada. I/C Revista científica de información y comunicación, (6), 175-192. Recuperado de http://icjournalojs.org/index.php/IC-Journal/article/view/207/204

Martín-Barbero, J. (2010). Jóvenes: entre la ciudad letrada y el mundo digital. En G. Lluch (Ed.), Las lecturas de los jóvenes. Un nuevo lector para un nuevo siglo (pp. 39-58). Barcelona, España: Anthropos.

Martín-Barbero, J. (2017). Jóvenes: entre el palimpsesto y el hipertexto.

Barcelona, España: Nuevos emprendimientos editoriales.

Mata, M. C. (1985). Nociones para pensar la comunicación y la cultura masiva [Módulo de clase]. Especialización en Educación para la comunicación. Ciudad Autónoma de Buenos Aires: La Crujía.

McLaren, P. (1998). Multiculturalismo revolucionario. Pedagogías de disensión para el nuevo milenio. Ciudad de México, México: Siglo XXI.

Moliner, M. (1998). Diccionario de uso del español. Madrid, España: Gredos.

Moreno, I. (1991). Identidades y rituales. En J. Prat, U. Martínez, J. Contreras e I. Moreno (Eds.), Antropología de los pueblos de España. Madrid, España: Taurus.

Morin, E. (1984). Ciencia con consciencia (Trad. Ana Sánchez). Barcelona, España: Anthropos.

Morin, E. (1994). Introducción al pensamiento complejo (Trad. Marcelo Pakman). Barcelona, España: Gedisa.

Morin, E. (1999). La cabeza bien puesta. Ciudad Autónoma de Buenos Aires, Argentina: Nueva Visión.

Morin, E., Ciurana, E. R. y Motta, R. D. (2003). Educar en la era planetaria. Barcelona, España: Gedisa.

Morley, D. (1996). Televisión, audiencias y estudios culturales. Ciudad Autónoma de Buenos Aires, Argentina: Amorrortu.

Murolo, L. (13/02/2019). ¿Por qué Netflix? Recuperado de https://www.pagina12.com.ar/174666-por-que-netflix 
Murolo, L. y Aon, L. (2018). Maratón en Netflix. House of cards, entre la narrativa de la televisión y la web. Tram[p]as de la comunicación y la cultura, (82), e023. https://doi.org/10.24215/2314xeo23

Negroponte, N. (1995). Ser digital. Nueva York: Estados Unidos: Alfred A. Knopf.

Nemirovsci, O. M. (2013). TV Digital, un nuevo modelo cultural. En S. Pauloni (Comp.), Tv digital. Un diálogo entre disciplinas y multipantallas (pp. 13-32). La Plata, Argentina: Ediciones de Periodismo y Comunicación.

Nietzsche, F. [1882] (2016). La gaya ciencia. Madrid, España: Tecnos.

Panaccio, M. (marzo 2010). Los primeros pasos de la TV educativa. El Monitor, pp. 52-53. Recuperado de http://www.me.gov.ar/monitor/nroo/pdf/monitor24.pdf

Pauloni, S. (Comp.) (2013). Tv digital. Un diálogo entre disciplinas y multipantallas. La Plata, Argentina: Ediciones de Periodismo y Comunicación.

Pauloni, S. y Novomisky, S. (2013). Contextos y conceptos sobre la TV. En S. Pauloni (Comp.), Tv digital. Un diálogo entre disciplinas y multipantallas (pp. 62-85). La Plata, Argentina: Ediciones de Periodismo y Comunicación.

Pauloni, S., Novomisky, S., Codoni, M. F. y Gómez, A. J. (2016). Argentina. Televisión educativa: nuevos debates y formatos. En S. Novomisky y M. Américo (Comps.), Convergencia. Medios, tecnologías y educación en la era digital (pp. 47-72). La Plata, Argentina: Edulp. Recuperado de http://sedici.unlp.edu.ar/bitstream/handle/10915/55418/Documento completo .p df-PDFA.pdf? sequence=3\&isAllowed $=y$

Pècheux, M. (2005). El mecanismo del reconocimiento ideológico. En S. Zizek (Comp.), Ideología. Un mapa de la cuestión (pp. 157-167). Ciudad Autónoma de Buenos Aires, Argentina: Fondo de Cultura Económica.

PlaySeries (19 de abril de 2017). El gran competidor de Netflix es el sueño. Recuperado de https://www.abc.es/play/series/noticias/abci-gran-competidor-netflix-sueno201704192030 noticia.html

Puiggrós, A. (2003). Qué pasó en la educación. Breve historia desde la conquista hasta el presente. Ciudad Autónoma de Buenos Aires, Argentina: Galerna. 
Puiggrós, A. (23 de mayo de 2019). Conferencia de presentación de la Cátedra Libre Paulo Freire. Facultad de Humanidades y Ciencias de la Educación, Universidad Nacional de La Plata.

Puiggrós, A. (30 de mayo de 2019). La escuela, plataforma de la patria. Página/12. Recuperado de https://www.pagina12.com.ar/197070-la-escuela-plataforma-de-lapatria

Quiroz, M. T. (1984). Los medios: ¿una escuela paralela? Lima, Perú: Centro de Investigación en Comunicación Social de la Universidad de Lima (CICOSUL).

Ramírez Cabanzo, A. B. (diciembre de 2014). Una mirada a las tecnicidades mediáticas de las infancias en Bogotá - Colombia, en clave de etnografía multisituada Trabajo presentado en las VIII Jornadas de Sociología de la UNLP. Ensenada, Argentina. Recuperado de http://www.memoria.fahce.unlp.edu.ar/trab eventos/ev.4794/ev.4794.pdf

Ramsey, C. (16 de mayo de 2018). Netflix to reach 201 million subscribers by 2023. Recuperado de https://www.tvbeurope.com/data-centre/netflix-to-reach-201million-subscribers-by-2023

RedHat (s/f). El concepto de cloud computing. Recuperado de https://www.redhat.com/es/topics/cloud

Resolución 1831 (2006). Comité Federal de Radiodifusión.

Rincón, O. (Comp.) (2005). Televisión pública: del consumidor al ciudadano. Ciudad Autónoma de Buenos Aires, Argentina: La Crujía.

Rincón, O. (2006). Narrativas mediáticas. Barcelona, España: Gedisa.

Ruiz, A. (2018). La incorporación de citas en los textos científico académicos. Estilos y consideraciones para su redacción (apunte de cátedra). Taller de Edición Técnica, Facultad de Periodismo y Comunicación Social, Universidad Nacional de La Plata. Recuperado de http://sedici.unlp.edu.ar/handle/10915/73792

Sadin, E. (2017). La humanidad aumentada. La administración digital del mundo. Ciudad Autónoma de Buenos Aires, Argentina: Caja Negra. 
Saintout, F. (2007). Los estudios socioculturales y la comunicación: un mapa desplazado.

ALAIC. Revista Latinoamericana de Ciencias de la Comunicación,

5(8-9). Recuperado de

https://www.alaic.org/revista/index.php/alaic/article/view/64

San Martín, R. (28 de junio de 2003). Nueva apuesta al portal Educ.ar. La Nación. Sección Cultura. Recuperado de http://www.lanacion.com.ar/507247-nueva-apuesta-alportal-educar

Schmucler, H. (1984). Un proyecto de comunicación/cultura. Comunicación y cultura, (12).

Schwab, K. (2016). La cuarta revolución industrial. Madrid, España: Debate.

Scolari, C. (2008). Hipermediaciones. Elementos para una Teoría de la Comunicación Digital Interactiva. Barcelona, España: Gedisa.

Scolari, C. (2013). Narrativas transmedia. Cuando todos los medios cuentan. Barcelona, España: Planeta.

Scolari, C. (1o de junio de 2018). La IV Revolución Industrial [entrada de blog]. Recuperado de https://hipermediaciones.com/2018/o6/10/la-40-revolucionindustrial

Scolari, C. (2018). Alfabetismo transmedia en la nueva ecología de los medios. Libro blanco. Recuperado de http://www.codajic.org/sites/www.codajic.org/files/Alfabetismo\%2oTransmedia\% 20.\%20Scolari o.pdf

Scolari, C. (19 de mayo de 2019).La guerra de las plataformas (III). Recuperado de https://hipermediaciones.com/2019/05/19/la-guerra-de-las-plataformas-iii

Sibilia, P. (2009). El hombre postorgánico. Cuerpo, subjetividad y tecnologías digitales. Ciudad Autónoma de Buenos Aires, Argentina: Fondo de Cultura Económica.

Smerling, T. (2015). La otra pantalla: educación, cultura y televisión. 2005 -2015. Una década de Canal Encuentro, Pakapaka y las nuevas señales educativas. Ciudad Autónoma de Buenos Aires, Argentina: Ediciones Educ.ar. 
Sociología y redes sociales (06/04/2010). Economía de la atención III - Análisis del concepto de Michael Goldhaber. Recuperado de http://sociologiayredessociales.com/2010/04/economia-de-la-atencion-iii-analisisdel-concepto-de-michael-goldhaber/

Srnicek, N. (2018). Capitalismo de plataformas (Trad. Aldo Giacometti). Ciudad Autónoma de Buenos Aires, Argentina: Caja Negra.

Tapscott, D. y Williams, A. D. (2006). Wikinomics. How Mass Collaboration Changes Everything. Nueva York, Estados Unidos: Penguin Group.

Tufte, T. (2004). Eduentretenimiento en la comunicación para el vih/sida más allá del mercadeo, hacia el empoderamiento (Trad. Tanya Escamilla). Investigación $\mathcal{E}$ Desarrollo, 12(1), 24-43. Recuperado de http://www.redalyc.org/articulo.oa?id=26800102

Van Dijck, J. (2016). La cultura de la conectividad. Una historia crítica de las redes sociales (Trad. Hugo Salas). Ciudad Autónoma de Buenos Aires, Argentina: Siglo XXI.

Velilla, J. (15 de enero de 2010). Economía de la atención: "la abundancia de la información da lugar a la pobreza de la atención". Recuperado de http://www.javiervelilla.es/wordpress/2010/o1/15/economia-de-la-atencion-laabundancia-de-la-informacion-da-lugar-a-la-pobreza-de-la-atencion/

Verón, E. (1992). Interfaces. Sobre la democracia audiovisual avanzada en el nuevo espacio público. Barcelona, España: Gedisa.

Verón, E. y Sigal, S. (1986). Perón o muerte. Ciudad Autónoma de Buenos Aires, Argentina: Legasa.

Villamayor, C. (2011). La subjetividad oxidada (apunte de cátedra). Facultad de Periodismo y Comunicación Social, Universidad Nacional de La Plata. Recuperado de http://amarcargentina.org/wp-content/uploads/2011/11/La-subjetividadoxidada Villamayor.pdf

Villamayor, C. (2014). Disrupción, comunicación y emancipación. Oficios Terrestres, (31), 49-59. Recuperado de https://perio.unlp.edu.ar/ojs/index.php/oficiosterrestres/article/view/2438 
Wikipedia (s/f). Aprendizaje profundo. Recuperado de https://es.wikipedia.org/wiki/Aprendizaje profundo

Wikipedia (s/f). Programación. Recuperado de https://es.wikipedia.org/wiki/Programaci\%C3\%B3n

Wikipedia (s/f). Software como servicio. Recuperado de https://es.wikipedia.org/wiki/Software como servicio

Wolton, D. (2000). Internet, ¿y después? Una teoría crítica de los nuevos medios de comunicación. Barcelona, España: Gedisa.

Xataka (24 de noviembre de 2016). ¿Sabemos cuánto ocupa todo el contenido que hay en Internet en este momento? Recuperado de https://www.xataka.com/tecnologiazen/sabemos-cuanto-ocupa-todo-elcontenido-que-hay-en-internet-en-este-momento 
